\title{
Assessment of a snow storage gradient across a maritime mountain environment; a ground penetrating radar investigation.
}

\author{
A thesis submitted to Victoria University of Wellington, \\ as fulfilment of the requirements of a \\ Master of Science in Geophysics, 2011
}

By

Lawrence J. Kees

On the $14^{\text {th }}$ day of June 2011

Antarctic Research Centre

School of Geography, Environmental and Earth Sciences

Victoria University of Wellington

Wellington, New Zealand 


\begin{abstract}
The Southern Alps of New Zealand experience some of the highest precipitation rates globally, and dramatic west to east climatic gradients. Our current knowledge of this precipitation distribution is based on weather station data and river discharge measurements, but there is a clear data gap in the high elevation, central Southern Alps. Here, estimates of precipitation strongly diverge. This problem exists because of the difficulties of quantifying the depth and distribution of snow in a remote, high-altitude mountainous region.
\end{abstract}

In order to improve our knowledge of snow distribution within this data-poor region, snow depths of $(<10 \mathrm{~m})$ were assessed parallel to the prevailing westerly wind direction at five locations across the mountain range, between the névé of Franz Josef Glacier, Waiho catchment, to the west and Jollie Valley, Pukaki catchment, in the east. The geophysical method of Ground Penetrating Radar (GPR) was used because of its ability to image the deep snow packs experienced in the study region.

Comparison of measurement techniques over the $(<3 \mathrm{~km})$ surveyed transects showed that ground-based GPR gave the best sample size (41000 samples) and accuracy due to the high spatial resolution. Airborne GPR (8571 samples) overestimated snow depth by $8 \%$ in lowgradient homogenous terrain, and $24 \%$ in steep heterogeneous terrain. The difference is ascribed to the larger view area of the GPR in the airborne survey. Direct probing of snow depth also performed poorly in comparison to ground-based GPR when generalising snow distribution over an area.

Across-mountain precipitation peaked $\sim 5 \mathrm{~km}$ west of the main divide, between 1700 and $2000 \mathrm{~m}$ a.s.l, providing the first empirical support to existing estimates of the location of peak precipitation. Results show decreasing precipitation from $12 \mathrm{ma}^{-1}$ at Franz Josef Glacier, in the Waiho catchment, to $1.8 \mathrm{ma}^{-1}$ at Jollie River valley, in the Lake Pukaki catchment, $25 \mathrm{~km}$ to the south-east.

Internal reflection horizons in snow-pack radargrams allowed snowfall events to be tracked, and a relationship lowland and mountain precipitation to be established. Snowfall accumulation 'factors' were derived for different atmospheric circulation indices, and these will enable improved accuracy in modelling of snow accumulation processes. Further 
research is required to refine the relationship between synoptic-classed accumulation rates and inter-annual variations in climatic circulation.

These refinements of measurement techniques and quantification of and snow distribution and depth allow for better estimation of river discharge and timing estimates for, hydroelectric power generation, and glacier mass balance. 


\section{Contents}

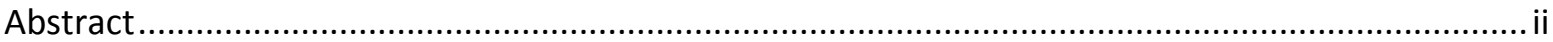

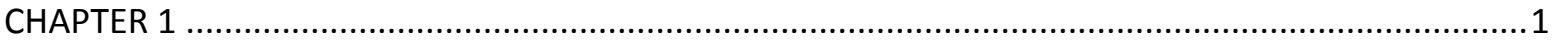

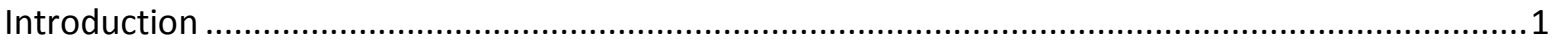

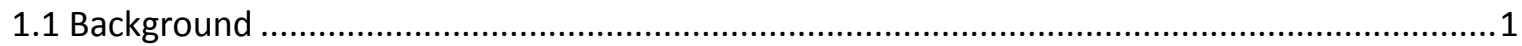

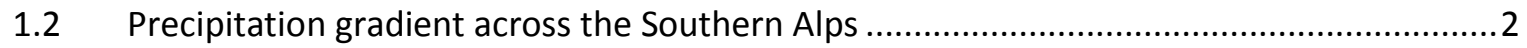

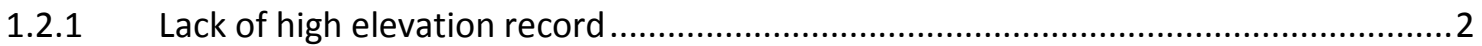

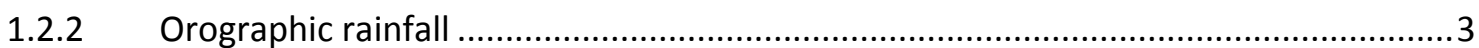

1.3 Estimation of high elevation precipitation from snow measurements .............................. 4

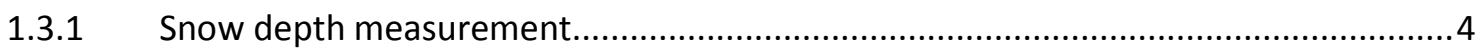

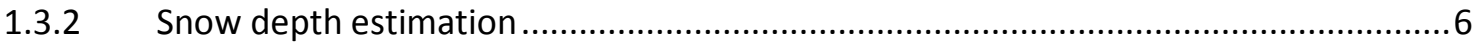

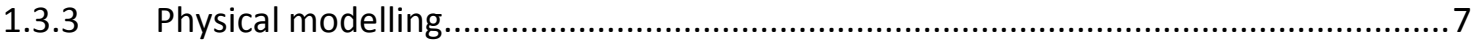

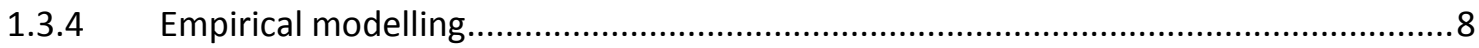

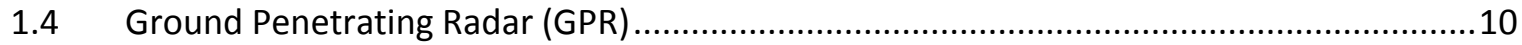

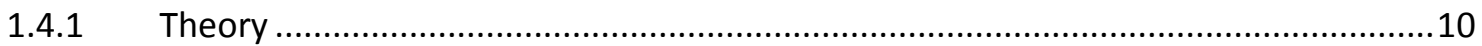

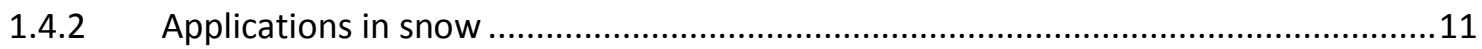

1.4.3 Profile validation and Two Way Travel Time (TWTT) calculation ..............................12

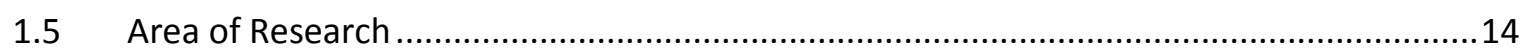

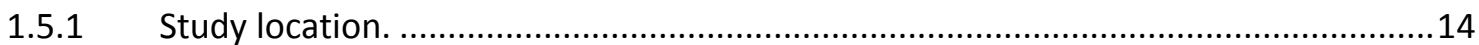

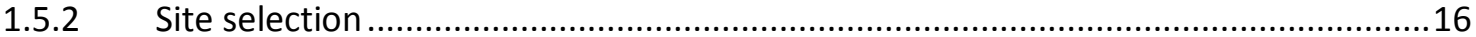

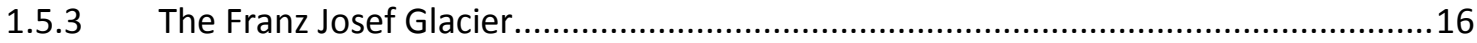

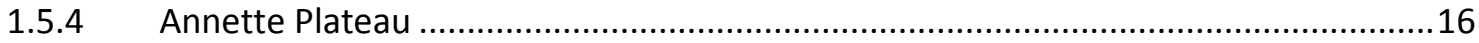

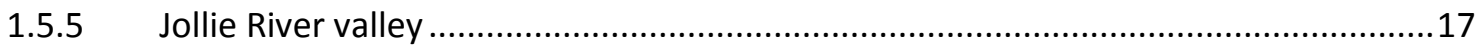

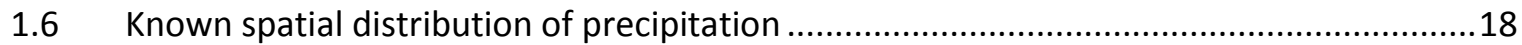

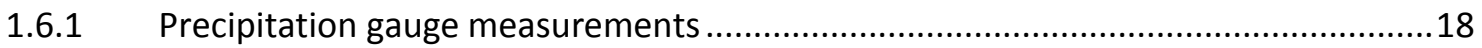

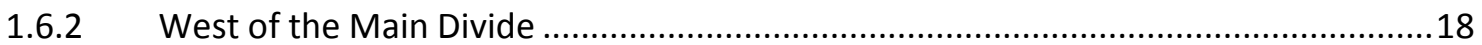

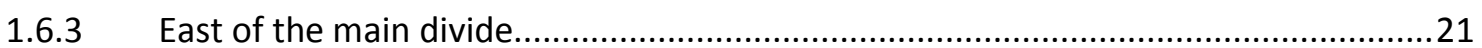

1.6.4 Contrast between eastern and western Southern Alps precipitation curves.............23

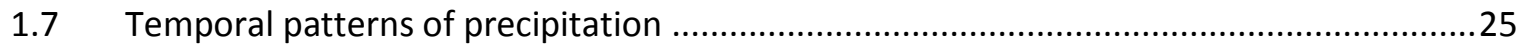

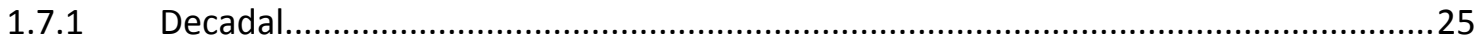

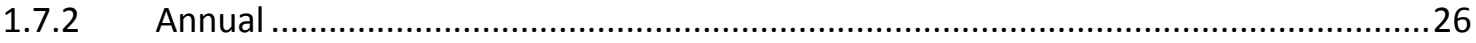

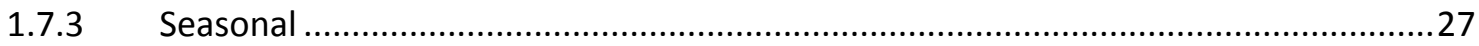

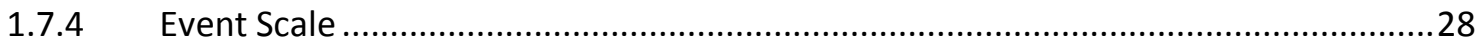




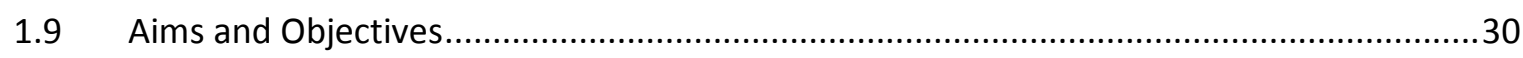

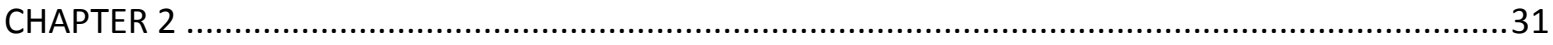

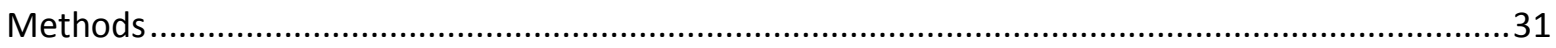

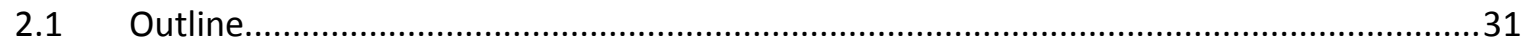

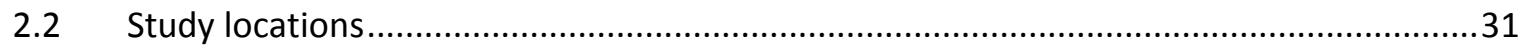

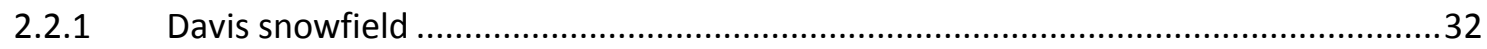

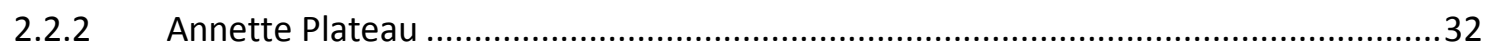

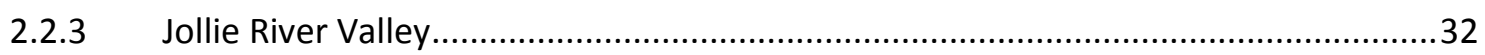

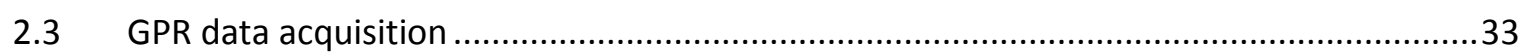

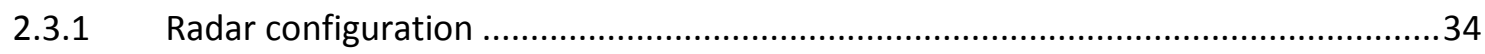

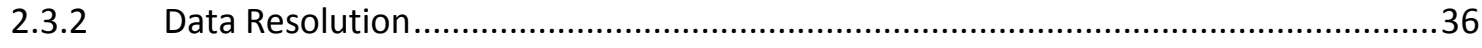

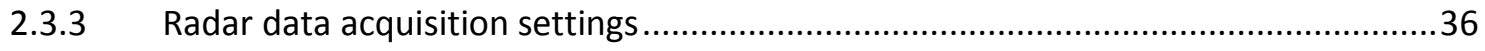

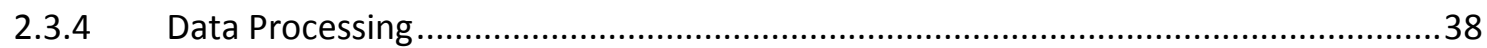

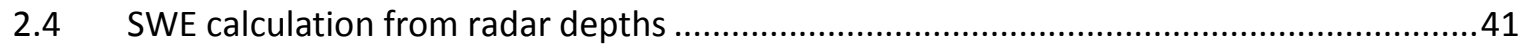

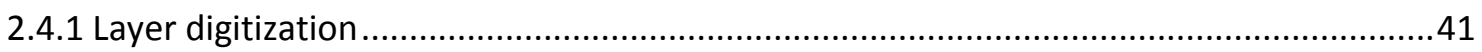

2.5 Traditional snow depth and density measurements ....................................................4

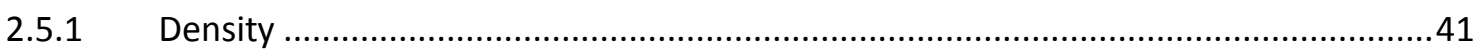

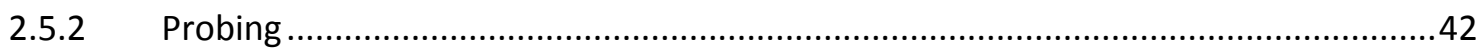

2.5.3 Establishing the relationship between SWE and TWTT ......................................43

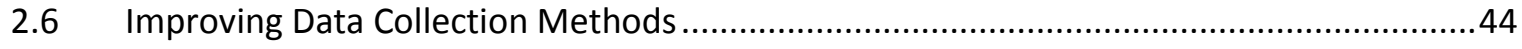

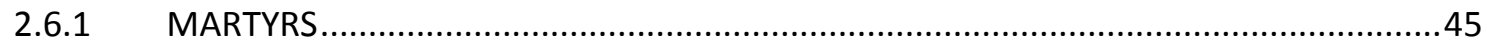

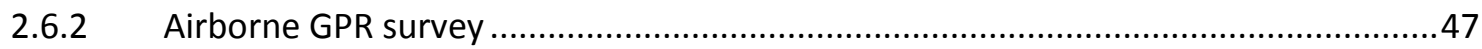

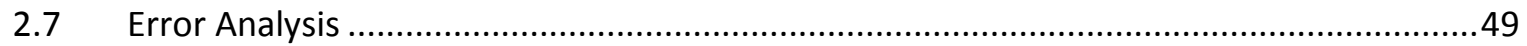

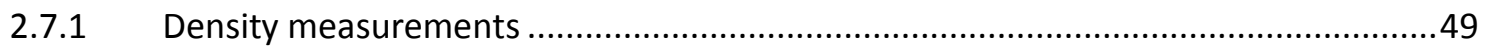

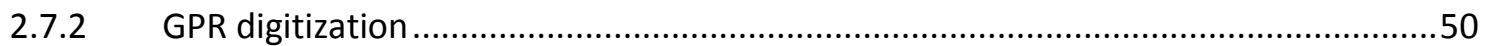

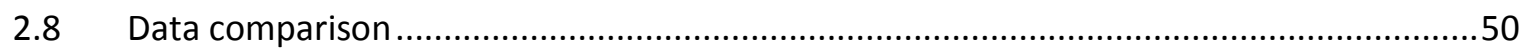

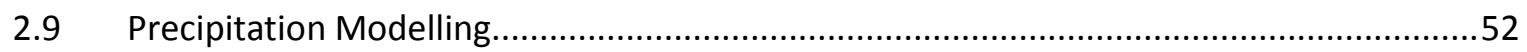

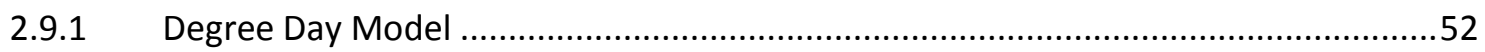

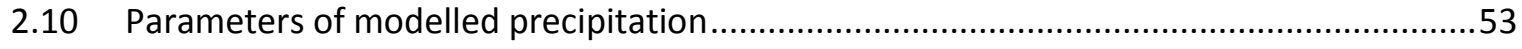

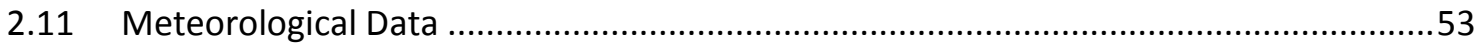

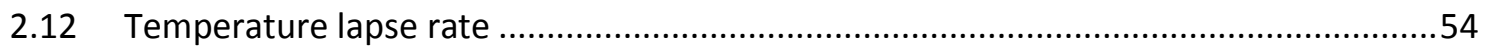

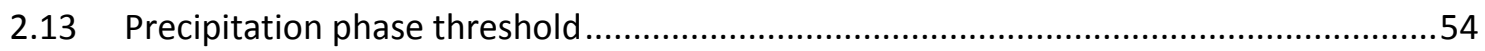

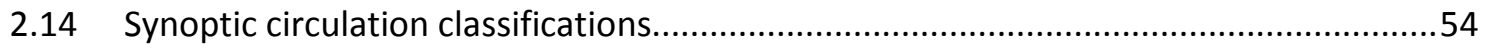

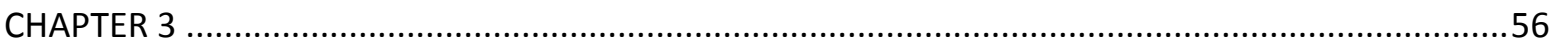

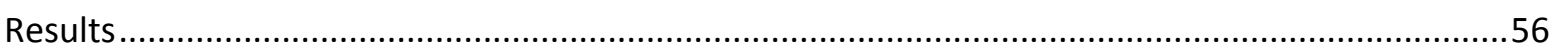




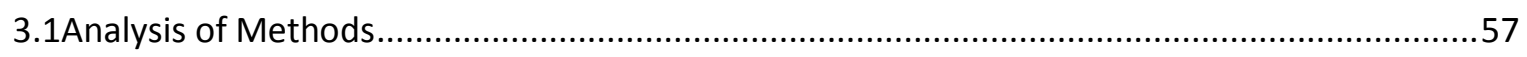

3.1.1 Relationship between Two-Way Travel Time and Snow Water Equivalent ..............57

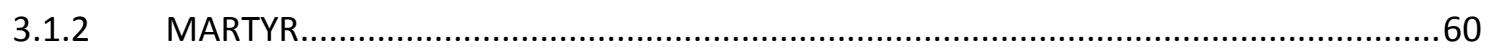

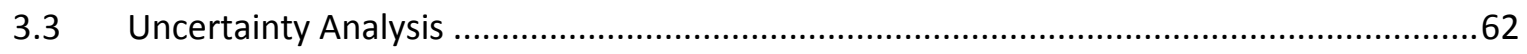

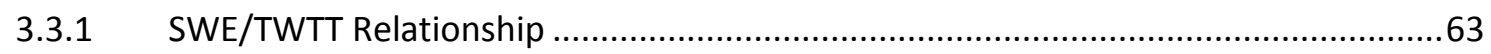

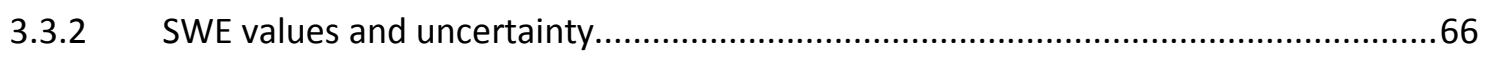

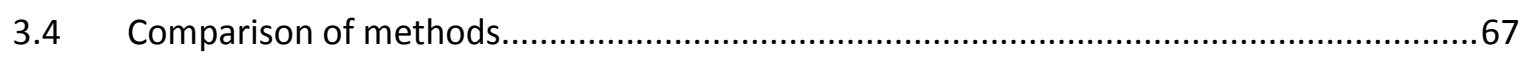

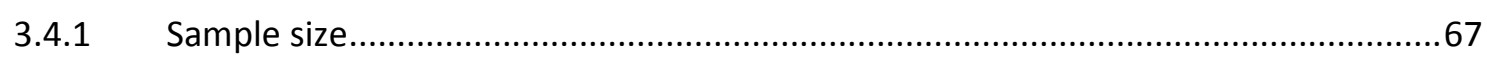

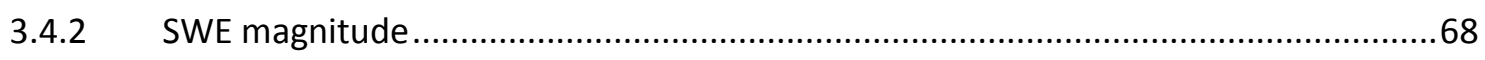

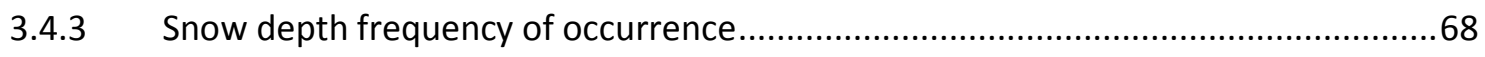

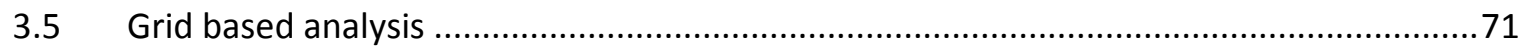

3.5.1 Grid based comparison uncertainty ....................................................... 71

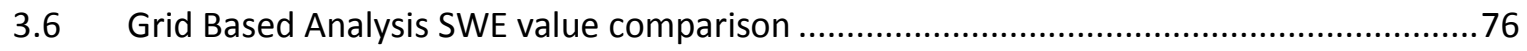

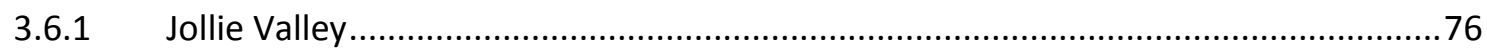

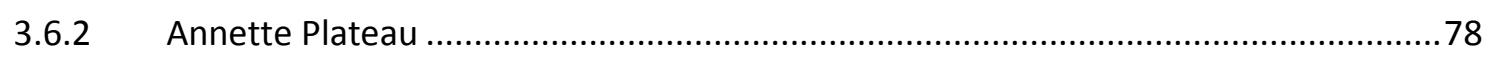

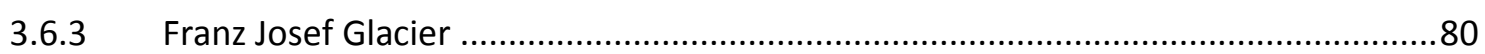

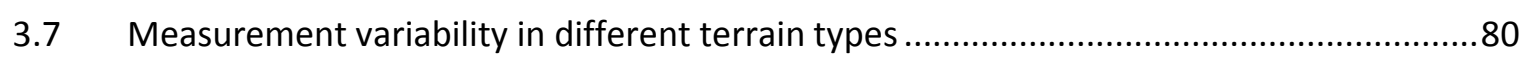

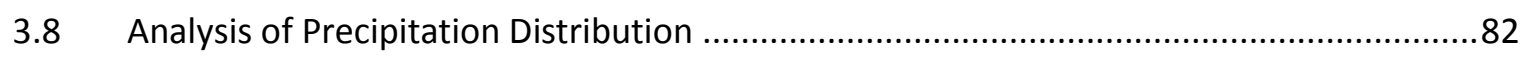

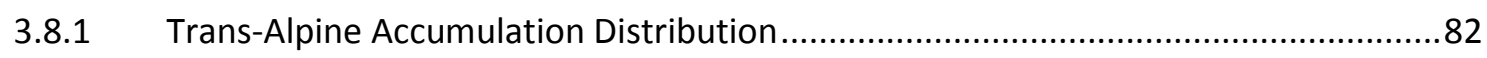

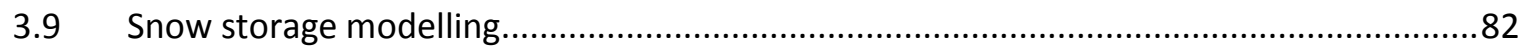

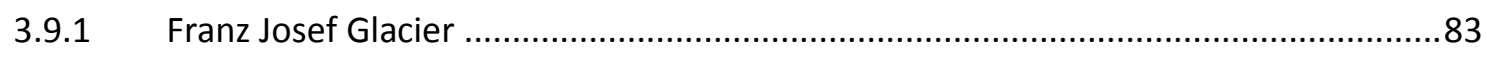

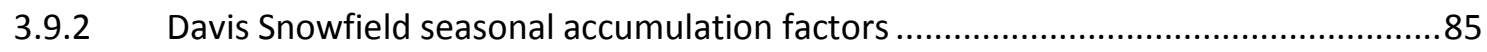

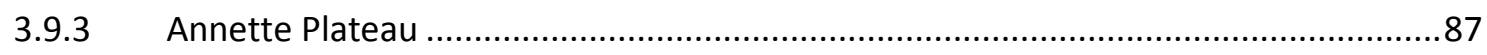

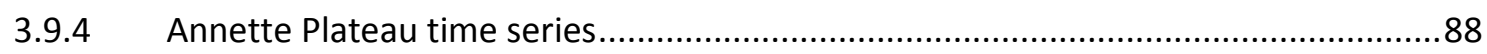

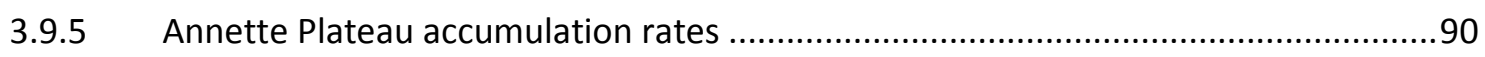

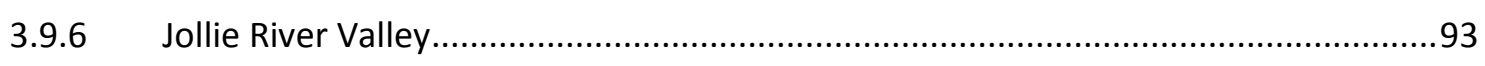

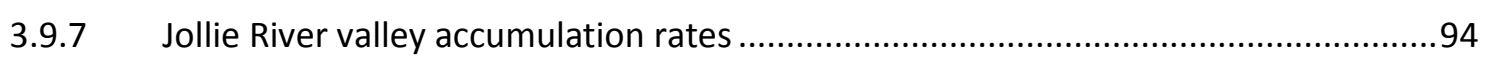

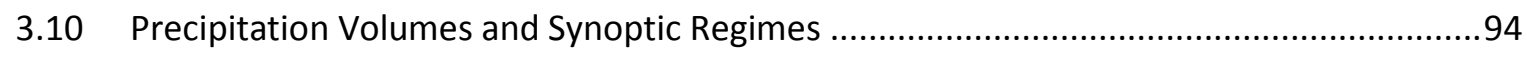

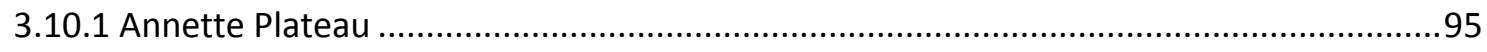

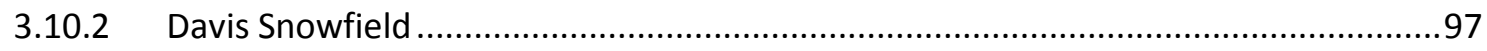

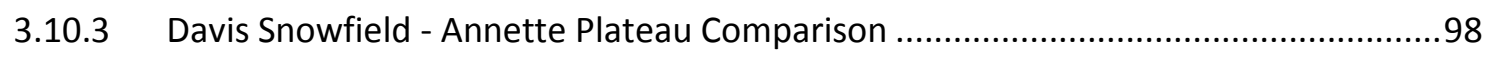

3.10.4 Spillover; simultaneous accumulation events ..............................................99

3.11 Trans-Alpine snow distribution.................................................................... 101

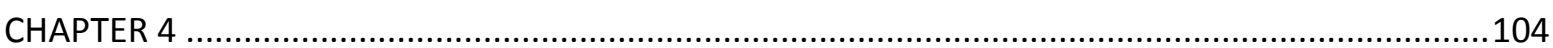


4.1 Techniques for measuring snow accumulation in maritime environments .....................104

4.2 Snow depth measurement in deep snow packs ..........................................................105

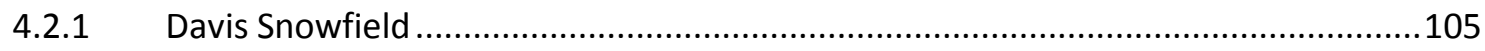

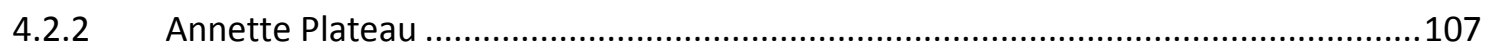

4.3 Snow depth measurements in complex terrain...........................................................108

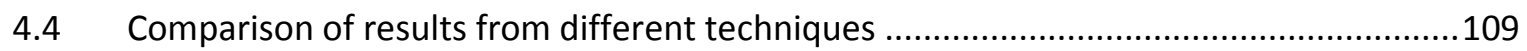

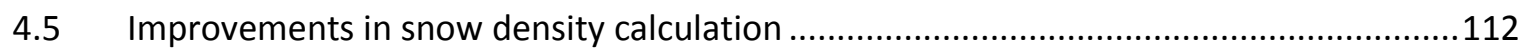

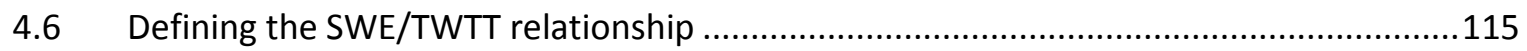

4.7 Using Snow accumulation estimates to estimate long term precipitation ......................117

4.8 Trans Alpine Precipitation; location of the precipitation peak ..........................................118

4.8.1 Comparison with the precipitation measurements west of the divide ....................120

4.8.2 Comparison with precipitation measurements to the east of the divide..................122

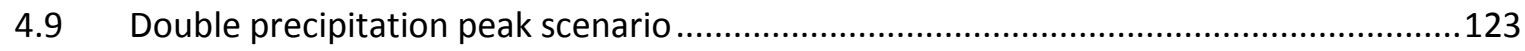

4.10 Relationship between synoptic type and accumulation volumes ..................................124

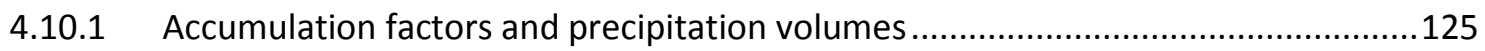

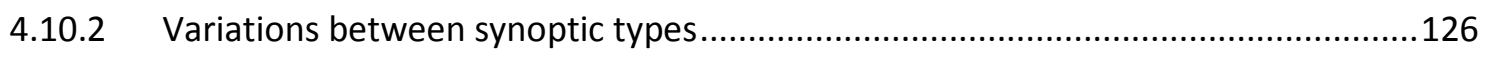

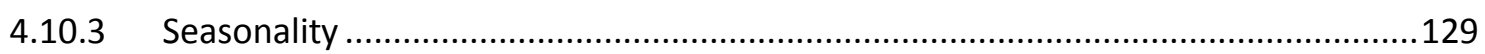

4.11 Implications for glacier mass balance and hydro lake inflow modelling ..........................131

4.12 Implications of this data with patterns of IPO, ENSO and SAM ......................................132

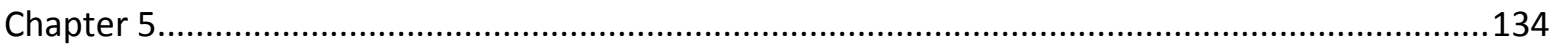

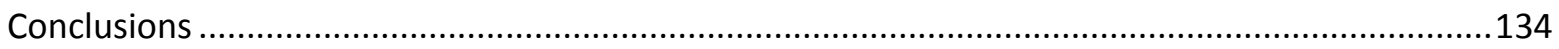

5.1. Improvements over traditional snow measurement techniques ..........................................134

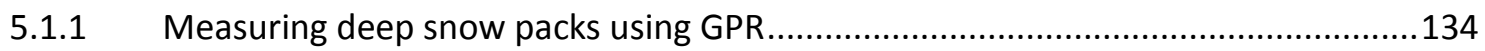

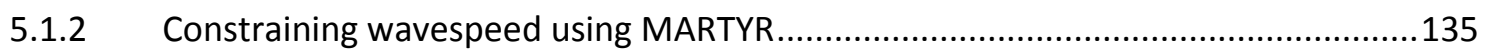

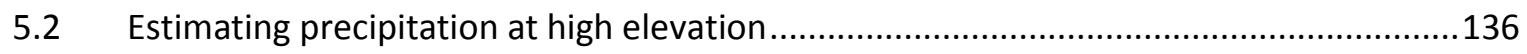

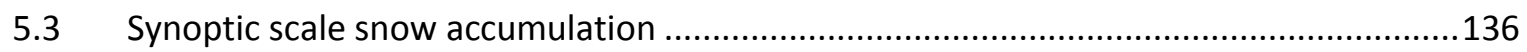

5.4 Implications for glacier mass balance and hydro inflow modelling .................................137

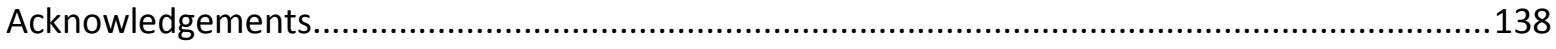




\section{CHAPTER 1}

\section{Introduction}

\subsection{Background}

High albedo, low thermal conductivity and considerable spatial and temporal variability, seasonal snow cover over land plays a key role in governing the global radiation balance, the primary driver in the earth's atmospheric circulation and climate. The location and duration of snow cover are of important seasonal variables. Snow cover is the most seasonally variable land cover feature on earth, for the northern hemisphere snow cover ranges from $7 \%$ to $40 \%$ of total land area (Hall, 1988).

Little is known of high-altitude precipitation and snow accumulation rates in the Southern Alps of New Zealand. Much of the precipitation falls as snow resulting in deep snow packs. Although the precipitation falls in remote areas, the economic benefit from this resource is considerable. East of the Southern Alps, discharge from the mountainous Pukaki catchment, of which Tasman Glacier provides $10 \%$ of the discharge (Thompson, 2002), supplies the Waitaki hydroelectric scheme which produces $30 \%$ of New Zealand electricity (Fitzharris, 2004), and irrigation for lowland agriculture. The 'iconic' Franz Josef, Fox, and Tasman glaciers are driven by snow accumulation and are of economic value by way of tourism revenue.

Orographic processes are the main driver of precipitation distribution across the Southern Alps (Wratt, et al., 1996). Previous catchment-based precipitation measurement studies have not resolved the pattern of orographic precipitation, especially at high elevation where traditional rainfall measurement is impossible because of the high proportion of solid precipitation. Despite these uncertainties, snow distribution modelling has been used to estimate the water resources in seasonal snow (Fitzharris \& Garr, 1995) and glacier mass balance (Anderson et al, 2006) with little constraining data. 
Ground-penetrating radar (GPR) is proposed as a useful tool for resolution of snow accumulation and precipitation rates at high elevations. As terrain in mountainous regions is diverse in type and remote by nature, accumulation and precipitation assessment can be influence by surrounding topography. GPR can be used to produce spatially-extensive measurements of snow accumulation in an efficient manner (Machguth et al., 2006) allowing this small-scale spatial variability to be assessed. Analysis of internal reflection horizons within the snow-pack radargrams allows sub-seasonal analysis of temporal patterns of snow accumulation. A simple snow accumulation model can then be used to infer precipitation rates, on long term, annual, and synoptic scales.

\subsection{Precipitation gradient across the Southern Alps}

\subsubsection{Lack of high elevation record}

Despite seasonal snow being a sensitive indicator of climate change, and of economic importance, there is little information on high elevation precipitation or snow accumulation in New Zealand. Collection of such information is a difficult task as snow distribution patterns in complex terrain are difficult to measure. Traditional precipitation measurements from in-situ liquid precipitation gauges are not suitable for recording precipitation affected by wind, topography and vegetation. These influences are compounded by the burying, blocking, and freezing of gauges in cold temperatures (Henderson \& Thompson, 1999; Kerr, 2009 b) resulting in the under recording of precipitation depth in high accumulation areas.

The relationship between snow accumulation and precipitation is not straight forward. During deposition snow is subjected to the influences of the relationships of wind, topography and vegetation (Lehning et al., 2008b; Liston \& Sturm, 2002; Winstral et al., 2002). Post deposition redistribution of snow driven by wind, gravity and preferential deposition by topographic undulations and ground cover shroud how representative point measurements of snow depth are over larger areas (Dadic et al., 2010b). In order to develop an intimate knowledge of snow distribution processes, intensive manual measurements must be made over large areas (Anderson et al., 2006; Purdie et al., 2011b; Taurisano et al., 2007). Such studies are highly intensive, and realistically, only suitable for short term periods due to the high expense and the harshness of the environment. Widespread and accurate 
assessments can be achieved though efficient sampling techniques such as GPR under these conditions (Taurisano, et al., 2007).

\subsubsection{Orographic rainfall}

The process of orographic precipitation in its most basic state is one of the passage of moist air over a topographic barrier. An air parcel is forced to rise to pass over the barrier and in doing so the air cools, reaches saturation point, then depending on atmospheric temperature, ice particles or liquid precipitation form (Sturman \& Tapper, 1996). The size of the upwind barrier has been shown to have a relationship with the amount of precipitation (Barstad et al., 2007). Although the height of the Southern Alps is significant and comparable to other coastal ranges throughout the globe i.e. the Norwegian Alps, and Madagascar, the narrow coastal plane on the Southern Alps western edge creates uplift gradients of $100 \mathrm{~m} / \mathrm{km}$, double that observed in the Andes (Ibbit et al., 2001).

The process of orographic rainfall is site specific. A review of global orographic precipitation studies by Kerr (2009b) describes how the influential factors of orographic precipitation process remain the same, yet the relative importance of wind speed, wind direction, season, slope orientation and elevation vary with location (Winstral, et al., 2002). The consequence of this is that orographic precipitation peaks may be located to windward, at the crest, or to the lee of various topographic barriers. The patterns of these distributions vary at storm, seasonal, annual and longer time scales.

Despite the high orographic uplift rates in the Southern Alps, the intensity and duration of precipitation suggests the requirement for enhancement of the orographic process. An explanation for this process and western bias for the precipitation peak is explained through the formation of a barrier jet flow during frontal passage (McCauley \& Sturman, 1999; Revell et al., 2002; Sinclair et al., 1997; Wratt et al., 2000). Observations of a north-easterly wind during an otherwise north-west flow preceding cold frontal systems have been made up to $60 \mathrm{~km}$ off shore, in conjunction with the presence of sub-peak elevation wind shear. Most of the deceleration and change of wind direction occurs in the lowest $500 \mathrm{~m}$ of the atmosphere and generally below $2000 \mathrm{~m}$ a.s.l (McCauley \& Sturman, 1999) and normal to the orientation of the reduction in pressure gradient. The barrier jet occurs in $11 \%$ of weather observations. The upper level climate data associated with the barrier jet flow is always of north-west orientation (McCauley \& Sturman, 1999). The effect of this process is 
the development of a gentler uplift gradient creating a four to six hour uplift time before reaching the divide. Such processes allow for a more gradual growth of precipitation droplets and provide a seeder mechanism for coalescence. Following on from this seeded rainfall theory a relationship between rainfall and the presence of pre-existing synoptic cloud has been established (Purdy \& Austin, 2003). The synoptic cloud acts to ripen orographic cloud allowing high rainfall rates to occur. Another form of cloud seeding and enhanced orographic coalescence is the provision of ice particles from pre-existing synoptic cloud (Purdy et al., 2005) indicating that this process is not seasonal. The extent that this process has on rainfall totals is not yet known.

\subsection{Estimation of high elevation precipitation from snow measurements}

An indirect method of estimating high elevation precipitation is from river discharge (Thompson, 2002). Draining rivers reflect the volume of glaciarisation of their catchments. Rivers with higher elevation catchments tend to receive more frozen precipitation and consequently have a lag in discharge between observed precipitation and increase in stream flow. To this end, glaciated catchments, which are at high elevation store precipitation longer? This lag in discharge creates a seasonal component in hydrographs. Winter is represented in these seasonally affected hydrographs by a reduction in flow through the storage of frozen precipitation. Timing of melt is controlled by the length of time that the accumulation season lasts, a function of elevation and climate interacting to affect temperature. Higher elevation catchments, such as the Hooker River (within the study area) peak in discharge during late spring and summer. For lower un-glaciated catchments such as the Jollie River valley, peak discharge occurs earlier and winter and spring discharges are relatively higher than catchments close to the Alps (Anderton, 1973). Snow volumes have been estimated by subtracting base flow from hydrographs to give the seasonal snowfall component (McKerchar \& Henderson, 2003).

\subsubsection{Snow depth measurement}

The pattern of precipitation, storage, lag and discharge is of interest to end users of water resources. Users include hydroelectric power generators, agriculture, and ski fields. Snow storage is also important in calculating glacier mass balance and ultimately in driving glacier advance and retreat (Anderson, et al., 2006). Early efforts of surveying snow 
distribution were carried out by power companies (Anderton, 1973; Archer, 1970; Henderson, 1993). There is also a concentrated focus on avalanche control on the Milford Road, which is susceptible to severe avalanching (Hendrikx et al., 2005).

Snow accumulation measurement techniques have been derived for several end uses and at different spatial scales. The ski industry uses a daily measurement approach via self standing rulers attached to boards that sit on top and within the snow pack (Purdie et al., 2011b). This method is useful for daily accumulation measurements, but requires high maintenance. Using a metal rod to probe to a known surface is a well used methodology in snow depth measurement (Clark et al., 2011). This method is reliable when snow depth is shallow and a hard subsurface layer exists, but can prove to be difficult at deeper snow depths and has been identified as being in need of verification by other means such as snow coring (Kjøllmoen, 2005 ). At the time of this study winter time precipitation records were limited to one climate station with snow pillow at $2000 \mathrm{~m}$ a.s.1 at Rose Ridge. This station produces data of variable and unreliable, but not inaccurate, quality from its snow pillow (Andrew Harper, 2009 pers com.).

Management of New Zealand's vast regions of difficult-to-access seasonal snow would benefit from satellite remotely sensed data (Fitzharris \& McAlevey, 1998). Remotely sensed investigations of snow extent have been undertaken (Sirguey et al., 2009) but can be subject to misrepresentations of snow extent by atmospheric and terrain interference. The interaction of cloud cover, shadowing and reflectance exaggeration brought about by steep terrain reduces the accuracy of such assessments. Although some attempt has been made at reducing these uncertainties make remotely sensed data difficult to interpret. The satellite sample pixel resolution of $250 \mathrm{~m}$ and above is too large to accurately resolve snow quantity at terrain scale distributions that can affect snow melt estimation without a large validation campaign. In addition to all of the deficiencies, snow density and depth measurements must still be used to calibrate satellite data in order to determine snow water equivalent snow depths (Stanzel et al., 2008).

Crevasse stratigraphy measurements where end-of-summer net accumulation depths are measured on crevasse walls are point measurements of the linear structure of the previous summer surface. The contrast of a sediment rich summer layer from the snow of the accumulation season is relatively easy to locate at the end of the accumulation season. 
Crevasse stratigraphy investigations suffer from similar aspects of data misrepresentation as liquid precipitation measurements and other point measurements (Meier et al., 1997; Pelto, 1997). Variation of measured snow depth values may be attributed to the interaction of site exposure at the time of deposition and turbulent air masses, and deposition from local mass gravitational transport. Variations in the local representativeness of crevasse stratigraphy based snow depth measurements that are more difficult to account for are turbulent heat fluxes, which cause preferential melting during the ablation season. This is important as the movement of a glacier over a mass balance year may expose the measured site to processes which under or over estimate precipitation values for the specific measured location (Anderson, et al., 2006).

Snow measurement efforts have generally been short term projects spurred on by hydroelectric companies or glacier mass balance studies, with no formal long term catchment wide studies at a resolution appropriate enough to encompass terrain scale variation in snow distribution, with the recent exception of Clark et al., (2011). A culmination of factors, including remoteness, inappropriate equipment and lack of long term interest has led to this situation. Numerical estimation of snow volume goes some way towards solving this problem, but appropriate verification data is still required.

\subsubsection{Snow depth estimation}

Measuring snow depth directly is the most accurate method to assess snow depth, but point measurement results are difficult to extrapolate over large areas of complex terrain. However, point measurements of snow depth provide the basis on which snow volume estimations are made or validated, at either the point scale or in a distributed manner (Lundberg et al., 2006).

Snow distribution is modelled either by empirical models, or physically based models. There may be no clear boundary between a physical process based model may use a covariate to derive a result for the modelled variable as part of an algorithm to mathematically replicate a natural process. For instance gravitational mass transport of snow is often parameterised on the basis of slope angle (Gruber, 2007). Aspects of both modelling types are provided for comparison below. 
Precipitation model outputs in cold regions are usually presented in terms of snow water equivalence (SWE) to account for the variations in snow density with depth. This allows comparison with liquid precipitation estimates and with snow estimates from different regions.

\subsubsection{Physical modelling}

Physical process based models attempt to describe variables in natural systems using laws that express general principles natural systems (Guinot \& Gourbesville, 2003). The necessary data input for such models include geometric descriptions of environmental parameters (terrain, energy inputs/outputs) which serve as controlling influences for the modelled physical variables. The use of natural laws when calculating physically based models affords the assumption that physical models are valid for a wide range of situations, including situations that have not yet been observed as the laws used to calculate the physical process are not expected to change.

Modelling snow distribution requires the calculation of individual natural processes such as but not exclusively; deposition, ablation, redistribution via wind and gravitational influence. Such processes may be regulated by the cold content of snow (Pfeffer \& Humphrey, 1998) influencing internal accumulation (Marshall et al., 1999), and seasonal alterations in albedo (Dadic et al., 2010a; Jaedicke \& Gauer, 2005; Lehning et al., 2006; Liston \& Sturm, 2002; Winstral \& Marks, 2002). These influences operate on micro to regional scale (Jaedicke \& Gauer, 2005), the scale and complexity of such influences can be difficult to measure and computationally intensive to model (Dadic et al., 2008; Lehning, et al., 2006; Liston \& Sturm 2002; López-Moreno \& Nogués-Bravo, 2005). Increasing the range of modelled processes does not necessarily increase the accuracy or precision of the model output; physically based models are generally a simplification of reality and reduce data inputs to the necessary parameters.

Physically based models require detailed and accurate validation data to allow confidence in the representation of reality. Information on climate and habitat, including wind fields, terrain models, vegetation type and cover needed to validate the snow process can be scarce. Such data scarcity is especially problematic when attempting to calculate a snow volume in a non-homogenous terrain environment as dynamic variables such as snow density may at 
times vary greatly, and other times insignificantly (Stanzel, et al., 2008). Good replication of snow cover and depth and density distribution have however come from these models in both rolling (Jaedicke \& Sandvik, 2002; Liston \& Sturm, 2002) and mountainous terrain (Dadic, et al., 2010a; Lehning et al., 2008a) and in shallow and deeper snow packs respectively.

The data to constrain a physically based model and computational effort to calculate snow distribution was not available for this study. A simpler methodology was sought that required know data inputs in order to compare with measured data at a location in order to calibrate the snow accumulation model.

\subsubsection{Empirical modelling}

Empirical models aim to relate a given set of 'input' variables to 'output variables' without attempting to identify and describe the physical processes that relate these inputs (Refsgaard 1996). The use of a co-variate in determining a predictive equation might include measured data such as rainfall intensity to calculate river discharge.

To model precipitation the empirical modelling approach uses an extrapolation of data from a known point, often in a lowland setting, to produce a precipitation estimate for the location of interest. Often only the effect of topography is accounted for, and only for the purpose of controlling temperature via elevation through an environmental temperature lapse rate. These are the controlling influences on precipitation type, accumulation and melt rates (Hock, 2005). Subsequently, no estimation of the effect of redistribution of snow by wind, gravity, or the effect topography may have on the snow pack are made, but they are included in the calculated accumulation product (Schuler et al., 2008). The effects of these influences are averaged within the model by the accumulation and melt indices which incorporate precipitation type, density, albedo and redistribution, snow particle evolution, debris content of snow, slope angle, aspect and shading, and other processes influencing snow morphology.

A snow and ice temperature index model, often referred to as a degree - day model, relates melt and accumulation by a relationship between measured precipitation to the sum of the air temperatures for the same time period (Hock, 2005). Such models can also reflect 
smaller time period to index the input data by, such as the degree-hour model. The advantage of this approach is that it requires only two data inputs and calibration through empirical relationships to estimate the accumulation and melt of precipitation for a specific point. Therefore it is important to have accurate data inputs. The error in some precipitation estimates in New Zealand is around 17\% (Kerr, 2009b). Errors in precipitation measurement using gauges are caused by wind, evapotranspiration, and precipitation phase can be calculated to give under-catch estimates. The estimation can then be added back into the precipitation record to 'correct' the data (Kerr, 2009b). Recognition of the corrected data not being actual measured data is important. Temperature data, the other component of the model, is widely available and is extrapolated to site elevation using a known environmental temperature lapse rate (Stuart, 2009). The availability of lowland temperature and precipitation data, and the extrapolation to high altitude sites form the backbone of snow accumulation modelling in New Zealand (Anderson, et al., 2006; Fitzharris \& Garr, 1995; Kerr, 2005; 2009b; Stuart, 2009).

Temperature index models have been improved by the addition of seasonal and storm scale relationships between snow processes such as albedo and melt (Hock, 2005; Woo \& Fitzharris, 1992b). Wind, which effects the turbulent heat fluxes for melt (Brock et al., 2006) has been related to the depth and likelihood of precipitation occurring at a location represented by a point data input (Kerr, 2009b). The empirical nature of models limits the applicability of the relationships to unmeasured regions because of the need for site specific calibration based on detailed measurements and the spatial variability of snow accumulation (Liston, 1999; Schuler, et al., 2008).

Estimated deposited snow depth values can change throughout the course of an accumulation season. Climatic influences may not be well represented by the controlling multipliers for precipitation of snow melt within a temperature index calculation. With elevation being the major controlling element for phase of precipitation and melt, cross mountain distribution may not necessarily be accurately represented. This is especially so if verification data is collected in a location or at a time not representative of the larger area being modelled (Anderton, 1973; Machguth et al., 2006; Yamaguchi et al., 2004).

Understanding all of the processes that occur, and to what extent they occur at each location is important in interpreting and calculating estimations of precipitation at the slope scale. 
The results of empirical modelling tend to be spatially lumped, leaving no appreciation for variance in the estimate or the individual effects of slope scale processes. Calculating precipitation at small scales using empirical relationships is therefore only accurate if calibration measurements encompass the variation at the study site.

Direct measurements of snow data for verification of models is either of small spatial scale (Halstead, 2009), and generally for one temporal point at the end of a season. In situations where direct measurement data is not available estimations have been compared with satellite imagery and snowline elevation recession curves (Fitzharris \& Garr, 1995) and tuning with known water balance (Kerr, 2009b). These models have produced good results in the estimation and prediction of glacier mass balance and stream flow discharge estimates in New Zealand and (Anderson, et al., 2006; Braithwaite \& Zhang, 1999; Hock, 2005; Jo'hannesson et al., 1993) at the seasonal scale but are less able to replicate small time scale patterns such event or flood flow stream discharge estimates. Development of shorter time frame melt or accumulation factors within temperature index models may further increase the applicability of temperature index models.

\subsection{Ground Penetrating Radar (GPR)}

Problems associated with SWE calculation in New Zealand are little different to what has been experienced in many mountainous ranges where measurements of snow is of interest. Measurement of snow on a scale large enough to yield catchment wide data is labour intensive, often requiring large teams deployed in high risk situations, yielding datasets that are limited by the problems associated with snow depth determination in high accumulation areas.

\subsubsection{Theory}

The geophysical technique of Ground Penetrating Radar (RAdio Detection $\underline{\text { And }}$ Ranging) involves the propagation of electromagnetic energy from a transmitter to a receiver. The energy is transmitted in short successive pulses which travel with a radio wave speed governed by the dielectric constant and electrical conductivity of the material of interest. The reflected wave form is recorded showing amplitude variations. High amplitude reflections occur at changes in relative dielectric permittivity $\left(\varepsilon_{\mathrm{r}}\right)$. 
Dielectric permittivity describes a materials ability to attenuate the radar signal, and is described relative to a vacuum. The electrical conductivity $(\sigma)$ of a material is the ability that it has to conduct electrical charges. In snow and ice this equates to impurities within the snow at grain boundaries, as ice is relatively transparent to electromagnetic radiation. These two factors combined control the wave speed and strength of radar reflections through snow.

In snow, the returned radar signal traces that contain information on the state of the snow pack at the date of survey, which may be used as a proxy for determining previous environmental conditions. GPR investigations identify Internal Reflection Horizons (IRH), interpreted as surfaces that underwent process of metamorphosis at the same time, enabling the development of an area-wide homogeneous isochrones that share dielectric properties. The snow stratigraphy is then assumed to maintain these qualities throughout subsequent depositional sequences. This is the basis of spatial investigations of snow pack characteristics. Successive depositional periods further develop the IRH allowing for the interpolation of snow pack information between calibration points over known periods of time.

\subsubsection{Applications in snow}

The ability of GPR to resolve internal snow pack stratigraphy has seen the technique become a common tool in polar and alpine glaciology. In the Northern Hemisphere GPR has been utilised on snow and ice masses in Greenland (Dunse et al., 2008; Maurer, 2006), Svalbard (Dunse et al., 2009; Pälli et al., 2002; Pälli et al., 2003; Pinglot et al., 2001; Taurisano, et al., 2007; Winther et al., 1998) and northern and central Europe in Norway, Sweden and Switzerland (Chasseriau et al., 2006; Kohler et al., 1997; Machguth, et al., 2006; Marchand et al., 2003). Investigations on the Austfonna icecap and Nordenskjöldbreen, Svalbard, have enabled accumulation rates to be assessed over a wide scale (Pälli, et al., 2002; Pinglot, et al., 2001). The high resolution data available from a GPR enabled the calculation of an area wide precipitation accumulation index for the Austfonna icecap (Dunse, et al., 2009; Pinglot, et al., 2001; Taurisano, et al., 2007). Snow distribution model validation and hydrological studies have also been improved using GPR (Jaedicke \& Sandvik, 2002). 
The tracking of IRH allows the calculation of seasonal mass balance of a glacier by mapping the distribution of its glacier facies (Dunse, et al., 2008; Dunse, et al., 2009; Machguth, et al., 2006). The high resolution and ability to cover large areas quickly has enabled snow distribution variations to be mapped, refining the error associated with point measurements of accumulation (Winther, et al., 1998). Successive mass balance years are have also been calculated by mapping of radioactive layers of a known date determined from ice cores in Austfonna, Svalbard. Large scale accumulation rates and variability were described from 1963 to 1986, and 1986 to 2001. The deposition variability is of significant interest at scales of slope $(50-100 \mathrm{~m})$ and cross mountain $(1-10 \mathrm{~km})$ scales. Variations in larger spatial dimension accumulation rates were averaged out with scale. Most of the variation was attributed to redistribution by wind (Pinglot, et al., 2001).

The ability to extract information and accumulation rates from strong IRH is interesting for a mid-latitude investigation in deep annual snow packs, as the climate is such that IRH may present themselves clearly at the time scale of passing weather systems. This may enable accumulation rates to be established at the storm scale in remote regions where these rates have not previously been measured. The product of such an investigation may provide snow storage estimates which may be useful for resource planning.

Few GPR snow accumulation surveys have been carried out in the mid latitude Southern Hemisphere. The undertaken surveys have been small scale point specific surveys with no accompanying validation for collected accumulation figures (Jol et al., 2004; Watson, 2008). In the study undertaken by Jol et al. (2004) validation of the previous end of summer snow is difficult due to high accumulation figures ruling out the use of snow pit and probe validation, and no crevasse stratigraphy data was taken. The estimation of approximately 10 $m$ snow depth was made. The investigation by Watson (2008) was a low frequency ice depth study that produced a series of sub-horizontal IRH that were interpretable as accumulation layers.

\subsubsection{Profile validation and Two Way Travel Time (TWTT) calculation}

The non homogeneous nature of snow density within a snow pack is due to a combination of atmospheric and topographic factors including temperature, relative humidity, radiation and wind. Rain on snow pack events and melt/freeze sequences are common in maritime 
environments resulting in higher values of snow densities than in more continental Scandinavian and European regions (Lundberg, et al., 2006). Altitudinal changes in density are observed when the local atmospheric conditions may bring rain on snow events therefore altering the structure and continuity of insitu isochronous layers (Dunse, et al., 2008; Dunse, et al., 2009; Machguth, et al., 2006). Wind redistribution of snow, as a result of local and small scale topography alter the patterns of snow deposition (Jaedicke \& Sandvik, 2002). Surface roughness from wind scour may disguise changes in dielectric permittivity, as it effectively mixes precipitation event layers together beyond the resolution of GPR (Maurer, 2006; Pinglot, et al., 2001). This means that having sufficient and logically located calibration points for radar profiles to ensure good correlation between the two data sets. This may result in more efficient (Lundberg, et al., 2006) and accurate calculations of snow depth and water equivalence (Bradford et al., 2009) for hydrological and ice core investigations.

There are a range of techniques available to collect necessary data with varying level of disruption to the area of investigation. The standard and least invasive method for collecting calibration data is the common mid-point (CMP) survey (Bradford, et al., 2009). CMP surveys involve the separation of transmitting and receiving antennae about a point usually comprising of a strong reflector. This technique yields a series of known distances and TWTT enabling density to be calculated. This technique is suitable for cold snow as the increased distance of each sample will undergo an increase in attenuation through increasing $\varepsilon_{\mathrm{r}}$ relative to the last trace if there is water content in the snow. A GPR with individual transmitting and receiving antennae is required to perform this technique.

Direct dielectric permittivity measurements can be acquired through portable and laboratory based dielectric probe measurements of shallow core data (Eisen et al., 2003; Kohler, et al., 1997). Direct electronic density measurements have been made with neutron scattering probes (Dunse, et al., 2009; Morris \& Cooper, 2003). These techniques require technology that was not available for this study.

Calculated permittivity derived from density measurements from snow pits (Jaedicke \& Sandvik, 2002; Machguth, et al., 2006; Sinsalo et al., 2003; Yamamoto et al., 2004) is a more invasive and labour-intensive technique, yet can be completed with cheap and widely available equipment. These direct and calculated techniques produce results that compare 
well with each other (Harper \& Bradford, 2003; Hawley et al., 2008), and manual techniques such as manual probing of the snow pack along a radar transect (Marchand \& Killingtveit, 2005).

\subsection{Area of Research}

\subsubsection{Study location.}

The Southern Alps of the South Island of New Zealand are located in the mid latitudes between $-44^{\circ} 30^{\prime} 00 ; \quad 168^{\circ} 20^{\prime} 00$ and $-42^{\circ} 23^{\prime} 00 ; 172^{\circ} 20^{\prime} 00$. The Southern Alps are a product of the Alpine Fault plate boundary of the Pacific and Indo-Australian tectonic plates. The Southern Alps run roughly parallel to the west coast, but preferentially on the western side of the SE/NW orientated relatively long thin South Island. This geographic configuration results in a narrow, $\sim 15 \mathrm{~km}$ coastal plain extending from the Tasman Sea to the foot of a mountain range with a main axial ridge of around $2000 \mathrm{~m}$, but extending up to Mount Cook at $3754 \mathrm{~m}, \sim 35 \mathrm{~km}$ from the west coast. The range reduces in elevation to the plains $75 \mathrm{~km}$ to the east which extend for around $50 \mathrm{~km}$ to the Pacific Ocean (Figure 1.1).

The two catchments used in this study, the Franz Josef / Waiho to the north-west and Lake Pukaki to the south-east are separated by a $29 \mathrm{~km}$ section of the $500 \mathrm{~km}$ long main axial ridge of the South Island. The study area comprises the accumulation area of Franz Josef glacier (Davis Snowfield region), the Annette Plateau, and the Jollie River catchment in the east (Figure 1.2). This area encompasses the highest peaks in the Southern Alps with a mean peak height of 2761m (Figure 1.1) including Aoraki / Mount Cook (3754m).

It is New Zealand's geographic position in relation to the mid latitude Southern Hemisphere westerly flow (Sinclair, et al., 1997), the $2000 \mathrm{~km}$ distance from the closest upwind landmass (Ibbit, et al., 2001), and the high topographic barrier of the Southern Alps, perpendicular to the synoptic flow, which provides the conditions for the large precipitation gradient across the Alps (Chinn, 1979). Proximity to the coastline in all directions means that New Zealand's climate, and therefore snowpack, is of a maritime nature. 


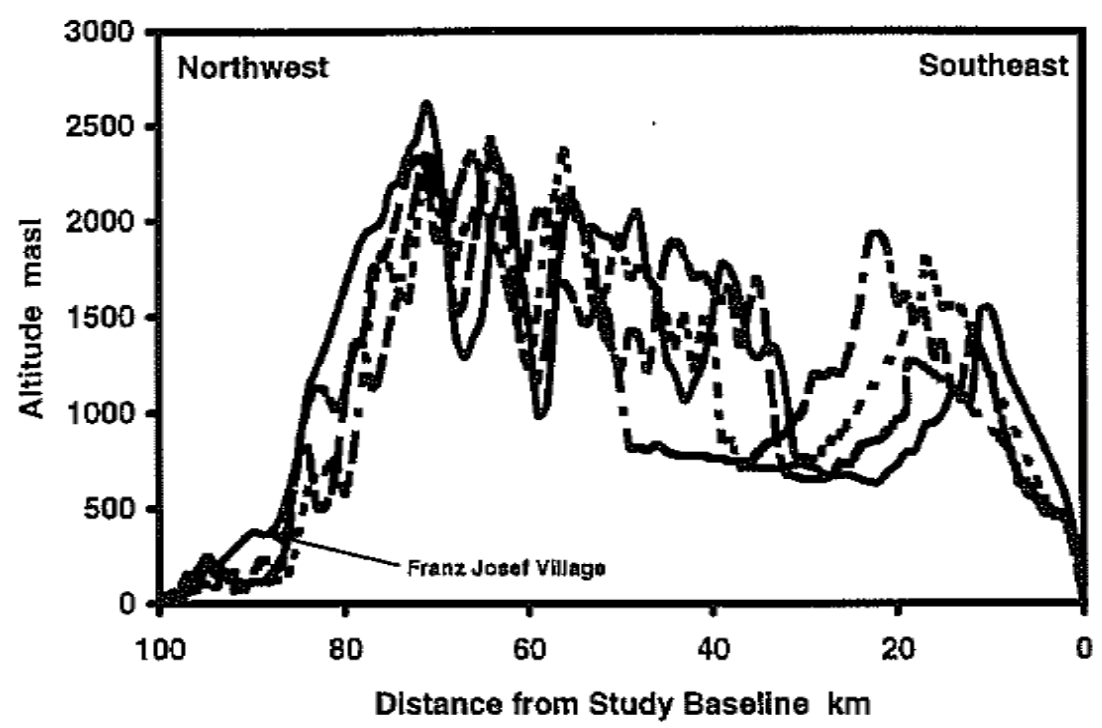

Figure 1.1. Elevation transect lines at $4 \mathrm{~km}$ resolution, perpendicular to the Southern Alps in the Franz, Josef / Mount Cook region (Henderson \& Thompson, 1999). The precipitation baseline refers to an arbitrary line extends from Puyseguer Point in the south-west South Island to Oxford in Canterbury. The line runs parallel to the main divide of the Southern Alps.

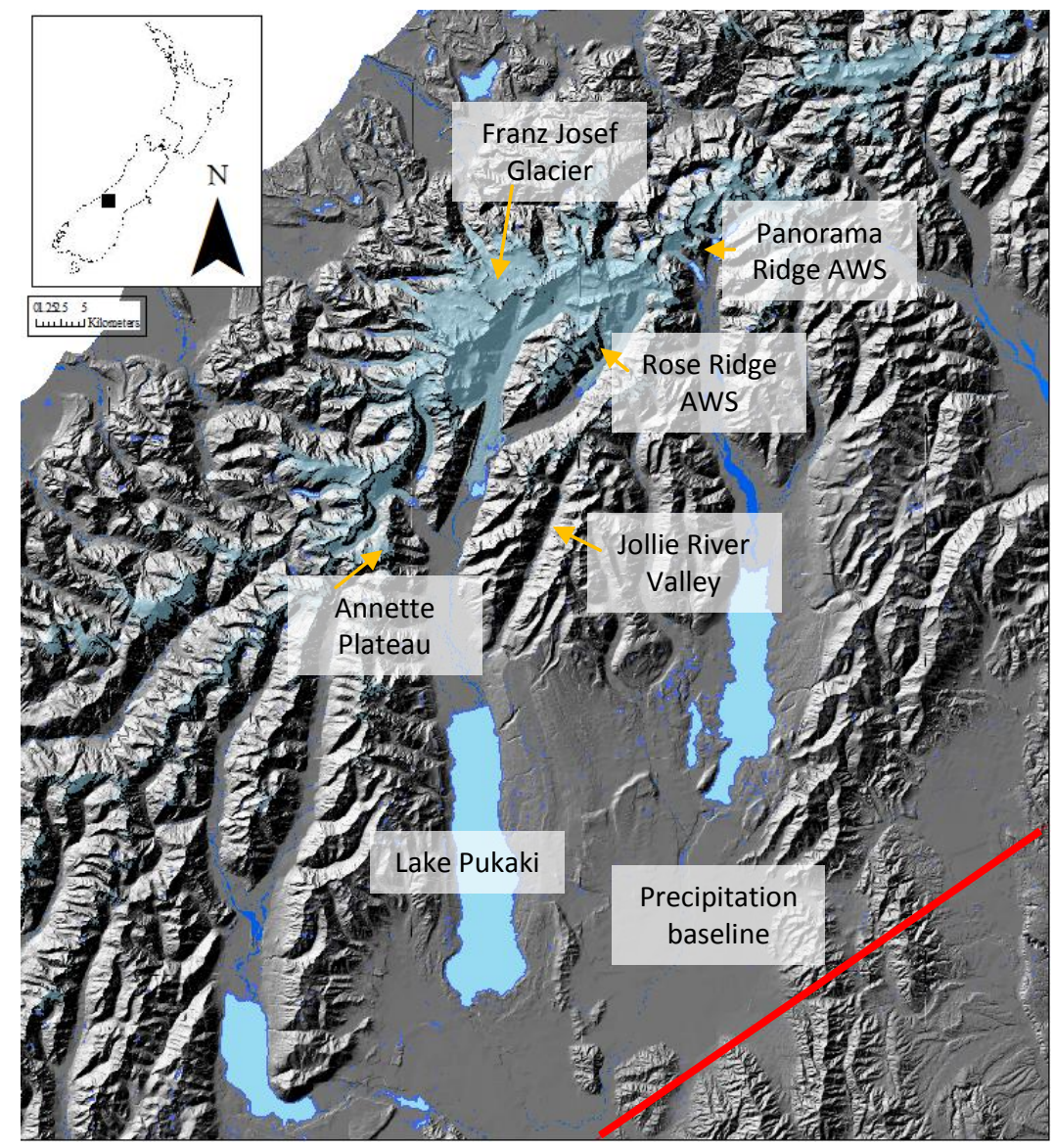

Figure 1.2. A regional map showing the Southern Alps. In the study region both flanks of the Southern Alps are heavily glaciated. River discharge is to the Tasman Sea in the west, and Lake Pukaki in the east. The precipitation baseline for which precipitation measurements are made relative to (figure 1.1) (Henderson \& Thompson, 1999) is the red line in the lower left corner. The west coast is $\sim 100 \mathrm{~km} \mathrm{NW}$ of the baseline. 


\subsubsection{Site selection}

In view of the shortcomings of previous work (Anderson et al., 2006, Kerr, 2009b) and the constraints of GPR, sites were selected with the following in mind.

○ Position of site in relation to the main axial divide

○ Accessibility

- Existence of previous research for validation of data sets

$\circ$ Minimising the effect of topography on local snow distribution measurements

The following three sites were deemed suitable according to these three constraints

\subsubsection{The Franz Josef Glacier}

This dynamic valley glacier consists of a $31 \mathrm{~km}^{2}$ accumulation area reaching elevations of up to $3000 \mathrm{~m}$ a.s.l. The lower $4 \mathrm{~km}$ ablation area is confined within the steep walled Waiho valley. The glacier terminates at approximately $300 \mathrm{~m}$ above sea level. The glacier is the source of the Waiho River which discharges to the Tasman Sea, $17 \mathrm{~km}$ to the west.

The lower few kilometres of the glacier are easily accessible by walking parties up to the lowest major icefall. Most of the elevation is gained within three icefalls, with the greatest elevation gained between $800 \mathrm{~m}$ and $1800 \mathrm{~m}$ a.s.l in the third icefall which terminates within the névé and above the Equilibrium Line Altitude (ELA) of 1850 m (Anderson, et al., 2006).

The névé is divided into three separate snow and ice fields, the Gieke, Chamberlin and the Davis Snowfield. The Davis Snowfield region is the preferred area of the névé to survey. It is the most regular in terms of slope and surface. The gradual increase in elevation results in a less crevassed surface nature over the majority of the survey area, although the Agassiz Icefall separates the lowest survey location from the two higher elevation sites. Similar surface characteristics are found on the northern most snowfield (Gieke). The Davis snowfield has a larger elevation range and follows the north-west to south-east orientation of the study transect and glacier.

\subsubsection{Annette Plateau}

Annette Plateau is situated in the northern end of the Sealy Range adjacent to and immediately south of Mount Cook Village. The Sealy Range is the first range east of the 
main divide in the Pukaki catchment and is bounded by the Mueller Glacier valley immediately to the west, and the glaciated Tasman Valley and Lake Pukaki to the east.

The surface terrain of Annette Plateau is broad and gently sloping from NW to SE, the glacier is largely free of crevasses. Of topographical interest is the large wind scoop of approximately $30 \mathrm{~m}$ high which is incised into the glacier's northern flank at the junction with Mount Annette. This feature is evidence of strong and persistent lee-side winds from the Main Divide to the westerly half.

The gentle terrain character and small size of the glacier was favourable for an area-wide survey. The survey layout consisted of a medial transect parallel with the fall line of the terrain. The three shorter transects are evenly distributed in a perpendicular fashion to the medial transect. In the past there have been some studies of accumulation at Annette Plateau, however strong wind repeatedly destroyed survey equipment (Chinn, 2009).

\subsubsection{Jollie River valley}

The Jollie River valley is also to the east of the main divide. The Malte Brun range and the Liebig range run roughly parallel to the main divide to the west of the Jollie River valley. The catchment drains to the SW from the NE opening out discharge contributing to the Tasman River and the Lake Pukaki hydropower scheme and Mackenzie basin.

The Jollie catchment, including Pinnacle stream, is approximately $30 \mathrm{~km}^{2}$ in size with an elevation range from $1067 \mathrm{~m}$ to $2726 \mathrm{~m}$ a.s.l. Slope angles for the whole catchment vary between 0 and $62^{\circ}$ with an average of $33^{\circ}$ (Clark, et al., 2011). The surface terrain is comprised of talus and bare rock in the highest and steepest sections. The slope angle at the location of the survey is representative of the average for the whole basin. The slope aspect is westerly, and gully incision provides a non uniform cross slope profile. 


\subsection{Known spatial distribution of precipitation}

\subsubsection{Precipitation gauge measurements}

Precipitation distribution is measured by a network of rain gauges throughout the Southern Alps. Previous work suggests that more rain gauges would aid in constraining precipitation isohyets at a catchment scale (Griffiths \& McSaveney, 1983; Henderson \& Thompson, 1999; Rodda, 1995). Precipitation records are of lower quality at higher altitude due to the seasonal change in state of hydrometeors, and the often strong and turbulent winds around the gauge orifice. The liquid or solid state of precipitation can be under represented by up to 30 and 80 percent respectively (Rodda, 1995). This means that individual precipitation records may not be representative. Averaging over long periods helps to compensate for most of the discrepancies other than the orifice effect (Sinclair et al., 1996) although incorporation of an under-catch component went some way to 'naturalise' rain gauge based precipitation enabling comparison between different data sets (Kerr, 2009b).

\subsubsection{West of the Main Divide}

West Coast precipitation is monitored by a series of gauges along the lowland plains and across major drainage transects of the West Coast. Rainfall data is collected via automated and manual daily measurements by the National Institute of Water and Atmospheric Research (NIWA) and the West Coast Regional Council (WCRC). Cross mountain transects extend across the Taramakau/Waimakariri to Whitcombe/Rakaia valleys and the Franz Josef/Waiho to Mount Cook approximately 100km south-west (Figure 1.2). The majority of the alpine transect rain gauges have been in service since the late 1970's and the early 1980's. These transects have been augmented from time to time with higher density precipitation gauge distribution (Griffiths \& McSaveney, 1983; Wratt et al., 1996). Rain radar data at permanent sites in Auckland, New Plymouth, Wellington, Christchurch and Invercargill by the New Zealand Meteorological Service (NZMS, 2008) and temporary portable radar (Purdy, et al., 2005; Revell, et al., 2002) have augmented established transects enhancing understanding of precipitation distribution and related processes in the region. 
The longest climate record incorporating temperature and precipitation on the West Coast is from Hokitika. The currently operational Hokitika climate station has an essentially complete record extending back 115 years. The Franz Josef township has maintained a complete climate record from 1956. Due to problems with data quality (Salinger, 1981) a relationship of Franz Josef temperature and precipitation has been established with Hokitika from 1982 (Anderson, et al., 2006). The addition of an automatic weather station at the Franz Josef airport $7 \mathrm{~km}$ south of the township at $85 \mathrm{~m}$ a.s.1 has added further reliability to this climate record. Up-valley from the AWS, rain gauges have been installed at elevations of up to $1700 \mathrm{~m}$ a.s.l in the valley and glaciated reaches (Figure 1.2). These data have been normalized to the Franz Josef record, allowing a reasonable estimation of long term climate at the lower glacier.

There is agreement that the peak precipitation location in the Franz Josef Glacier region is approximately $12000 \mathrm{~mm} \cdot \mathrm{a}^{-1}$ (Anderson, et al., 2006; Chinn, 1979; Henderson \& Thompson, 1999). Estimates of up to $15000 \mathrm{~mm} \cdot \mathrm{a}^{-1}$ have been made at the Main Divide (Griffiths \& McSaveney, 1983).

Rainfall intensity for the region has been as high as $1810 \mathrm{~mm}$ at Alex Knob $1200 \mathrm{~m}$ a.s.1 over a three day period in the Waiho Valley (1984), $3 \mathrm{~km}$ from Franz Josef village (Henderson, 1993). This value is especially high given that the next highest three day total is $1057 \mathrm{~mm}$. Weekly totals can be as high as $1433 \mathrm{~mm}(8.5 \mathrm{~mm} / \mathrm{hr})$ (Henderson \& Thompson, 1999), rainfall rates of $5.5 \mathrm{~mm} / \mathrm{hr}$ are considered heavy but are not rare events in any region of New Zealand (Sinclair, et al., 1996), although rainfall events can persist for some time.

High elevation measurements, such as that at $1700 \mathrm{~m}$ a.s.l at Almer Hut may be an underestimation of local precipitation (Stuart, 2011). The limitations of rain gauges in snowy mountainous terrain are evident in this record (Rodda, 1995; Stuart, 2011). In particular the site is subject to burial by snow and strong winds. The summer time Almer hut precipitation record was correlated with nearby rainfall measurements. A reasonable correlation was found, so an annual estimate of precipitation at high elevation was made and deemed reliable as it was based on the summertime record correlation, and compared with the precipitation distribution pattern made using crevasse stratigraphy based rainfall estimates (figure 1.3) (Anderson, et al., 2006). The Almer Hut inferred annual relationship was supported by the knowledge that the north-west orientated wind patterns that create the 
rainfall gradients recorded during periods of intense precipitation, closely match the annual rainfall distribution record (Sinclair, 1996). Erroneous snow distribution records can affect glacier mass balance calculations and discharge estimates.

The necessity of season specific precipitation monitoring is emphasised by the apparent good relationship that Almer Hut precipitation records had with prevailing precipitation patterns (Anderson et al., 2006). The effects of extrapolation of seasonal precipitation volumes into an inferred annual relationship has been observed was supported by the knowledge that the north-west orientated wind patterns that create the rainfall gradients recorded during periods of intense precipitation, closely match the annual rainfall distribution record (Sinclair, 1996).

Solutions to the problem of quantifying winter time precipitation include a recent intensive short time scale study, in which the névé's of the Franz Josef and Tasman Glaciers were simultaneously measured at each location using the snow board methods as employed in the ski industry (Purdie, et al., 2011b). Annual glacier mass balance has been quantified by determining snow accumulation via the crevasse stratigraphy method (Anderson, et al., 2006; Pelto, 1997; Purdie et al., 2011a), further assisting the understanding of accumulation and distribution of frozen precipitation. The Franz Josef Glacier crevasse stratigraphy data (Anderson, et al., 2006) represent the longest term high altitude accumulation dataset in this region.

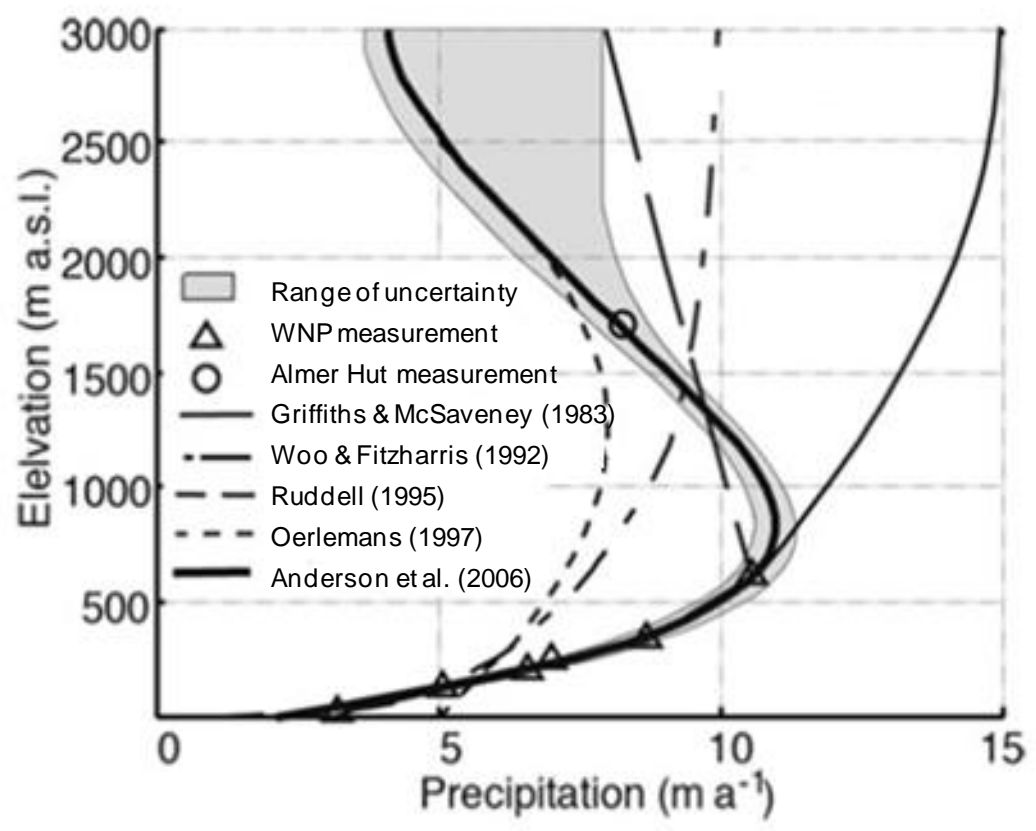


Figure 1.3. Refined precipitation peak for the Western side of the divide with addition of constraining data from 1700m and crevasse stratigraphy measurements (Anderson, et al., 2006).

\subsubsection{East of the main divide}

Most of the precipitation in the Southern Alps is a product of north-west flow (Chinn, 1979). Rain-shadow effects mean that precipitation to the east of the Southern Alps main divide is considerably less than that on the western side of the Alps. The volume of precipitation that spills over to the lee side, like west coast precipitation, is storm dependant and primarily subject to the same factors that influence precipitation in the west.

In an investigatory study for the Southern Alps Experiment (SALPEX) (Wratt, et al., 1996), a Regional Atmospheric Model (RAMS) showed that the incorporation of cloud physics relative to both snow fall and liquid precipitation into RAMS increased spillover to the eastern catchments of the Southern Alps. The modelled outcome more accurately represented observed precipitation patterns. This study highlighted the importance of the free air freezing level and wind speed in the distribution of precipitation. A short term study into the precipitation pattern within a storm showed a marked precipitation shift from west of the divide to a more easterly position at different stages in the climatic forcing (Sinclair, et al., 1996). Throughout the early stages of cyclogenisis, and the formative period of moderate wind speeds in barrier jet flow spill over to the lee is not significant (Sinclair, et al., 1997). Once wind speed increased, the blocking mechanism decreased the rates of spill over from the western side increased from 12 to $70 \%$ of the total precipitation. The distance which spillover occurs is between 6 and $29 \mathrm{~km}$ east of main divide.

The critical influences of precipitation spill over include relative humidity, wind velocity normal to the mountains at $700 \mathrm{hPa}$, a potential temperature difference between 850 and $500 \mathrm{hPa}$, and synoptically induced upward motion at $850 \mathrm{hPa}$ (Wratt, et al., 2000). The critical factors were determined by regression analysis of climatic variables over 5 years. Readily saturated humid air, strong cross mountain winds and terrain effects cause vertical shear in the air column, with higher condensation rates resulting. The strong cross mountain wind speed then serves to distribute precipitation downwind. Strengthening of fronts as they proceed along the alps may also serve to reduce the elevation of the free air freezing level allowing further distribution of solid precipitation (Wratt, et al., 1996). This process is applicable for any season of the year (Chater \& Sturman, 1998; Hessell, 1983). Yet the 
strength of each factor seems to vary with location. Previous work has noted that wind speed was a stronger prerequisite for lee side precipitation than relative humidity at Mount Cook village (Sinclair, et al., 1997; Wratt, et al., 2000).

The most recent Pukaki catchment precipitation study combines all known precipitation records in the Lake Pukaki catchment to create one precipitation surface (Kerr, 2009b). This data is augmented by supplementing the historic rainfall recorder distribution with new precipitation recorders in underrepresented areas of the catchment. Homogeneity between the numerous datasets is ensured through the normalization of data by incorporating the volume of rain gauge under-catch specific to each recorder and the location of that record within the Pukaki catchment. The product is the most comprehensive catchment-wide precipitation distribution map for the Pukaki catchment (Figure 1.4) which demonstrates the north-west to south east reduction in precipitation amounts on the eastern side of the Alps down to $1000 \mathrm{~mm} \cdot \mathrm{a}^{-1} \pm 200 \mathrm{~mm} \cdot \mathrm{a}^{-1}$ in the south east quarter of the Pukaki catchment (Figure 1.2 and 1.3) (Chinn, 1979; Kerr, 2009b) and the $1000 \mathrm{~mm} / \mathrm{km}^{-1}$ orographic gradient experienced on both flanks of the Southern Alps.

Investigations of snow for the hydroelectric stakeholders in the Pukaki catchment are undertaken by the assessment of four snow courses by shallow coring and probing (Halstead, 2009). These data are supplementary to the snow pillow and sonic ranger measurements recorded at Rose and Panorama ridges (Figure 1.2). Snow pillows and sonic rangers provide a recordable dataset for long term investigations (Sorteberg et al., 2001). Used in conjunction with other meteorological data, the weight and depth information provided by snow pillows and sonic rangers can provide useful information about ablation and or redistribution of snow. These instruments response to snow evolution such as accumulation of liquid precipitation is not well quantified, especially if there is a through flow component or solidification of snow and bridging of the snow pack over the snow pillow, which can occur in maritime climates (Sorteberg, et al., 2001). 


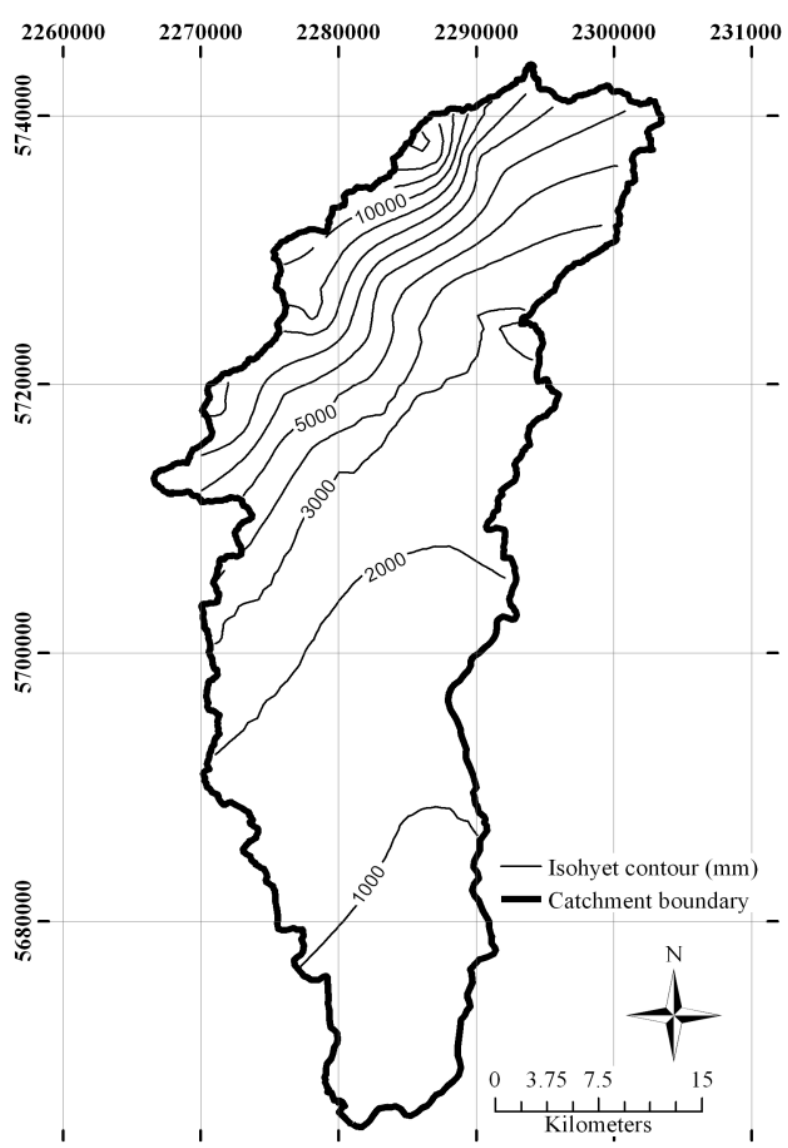

Figure 1.4. The precipitation distribution map of the Pukaki catchment on the eastern side of the main divide, Southern Alps. Large snowfall totals in the high altitude north-west edge of the catchment, decreasing with distance from the South West / North East orientated Southern Alps.

\subsubsection{Contrast between eastern and western Southern Alps precipitation curves}

Previous estimates of cross mountain precipitation in the Southern Alps of New Zealand indicate a single peak profile (Figure 1.5) with precipitation magnitude varying according to height of the upwind alpine barrier and relative to a baseline of the foot position of the windward slope (Henderson \& Thompson, 1999).

The location of the peak has also been a subject of discussion in various studies (Anderson, et al., 2006; Griffiths \& McSaveney, 1983; Henderson \& Thompson). The precipitation peak is considered to be situated up glacier of Luncheon Rock (800 m a.s.l) at around 2000 m a.s.l (Figures 1.3 and 1.5) (Anderson, et al., 2006; Henderson \& Thompson, 1999). The location of the peak was thought to be constrained by the addition of the Almer Hut precipitation data at $1700 \mathrm{~m}$ to $8.3 \mathrm{~m} \mathrm{a}^{-1}$ with the precipitation maxima of around $11 \mathrm{~m} \mathrm{a}^{-1}$ 
at $1200 \mathrm{~m}$ a.s.l. (Figure 1.3) (Anderson, et al., 2006). The refined long term dataset and increased density of measurement provided by Kerr (2009b) reshape the eastern reaches of the established transalpine estimates (Figure 1.4). The largest deviation from the Henderson and Thompson (1999) precipitation curve is at about $70 \mathrm{~km}$ from the precipitation baseline (Figure 1.5) whereby a precipitation maxima of 10 to $12 \mathrm{~m} \mathrm{a}^{-1}$ is located east of the main divide (Figure 1.4) (Kerr, 2009b).

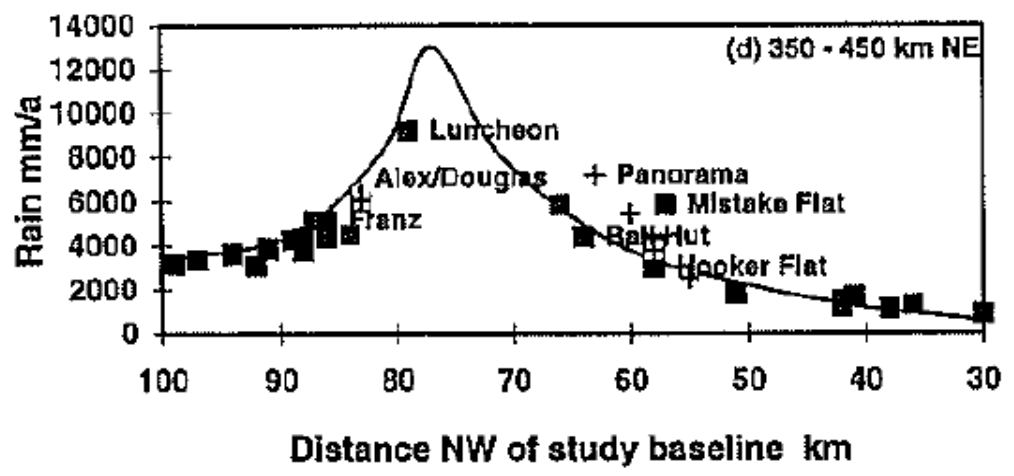

Figure 1.5. Graph of rainfall norms from 1951 to 1981 (in mm year) for the Franz Josef to Mount Cook north west to south east precipitation distribution. The axis base line refers to a straight line drawn parallel to the main axis of the Southern Alps $85 \mathrm{~km}$ to the SE. (Henderson \& Thompson, 1999)

The upper elevations of the precipitation distributions of Anderson et al. (2006) and Kerr (2009b) sit more or less back to back with each other, along a similar transect to Henderson and Thompson (1999), to produce a discrepancy at the junction of the accumulation distribution maps in the range of 5 to $10 \mathrm{~m} \mathrm{a}^{-1}$ w.e. (water equivalent). The discrepancy of estimates occurs in a region where there is little knowledge of accumulation rates or processes at the end of an accumulation season. Such information is useful when considering in the construction of glacier mass balance (Machguth, et al., 2006; Oerlemans, 1997), and the reliance on snow melt modelling using empirical relationships to determine resource quantity for flood forecasting and resource allocation.

The location of the trans-alpine precipitation peak has been observed to migrate across the main divide of the Southern Alps throughout a storm cycle ( Sinclair, et al., 1996; Sinclair, et al., 1997). The latitudinal progression of a weather system up the Southern Alps would generally take no more than 4 hours. It is then reasonable to look at different areas in a trans-alpine context as experiencing the passing weather system close to simultaneously, although precipitation type and spill over distance (Chater \& Sturman, 1998) may vary throughout the progression of a weather system (Henderson \& Thompson, 1999). A two 
peak style of precipitation profile has been observed to form in models of idealized topography and atmospheric state (Sarker, 1966; Zängl, 2005; 2008), conditions that may manifest in this portion of the Southern Alps of New Zealand (Kerr, 2009b).

The assessment of previous work and reflection on the end data usage for accumulation totals in resource planning through hydrological and glaciological prediction highlights the need for reliable high altitude observations of precipitation totals. Further research is therefore worthy to undertake to reduce discrepancies between current snow precipitation distribution knowledge.

\subsection{Temporal patterns of precipitation}

Inter-annual patterns of snow accumulation at specific locations can be relatively stable given that a particular region has reliable and similar circulation patterns between years (Fitzharris, 2004; Liston, 1999; Liston \& Sturm, 1998; Sturm et al., 1995). The processes that control spatial variability of net accumulation in the Southern Alps can vary within glaciers and between years (Purdie, et al., 2011a; Purdie, et al., 2011b). Short term precipitation studies should be viewed with the understanding that they may not be representative of long term average patterns of precipitation volumes and distribution. If the measured distributions are correlated with long term precipitation measurements from climate stations, then they may be viewed in terms of a long term data comparison.

\subsubsection{Decadal}

The phase intervals of IPO affect the long term phase frequency of the El Nino Southern Oscillation (ENSO) (Folland et al., 2002). Tropical sea temperature anomalies are closely related to SOI and currently important predictors for seasonal forecasting in NZ (Francis and Renwick, 1998). The IPO is indexed by the state of the oscillation of normalised standard deviation of the mean monthly sea level baroclinicity between Tahiti and Darwin. Negative phases of this phenomenon refer to periods of low pressure in the Tahiti region of the Pacific Ocean and above average atmospheric pressures above Darwin (McKerchar et al., 1996).

IPO oscillations are when sea surface temperature deviates $+/-0.5^{\circ} \mathrm{C}$ around mean sea surface temperature (MSST). Periods of oscillation occur over 20 to 30 year intervals. 
Positive phases of the IPO occur when MSST is $+0.5^{\circ} \mathrm{C}$; negative phases are when MSST is $-0.5^{\circ} \mathrm{C}$ MSST. Shifts in the phase state of the IPO occurred in the mid 40's, again in 1977 and more recently believed to have shifted in 1999 ( Salinger et al., 2001). These shifts alter the frequency of occurrence of El Nino and La Nina and their intensity. It has been noted that the resultant effect on the SOI and ENSO creates a net increase in precipitation in the south-west of New Zealand. Precipitation increased $>8 \%$ and stream flow discharge of $14 \%$ in the 1978-1998 period of positive IPO to the 1946-1977 period of negative phase IPO (McKerchar \& Henderson, 2003; Salinger, et al., 2001). This is largely attributed to the increase in south-west flow over the West Coast of the South Island of New Zealand during positive phases of the IPO.

Increased median and flood flow for rivers in the south to south west of the South Island have been noted since the shift in the IPO since 1977/1978. This pattern was found in all rivers and lakes from the Rakaia river south with the exception of lake Tekapo to the east of the Alps. The increases in flow were also noted for low flow events (Salinger 2001; McKerchar and Pearson 2003).

\subsubsection{Annual}

The El Nino Southern Oscillation (ENSO) has been observed to affect the year to year volumes of snow storage in the Southern Alps (Salinger, et al., 2001) and consequently glacier mass balance (Woo \& Fitzharris, 1992a). In the snow accumulation proxy provided by a long term photographic glacier inventory (Chinn, 1995) the end of season snowline (EOSS) elevations are correlated with SOI. In a 7 year study on snow depth across New Zealand the snow storage varied from $6004 \times 10^{-6} \mathrm{~m}^{3}$ water in La Niña years to $14555 \times 10^{-6}$ $\mathrm{m}^{3}$ in El Niño years (Fitzharris, 2004). The lighter snow years tend to peak in accumulated volume around July and August, whereas heavier accumulation seasons peak in volume in October and as late as November (Fitzharris, 2004; Harrison, 1986). The net annual effect on snow line from the prevailing weather trend is lower snowline elevations on the windward side of the topographic barrier. Circulations which bring with them anomalous south and easterly flows reduce the snowline elevation on the east. A shallower snow line elevation gradient is seen when flows are from the westerly quarter and the eastern divide is more reliant on spillover precipitation (Lamont et al., 1999). River discharges as a result of 
lean snow years reduce by 55\% compared to the discharge of heavy snow years (Harrison, 1986).

In the negative phase SOI there is a higher frequency of occurrence of cyclonic trough weather types with prevailing south-westerly to westerly flow with reduced frequency of blocking regimes (Figure 1.6) (Kidson, 2000, Jiang, 2010). The reverse of this pattern is the case during positive state SOI state which is associated with a higher frequency of anticyclonic types (Jiang, 2010). Both papers highlight that synoptic variability is greatest in the positive phase of SOI. The variability of synoptic type results in a cancelation of the SOI signal over the year as a whole (Jiang, 2010). El Nino winter time frequency of variation and change of synoptic types are greater than the frequency of change of synoptic types during periods of La Nina ENSO (Jiang et al., 2004).

\subsubsection{Seasonal}

The Southern Annular Mode (SAM) has been found to correlate well with the seasonal regional distribution of precipitation (Kidston et al., 2009). Negative anomalies of the SAM are associated with increased westerly rainfall with warmer temperatures in the east. Temperatures and spill over distances are still subject to the intensity and air-mass properties of individual storms. The pattern of north-south flow and east-west winter and summer circulations will also have an effect on lapse rate calculation on either side of the main divide as föhn effect increases temperatures in the lee of the phase pattern of weather. The importance of applying the correct lapse rates for snow accumulation and melt modelling applications is stressed as an incorrect application could generate estimations out of character with a particular circulation patterns.

The Southern Annular Mode (SAM) is not yet directly related to synoptic weather classifications. However the positive and negative phases of this circulation are shown to influence the general circulation across the country (Kidson et al., 2009) thus synoptic flow and precipitation volumes associated with each flow. The effects of this circulation on New Zealand weather are similar to that of ENSO. For instance, a positive phase state of the SAM over winter is associated with a west to northerly flow bringing higher than normal temperatures and rainfall to the west. The negative phase of SAM is associated has effectively the opposite effect of the positive SAM phase on southern latitude weather. An 
easterly flow suggests an increase of the blocking mechanism would infer an increase in precipitation on the east of the country. The findings of Purdie et al., $(2011 \mathrm{~b})$ suggest that such processes do not necessarily translate to a contribution to snow accumulation from precipitation (Table 3.2.8) due to associated high wind speeds which may strip the snow pack, and generate lower than actual precipitation estimates..

\subsubsection{Event Scale}

In the construction of the precipitation map for the Pukaki catchment Kerr (2009b) was able to establish a wind classed estimate of precipitation likelihood and volume incorporating climate station data from neighbouring areas for a particular storm period. The eight directional wind direction classes are able to suggest how changes in the phase state of ENSO and IPO will impact on precipitation and snow storage characteristics of the Southern Alps. Of the classified wind classes, westerly wind directions again showed the likelihood and volume of precipitation spillover into the Pukaki was dominant over other wind classes.

There are abundant and rapidly evolving climatic processes which affect the accumulation and evolution of the snow pack in the study region. There is a lack of understanding of the relative importance of each process, and how processes affecting the snow pack vary with larger climate cycles. But there are established empirical relationships with precipitation volume and certain climatic factors such as temperature and wind (Kerr, 2009b). There is scope to establish empirical snow accumulation factors and consequently volumes from relationships with climatic cycles in order to infer how snow accumulation volumes may vary from year to year. The issue being the ability to calibrate such accumulation models in a way that can handle very high seasonal accumulation rates, wind and redistribution of the snow pack. Such relationships have been derived for part of an accumulation season (Purdie, et al., 2011b) based on the synoptic weather classifications of Kidson (2000) (Figure 1.6) although full accumulation season measurements, and to that end such campaigns in consecutive years are impractical using manual data collection methods. 
"Trough" group
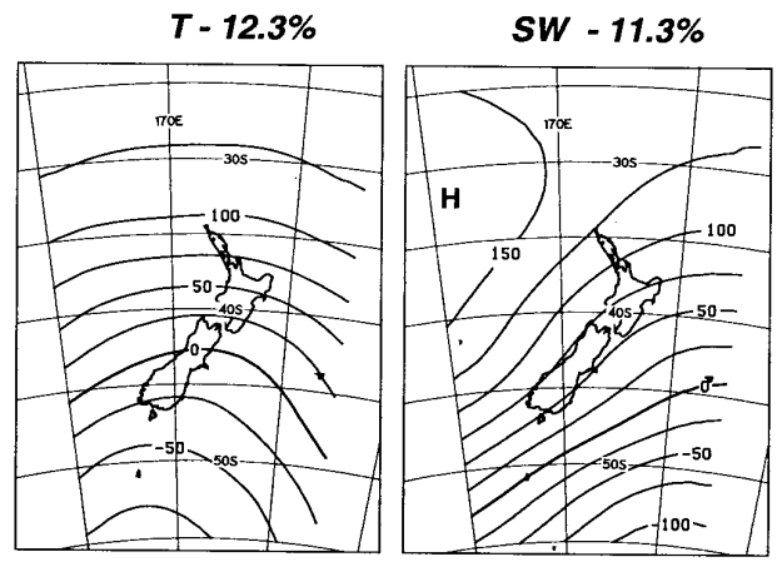

TNW - 7.6\%

TSW $-7.3 \%$
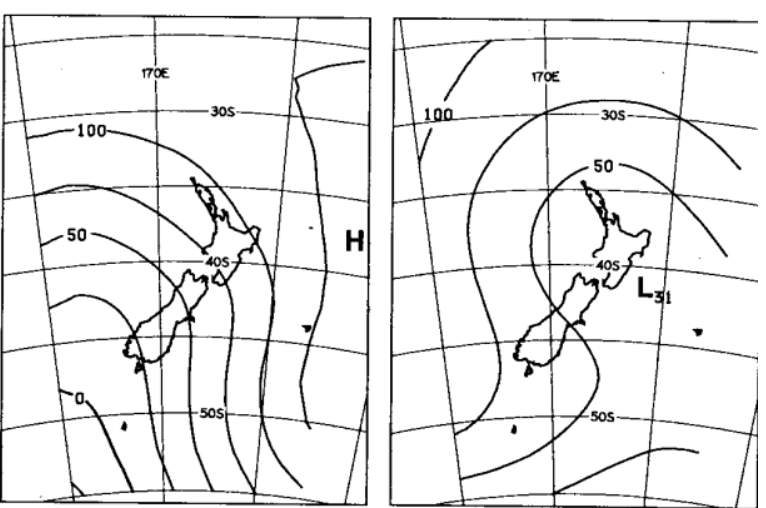

"Zonal” group
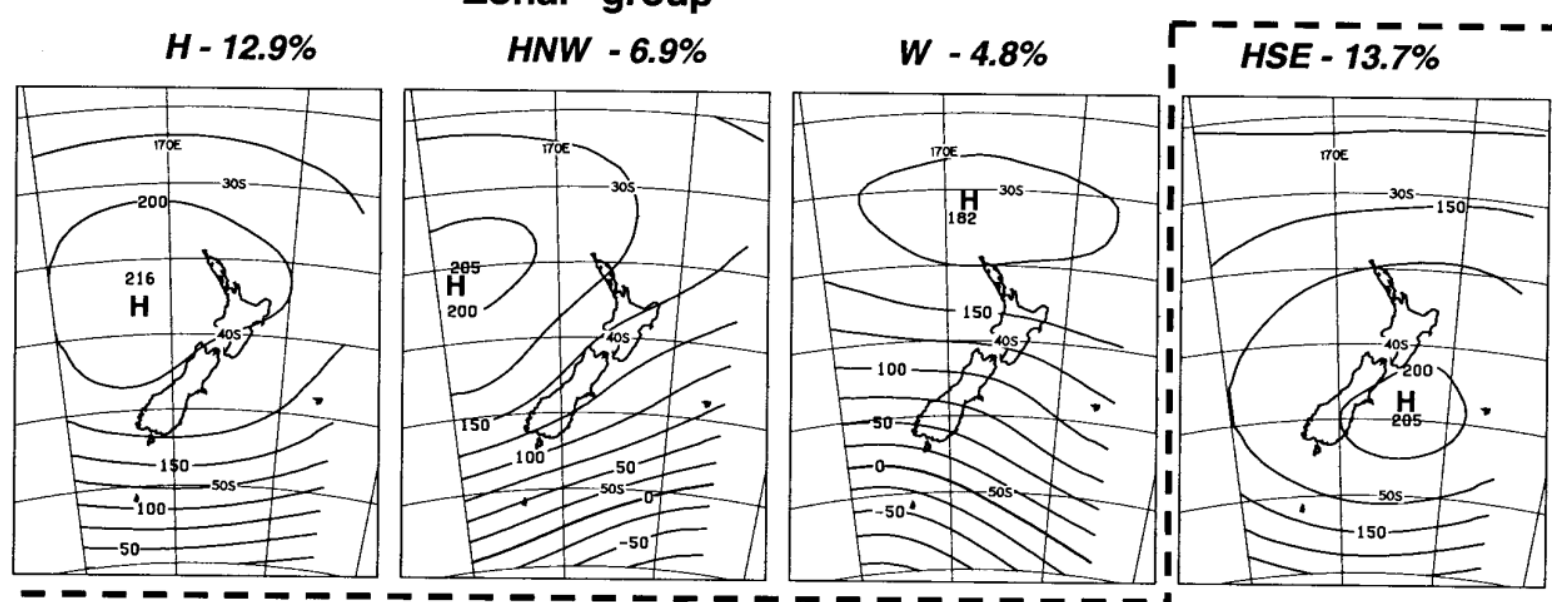

“Blocking” group
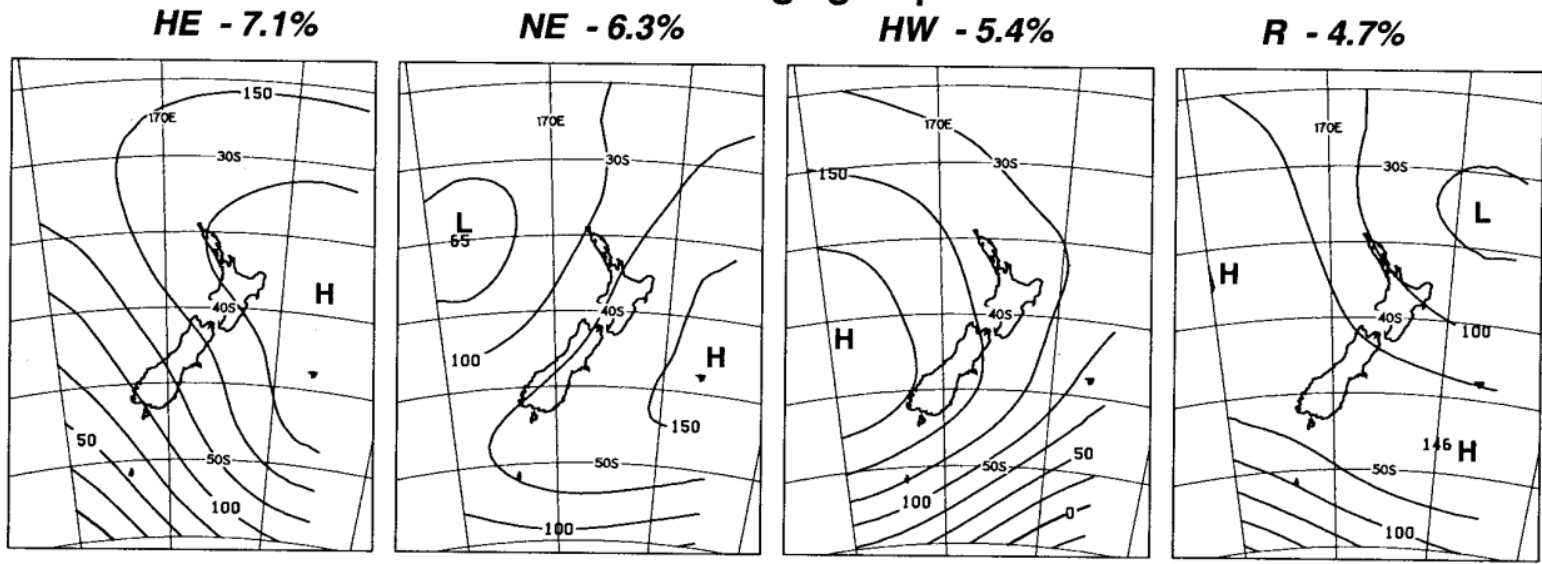

Figure 1.6. Synoptic weather classifications with annual values of occurrence (Kidson 2000). 


\subsection{Aims and Objectives}

There is a deficit of knowledge of high altitude precipitation distribution in the Southern Alps. Previous studies have approached the problem from the west (Anderson and others, 2006) and the east (Kerr, 2009b) but their results are inconsistent at the main divide. Part of the problem has been the lack of suitable techniques to measure the magnitude of seasonal snow depths in the study area. Ground Penetrating Radar is a useful tool for collecting data to fill this gap in knowledge.

It is the aim of this study to; -

1) Refine and extend GPR methodology and test these developments in deep maritime snow packs, with a focus on increases in efficiency in wavespeed calculation and data collection.

2) Assess seasonal and perennial snow depth and distribution at high elevation within the Southern Alps of New Zealand.

The specific objectives of this study are to;-

1) Measure snow accumulation in a north-west to south-east transect parallel to the orographic flow experienced in this region.

2) Infer a trans-alpine snow storage gradient, and establish the relationship of lowland climate station data to high altitude sights to provide a precipitation index to calculate precipitation at unmonitored locations.

3) Assess the relationship between snow stratigraphy observed in GPR radargrams and precipitation accumulation associated with synoptic weather classifications.

4) Assess the value of the above within the context of water resource usage and glacier mass balance calculation. 


\subsection{Outline}

This chapter describes the study location, the SWE data collection methods and applications towards precipitation modelling used in this thesis. These topics will be described in the below listed order.

- Study location characteristics

- A description of radar acquisition settings

- GPR data processing steps

- Establishing the relationship between SWE and TWTT

- Improving data collection methods

- Error Analysis

- Data comparison methods

- Precipitation modelling

\subsection{Study locations}

The five surveyed snow courses represent three catchments that span the Southern Alps. These three sites are representative of the orographic precipitation curve across the Southern Alps. The sites cannot be measured relative to any significant topographic feature, such as the main dividing ridge, due to the irregular nature of the terrain, consequently a proxy measurement of a baseline parallel to the Southern Alps was developed in previous studies (Henderson \& Thompson, 1999). For comparative purposes the same baseline will be used in this study.

The timing of the field work was governed by interest in obtaining the maximum snow accumulation for the season whilst maintaining a cold snow pack from which to obtain useful snow stratigraphy data from the snow pack before the snow density profile turns homogenous from warn temperatures. Periods of weather suitable for helicopter access (fine 
weather with low wind speeds) were taken advantage of in early spring near the end of September and early October.

\subsubsection{Davis snowfield}

The Davis Snowfield study region consists of three $100 \mathrm{~m}$ x $100 \mathrm{~m}$ square snow courses which are made up of four $50 \mathrm{~m}$ x $50 \mathrm{~m}$ quadrates. The survey grids were spread as practically as possible over the elevation range from below the Agassiz icefall (2000 $\mathrm{m}$ a.s.l) to the Main Divide (2450 $\mathrm{m}$ a.s.1). The three snow courses are to provide point measurements of snow depth over an area representative of sub grid snow distribution (Clark, et al., 2011), allowing as accurate as possible average snow depth for the three elevations and, if possible, pin-point the region of maximum accumulation within the orographic precipitation curve.

The field work was undertaken on 19 September 2009.

\subsubsection{Annette Plateau}

The surveyed study region at Annette Plateau covers most of the glacier encompassing an altitudinal range of $<50 \mathrm{~m}$. The glacier is further south-east of the Davis Snowfield (Table 2.1) in a region that is expected to receive around half as much precipitation and the western snow courses (Figure 1.3). The snow course consist of a $600 \mathrm{~m}$ log medial spine, with three east west running ribs perpendicular to the spine transect, around $200 \mathrm{~m}$ apart from each other. The initial accumulation surface in May 2009 was glacial ice.

The field work was undertaken on 6 October 2009.

\subsubsection{Jollie River Valley}

The Jollie River valley snow course is expected to have the most complex snow pack and the least likelihood of extracting IRH information from within the snowpack. The slope angle and terrain features make avalanches likely; this will test the ability to model snow accumulation through internal reflection horizons. The distance between Jollie River valley and the most western site is close to $20 \mathrm{~km}$ (Table 2.1). The snow survey spans from $1800 \mathrm{~m}$ 
a.s.1 to $2222 \mathrm{~m}$ a.s.l. along five evenly spaced elevation isohyets. The dielectric contrast provided by the bed material on which snow accumulates will provide a useful control of snow depth measurement techniques applied to deep unverifiable snow depths such as those at Davis Snowfield.

The field work was undertaken on 5 October 2009.

\begin{tabular}{|c|c|c|c|c|c|c|c|}
\hline & \multirow{3}{*}{$\begin{array}{l}\text { Easting } \\
\text { NZMG } 49\end{array}$} & \multirow{3}{*}{$\begin{array}{l}\text { Northing } \\
\text { NZMG } 49\end{array}$} & \multirow{3}{*}{$\begin{array}{l}\text { Distance } \\
\text { from } \\
\text { Baseline }\end{array}$} & \multirow{3}{*}{$\begin{array}{c}\text { Altitude } \\
\text { m a.s.l }\end{array}$} & \multirow{3}{*}{$\begin{array}{c}\text { Accumulation } \\
\text { surface } \\
\text { type }\end{array}$} & \multirow{3}{*}{$\begin{array}{l}\text { Terrain } \\
\text { Gradient }\end{array}$} & \multirow{3}{*}{$\begin{array}{c}\text { Terrain } \\
\text { type }\end{array}$} \\
\hline \multirow[t]{2}{*}{ Snow course } & & & & & & & \\
\hline & & & & & & & \\
\hline FJG below Agassiz Icefall I & 2285508 & 5741683 & 72.8 & 2050 & Glacier firn & Shallow & Crevassed \\
\hline \multirow{2}{*}{$\begin{array}{l}\text { FFJG above Agassiz Icefall } 1 / \\
\text { FJG Spencer-Mallory }\end{array}$} & 2285112 & 5741683 & 72 & 2300 & Glacier firn & Shallow & Crevassed \\
\hline & 2284905 & 5738922 & 70.9 & 2450 & Glacier firn & Shallow & Crevassed \\
\hline Annette Plateau & 2272966 & 5713208 & 57.2 & 2250 & Glacier ice & Shallow & Not crevassed \\
\hline Jollie River valley & 2293950 & 5721369 & 51.4 & $1800<2200$ & Bedrock/talus slope & Steep & Complex \\
\hline
\end{tabular}

Table 2.1. Study site characteristics including distance from the baseline, altitude, accumulation surface type, terrain gradient and type.

\subsection{GPR data acquisition}

Snow packs respond to meteorological influences both during and after deposition. Wind, solar radiation and relative humidity (Hagen \& Reeh, 2004) alter surface snow properties in the form of crystal metamorphosis and ice lens formation by mechanical alteration, liquid moisture and moisture vapour transfer. These phenomena, especially the volume and depth of infiltration of percolating melt water are governed by the cold content of the snow pack and influence the density of snow at the time of deposition and thereafter (Pfeffer \& Humphrey, 1998).

The snow pack comprises many layers of varying density. When investigating IRH it is assumed that the entire surface underwent a similar process of metamorphosis at the same time enabling the development of an area-wide homogeneous isochrone. This surface is subsequently buried, but retains characteristics which allow it to be differentiated from subsequent depositional sequences. The tracking of IRH allows the calculation of seasonal mass balance of a glacier by mapping the distribution of its glacier facies (Dunse, et al. 2008).

The quality of the snow pack information in the vertical domain is largely dependent on the vertical resolution of the radar. The vertical resolution is primarily governed by the 
wavelength of the radio waves, although there are user definable settings that affect data resolution.

\subsubsection{Radar configuration}

The GPR utilized in this study was a commercially available Malå RAMAC impulse radar unit produced by Malå Geoscience, utilizing a Malå Pro ex control unit conjunction with $500 \mathrm{MHz}$ shielded antennae of parallel broadside configuration and $18 \mathrm{~cm}$ antenna separation. Due to the objectives and locations of this research, three different mounting configurations of the radar components and survey techniques were utilised. The configurations were a skier towed sled, a skier towed antenna and backpack mounted control unit, and a helicopter mounted radar configuration. These configurations were more suited to the different terrain of each study location enabling the survey of steep terrain, crevassed terrain and wind affected surfaces with minimal risk to data quality and operator safety.

The most widely applied radar configuration was the sled mounted radar. The radar unit was towed along the survey transect by snowmobile or skier in a sled of non-metallic construction. This method is particularly useful in relatively flat, open terrain allowing the operator to be free of any equipment. A skier based survey method was employed at the Davis Snowfield and Annette Plateau. The entire radar unit was mounted in a skier-towed sled of PVC construction similar to that used by Jaedicke and Sandvik (2002) and Bradford, Harper and Brown (2009) (Figures 2.1.1 \& 2.1.2). By mounting the antennae in the sled the physical footprint area of the antennae was increased fourfold reducing the pitch and roll of the antennae over small scale surface features such as sastrugi (Figure 2.1.1). The sled configuration was also considered useful while working in crevassed areas where the sled could be jettisoned if recovery of operator or equipment became necessary. 


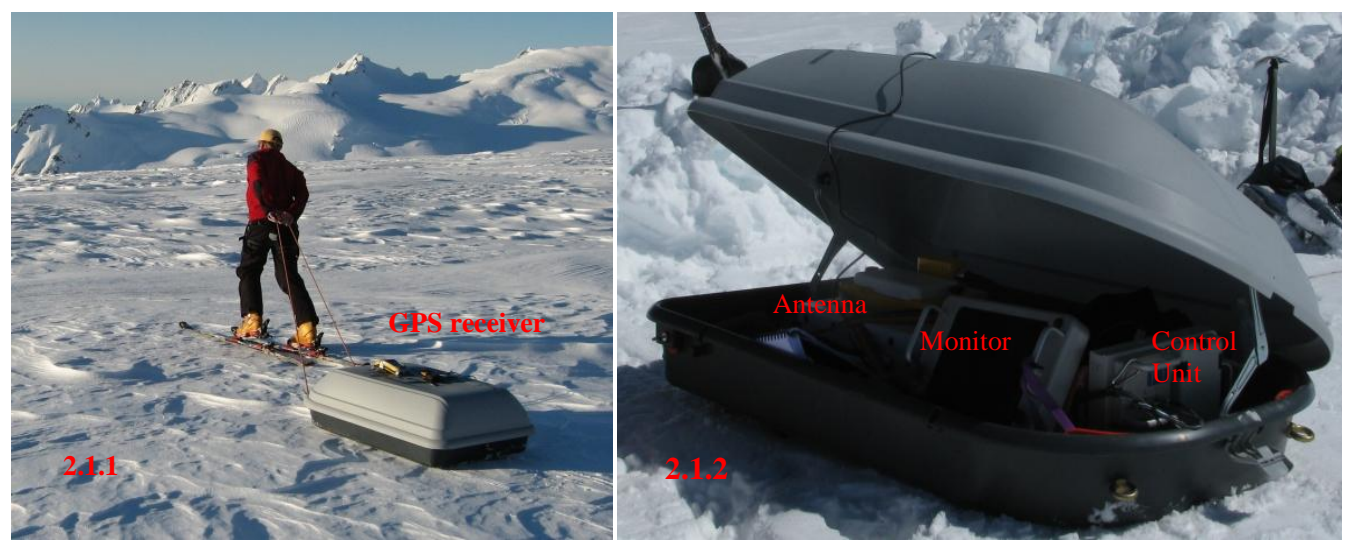

Figures 2.1.1 and 2.1.2 Skier towed sled in operation with GPS receiver mounted on the lid of the sled, 2.1.1. Internal layout of GPR equipment in the sled 2.1.2

The second configuration of the radar unit consisted of an arrangement in which the monitor was suspended from the operator, the control unit was mounted in a backpack and the antenna was towed by the operator and kept in position by an assistant. Such a configuration was used at the steeply-sloped study area of the Jollie River valley due to the difficulty of manoeuvring the sled configuration in steep terrain, and hazards associated with losing control of the sled.

Figure 2.2.GPR equipment configuration in the Jollie River valley. This method allowed for easy manoeuvring of the antenna in steep terrain.

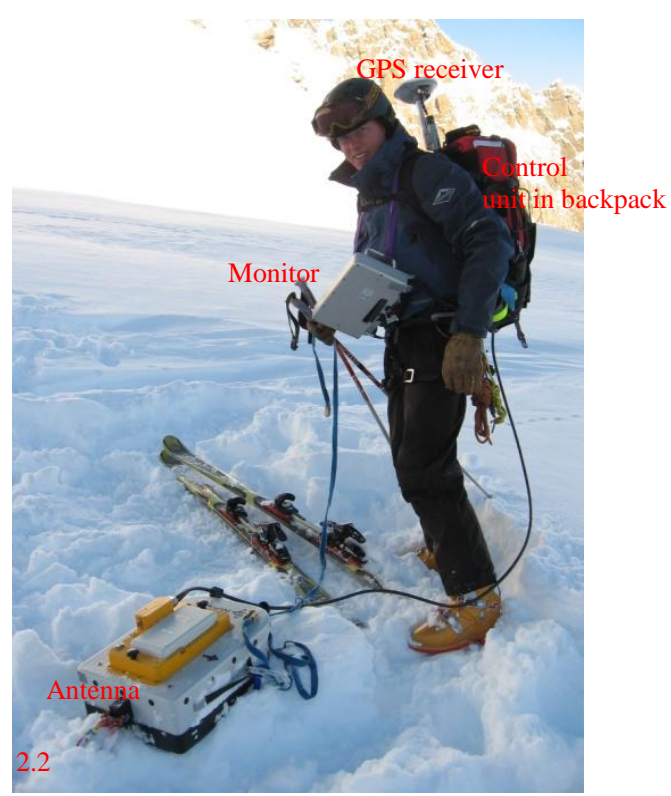




\subsubsection{Data Resolution}

Wavelength

The vertical resolution of radar data is dependent on the wavelength of the radar antenna. The theoretical resolution of a GPR signal is $1 / 2$ to $1 / 4$ of the wavelength (Sheriff and Geldart, 1982). Wavelength is related to frequency through;

$$
\lambda=v / f
$$

Where $\lambda$ is the wavelength, $v$ is the radio wave velocity, and $f$ is the centre frequency of the antenna. Reliable estimates of SWE have been made with frequencies as low as $50 \mathrm{MHz}$ (Pälli, et al., 2003) but most studies focused on establishing snow volumes using frequencies between 300 and $900 \mathrm{MHz}$ (Arcone et al., 2005; Jol, et al., 2004) (500 MHz) Hagen et al., (2008) (900 MHz)). The antennae frequency used in this study is $500 \mathrm{MHz}$ which produces a wavelength of $0.6 \mathrm{~m}$. Therefore features of .15 to $.3 \mathrm{~m}$ depth are expected to be resolved. Boundaries smaller than this could be observed given a distinct change in density, or fluctuations in amplitude may reflect represent a series of closely spaced horizons.

To estimate snow accumulation the internal reflection horizons and structure of the snow pack need to be satisfactorily resolved by the radar traces. The three factors which affect the quality of the data are the vertical resolution, horizontal step size and width of the time window.

\subsubsection{Radar data acquisition settings}

Step size refers to the horizontal distance between radar traces. If this distance is not considered prior to the investigation, the ability of the radar data to resolve stratigraphy can be compromised. A large step size will be unable to image steeply dipping reflectors or diffraction tails, yet it would enable large areas to be imaged quickly and may be suitable for investigations of large reflectors that extend over the area of interest. The survey areas in this study are between $100 \mathrm{~m}$ and $1000 \mathrm{~m}$ in length. Internal reflection horizons will be resolved up to this extent and are expected to be able to be resolved continuously at this scale. A high rate of sampling (reduced step size) requires a slow horizontal antennae travel velocity to enable deep reflectors to be imaged before moving away from the transmitted frequency. The product is high resolution data, but in a less timely fashion (Jol \& Bristow, 
2003). A sampling rate that is too long may result in the receiving antenna moving past the limits of the reflected transmitted antenna, creating a data set with gaps where there was no received GPR trace.

The horizontal step size should adhere to the Nyquist principle by which the distance between sample traces is no more than $1 / 4$ to $1 / 2$ of the radar wavelength in the host material (Keary \& Brooks, 1991). The consideration of the spatial extent and amplitude of subsurface features is desirable to prevent aliasing of data and a resultant incorrect interpretation of the output (Jol \& Bristow 2003). At the onset of this field work there was an expectation that the internal reflection horizons will be spatially contiguous with little variation in the internal structure of the snow pack similar to that of GPR investigations elsewhere. Some variation was expected at the interface of the snow pack and bed at Jollie River valley with later snow deposition being sub parallel to the bed profile. The sampling interval, usually given as a distance, was $\sim 0.1$ to $0.15 \mathrm{~m}$. The distance was actually governed by the sampling interval of the radar signal transmission to $0.1 \mathrm{~s}$ so it was therefore dependant on the speed at which the radar moved across the surface, generally $\sim 0.8$ to $1 \mathrm{~ms}^{-}$ 1 .

The above radar acquisition settings influence the horizontal data resolution of the collected radar data. The time window for the radar trace refers to the length of time that the radar will allow a trace to be received and therefore the depth at which can be interpreted in the output data. It is therefore important to set the target depth in excess of what could be expected. This is especially so in variable terrain such as Jollie valley where topographic features may not be fully captured if a time window is set too short. Similarly at Davis Snowfield, where the accumulation for the season will be determined from subsurface features alone, it was important to set the time window deep enough to attempt to capture several previous net accumulation layers to ensure the identification of the most recent IRH is reliable.

Good practise suggests an allowance of $+30 \%$ of the expected measured depth of the lowest feature to be collected (Jol \& Bristow, 2003). The physical maximum of radar wave twoway signal propagation is around $20 \mathrm{~m}$ in snow and firn at $500 \mathrm{MHz}$, This was the depth used at the Davis Snowfield and Annette Plateau, equating to a time window of around 230 ns assuming an average wave speed of $0.214 \mathrm{~m} / \mathrm{ns}$. With the expectation that the snow pack 
was considerably shallower at Jollie River valley, a time window of $112 \mathrm{~ns}$ was used, equating to around $10 \mathrm{~m}$ snow depth, to allow for enhanced accumulation from avalanche deposits and preferential deposition from the interaction of terrain and wind. At each site the sampling frequency was set for each trace to a level determined to give a clear signal and ranged from $1317 \mathrm{MHz}$ at Davis Snowfield and 2844.1MHz at Jollie River valley

A degree of stacking was also applied to the received traces to increase the signal-to- noise ratio (SNR) at the time of data collection. In deep snow packs on relatively flat terrain traces were stacked 16 times due to the little variation across the snow pack resulting in little chance to spatially alais the output. At Jollie valley stacking was reduced to 4 traces to get a better representation of the variable terrain underneath the snow pack.

\subsubsection{Data Processing}

All GPR data post-processing, up to the point of IRH digitisation, was undertaken using REFLEXW Version 5 processing software. Exported digitized depth data was related to other data sources using standard proprietary software.

The objective of processing GPR data is to provide the clearest possible visual representation of the retrieved data for interpretation and digitization, enabling accurate comparison with ground truth data such as manual snow depth probing and snow pits. When undertaking processing of GPR data the overarching aim is to improve the SNR, without stripping any interpretable data away (Woodward et al., 2003). Processing GPR data however will not counteract the effects of collecting low quality data in the field (Jol \& Bristow, 2003). The desired outcome of the signal processing in this study is to process data to show the reflection horizons that can be interpreted with certainty, as the end of the ablation season and the beginning of the accumulation season, or other shorter timescale accumulation events. This includes any englacial structure or firn that may assist with this interpretation.

A static correction was imposed on the raw radar data as the first processing step. Delays in electronics and the fibre optic cabling of the radar unit cause an initial delay on the arrival time of the radar trace (Woodward, et al., 2003). Static correction removes this electronics delay. Due to the change in resistance of electronics with temperature, the time that the static correction occupies changes with ambient and operating temperatures of the 
atmosphere and equipment. The static correction processing function can also be applied to airborne GPR data to remove the altitude of helicopter from the ground surface (Machguth, et al. 2006).

A "dewow" filter was then passed over the raw data. The dewow filter is effectively a high pass filter that removes the initial low frequency spike and is commonly used with closelyspaced common-offset high-frequency antenna. It reduces the effect of the large amplitude direct and ground waves from the transmitted radar signal on the received radar signal. The high amplitude reflections create a low frequency noise in the received radar signal. The regularly spaced horizontal banding is caused by the saturation of the radar electronics from the emitted electromagnetic energy creating high amplitude direct and ground waves which move unimpeded along the ground air interface (Daniels et al. 1998). The presence of these high amplitude reflections induces a slowly decaying low frequency wave (wow) which is superimposed on the received high frequency radar reflections.

Removal of amplitude noise at the high and low ends of the amplitude spectrum was achieved through the application of a frequency band-pass filter. The dewow filter performs some of the function of the high pass aspect of the frequency band-pass filter. This processing function serves to alter the slope of the wave amplitude in the returned frequency spectrum. The upper and lower limits of wave amplitude were considered so as not to eliminate genuine reflections, and the respective tapered sections of the frequency spectrum were decided on by the application of paired octaves as suggested by Woodward et al. (2003). The values of the upper and lower limits of the band pass frequency used are 150 and $1100 \mathrm{MHz}$ for the upper and lower frequency cut off, and 300 and $500 \mathrm{MHz}$ for the plateau at the upper amplitude spectrum.

Even after these processing steps were undertaken there was still an artificial horizontal banding evident in the processed data, uniformly regular and parallel to the surface wave. To remove these waves a "background removal" filter was applied. The average of a window (user selected number of traces) of traces is removed from each trace. The difference between the averaged window and the subtracted trace is considered to be noise and is removed. If the window for this function is too large it may remove actual horizontal reflectors. Considering the nature of the reflector expected in this survey the number of traces in the averaged trace window was unlikely to remove any reflector of interest. 
In some cases a "mean trace" was subtracted from all of the trace profile within the upper part of the time domain in an attempt to strip the saturated upper part of the trace spectrum. This was generally done after the application of the "background removal" filter. The aim of this filter application was to reveal any reflections that may be located within this part of the time domain. This was applied when looking for point reflectors and near-surface horizons.

A gain function was also applied to reduce the effect of transmission loss through the spherical spreading pattern of the transmitted GPR frequency. Both "Automatic Gain Control" (AGC) and a "linear gain" were used where necessary to return the most visible interpretation of IRH. In general the AGC was applied on the eastern transects with linear gain applied to the Davis Snowfield.

A Kirchoff migration function was applied to the radar data collected in steeply angled complex terrain. This process is necessary where steeply dipping and complex reflectors are encountered. The process function increases accuracy by providing more correct depth estimates and reducing noise. Shallower than actual depth estimates occur as the arc shaped wave front may reflect off of sloped terrain through the shortest wave path before the reflection of the intended radar wave trajectory is received. The migration function intends to correct for depth underestimation and 'migrate' the received reflection from the apparent location, back to the true location. The Kirchoff migration also sums and centres the diffraction tails of a reflector to the location of greatest arc in the reflection. In doing so the diffraction tails of the reflectors are reduced enabling better interpretation through reduced noise in the data. Jollie River valley ground-based radar transects were especially susceptible to complex reflections due to the multiple dipping ground reflectors and the high spatial resolution of the data. Migration correction was trialled with the airborne data but results were more difficult to interpret than the non-migrated data due to an expansion of the surface and ground reflectors in the time domain. The effect of migration in the less steep study locations was negligible and so the Kirchoff migration was not applied. 


\subsection{SWE calculation from radar depths}

\subsubsection{Layer digitization}

In order to determine the time scales of snow accumulation from within the snowpack it is necessary to identify and digitise IRH. This process reveals the TWTT and positioning signature of each trace thereby facilitating spatial analysis.

The digitization of interpreted layers within the radar profile was performed by a combination of manual selection of points across the IRH in question and an automatic interpolation that is not dependant on trace amplitude between those points. The distance between each point selection was determined by assessing the change in slope angle of the reflection horizon with manual trace selection at changes in visible IRH slope. Consideration was also given to the distance that points between the manual pick selections would be automatically interpolated. The time value of the isochrone selection was determined by magnification of the profile to directly inspect the trace amplitude.

\subsection{Traditional snow depth and density measurements}

\subsubsection{Density}

Snow density has a strong influence on the calculation of snow water equivalence.

Variations in terrain, altitude and snow depth, affect the spatial distribution of snow density and consequently SWE calculations (Lundberg \& Bergstrom, 2000; Lundberg, et al., 2006; Marchand, et al., 2003; Pinglot, et al., 2001). Density variations influence not only the SWE for a given depth of snowpack, but also the radio wave speed.

Snow pit analysis is the most reliable traditional method for obtaining snow pack density data at a resolution suitable for the study. Limitations of this method arise from the time it can take to dig a snow pit suitable to yield enough information on snow depth, and the amount of human power needed to undertake it. If the snow pack thickness is too great then it is not possible to establish how much accumulation is present, although probing from the bottom of the snow pit may be able to constrain the overall snow pack depth, but not density. 
Snow pits of $4 \mathrm{~m}$ depth were made on Davis Snowfield and Annette Plateau at the upper (2350 $\mathrm{m}$ a.s.l) and lower (2000 $\mathrm{m}$ a.s.l) elevation locations of the survey. Data from only the higher elevation snow pit could be obtained from Annette Plateau due to failure of the electronic scales. The snow pits were not dug down to a base due to the depth of snow accumulation at these sites. Snow density samples were made via snow pits at each sampled elevation at Jollie River valley.

\subsubsection{Probing}

Snow pits provide high quality density measurements. However, the snow pit technique is naturally limited in spatial coverage. A method of increasing the spatial coverage of snow depth measurements is the repeated probing to a recognisable layer such as a snow-ice boundary at Annette Plateau or snow-rock boundary at Jollie River valley. Accumulation rates at Jollie River valley and the complex terrain at this site means that probing was viable and necessary to conduct in verification of GPR data. At each elevation transect probed depths were made at $10 \mathrm{~m}$ intervals up to $100 \mathrm{~m}$ across the elevation transect. The averages of five probed depths at each $10 \mathrm{~m}$ intervals along investigated elevation bands were taken.

Probed snow measurements were not made at Annette Plateau or Davis Snowfield as accumulation volumes and the presence of multiple internal ice layers meant that probing for total snow depth would be impractical and probing for a particular internal ice layer would be subject to error. The smooth glacial topography of Annette Plateau and the crevassed firn observed at Davis Snowfield at the beginning of the accumulation season provided the knowledge that the initial accumulation surface could be expected and interpreted from both sites, with ice providing a uniform dielectric boundary to be observed in the radargram. The end of summer surface at Davis Snowfield was punctuated by crevasses and therefore diffraction hyperbole stacks could be expected to be seen in profiles at this site. These observations provide the basis for verification of the initial accumulation surface. 


\subsubsection{Establishing the relationship between SWE and TWTT}

A relationship was established between the cumulative two-way travel time (TWTT) (m ns ${ }^{-1}$ ) of the radio waves and the cumulative $\operatorname{SWE}(w)(\mathrm{mm})$ from the density $(\rho)\left(\mathrm{kg} \mathrm{m}^{3-1}\right)$ at sampling resolution of $10 \mathrm{~cm}$ defined by the manually measured snow density:

$$
w=\rho \frac{d_{\rho}}{\rho_{w}}
$$

Where $d_{\rho}$ represents the depth increment $(\mathrm{mm})$ of the density measurements down the snow column, $\rho_{w}$ is the density of water $1000 \mathrm{~kg} \mathrm{~m}^{-3}$.

The relationship of density to two way travel time, defined by Lundberg et al., (2000) based on the expression of (Tiuri et al., 1984), determines that the relative dielectric constant of dry snow $(K s)$ is dependent on the density of dry snow.

The TWTT $(t)$ of which each manual density measurement is correlated with digitised GPR values is calculated:

$$
t=\frac{2 d_{p}}{u}
$$

Where $u$ is the radar wave speed through the snow column which can be calculated:

$$
u=\frac{c}{\sqrt{K S}}
$$

Where $c=2.998 \times 10^{8} \mathrm{~m} \mathrm{~s}^{-1}$ and represents the constant velocity of the speed of light/radio waves.

Laboratory experiments show that if the effect of liquid water volume in dry snow is established as negligible that $K s$ can be approximated from $\rho$ by:

$$
\sqrt{K s}=1+c_{1} \rho
$$

Where $c_{1}$ is $0.000851\left(\mathrm{~m} \mathrm{~ns}^{-1}\right)$.

Combining equations 2.3 and 2.5 the TWTT can be expressed as a function of the density depth relationship:

$$
t=\frac{2 d_{m}(1+0.000851 \rho)}{0.298}
$$

Where $d_{m}$ is depth (mm) of the measured snow density.

This function is summed for the depth of the snow pit allowing the relationship of cumulative TWTT $\left(t_{\text {cum }}\right)$ and cumulative SWE $\left(w_{\text {cum }}\right)$ to be established. 


\subsection{Improving Data Collection Methods}

The successful completion of field work in remote areas is dependent on time and resources. In New Zealand's remote and mountainous upper catchments access is generally only viable via helicopter. This limits survey times to when flying is suitable and influencing factors such as wind and visibility further restrict the amount of time available to undertake such work (Marshall et al., 2008). Periods of inclement weather can be sustained for weeks in the Franz Josef and Mount Cook regions. Such meteorological situations are common in the period of maximum snow accumulation in late winter and early spring. Implicit within this meteorological state are fluctuations in the free air freezing level, therefore defining the phenomenological state of hydrometeors.

The selection of a survey date is dependent on the availability and suitable length of a weather window at the correct time and enabling sufficient human and mechanical resources around what can be a rapidly moving target. GPR surveys reduce the number of people required, and the time taken to undertake alpine snow survey and could go some way to alleviating the reliance on the longer time periods required for snow surveys. However, verification of snow depth and density to calibrate GPR data is still demanding of labour and time (Taurisano et al., 2007). The relative efficiency of a GPR survey to a manual survey can be further bettered if the speed of calibration techniques can be improved. This would reduce the logistical difficulty and expense in undertaking large-scale snow surveys.

To consider verification techniques that may increase efficiency it is important to look at the current techniques and where improvements can be made. The level of desired reliability and accuracy of captured data for the intended end use is also an important consideration. It is therefore important to consider the equipment to be used in the field investigation.

Shallow snow cores are a relatively quick method to quantify snow pack depth and density. Coring is susceptible to misrepresentation of density values as snow may be ejected from the sampled column in the auger when it is removed from the snow pack for weighing, and compression of snow within the column may cause error in such estimates.

Probed snow depth measurements are fairly reliable results when surveying to a uniform substrate through accumulated snow to the ablation area of a glacier (Machguth, et al., 2006), or gently angled slopes. Error increases when the snow pack has inherent multiple ice 
layers, the snowpack is too deep to find the bottom with the probe, the bed is rough. For comparison to GPR data, additional error occurs if the probe is not inserted at an angle equal to that of the GPR sampling angle, a problem in steeper terrain.

The non invasive and relatively quick and accurate geophysical method of Common Mid Point (CMP) survey (Baker, 2007) will yield radio wave and hence density information through equations $2.4-2.5$. If there is a strong change in dielectric constant, such as at the boundary of snow and ice, water, and rock then depth can be reliably calculated. This method involves the incremental separation of both the transmitting and receiving antenna around a fixed point. This fixed point, usually a diffraction hyperbole, may be difficult to obtain in deep and relatively spatially homogenous snowpacks. This method is also reliant on antennae that are able to be separated from each other. CMP methodology is not applicable in the case of this study as the equipment utilized does not have provision for antennae separation.

\subsubsection{MARTYRS}

In consideration of the above notions a quick, non-invasive, labour-efficient and accurate method of radio wave speed assessment of SWE would be beneficial. The concept of utilizing a metallic reflector at a known angle was trialled (Watson, 2008). A geophysical method was derived where by two $13 \mathrm{~mm}$ diameter solid aluminium snow probes were inserted parallel to each other and at a 45 degree slope to the snow surface. This provided a reflector with depths that could be approximated along the y axis (or time domain) with consideration of the distance along the $\mathrm{x}$ axis, which represents the expected projection of the rod onto the snow. I named this technique MARTYRS after Matt's Angled Rod Technique to Yield Radio wave Speed.

The radar antennae were twice passed at fixed intervals perpendicular to the $\mathrm{x}$ axis directly above the location of the probe for approximately $1.5 \mathrm{~m}$ either side of the probe (Figure 2.3 ). Passing the radar twice over one location provided two diffraction hyperboles within each radargram at the same depth to identify the location of the probe and separate the deliberately made hyperbole from those possible hyperboles that may be inherent within the snow pack. 


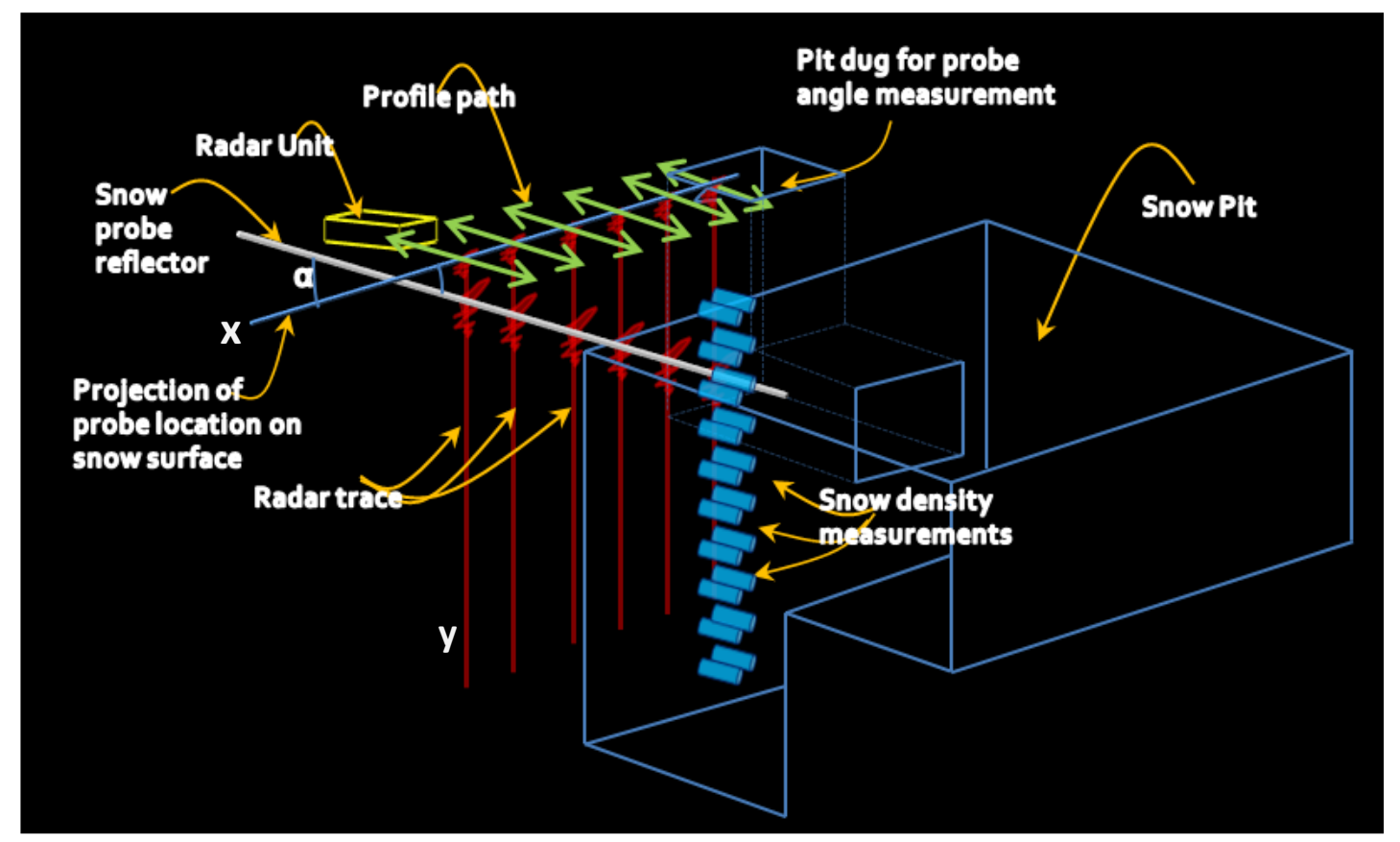

Figure 2.3. Schematic of the snow pit manual density measurements and the arrangement of the MARTYRS GPR derived snow density measurements.

Verification of the angle of the reflector was made by digging down to the probe at a $1.5 \mathrm{~m}$ distance from the origin along the $\mathrm{x}$ axis (Eisen, et al., 2003) and down to the probe. Due to slight curvature of the probes when inserted and slight veering off of the intended 45 degree angle a polynomial relationship of y axis depth $(d)(\mathrm{mm})$ to distance $x_{d}(\mathrm{~mm})$ was produced

$$
\mathrm{d}=-0.0004 x_{\mathrm{d}}^{2}+0.961 \mathrm{x}_{\mathrm{d}}
$$

and could be incorporated into a conversion to a value of density by rearranging equation 2.6 to give;

$$
\rho=\frac{0.298 t-d_{m}}{\left(2 d_{n}\right) 0.000851}
$$

Therefore allowing SWE to be calculated (Equation 2.2)

The $t$ value was determined from the post processed GPR profiles and represents the picked values and diffraction hyperbole maxima (Figure 2.4). Regularity in selection of pick depth was determined by the recurrence of a flat peaked wave form that occurred in relation to the 
observed diffraction hyperbole. The observed wave form had a positive and negative deflection in amplitude of equal value and time and set the location.
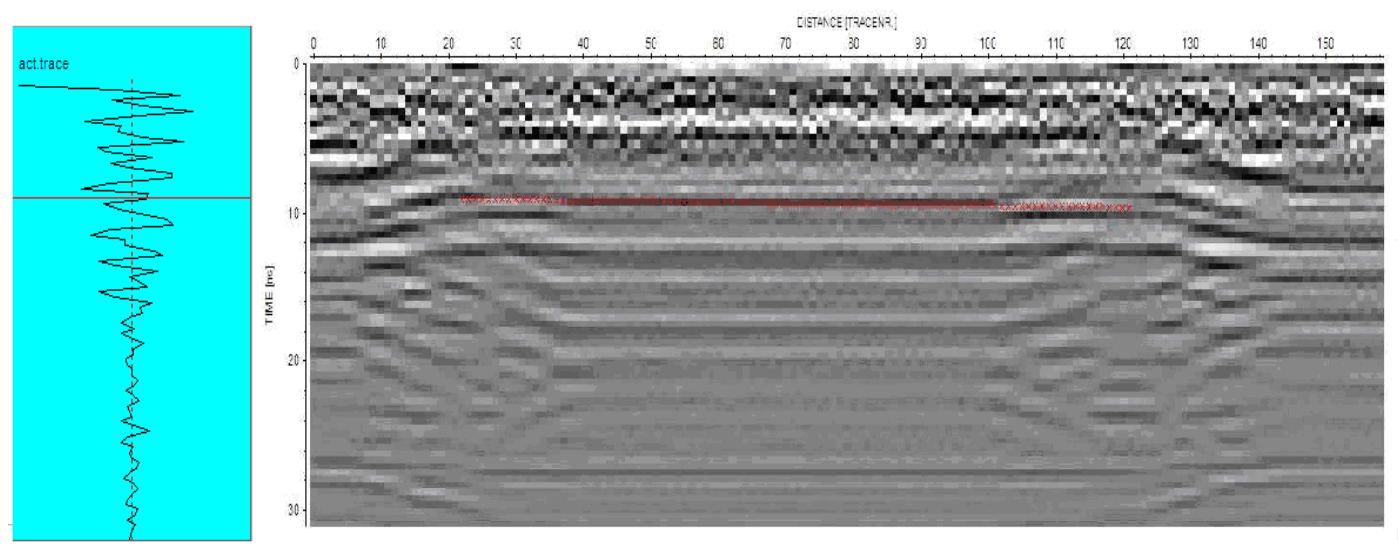

Figure 2.4. Radargram depicting the location of the $x=1200 \mathrm{~mm}$ diffraction hyperbole. Red markers represent picked time value. The blue trace box on the left represents the diffraction hyperbole on the left. The location of the pick is represented with the red line. Two diffraction hyperbolas were assessed to reduce spurious error in data interpretation.

A sequence of post-processing procedures similar to that used in the spatial SWE depth analysis was used. This incorporated a migration function as the reflector was dipping at $45 \%$ to the plane that the radar survey was taken on (Jol \& Bristow, 2003). As stated in the previous section, the migration analysis computation requires knowledge of a wave speed which in turn requires knowledge of snow density. This is just the factor that is being determined, and is not known at this step of the analysis. A nominal wave speed value of $0.222 \mathrm{~m} \mathrm{~ns}^{-1}$, equating to a snow density value of $400 \mathrm{~kg} \mathrm{~m}^{-3}$ (Equation 2.6) was assigned to all migration computations. As such the migration function is an approximate correction of diffraction hyperbole location in this instance.

\subsubsection{Airborne GPR survey}

Coupling a GPR to a motorised vehicle has been utilised in many cryospheric studies. Motorised vehicles such as snow cats and snow mobiles have been used in the Antarctic, Greenland, for high and low resolution snow surveys investigating snow distribution and accumulation rates, crevasse location identification, and ice depth. Aerial tramways have been used in feasibility studies of finding avalanche victims (Heilig et al., 2008). Light aeroplanes have also been used for low frequency airborne surveys (Kanagaratnam et al., 2004). 
A helicopter is a very useful tool for undertaking aerial snow surveys due to its slow flight speed and manoeuvrability. It has been used with success in SWE calculation by Marchand et al., (2003), Machguth et al., (2006), and in the investigation of buried objects by Negi et al., (2008). Airborne GPR has also been used to investigate snow structure to infer slope stability for avalanche assessment (Marshall et al., 2008).

A methodological comparison survey was made in this study employing airborne GPR on flat terrain at Annette Plateau and on steeper terrain complex terrain at the Jollie Valley. In this study the radar antenna was mounted centrally to the bottom of a helicopter in a similar position to previous studies (Figures 2.5.1 \& 2.5.2). The operator sat in the front of the helicopter, with the monitor. The GPS receiver was placed at the front of the machine.
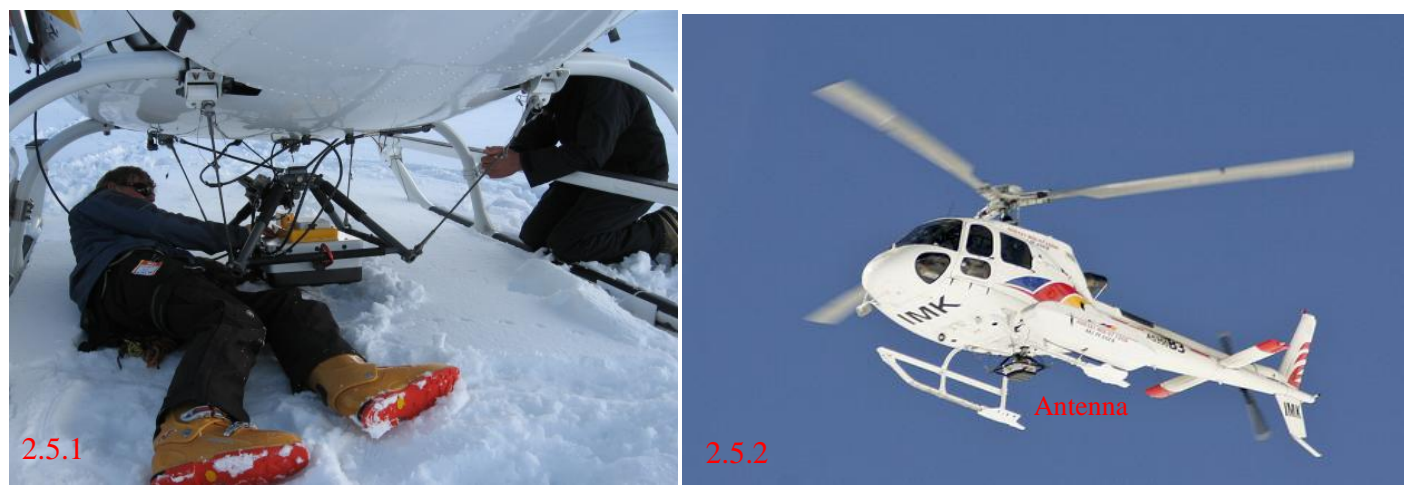

Figures 2.5.1 and 2.5.2; Mounting the antenna to the support frame underneath the helicopter (2.3.1), Helicopter undertaking GPR survey 2.3 .2

Due to time constraints while working with the helicopter the radar data acquisition settings were not able to be tuned for the specific site but are expected to make little difference to the overall result. The parameters used were adapted from Machguth et al., (2006). For the comparison airborne radar survey at Annette Plateau the same acquisition parameters as the ground based survey were used (Table 2.2).

The helicopter flight path for both sites was made directly above the ground-based survey as identified by the ski tracks and snow pits. These were clearly visible as the airborne survey was undertaken on the same day as the ground based survey at Jollie River valley and the day after the ground-based survey at Annette Plateau. GPS positioning data was collected as per the ground based profiles with the GPS receivers mounted in the front of the helicopter. There was likely some offset from the skied track especially in the steeper and more complex slope terrain. The effects of this offset are likely to be reduced by the large spatial 
averaging effect that is inherent in the helicopter survey due to the beam angle of the antenna and the resultant $<10 \mathrm{~m}$ Fresnel zone radius due to the helicopter elevation.

\subsection{Error Analysis}

\subsubsection{Density measurements}

The accuracy of SWE estimates from GPR profiles is dependent on the quality of the snow density measurements, and the judgements made when digitizing GPR data. Snow density measurements were made by weighing a snow tube that had been pushed into the shady wall of a snow pit. Once removed the ends of the filled tube were trimmed of protruding snow. The tube was then weighed using a combination of digital scales and spring balance subject to the availability of the equipment. The snow density equals the weight of snow inside the tube divided by the volume of the tube.

Utilizing this methodology, errors in the sampling process can be carried into density calculations by,

1) Under and overstuffing the sampling tube,

2) Error within the balances used to measure mass,

3) Error in the snow mass calculation from measurements of the full and empty sampler tube of both weight and dimensions of the tube,

4) Variation of snow density across slope,

The snow pit sample density error $\left(e_{\rho}\right)$ was calculated as the square root of the squared product of the proportional influence that the scale measurement error (grams) $\left(s_{e}\right)$ has on the snow mass measurement $\left(\mathrm{mm}^{3}\right)(m)$ summed with the squared volumetric error $\left(\mathrm{mm}^{3}\right)$ $\left(v_{e}\right)$ calculation from errors in the dimensions of the sampler tube.

$$
e_{\rho}=\sqrt{\left(\frac{\left(2 s_{e}\right)^{0.5}}{m}\right)^{2}+v_{e}^{2}}
$$

Due to various operators sampling snow density, and the inherent variations in the sampling technique due to this, it was not possible to quantify the effect of under or overstuffing the sampler tube (1) (Kerr, 2009a). The effects of across slope density variations are also not considered in the calculation of SWE. This is unlikely to cause too much error in SWE 
calculations in homogenous terrain (Harper \& Bradford, 2003) but may have more effect in the more complex terrain of the Jollie River valley (Elder et al., 1991).

\subsubsection{GPR digitization}

The accuracy of SWE estimates as a result of this method are similar to that of Pinglot et al., (2001) and determined to be susceptible to the effects of;

5) The loss in returned GPR signal strength in deep snow packs from signal spreading loss,

6) The roughness surface that the radar is sitting on creating pitch and yaw of the antennae and subsequent misrepresentation of depth,

7) The roughness of the snow-ice/firn/scree interface,

8) Strength of reflection at the interface as determined by the variation in dielectric constants of the respective upper and lower strata.

Correction of 5 through 8 was made by assigning a nominal value of error in $n s$ to the SWE calculation from TWTT. The cumulative effect of these errors on SWE estimates are between 9 and $13 \%$ with the effect of the picking error reducing with an increase in depth of the snow pack. These error estimations compare well with that by Pinglot et al., (2001).

For the snow packs that are deeper than the $4 \mathrm{~m}$, verification pits such as those at Annette Plateau and Davis Snowfield, an increase in density with depth is assumed down to the reflection horizon of the respective snow-ice firn layer. The SWE calculations use a linear interpolation of snow depth for this purpose.

\subsection{Data comparison}

All data collected were spatially referenced in the field using GPS with measurement accuracy in the range of 5 to $15 \mathrm{~m}$. This inaccuracy created differences in the apparent location of the samples between the airborne and ground-based surveys despite data being collected at the same location on the ground as determined by the ski tracks of the ground based survey which was done before pit and probing verification, and airborne comparison. 
The sampling frequency of each method also varied in space due to the different speeds at which the radar travelled on the ground and in the air, and the number of probed measurements practical to take in one location. It is also important not to consider GPR measurements over a grid square as a pure point measurement. The propagation of electromagnetic energy from the radar is in a conical shape with an oval shaped footprint called the Fresnel zone (Annan, 2005). This study assumes an electromagnetic ray path that is perpendicular to the base of the antennae. The Fresnel zone increases as the antennae is moved away from a horizontal position with the slope and distance from the snow surface, therefore there is a certain amount of averaging of bed shape and snow depth.

Comparison of the ground based, airborne and probed data sets were made using ArcGIS 9.3 by application of a grid based comparison similar to that of Marchand et al., (2003). A matrix of $10 \times 10 \mathrm{~m}$ and $20 \times 20 \mathrm{~m}$ grids were laid over the two data sets (Figures 2.6.1 and 2.6.2). These grid sizes were chosen as they were of a large enough size to incorporate inaccuracies in GPS positioning and to incorporate the effects of the spatial averaging caused by the antenna Fresnel zone and any deviation from the profile path taken by the helicopter. A grid size larger than $20 \mathrm{~m}$ was considered to be too large, as it would incorporate terrain that was not representative of the points in comparison. In this methodology all points that fell within the grid were averaged giving one point measurement for each technique from each grid cell location.

The grid was applied in a north-south orientation and independent of the consideration of the direction of the survey measurement paths. The independent orientation results in some points not being able to be correlated with others (Figures 2.6.1 and 2.6.2). In Marchand et al., (2003) there were sections of the profile where there were points with no comparable value from another measurement technique as GPS error meant that some measurements did not fall within the grid cell of the adjacent measurement. There is expectation that the high resolution of measurement, and the footprint area of the Fresnel zone will go some way to reduce this characteristic of the comparison technique. 

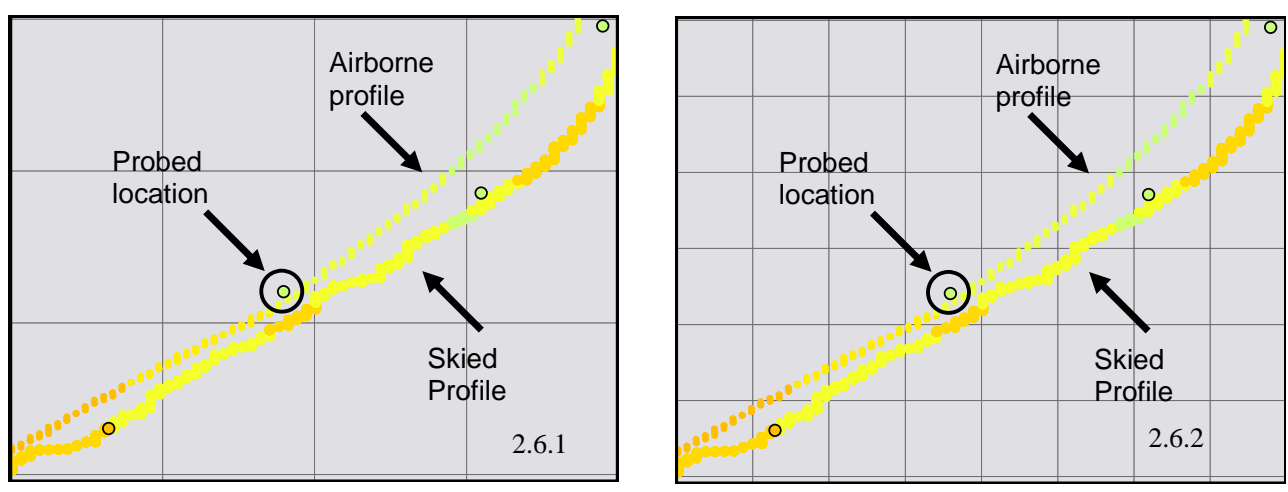

Figures 2.6.1 and 2.6.2. A schematic showing the spatial relationship between data points when both $10 \times 10 \mathrm{~m}$ and $20 \times 20 \mathrm{~m}$ grids are placed over the data.

\subsection{Precipitation Modelling}

As one of the objectives of this thesis is to use the snow accumulation data measured with GPR to assess precipitation rates in different parts of the Southern Alps, a method of relating snow accumulation to precipitation is required.

Modelling of accumulation is often done using empirical relationships of climate data and a location. These models are often untested due to no practical means to test empirical relationships at high precipitation and high altitude locations. An example of this is the use of temperature and an index such as elevation in a way that incrementally increases precipitation with altitude (Fitzharris \& Garr, 1995 2006; Purdie, et al., 2011b). This type of model accounts for the general pattern of snow accumulation, but in reality snow accumulation is affected by terrain specific wind effects and mass gravitational transport cause the redistribution of snow (Machguth, et al., 2006) and can create unreliability in the assumption that precipitation increases linearly with altitude.

\subsubsection{Degree Day Model}

Measured SWE data obtained by using the GPR methodology outlined earlier is compared with estimated precipitation using the temperature index model approach. This is a commonly used accumulation estimation for glacier mass balance (Anderson, et al., 2006) and seasonal snow estimation modelling. This approach has been used in conjunction with other related climate data such as incorporating dependence of precipitation estimates on wind direction (Kerr, 2009b). An assessment of cross-mountain snow accumulation and the 
relationship with synoptic classifications at the accumulation maxima is unique to this study and as such offers an opportunity to offer accumulation estimation model parameters tuned to direct measurements of snow depth.

The outputs of the conceptual precipitation model estimates are commonly spatially projected by geographic mapping software providing a spatial context for the modelled estimates(Fitzharris \& Garr, 1995) The methodology used in this study offers spatially lumped point location calibration for each site. The temperature index calculation used closely resembles that used in Anderson et al., (2006).

\subsection{Parameters of modelled precipitation}

\subsection{Meteorological Data}

This study uses average hourly values of temperature and precipitation to drive the accumulation and ablation estimates of SWE. These data are sourced from the closest AWS to each site and is described in (Table 2.3). The temperature data is lapsed to the altitude of each study location from the respective AWS. Relation of snow pack accumulation sequences to climate data is achieved by synoptic circulation classifications.

There are two parameters that allow calculated accumulation at the location of estimated precipitation in this model. The selection of a temperature lapse rate and the selection of a temperature threshold to determine precipitation phase.

\begin{tabular}{lccccc}
\hline \multicolumn{1}{c}{ Climate Station } & $\begin{array}{c}\text { Northing } \\
\text { NZMG 49 }\end{array}$ & $\begin{array}{c}\text { Easting } \\
\text { NZMG 49 }\end{array}$ & $\begin{array}{c}\text { Altitude } \\
\text { m a.s.I }\end{array}$ & Data used & $\begin{array}{c}\text { Frequency } \\
\text { of } \\
\text { observation }\end{array}$ \\
\hline Franz Josef AWS & 5761778 & 2277589 & 80 & Temp ${ }^{\circ} \mathrm{C}$, Rainfall Hourly Average \\
Mount Cook AWS & 5756226 & 2277780 & 765 & Temp ${ }^{\circ} \mathrm{C}$, Rainfall Hourly Average \\
Rose Ridge & 5735558 & 2296646 & 1940 & Temp ${ }^{\circ} \mathrm{C}$ & Hourly Average \\
\hline
\end{tabular}

Table 2.3. Sources and locations of AWS climate stations. Franz Josef Glacier AWS and Mount Cook (village) AWS are used for precipitation modelling purposes. Rose Ridge AWS is used to calculate a lapse rate for the eastern alp snow modelling. Sites are all owned and maintained by NIWA except Rose Ridge AWS which data were provided by Meridian Energy and maintained by NIWA. 


\subsection{Temperature lapse rate}

The rate at which temperature changes with elevation is used to model precipitation type at study site elevations. The lapse rates are known to vary with synoptic condition and season (Kerr 2009a; Stuart, 2009). This study uses average seasonal lapse rates for each site. AWS temperatures were calculated for the site elevations at Davis Snowfield. The lapse rates were derived from an investigation into the near surface temperature lapse rate profile of the Franz Josef Glacier valley (Stuart, 2009). This work was a combination of data from AWS and temporary climate station data (Anderson, et al. 2006; Purdie, et al. 2011b) and is used due to lack of a permanent high climate station record on the West Coast. For Annette Plateau and the Jollie River valley the temperature lapse rate was calculated for the study period from the Rose Ridge and Mount Cook Village AWS (Table 2.3).

\subsection{Precipitation phase threshold}

The temperature threshold determines whether precipitation is accumulated within the temperature index model as a liquid or solid. The elevation lapsed temperature values are used to determine the phase state precipitation at $1^{\circ} \mathrm{C}$ (Anderson, et al., 2006; Purdie, et al., 2011b).

Liquid precipitation is recorded in the modelled snow pack as an increase in depth. Whilst liquid precipitation does not increase snow pack depth in reality, the units that the model output represents are in mm w.e (water equivalent), and is a standard precipitation reference. Liquid precipitation is accounted for in the GPR SWE sourced precipitation depth measurements through the snow density measurements used to calculate the electromagnetic wave speed, assuming that there is no through flow of precipitation in the snowpack.

\subsection{Synoptic circulation classifications}

The synoptic scale accumulation factors underwent a least mean square analysis to find the best estimate of accumulation factor to represent all accumulation periods for the whole season. Partial and whole season accumulation factors were calculated for the range error provided by the GPR survey regardless of synoptic type. 
Synoptic circulation classifications provide a climatic context for accumulation factors that represent snow accumulated within the boundaries of IRH within the snowpack (Kidson, 2000). The twelve synoptic classifications are grouped into three broad synoptic regimes, these are trough, blocking, and zonal. These data are supplied by Jim Renwick of New Zealand's National Institute of Water and Atmospheric research (NIWA).

The synoptic classifications represent the synoptic scale circulation over New Zealand at the $1000 \mathrm{hPa}$ mean sea level pressure fields of NCEP/NCAR dataset of $12 \mathrm{hr}$ analysis, for 40 years between June 1958 and 1997 (Kalnay et al., 1996). Synoptic classifications are suggested to be of potential value in predicting changes in frequency of extreme climatic events (Kidson, 2000). By applying synoptic classifications to snow column data the magnitude of climatic events, such as flooding, may be better quantified.

The 12 hour synoptic classifications are incorporated with snow accumulation data by aligning date and times with cumulative accumulation values and associated accumulation factors. Accumulation factors are applied seasonally for total snow pack depth, and for each IRH. Synoptic accumulation factors were calculated by manually fitting accumulation depths to IRH SWE values. The accumulation factors continued after deposition, for the period of no accumulation until the next snow fall, when the next appropriate accumulation factor was applied. 


\section{CHAPTER 3}

\section{Results}

\subsection{Overview}

The results from the field investigation of this study are divided into two sections. The first section (Analysis of Methods) presents the results obtained in the comparison of snow depth data collection methodologies in order to develop a relationship with previous GPR/SWE studies and test the performance of probed, ground-based GPR and airborne GPR in flat and steep terrain. Further comparison is made with a novel approach to snow density collection to established density collection techniques.

The second section (Analysis of Precipitation Distribution) uses the product of the GPR investigation and snow density data to relate low-altitude precipitation records with the higher altitude study sites. The derived 'accumulation factors', are presented for the three sites. The intra-season site visits at Annette Plateau allowed for a time series of accumulation factors to be presented. For Davis Snowfield and Jollie River valley accumulation factors for the entire winter season are presented. The vertical resolution of the GPR allowed an assessment of snow pack development, which was related to the synoptic weather regimes at the time of deposition, and so allowed further assessment of the development of a maritime alpine snowpack and offers a full season account of accumulation rates at the time scale of synoptic weather regimes. 


\subsection{Analysis of Methods}

\subsubsection{Relationship between Two-Way Travel Time and Snow Water Equivalent}

To compare the three different measurement techniques (GPR, snow pit, and probed snow depths) it is necessary to relate the measured snow densities from snow pits, the probed snow depths, and TWTT output of GPR surveys into a comparable common relationship (Equation 2.6).

The relationship between SWE and two way travel time (TWTT) form the basis for all of the snow accumulation measurements taken in this study. The relationship was used to model the snow density (consequently radar TWTT) within the snow pack at all sites (Figure 3.1.1). This relationship is based on the snow density measured in snow pits at a 10 $\mathrm{cm}$ resolution, and the relationship between snow density and electromagnetic wavespeed (Equation 2.6). The results can be can be represented by a linear relationship (Lundberg, et al., 2006). Snow pits represent snow density for the area of investigation. These pits were dug to a depth that was deemed practical for obtaining a density profile within the constraints of time available. Three $4 \mathrm{~m}$ deep snow pits were made at Davis Snowfield and Annette Plateau, for the end of season surveys. For the 2300 m Davis Snowfield an average of the two snow density profiles was used to develop the SWE / TWTT relationship. At the Jollie River valley five snow pits were dug down to the ground, one at each of the elevation profiles in conjunction with probed measurements along each elevation.

The relationships derived from the linear trend representing the relationship of SWE/TWTT reveals a pattern of higher snow densities on the eastern side of the Southern Alps (Table 3.1.1) although it is suspected that local terrain effects such as exposure contributes to the variability in the east-west density profile. The altitudinal relationship of the multiple measurements of snow density observed at the Jollie River valley may be obscured due to similar influences of terrain and aspect. The observation of increasing snow density with altitude at Davis Snowfield may be in part to do with increased exposure to wind resulting in mechanical densification of snow particles by sorting and compaction and the development of wind crusts. 


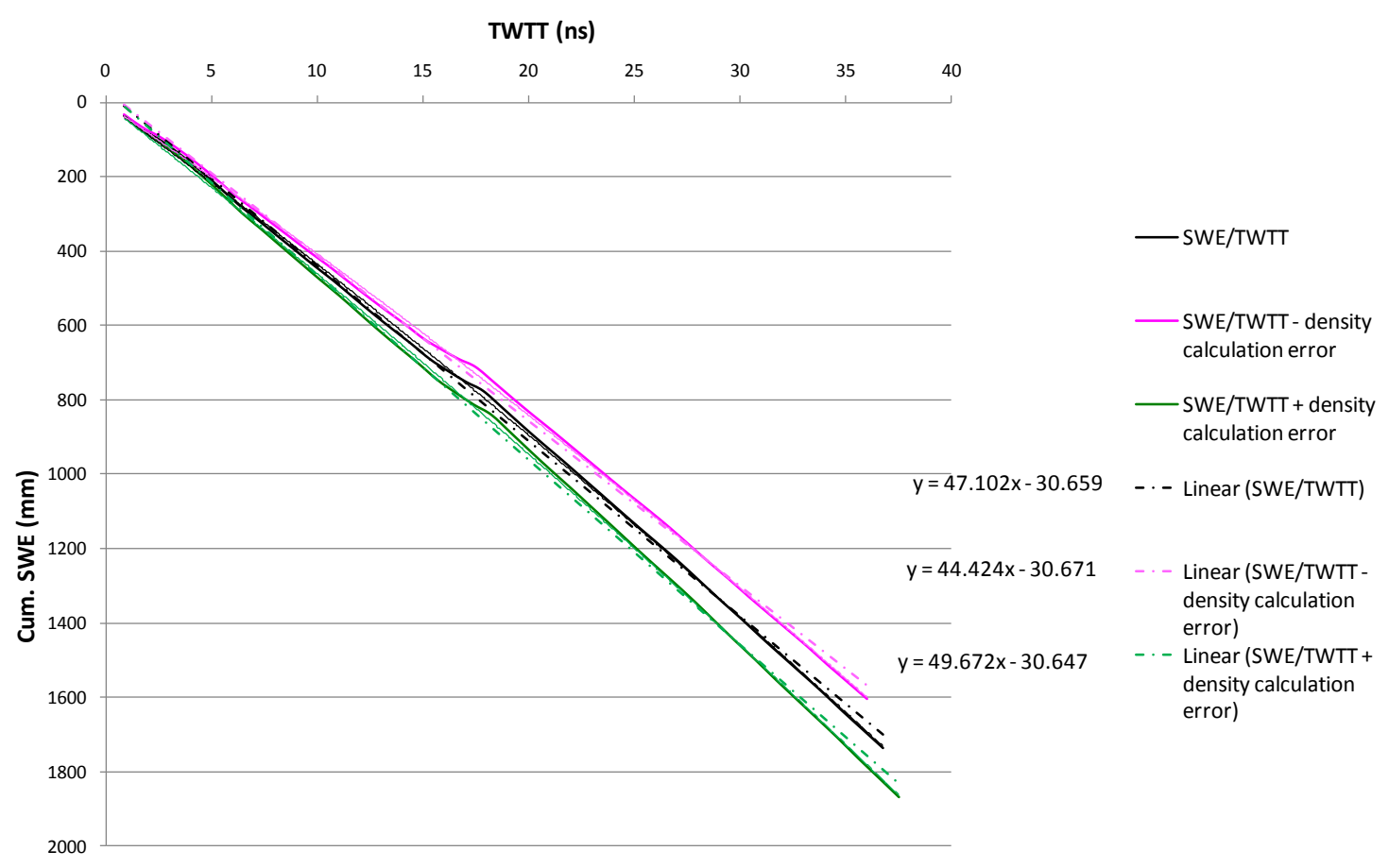

Figure 3.1.1. An example of the density depth relationship used to determine SWE across the study area at Annette Plateau. Also plotted are the error estimations from snow density measurement and the linear trends and equations that provide the basis for the snow depth calculations. The largest deviation from the snow pit measured snow density profile is between $700 \mathrm{~mm}$ and $800 \mathrm{~mm}$ SWE. Deviations such as this are evident in all snow profiles for all sites at a range of depths and are not considered to be significant.

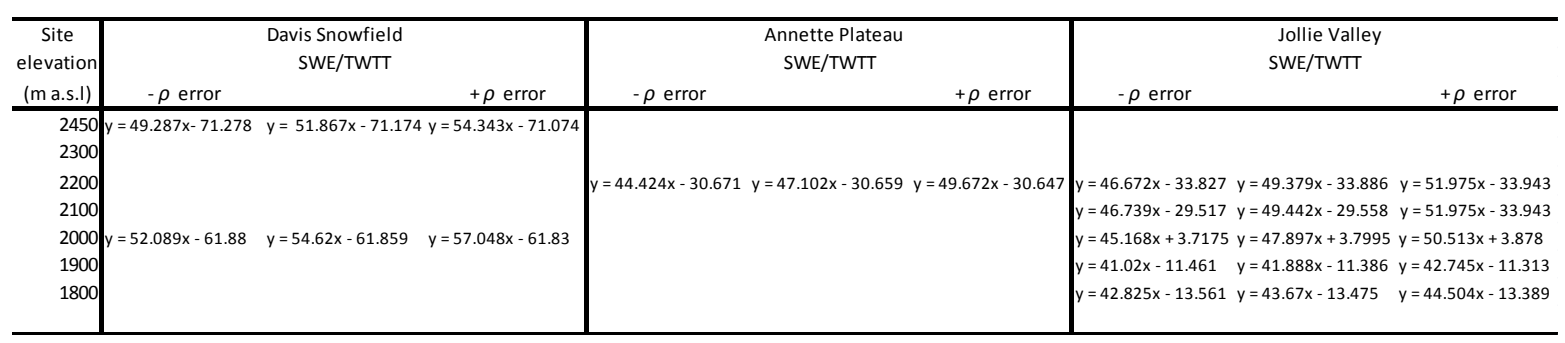

Table 3.1.1. Table of measured TWTT/SWE (depth and density) relationships for the study sites, where $y=S W E$ and $x=T W T T(n s)$ (Figure 3.1.1)

The manually measured snow depths required conversion to a snow density SWE/ TWTT profile derived from measured snow pits at each surveyed altitude profile. The snow pit density profile was applied to probed snow depth measurements. A best fit using a $\log$ relationship was used (Figure 3.1.2). In some instances a sixth order polynomial trend produced a better fit of the snow density/depth relationship, the quality of the fit varied from pit to pit. The log curve results were more consistent between snow pits, so were used for the remainder of the study. 


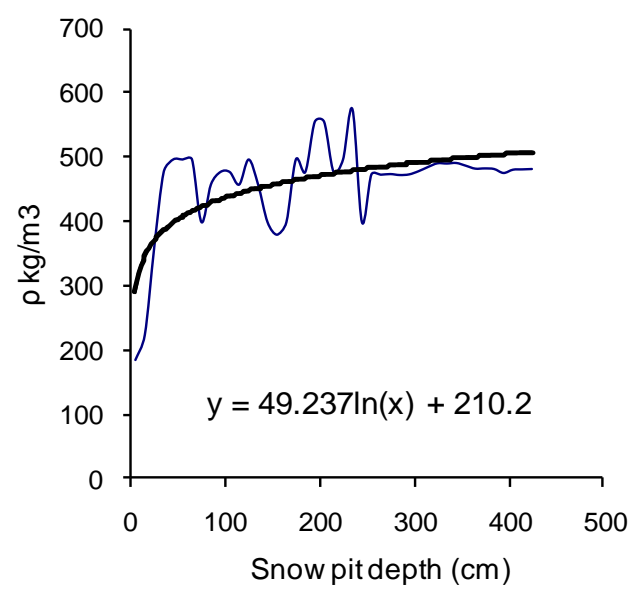

Figure 3.1.2. The log best fit relationship of the measured snow density data and corresponding depths for the comparison of GPR and probed measurements at the Jollie River Valley for $2100 \mathrm{~m}$ a.s.l.

For the comparison of GPR and probed measurements at Jollie River Valley, the snow depth/ density relationship was applied to the average of the five measurements at each probed location for each of the respective snow pits for the surveyed elevations. The relationships were defined in order to apply the density profile from the snow pit to all of the probed measurements using the assumption that the snow density profile is representative of each elevation (Table 3.1.2) and the snow density variation reduces with depth.

\begin{tabular}{r|c}
\hline \multicolumn{1}{c|}{$\begin{array}{c}\text { Site } \\
\text { elevation } \\
(m \text { a.s. } I)\end{array}$} & $\begin{array}{c}\text { Jollie River Valley } \\
\text { Density/depth profile }\end{array}$ \\
\hline 2200 & $y=38.943 \ln (x)+254.25$ \\
2100 & $y=49.237 \ln (x)+210.2$ \\
2000 & $y=19.516 \ln (x)+349.2$ \\
1900 & $y=36.641 \ln (x)+209.75$ \\
1800 & $y=26.71 \ln (x)+255.92$ \\
\hline
\end{tabular}

Table 3.1.2. The depth density relationships used to relate probed snow depths to SWE from the best fit log relationship. The depth density relationship was used for comparison of depth measurements with GPR measurements, not as a method for calibrating GPR surveys. 


\subsubsection{MARTYR}

The experimental method using an aluminium alloy probe as a reflector at known depths provided a reasonable estimation of snow density. There are deviations around the measured density and too few data points to deliver a strong statistical conclusion, yet the relationship of the data points around the trend shows a tendency for the MARTYR technique to slightly underestimate SWE, with one outlier (Figure 3.1.3). The outlier is the point with a MARTYR calculated snow density value of $66 \mathrm{~kg} / \mathrm{m}^{3}$. This is an unrealistic snow density value and measured snow density and MARTYR calculated snow density should be of close to equal value.

\section{Density method comparison}

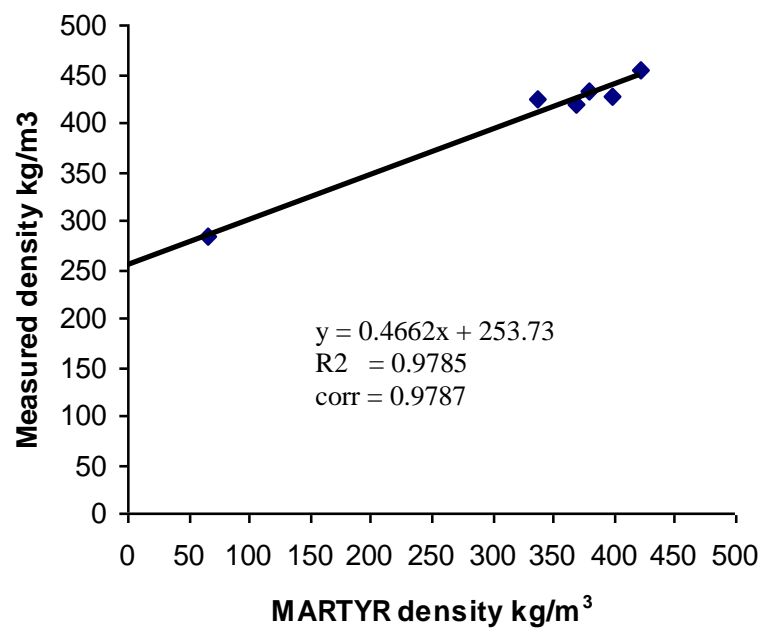

Figure 3.1.3. The relationship of density values derived from the MARTYR technique and measured snow pit density values.

The calculated density values from the MARTYR exercise produce a slight sinuous deviation of the MARTYR derived SWE around the measured value with a tendency to underestimate SWE at depths above approximately $6 n s$ (Figure 3.1.4). The results are provided with estimates of error for each the directly measured and MARTYR estimated SWE.

The error estimates for the picked data arises from a standard $2 n s$ estimate of error about the calculated value. The $2 n s$ value provides a phase envelope of error that encompasses the range of error provided by the measured density methodology and is sufficient to account for the manual digitisation of snow depths from the radargram. Deviations from the measured density may be made through; 
- inaccurate measurements pertaining to the distance of the radar from the origin of the reflector at the surface

- error in the angle measurement of the reflector measuring

- picking error at the digitisation stage

$\operatorname{TWTT}(n s)$

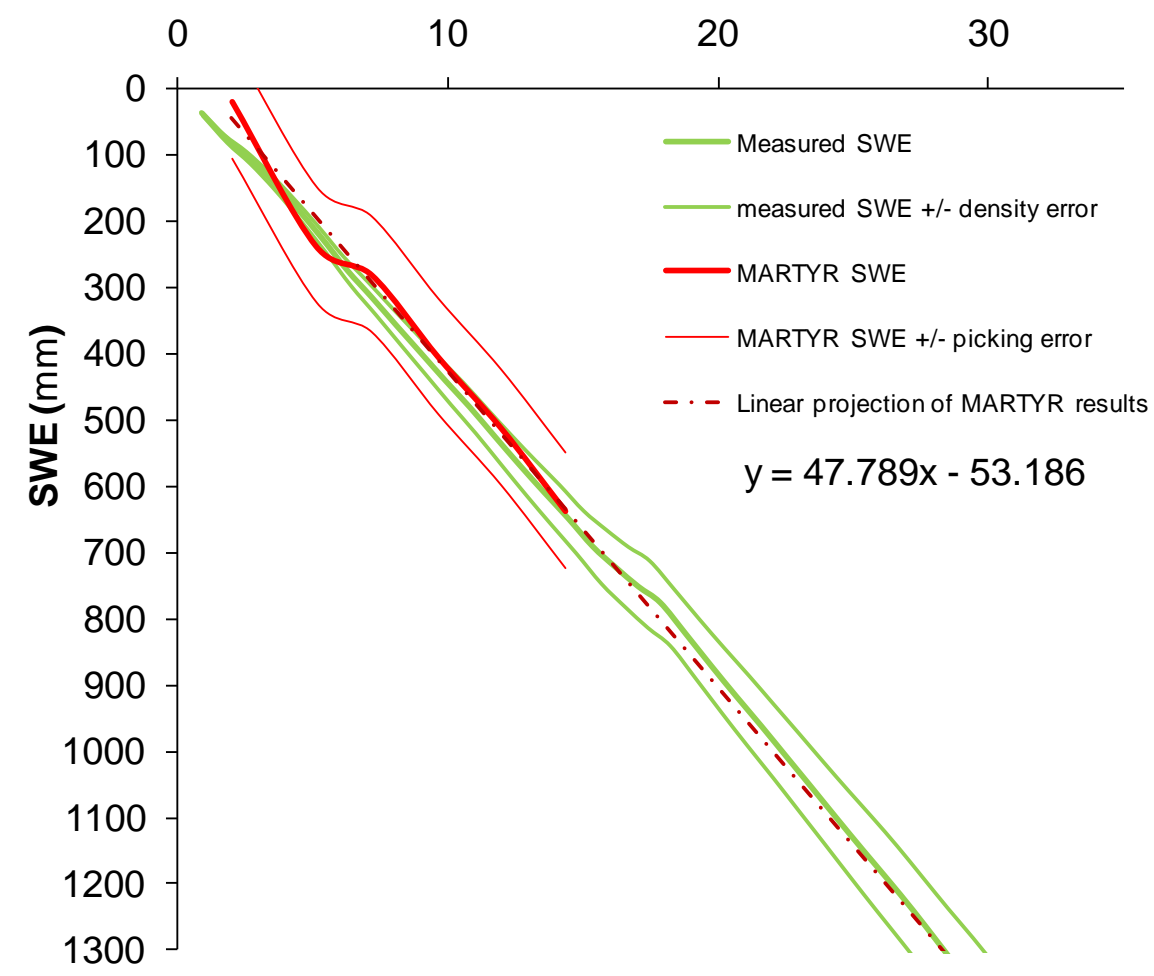

Figure 3.1.4. The relationship of TWTT and SWE using values of measured SWE from snow density measurements, and the MARTYR technique in which density and SWE are calculated from TWTT and depth. The projected relationship of the MARTYR investigation to depth of measured snow density is also provided.

A polynomial best fit was applied to the discreet measurement locations taken on the $\mathrm{X}$-axis of the MARTYR measurement (Figure 2.3). Using the relationship for TWTT and SWE derived from the polynomial best fit for probe trajectory, a linear extrapolation of the relationship was made down to 4 meters in the snow pack(Figure 3.1.4), or 1200mm SWE which is the maximum depth of measured snow density. The linear extrapolation of the MARTYR TWTT relationship with SWE showed some initial deviation from the measured SWE at depth up to $1 \mathrm{~m}(300 \mathrm{~mm}$ SWE) but fell to around $3 \%$ of the measured SWE at $4 \mathrm{~m}$ 
snow depth (1250mm SWE). The results of the new technique are good considering manual snow density measurements have an associated error of up to $10 \%$.

Of the above error sources, the issue most likely to contribute the largest error to the measurement is the distance of the antenna from the origin (distance along the $\mathrm{x}$ axis. (Figure 2.3)). The picking error can be made regular between samples by using procedural consistency and maintaining a digitisation protocol. The angle of the inserted snow probe is able to be calculated within a few degrees if depth and distance measurements are made with care. Small scale variations in reflector angle are unlikely to have an effect on the reflector positioning in the radargram. The source of error most likely affecting snow density estimations from this method is the, placement of the GPR antenna on the ground, and the measured distance from origin of the snow probe at the snow surface. An example of this distance measurement inaccuracy is the $66 \mathrm{~kg} / \mathrm{m}^{3}$ outlier value obtained at a point 30 $\mathrm{cm}$ from the origin of the probe the surface (Figure 3.1.3). If the distance from the probe origin was $24.5 \mathrm{~cm}$ from origin then the resultant density would be $372 \mathrm{~kg} / \mathrm{m}^{3}$ or a $>400 \%$ increase in density. The effect of measurement error is considerably less if the same under measurement of radar from distance from origin is made at $180 \mathrm{~cm}$. The difference between the $180 \mathrm{~cm}$ value and the $175 \mathrm{~cm}$ calculated density value being $10 \%$. This density error value is the same as what is applied to manual snow density measurements in this study. Hence care must be taken when surveying shallower snow depths with this technique, although it is quite useful when assessing the density within deeper snow packs.

\subsection{Uncertainty Analysis}

In the assessment of the quality of SWE calculation, and the comparison of probed, ground based GPR and airborne GPR it is important to recognise the characteristics of each methodology that may serve to add inaccuracies to the results. The sources of error that may be introduced stem from the calculation of the relationship between SWE and TWTT (Equation 2.8), and in the comparison of probed, ground-based GPR and airborne GPR data. Outlined below are the largest sources of error in the methodology used in this thesis. Presented first is a variation on the linear extrapolation of the snow depth/density relationship, the use of a polynomial alternative, and the constraint of this calculation to snow depths below that calculated by the linear SWE / TWTT relationship used in this study. Presented second is the assessment of the errors and limitations of the various data collection methods using a spatially discrete grid based comparison. 


\subsubsection{SWE/TWTT Relationship}

The extrapolation of snow density to depths past that which have been manually measured is necessary to resolve the GPR wavespeed equation, in order to calculate SWE at depth. There are known depth and density constraints (Ruddell, 1995), although the exact shape of this trajectory is not known. Two alternative scenarios of depth / density relationships are presented in order to test the accuracy of the method used in this study.

Snow pits depths were restricted to a depth of four meters in this study. Snow depths at Annette Plateau and at the Davis Snowfield exceed this depth by around two and six meters respectively for the study season. It is known that the relationship between snow density and depth is not linear from experiments involving shallow ice cores (Ruddell, 1995), who estimated that snow density reached $900 \mathrm{~kg} / \mathrm{m}^{3}$ at $18 \mathrm{~m}$ depth. An exponential relationship was found to best represent this relationship. The application of an exponential relationship in this work was deemed to produce unrealistic snow density values, so a polynomial relationship was instead used to represent the non linear density profile of increasing snow density relative to depth, at depths greater than that reached by snow pits.

The first relationship used in this study is a linear relationship of depth and density applied to the snow pit density $\left(\mathrm{kg} / \mathrm{m}^{3}\right)$ data down to the total snow pack depth $(n s)$. The two alternative snow density projection scenarios used were linear and polynomial relationships with density at depth intersecting $900 \mathrm{~kg} / \mathrm{m}^{3}$ at $18 \mathrm{~m}$ depth (Ruddell, 1995), projected from the measured snow density data set (Figure 3.1.5). All profiles used the snow pit measured snow density data as the basis for the projected trends, and all snow depth projections were not made further than $18 \mathrm{~m}$. 


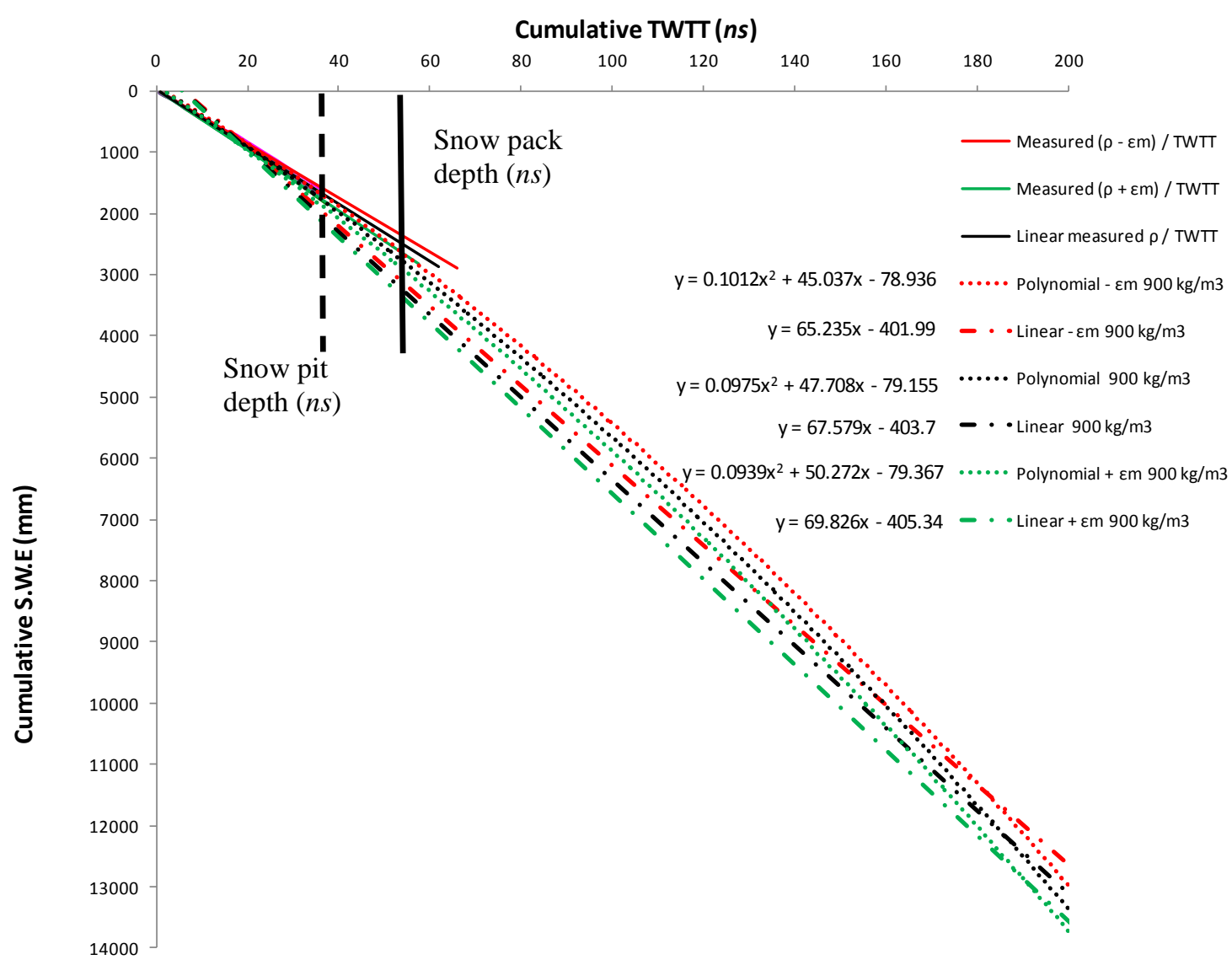

Figure 3.1.5. The extrapolated linear and polynomial relationship of SWE and TWTT to $18 \mathrm{~m} / 900$ $\mathrm{kg} / \mathrm{m}^{3}$ using the snow pit data from Annette Plateau and known upper limits of snow/firn density / depth relationships (Ruddell, 1995). Error associated with measuring $\left(\varepsilon_{m}\right)$ snow density $(\rho)$ is applied to each projection.

The depth of the snow pack at Davis Snowfield below Agassiz Icefall, $2100 \mathrm{~m}$ a.s.l and Annette Plateau $(2150 \mathrm{~m})$ was $97 n s$ and $55 n s$ respectively. The $4 \mathrm{~m}$ deep snow pits at all locations were $37 n s$ TWTT. These depths were calculated using the linear trend unconfined by known density depth relationships (Ruddell, 1995) using the measured snow density gradients (Table 3.1.1).

The quality of the relationship was assessed on how well the calculated trend, either polynomial or linear, represented the manually measured data from snow pits and the limits of snow density and depths (Ruddell, 1995). The linear relationship confined by density values at $18 \mathrm{~m} / 900 \mathrm{~kg} / \mathrm{m}^{3}$ (Ruddell, 1995) was the least appropriate to project snow density from GPR derived TWTT conversion to SWE within and outside the depth of the snow pit (Figure 3.1.5). The confined linear relationship initially underestimated measured snow 
density values, and then overestimated density from around $25 n s$ down to $140 n s$. The overestimation equated to $18 \%$ of snow pack depth at both Annette Plateau and Davis Snowfield (Tables 3.1.3 a and b). Deviation from the linear projection unconfined by the 18 m snow density value (Ruddell, 1995) at total calculated snow depths was $13 \%$ and $18 \%$ more for Annette Plateau and Davis Snowfield respectively (Table 3.1.3 c and d). The ranges of error of the projected relationships were confined by applying the density sampling error (Equation 2.9).

The results of the extrapolation investigation indicate that the methodology used to calculate SWE beyond the snow pit depth at the study sites was not appreciably different between the unconfined linear interpolation and the second order polynomial relationship constrained at $18 \mathrm{~m}$, the presumed more realistic density profile projection, for snow depths observed in the study year. Snow density was underestimated by the polynomial relationship at snow pit depth, SWE values were $-5 \%$ and $-7 \%$ of measured snow density respectively for Annette Plateau and Davis Snowfield (Tables 3.1.3 b and d). The total snow pack depth error associated with the polynomial density relationship was $-11 \%$ and $-8 \%$ less than the projected unconfined relationship used in this study for Annette Plateau and Davis Snowfield (Table 3.1.3 $\mathrm{b}$ and $\mathrm{d}$ ).

The linear extrapolation to of snow density to $18 \mathrm{~m}$, a pattern not expected to reasonably project a real representation of a density snow profile, is provided to offer an alternative to the unconfined linear projection used in this study. Although the polynomial relationship produces a more realistic non-linear SWE / TWTT relationship, the error involved in using an unconfined linear relationship to snow depths experienced on the Franz Josef Glacier (5.4 $\mathrm{m} \mathrm{SWE}$ or $100 \mathrm{~ns}$ ) with an average radio electromagnetic wave speed of $0.209 \mathrm{~m} \mathrm{~ns}^{-1}$ is within the error provided by combined GPR profile digitization and snow density sampling error quantities (Table 3.2.2). 
(a)

\begin{tabular}{|c|c|c|c|}
\hline Annette & Linear & Polynomial & Linear \\
\hline Plateau & $\mathbf{P i t}_{\mathrm{d}} \boldsymbol{\rho}_{\mathrm{m}}$ & $18 \mathrm{~m} / 900 \mathrm{~kg} \mathrm{~m}^{3}$ & $18 \mathrm{~m} / 900 \mathrm{~kg} \mathrm{~m}^{3}$ \\
\hline SWE - $\rho$ error & 1480 & 1416 & 1801 \\
\hline SWE & 1712 & 1542 & 2079 \\
\hline SWE $+\rho$ error & 2045 & 1669 & 2367 \\
\hline
\end{tabular}

(b)

(c)

\begin{tabular}{|c|c|c|c|}
\hline Davis & Linear & Polynomial & Linear \\
\hline Snowfield & $\mathrm{Pit}_{\mathrm{d}} \boldsymbol{\rho}_{\mathrm{m}}$ & \multicolumn{2}{|c|}{$18 \mathrm{~m} / 900 \mathrm{~kg} \mathrm{~m}^{3} 18 \mathrm{~m} / 900 \mathrm{~kg} \mathrm{~m}$} \\
\hline SWE- $\rho$ error & 4701 & 4367 & 5697 \\
\hline SWE & 5104 & 4777 & 6252 \\
\hline SWE $+\rho$ error & 5509 & 5201 & 6798 \\
\hline Annette & Linear & Polynomial & Linear \\
\hline Plateau & Tot. $_{\cdot d} \rho_{m}$ & \multicolumn{2}{|c|}{$18 \mathrm{~m} / 900 \mathrm{~kg} \mathrm{~m}^{3} 18 \mathrm{~m} / 900 \mathrm{~kg} \mathrm{~m}$} \\
\hline SWE- $\rho$ error & 2644 & 2375 & 3072 \\
\hline SWE & 2899 & 2772 & 3330 \\
\hline SWE $+\rho$ error & 3303 & 3016 & 3592 \\
\hline
\end{tabular}

(d)

\begin{tabular}{|c|c|c|c|}
\hline Davis & Linear & Polynomial & Linear \\
\hline Snowfield & Tot. $_{d} \boldsymbol{\rho}_{\mathbf{m}}$ & $18 \mathrm{~m} / 900 \mathrm{~kg} \mathrm{~m}^{3}$ & $318 \mathrm{~m} / 900 \mathrm{~kg} \mathrm{~m}^{3}$ \\
\hline SWE - $\rho$ error & 5477 & 5123 & 6712 \\
\hline SWE & 5105 & 4741 & 6193 \\
\hline SWE + $\rho$ error & 5846 & 5512 & 7212 \\
\hline
\end{tabular}

Table 3.1.3. The compared extrapolated linear and polynomial relationships of SWE and TWTT for Annette Plateau and the Davis Snowfield 2300m a.s.l site. Tables $a$ and $b$ present calculated SWE values using the three extrapolation techniques (unconfined linear and polynomial and linear relationships to $\left.\left(18 \mathrm{~m} / 900 \mathrm{gk} / \mathrm{m}^{3}\right)\right)$ to the snow it depths. Tables $c$ and $d$ present calculated SWE for the total snow pack depth. SWE measurements are provided with the range of error calculated from manual snow density measurements.

\subsubsection{SWE values and uncertainty}

SWE values presented in this thesis are provided with a range of uncertainty commensurate with known and estimated sources of error. The use of a formula to calculate values used in the results, and the breaking down of these values into smaller time scale allotments of precipitation meant that the total calculated figures were not rounded down. Instead all values of precipitation were calculated to four significant figures.

GPR and snow density data cannot be used to measure or calculate precipitation to accuracies of four significant figures. It is reiterated that the precipitation values presented, whilst realistic in magnitude, are not the exact representations of precipitation volume. 


\subsection{Comparison of methods}

Snow depth was measured using three different methods in this study: traditional probing, ground- based GPR and airborne GPR. Before the snow accumulation measurement results are presented these different measurement techniques are compared. The comparison is based on measurements at the Jollie River valley (representing steep and complex terrain) and Annette Plateau (representing gently sloping, simple terrain). Sample size, SWE magnitude, and SWE frequency distribution are considered.

\begin{tabular}{|c|c|c|c|c|c|c|c|c|}
\hline \multirow{2}{*}{$\begin{array}{l}\text { statistical } \\
\text { moment }\end{array}$} & \multicolumn{3}{|c|}{$\begin{array}{l}\text { All samples } \\
(\mathrm{mm})\end{array}$} & \multicolumn{3}{|c|}{$\begin{array}{l}\text { Jollie Valley } \\
(\mathrm{mm})\end{array}$} & \multirow{2}{*}{$\begin{array}{l}\text { Annette } \\
(\mathrm{mm}) \\
\text { Ground }\end{array}$} & \multirow{2}{*}{$\begin{array}{l}\text { Plateau } \\
\text { Airborne }\end{array}$} \\
\hline & Ground & Airborne & Probed & Ground & Airborne & Probed & & \\
\hline Count (n) & 40999 & 8571 & 82 & 32264 & 5027 & 82 & 7038 & 3544 \\
\hline Min & 137 & 3 & 269 & 137 & 3 & 269 & 2162 & 2335 \\
\hline Max & 3379 & 3450 & 1950 & 2384 & 3450 & 1950 & 2943 & 3096 \\
\hline Mean & 1549 & 1805 & 1233 & 969 & 1130 & 1233 & 2581 & 2761 \\
\hline median & 1218 & 1534 & 1237 & 919 & 1097 & 1237 & 2507 & 2734 \\
\hline Std dev & 867 & 879 & 452 & 393 & 436 & 452 & 205 & 196 \\
\hline $\mathrm{Cv}$ & 0.56 & 0.49 & 0.37 & 0.41 & 0.39 & 0.37 & 0.08 & 0.07 \\
\hline
\end{tabular}

Table 3.1.4. Statistical descriptors for point SWE values collected at Jollie River valley and Annette Plateau during the field campaign. Presented is the population count i.e. the number of post processed data points collected by GPR and probing. The minimum, maximum, mean, median standard deviation and coefficient of variance are also presented for each sampling methodology and location representing terrain type.

\subsubsection{Sample size}

The ground-based GPR produced the largest number of samples, followed by airborne GPR then probed snow samples (Table 3.1.4). The number of samples GPR samples is significantly greater than the traditional probed snow depth methodology. The number of point measurements taken by ground based GPR across the slope demonstrates the ability of the technique to effectively map the bed topography of the accumulation base surface. Probing snow depth produced $0.2 \%$ and $1.6 \%$ of the number of ground based and airborne samples respectively.

The sample size of each technique is a direct reflection of measurement resolution. Probed snow depth is representative of the average of five point measurements taken in a $2 \mathrm{~m}$ radius at $10 \mathrm{~m}$ intervals and not across the entire slope range of the GPR transects. The averaging 
of measurements within an area is similar to the "stacking" function performed at data collection and post processing stages of the GPR data collection in order to reduce the signal to noise ratio, decreasing interpretative uncertainty. The result of stacking the GPR signal (see Method chapter) produces a $15 \mathrm{~cm}$ separation of trace samples for ground based and $60 \mathrm{~cm}$ sample distance for airborne traces. The measurement resolution is the reason bed topography is mapped using GPR.

\subsubsection{SWE magnitude}

Of all of the samples collected in either terrain classification, the airborne method on average collected the largest SWE depth estimates. At Annette Plateau the airborne measurement was consistently higher (7\%) than ground-based GPR. For the Jollie Valley the probed estimates of SWE were the highest, and then airborne and ground-based methods were respectively smaller than other methods by $9 \%$ and $27 \%$.

The greatest range in SWE for the comparative method data sets comes from the airborne methodology in complex terrain (Jollie valley), followed by ground-based and probed data sets in the same terrain type. The largest range between two methodologies at either location is $1766 \mathrm{~mm}$ between ground-based and probed data at the Jollie valley. The range between airborne and ground-based methods in complex terrain extends $1200 \mathrm{~mm}$. The range in measurements is $157 \%$ greater at Jollie valley than the range in measurement techniques at Annette Plateau which has only a $20 \mathrm{~mm}$ difference in ranges between the airborne and ground based GPR methodology implying a much greater pattern of spatial uniformity in snow distribution. The increased variation in measurement ranges at Jollie valley is therefore assumed to be a result of terrain complexity.

\subsubsection{Snow depth frequency of occurrence}

The frequency of depth distribution charts (Figures 3.1.6 a, b and 3.1.7) allows the quantification of the occurrence of SWE to be made without the necessity of a spatial context. It does however incorporate bias that may be induced from irregular across slope travel speeds, therefore potentially adding bias to some depth values, despite the effort placed on maintaining a constant travel speed for each GPR sampling methodology. 
When considering the distribution of the average SWE values (Table 3.1.4) a systematic misrepresentation of depth throughout a survey would create a simple step shift of snow depth distribution. The overall shape of the frequency trace would remain the same but the trace would describe greater depths at a similar frequency of occurrence. Such a distribution is largely the case at Annette Plateau comparing ground-based and airborne GPR. Shallower depths are largely under represented when airborne data is compared to ground-based methodology, although there is a good fit of depth occurrence with depth values over 2650 $\mathrm{mm}$. The greatest departure from the frequency of occurrence appears in the 2850 to 2900 $\mathrm{mm}$ depth range, and again at the 2950 and $3050 \mathrm{~mm}$ SWE depth range. The origin and shape of these increases in depth estimation stem from airborne data reading greater depths at $100 \mathrm{~m}$ to $450 \mathrm{~m}$ along the transect (Figures 3.1.5a, and 3.1.6 a).

The distributions of depths acquired by both the airborne and ground based GPR methods at the Jollie Valley are even further removed from the relationship between measurement techniques at Annette Plateau. The most obvious departure from distribution is the significant under representation of depths between 750 and 1200mm SWE (Figure 3.1.6 b). This is compensated for by a general over representation of greater depth values. There is little resemblance to depth frequency patterns as seen at Annette Plateau (Figure 3.1.6 a).

There is not a simple step shift in snow depths with similar values of occurrence frequencies when combining bulk measurement data for the study site at Jollie River valley. Although there are a few similar peaks in depth values between $800 \mathrm{~mm}$ to $900 \mathrm{~mm}$ SWE, and 1200 $\mathrm{mm}$ to $1300 \mathrm{~mm}$ SWE. When comparing probed and GPR data, there is a much higher incidence of probed depths between 1550 and $1800 \mathrm{~mm} \mathrm{SWE}$, this is likely to be a result of the spatial coverage of the different measurement types. When observed on a single elevation transect a similar step shift in SWE depth values can be seen between GPR methodologies can be observed at Jollie Valley as is seen at Annette Plateau (Figures 3.1.6 a, 3.1.7). 
Normalized frequency of depth distribution, Annette Plateau; point values
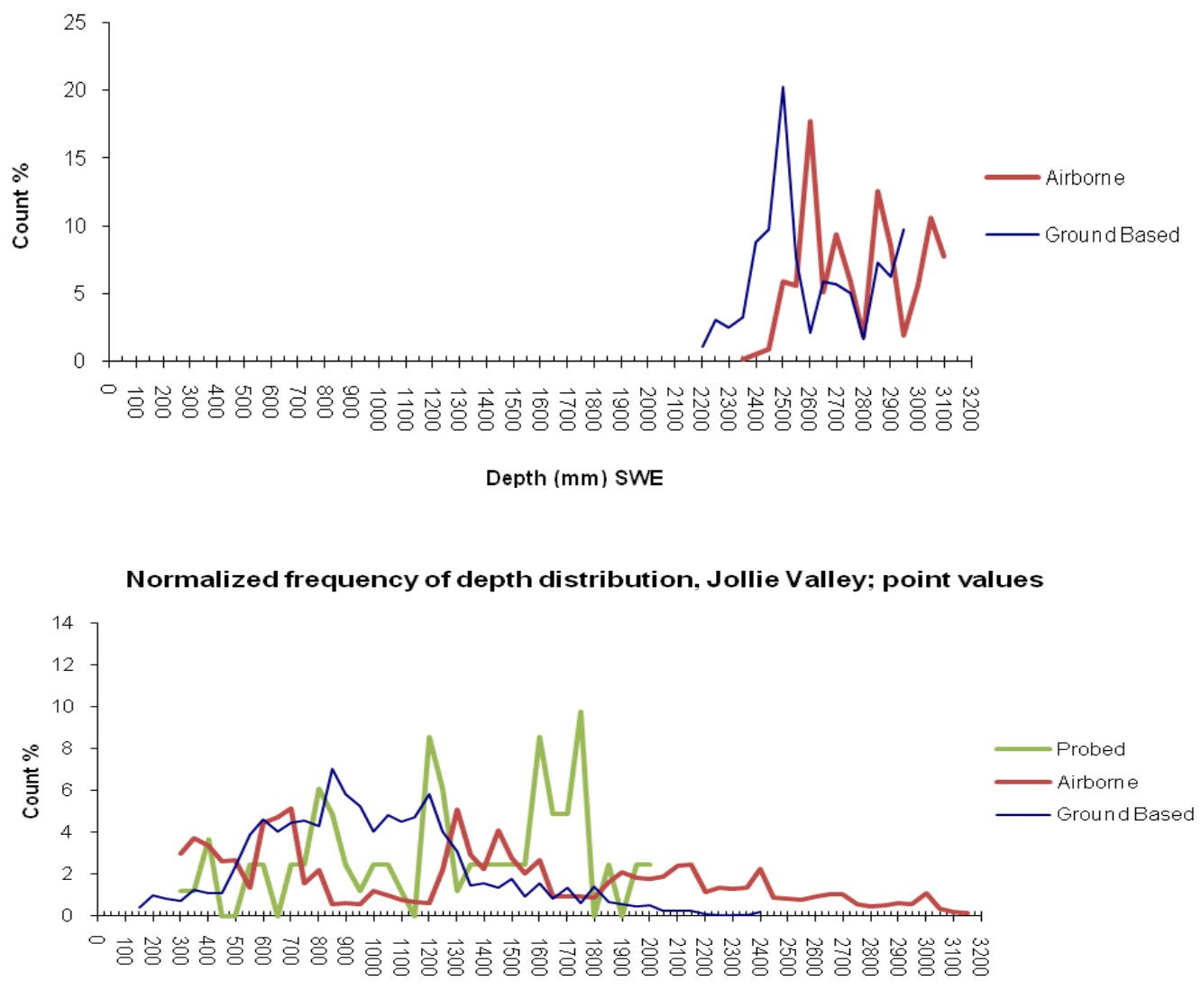

Figure 3.1.6 a and b. Representation of point measurements taken in low angled terrain at Annette Plateau, and steeper complex bed terrain at Jollie Valley. All Jollie valley measurements from all elevations are included in this frequency distribution. Frequencies are calculated at 50mm SWE bin values. A SWE value of $1152 \mathrm{~mm}$ is represented by the bin which incorporates depths greater than 1150 up to or equal to $1200 \mathrm{~mm}$.

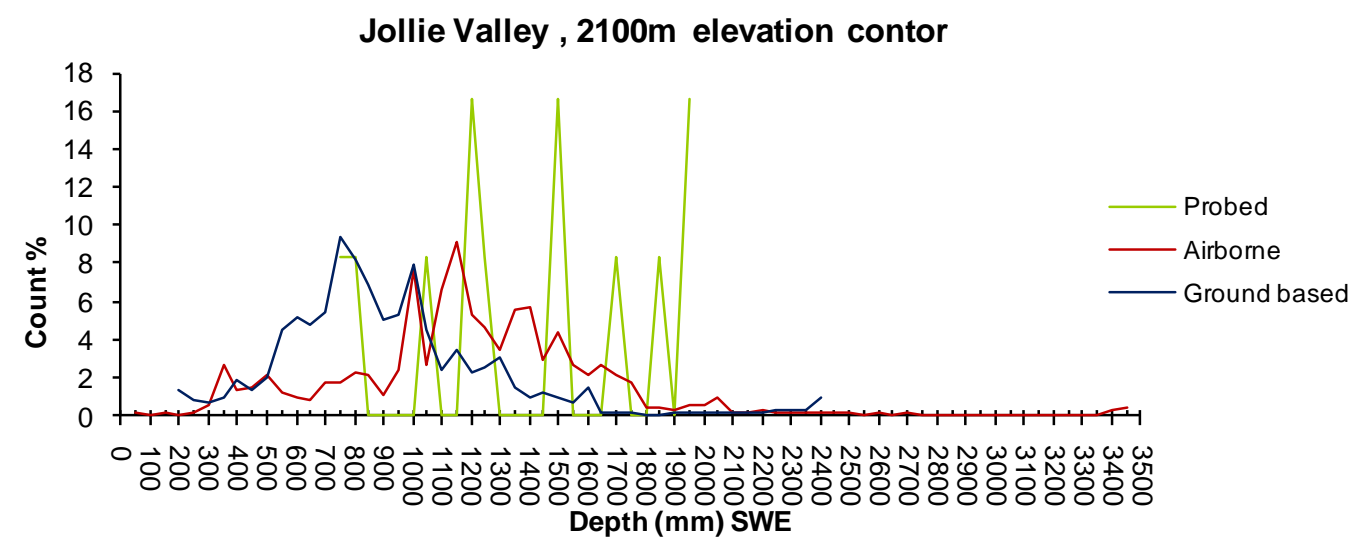

Figure 3.1.7. Normalized frequency distribution of the $2100 \mathrm{~m}$ elevation transect at the Jollie Valley. The shape of the airborne and ground based traces are similar although the airborne transect has a higher occurrence of deeper SWE measurements. The frequency of probed 
measurements has little resemblance to either GPR methodology; this could be due to the number of measurements taken and the reduced spatial coverage.

Frequency analysis is a useful tool for the analysis of different measurement methods as it removes the spatial aspect of the measurements to observe results as a function of methodology used (Figure 3.1.6 b). Analysis of the spatial aspect of measurements is useful as it may reveal the reasons for the variance in measurements between methods. The sources of error in data collection may compound to create the observed variation. The consistencies of speed along a survey transect and the view angle of GPR antenna, which may alter whilst negotiating various cross-slope terrain features, are considered important contributors to measurement inaccuracies. The zero-count of probed SWE measurements at a range of depth values (Figure 3.1.6 b) highlights the low spatial resolution of this technique.

\subsection{Grid based analysis}

In order to compare between collection techniques at each site with a spatial context a grid based analysis is made, as outlined in the method chapter. The effect of this analysis on the data is to group all measurements within a common boundary representing similar terrain. Grid sizes of $10 \mathrm{~m}$ and $20 \mathrm{~m}$ were used.

\subsubsection{Grid based comparison uncertainty}

Recognising the effects of the analysis on the results is necessary to properly interpret the results. There are a number of sources of uncertainty associated with this grid based comparison. Primarily these are determined as spatial aliasing, spatial referencing, and picking (digitisation) error.

The effects of spatial aliasing of bed topography, through both radar trace separation distance, and the averaging affect of the increased footprint area of airborne data are seen to smooth topography data within the radargram (Figure 3.1.8 a and b). The lower spatial sampling frequency of the airborne method compared with the ground based method reduces the number of comparable measurements per unit area. There is a noticeable reduction in the variability of depth, especially on small scale terrain features observed in 
the airborne transect compared to that of the ground based transect in (Figure 3.1.8a-b). The reduction in sample traces and reduced variation in the range of depths measured from the airborne methodology is expected to capture the variation in topography, as seen in the frequency analysis. The airborne measurements of SWE are effectively smoothed over variable terrain by the wider footprint area of the airborne radar.

The greater footprint area of the airborne transect compared with the ground based method is responsible for the protruding bedrock bluff that is apparent at trace 700 (Figure 3.1.8b). The corresponding position in the ground-based trace occurs at trace 4450 (Figure 3.1.8a). At the time of data collection the snow covered ground immediately downhill of the bluff was sampled during the ground based GPR survey. The airborne path over this location included the topographic feature within the Fresnel zone.

The lower spatial sampling frequency due to the airspeed of the helicopter in comparison with the ground speed of the skied profile reduces the number of comparable measurements per unit area. There is a noticeable reduction in the variability of depth, especially on small scale terrain features observed in the airborne transect compared to that of the ground based transect in (Figure 3.1.8a-b).

A similar effect from the spatial aliasing of SWE data is found in the comparison of probed measurements to that of the ground based technique. The representation of an average of 5 data points that represent approximately $1.5 \mathrm{~cm}^{2}$ point per measurement within a $2 \mathrm{~m}$ diameter radius at $\sim 10 \mathrm{~m}$ sampling interval are presented in the normalised frequency distribution (Figure, 3.1.7). The ground-based and airborne measurements have a similar pattern of frequency distribution, although with a characteristic higher frequency SWE estimation for airborne measurements. The probed data capture depths within the range of the GPR techniques however the lower depth regions are not well represented.

The accuracy of the comparisons is somewhat controlled by the spatial referencing attached to the data. The ground-based GPR positioning data is differentially corrected giving $<0.5 \mathrm{~m}$ accuracy. The GPS positioning data from the Jollie Valley airborne survey however was accurate to $15 \mathrm{~m}$ for the Jollie Valley, and linearly interpolated between the starting and finishing points of the ground based survey for Annette Plateau due to GPS receiver shielding whilst mounted in the helicopter, causing both Garmin standard and Trimble 
differentially correctable GPS data sets to be unusable. By interpolating the airborne positions and depths in this way the GPR trace spacing of the airborne data was made artificially uniform and resulted in a shorter than actual profile (Figures 3.1.9 a and b, 3.1.10a and b). This difficulty has removed any ability to account for speed changes of the helicopter and shortened the trace separation from what would have been the actual value. The added length from the slightly sinuous path of the skied trace could also not be accounted for. The outcome is an airborne GPR profile of compressed sample length and deviations from the ground-based path reducing the number of comparable depths used gridbased analysis (Figure 3.1.11).
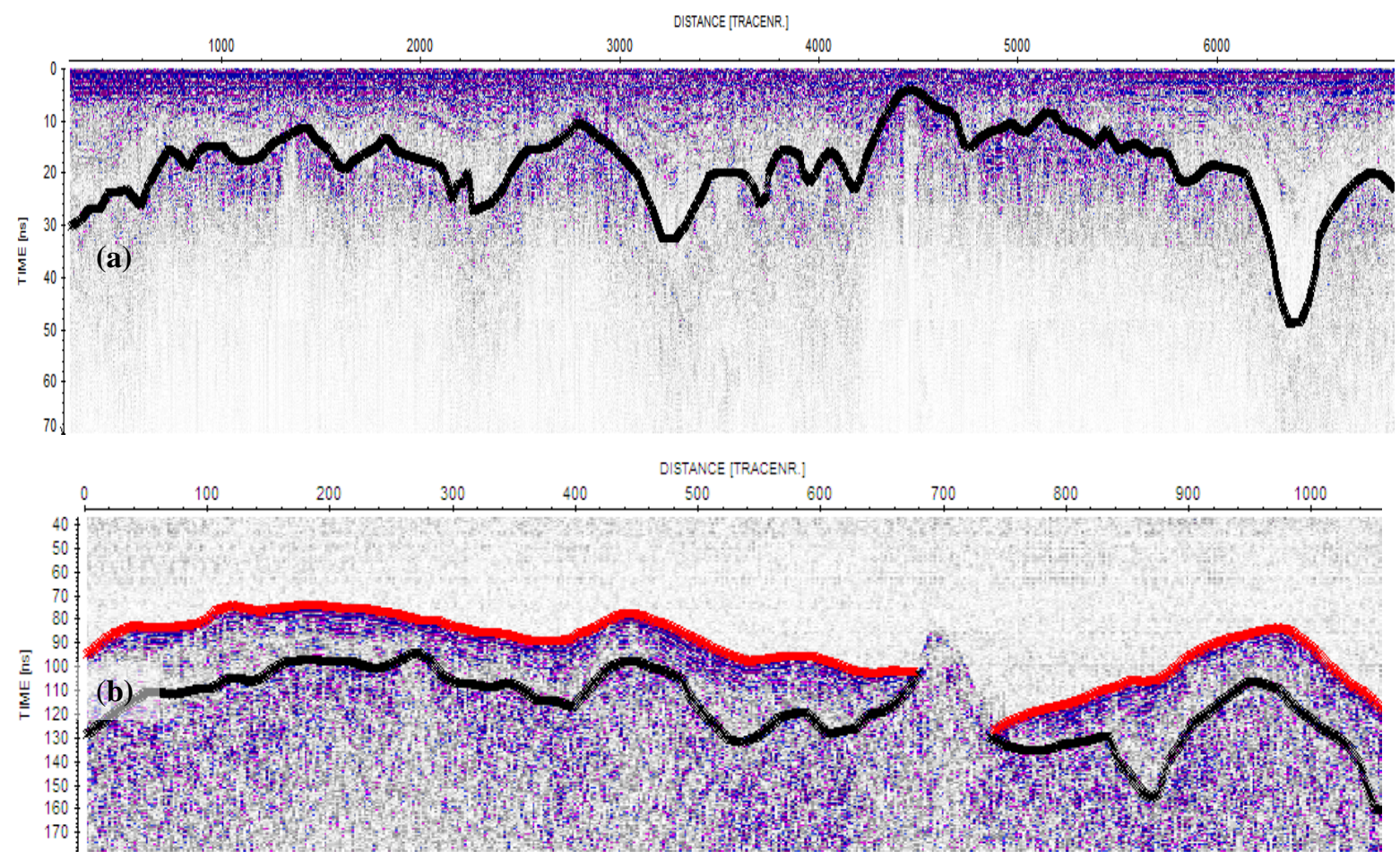

Figure 3.1.8 a-b. Radar grams of the 2100m elevation radar survey for both the ground based (a) and airborne (b) surveys. The red line illustrates the position of the picked snow surface of the airborne profile; the black line represents the interface between the snow and underlying summer surface.

A similar effect from the spatial aliasing of SWE data is found in the comparison of probed measurements to that of the ground based technique. The representation of an average of 5 data points that represent approximately $1.5 \mathrm{~cm}^{2}$ point per measurement within a $2 \mathrm{~m}$ diameter radius at $\sim 10 \mathrm{~m}$ sampling interval are presented in the normalised frequency distribution (Figure, 3.1.7). The ground-based and airborne measurements have a similar pattern of frequency distribution, although with a characteristic higher frequency SWE estimation for airborne measurements. The probed data capture depths are within the range 
of the GPR techniques however the lower depth regions are not well represented, a result of probed data site selection.

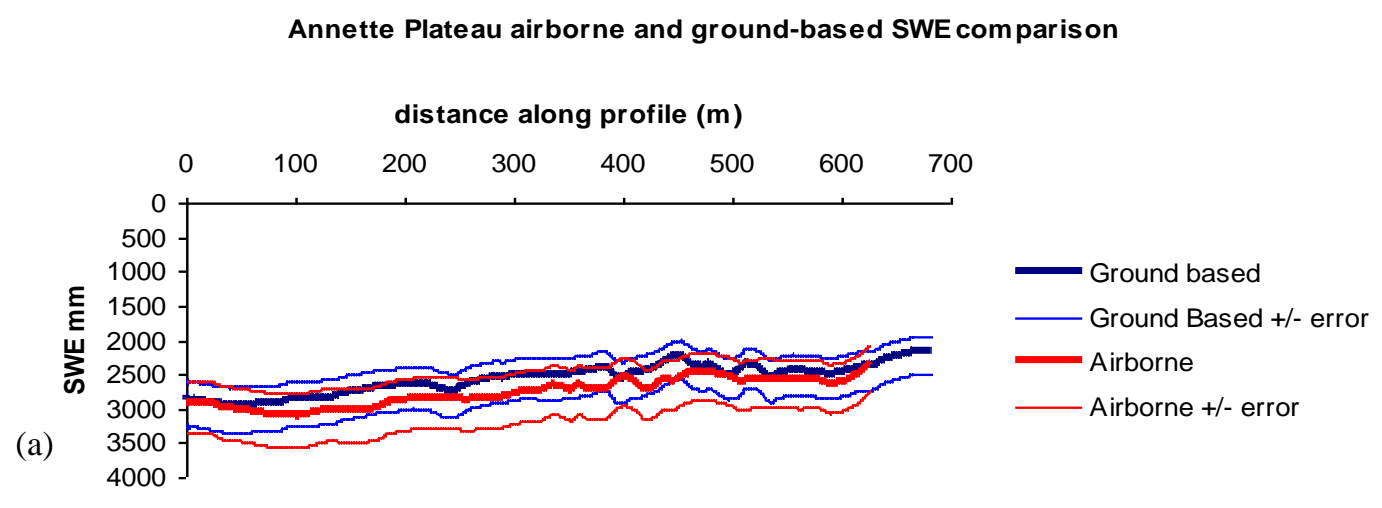

Annette Plateau airborne and ground-based TWTT comparison

(b)

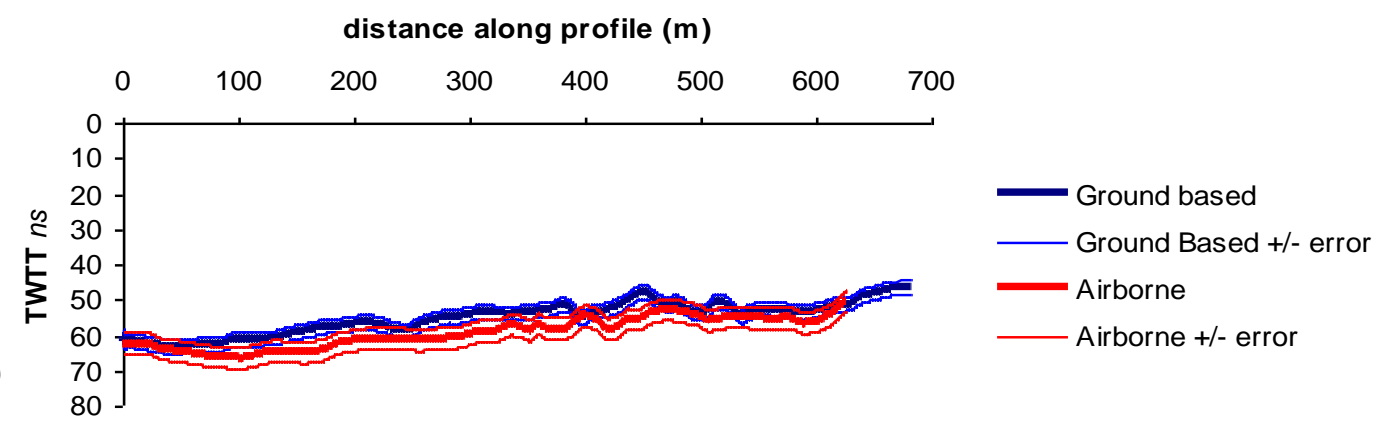

Figure 3.1.9 a-b. The airborne and ground based comparison including sources of error introduced by density measurements and digitization. Once error in density measurement is removed the variation in TWTT fits within the range of error introduced by the assigned digitizing picking error of 2 ns for ground-based GPR and 3ns for airborne GPR. The airborne trace appears shorter due to the linear interpolation of positions resulting from missing GPS data.

The accuracy of the comparisons is somewhat controlled by the spatial referencing attached to the data. The ground-based GPR positioning data is differentially corrected giving $<0.5 \mathrm{~m}$ accuracy. The GPS positioning data from the Jollie Valley airborne survey however was accurate to $15 \mathrm{~m}$. At Annette Plateau the distribution of the GPS points along the length of the transects was made by linear interpolation between the starting and finishing points of the ground-based survey. The GPS receiver in the airborne survey was shielded whilst mounted in the helicopter, causing both Garmin standard, and Trimble differentially correctable GPS data sets to be unusable. By interpolating the airborne positions and depths in this way the GPR trace spacing of the airborne data was made artificially uniform and 
resulted in a shorter than actual profile (Figures 3.1.9 $\mathrm{a}$ and $\mathrm{b}, 3.1 .10 \mathrm{a}$ and $\mathrm{b}$ ). This difficulty has removed any ability to account for speed changes of the helicopter and shortened the trace separation from what would have been the actual value. The added length from the slightly sinuous path of the skied trace could also not be accounted for. The outcome is an airborne GPR profile of compressed sample length and

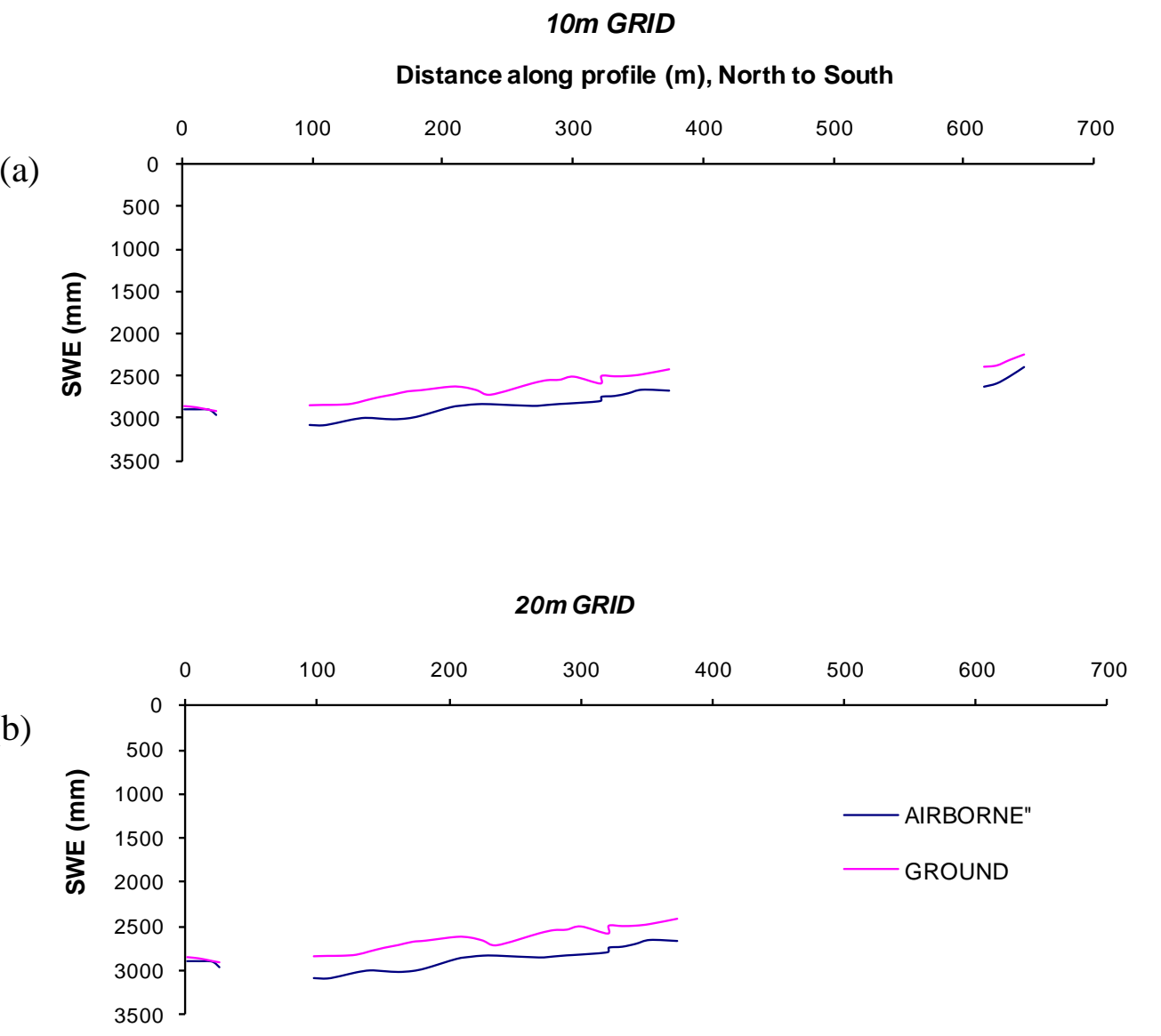

Figure 3.1.10 a-b. Sections of the airborne and ground-based transects available for comparison at Annette Plateau. Gaps in the line are representative of areas where the linear projection of the airborne GPR data artificially shifted the positioning of depth measurements to not correlate with the overlaid $10 \mathrm{~m}$ and $20 \mathrm{~m}$ grids (Annette Plateau, GPR transect 191, Figure 3.2.2).

The difference in calculated SWE between methods at Annette Plateau can be largely attributed to picking error during post processing and digitization of the GPR data (Figure 3.1.8 a- b). Removal of the error induced from the density error calculation (Figure 3.1.8 b) reveal the picking error estimation accounts for the majority of the difference in SWE calculation. Human induced error at the time of digitization is therefore a reasonable 
component of SWE estimation error when comparing two depth measurements taken with different techniques. This error is increased in the airborne survey through the necessity to remove the airborne portion of the radar trace from the snow portion of the trace profile (3.1.8 b). Consequently the difference in depths is largely a constant step offset (Figures 3.1.6 a, and 3.1.9 b).

\subsection{Grid Based Analysis SWE value comparison}

\subsubsection{Jollie Valley}

The statistical moments of the grid analysis are listed in Table 3.1.5. The count refers to the number of grid values available for analysis. In all but the analysis of ground based and airborne data the $20 \mathrm{~m}$ grid allowed more data for comparison than the $10 \mathrm{~m}$ grid. The number of comparative grid squares available represents $25 \%$ of the probed measurement samples at the $10 \mathrm{~m}$ scale and $39 \%$ at the $20 \mathrm{~m}$ scale. The airborne and ground based sample counts compose the average of all data points that fall within each grid. Probed values represent the average of five samples as outlined in the methodology.

The largest mean estimations of SWE are made by the probed depth derived SWE data set, then airborne and ground-based GPR techniques. The increase in grid square size from $10 \mathrm{~m}$ to $20 \mathrm{~m}$ generally reduced the difference in average grid depths between the various snow depth measurement techniques. The grid based SWE values average all of the sampled snow depths that fall within a grid square. The high sampling frequency of ground-based GPR means that average SWE for each grid cell is similar to that for all measurements combined (Table 3.1.4). The comparability of bulk areal SWE and grid-based SWE is most comparable between airborne and ground-based GPR are compared for both $10 \mathrm{~m}$ and $20 \mathrm{~m}$ sampled grid populations (Table 3.1.5). The general mean SWE values that compared techniques share in bulk averages (Table 3.1.4) are shared with each other as observed in the grid based data (Table 3.1.5). However there is a tendency for airborne GPR to produce mean grid cell SWE in excess ( > $100 \mathrm{~mm}$ SWE) of the bulk population SWE values (Table 3.1.4). A similar pattern occurs when comparisons are made between probed and groundbased GPR SWE measurements. 
The variation in mean SWE is within the error introduced into the SWE / TWTT calculations. Therefore, the sample populations are large enough to not be significantly skewed by lack of depth samples. Consequently the sample populations can be considered representative with some confidence.

\begin{tabular}{|c|c|c|c|c|c|c|c|c|c|c|c|c|}
\hline & $\begin{array}{l}\text { Ground } \\
20 \mathrm{~m}\end{array}$ & $\begin{array}{l}\text { Airborne } \\
20 \mathrm{~m}\end{array}$ & $\begin{array}{l}\text { Ground } \\
10 \mathrm{~m}\end{array}$ & $\begin{array}{l}\text { Airborne } \\
10 \mathrm{~m}\end{array}$ & $\begin{array}{l}\text { Ground } \\
20 \mathrm{~m}\end{array}$ & $\begin{array}{l}\text { Probed } \\
20 \mathrm{~m}\end{array}$ & $\begin{array}{l}\text { Ground } \\
10 \mathrm{~m}\end{array}$ & $\begin{array}{l}\text { Probed } \\
10 \mathrm{~m}\end{array}$ & $\begin{array}{l}\text { Airborne } \\
20 \mathrm{~m}\end{array}$ & $\begin{array}{l}\text { Probed } \\
20 \mathrm{~m}\end{array}$ & $\begin{array}{l}\text { Airborne } \\
10 \mathrm{~m}\end{array}$ & $\begin{array}{l}\text { Probed } \\
10 \mathrm{~m}\end{array}$ \\
\hline count & 89 & 89 & 132 & 132 & 38 & 38 & 35 & 35 & 32 & 32 & 20 & 20 \\
\hline $\min$ & 177 & 186 & 137 & 167 & 538 & 373 & 141 & 706 & 644 & 399 & 613 & 706 \\
\hline $\max$ & 1858 & 2269 & 1885 & 2311 & 1630 & 1830 & 1633 & 1932 & 2119 & 1830 & 2034 & 1830 \\
\hline mean & 940 & 1137 & 921 & 1113 & 1018 & 1353 & 962 & 1361 & 1226 & 1278 & 1235 & 1242 \\
\hline median & 915 & 1108 & 880 & 1082 & 1054 & 1476 & 991 & 1432 & 1186 & 1244 & 1254 & 1168 \\
\hline Std dev & 340 & 424 & 377 & 443 & 259 & 355 & 345 & 336 & 379 & 370 & 368 & 389 \\
\hline Cv & 0.36 & 0.37 & 0.41 & 0.40 & 0.25 & 0.26 & 0.36 & 0.25 & 0.31 & 0.29 & 0.30 & 0.31 \\
\hline
\end{tabular}

Table 3.1.5. Statistical descriptors of compared data set for the ground based, airborne, and probed methodologies at respective comparative grid scales. Comparisons are made within partitions in the table. The count refers to the available grid population for each comparison. The other descriptors refer to the lowest value of a grid square determined by the average of

If the path of the GPR survey for the grid based comparisons is assumed to run parallel to the overlaid $10 \mathrm{~m}$ and $20 \mathrm{~m}$ grid spaced grid border (Figure 2.6.1) estimations of the sample population count available for each analysis can be made. The grid count of the groundbased and airborne comparison represent around $26 \%$ of the point measurement value count (ground based data for a $10 \mathrm{~m}$ grid $=27 \%$, Airborne $10 \mathrm{~m} 25 \%$ ) at the $10 \mathrm{~m}$ scale and $35 \%$ at the $20 \mathrm{~m}$ grid scale (Ground $20 \mathrm{~m}=36 \%$ Airborne $20 \mathrm{~m}=34 \%$ ). The manually probed measurements available for comparison to ground based radar represented $42 \%$ and $92 \%$ of the available probed population at the $10 \mathrm{~m}$ and $20 \mathrm{~m}$ scales respectively. In the comparison of probed data to the airborne data set $23 \%$ and $75 \%$ of the probed data set were incorporated into the analysis at the $10 \mathrm{~m}$ and $20 \mathrm{~m}$ grid. The ground based and airborne component of the probed data comparison represent $7 \%$ and $15 \%$ of the each data set at the $10 \mathrm{~m}$ and $20 \mathrm{~m}$ grid scales.

The range of snow depths measured is not constant between compared measurement pairs and across snow depth analysis techniques (Table 3.1.4 and 3.1.5). The ranges differ from that of the point data (Table 3.1.4) due to the averaging of SWE values for the grid areas. The ground based data minimums for the grid analysis return lower SWE values than the airborne data at both grid scales (Table 3.1.5). There was no pattern in the minima for the ground based and 
probed data comparison. The airborne data has similar minima in comparison with compared probed grid squares at the both grid scales. The same methodological comparison produces a $43 \%$ smaller probed minima at the $20 \mathrm{~m}$ grid scale.

The airborne methodology produced the highest values of SWE compared to both ground based and probed techniques. The probed method produced higher maxima over the ground based data. The probed data is of note in that it returns a maximum of only $4 \mathrm{~m}$ snow depth, or $<2000 \mathrm{~mm}$ SWE. This is due to probe length limiting SWE estimations because snow depth measurements do not reach ground in some locations.

The standard deviations of the ground based data were smaller at the $20 \mathrm{~m}$ grid size than the $10 \mathrm{~m}$ grid equivalents for comparison against both airborne and probed data (Figure 3.1.5). The grid scale had an effect on the airborne data when compared to ground-based GPR data. The coefficients of variation were larger in the comparison ground-based GPR techniques with probed data although tended to reduce at the $20 \mathrm{~m}$ scale for both GPR techniques. The worst co-efficient of variation are found within the ground-based/airborne GPR comparisons but similar values were found in the ground-based / probed data set.

Probed measurements of snow depth compared best with airborne measurements at the $10 \mathrm{~m}$ grid scale at Jollie Valley. Increasing the sample grid size reduced the correlation between the methods reduced the significance of the relationship between snow distribution measurement techniques (Table 3.1.5 \& Figure 3.1.11 c-d). Between ground-based GPR / airborne measurement techniques, and ground-based GPR / probed the comparison are not significant (Table 3.1.5 \& Figure 3.1.11 a-b; e-f). That is not to suggest that there is inaccuracy in each measurement technique. It is suggested that the variation is the result of large differences in sampling resolution within each grid and subsequent spatial aliasing.

\subsubsection{Annette Plateau}

The statistical descriptors of the Annette Plateau methodological comparison show minimally larger mean SWE values at the $10 \mathrm{~m}$ grid scale. The range is also larger at the 10 $\mathrm{m}$ and $20 \mathrm{~m}$ grid scale for both ground based and airborne techniques (Tale 3.1.6), than that observed in the bulk site SWE values (Table 3.1.4). The increase in range is due to an increase in SWE minimum values. The reason for this is the reduction of sample area 
(Figures 3.1.9 a-b, and 3.1.10 a-b) reducing the sampled snow depth minima for each measurement technique. The reduction in range is minimal, for the purpose of comparing data collection techniques it will have no influence. If grid based data was used to calculate site wide precipitation then there would be insignificant change in calculated SWE values.

The grid analysis captured between $58 \%$ and $29 \%$ of the ground based and $28 \%$ and $15 \%$ of the airborne measurements at the $20 \mathrm{~m}$ and $10 \mathrm{~m}$ grid sizes (Tables 3.1.4 and 3.1.6). In this sample population the airborne mean depths differed from the ground based data by an additional $8 \%$ and $7 \%$ at the $10 \mathrm{~m}$ and $20 \mathrm{~m}$ scales. The difference between the two techniques is less than the standard deviation of either method at the $20 \mathrm{~m}$ scale, and $30 \mathrm{~mm}$ SWE more than the standard deviation between the two methods at the $10 \mathrm{~m}$ scale. The coefficients of variation are considerably reduced on the less complex terrain of Annette Plateau compared with those derived for the Jollie River valley.

\begin{tabular}{c|cc|cc}
\hline & $\begin{array}{c}\text { Ground } \\
\mathbf{2 0 m}\end{array}$ & $\begin{array}{l}\text { Airborne } \\
\mathbf{2 0 m}\end{array}$ & $\begin{array}{l}\text { Ground } \\
\mathbf{1 0 m}\end{array}$ & $\begin{array}{l}\text { Airborne } \\
\mathbf{1 0 m}\end{array}$ \\
\hline count & 31 & 31 & 33 & 33 \\
min & 2258 & 2452 & 2239 & 2383 \\
max & 2928 & 3082 & 2928 & 3091 \\
mean & 2576 & 2761 & 2635 & 2840 \\
median & 2496 & 2739 & 2629 & 2848 \\
Std dev & 198 & 197 & 188 & 175 \\
Cv & 0.08 & 0.07 & 0.07 & 0.06 \\
\hline
\end{tabular}

Table 3.1.6. Statistical descriptors of data sets for the ground based, airborne, methodologies at respective comparative grid scales at Annette Plateau. Comparable sample populations were available for each grid size. The CV indicates that at larger grid scale is associated with a larger range of snow depth values in homogeneous terrain. All data compares in a regular pattern with snow depth overestimation by airborne methods.

The characteristics of the data set are reflected in the methodological comparison charts (Figure $3.1 .6 \mathrm{~g} / \mathrm{h}$ ). The relationships at the $20 \mathrm{~m}$ scales bear good correlations with each other and a slight improvement at the $10 \mathrm{~m}$ scale. The statistical descriptors for each chart (Figure $3.1 .6 \mathrm{~g} / \mathrm{h}$ ) show a strong relationship between methodologies confirming the implications of Table 3.1.6. The strong correlation between the two methods can be seen in Figure 3.1.11. 


\subsubsection{Franz Josef Glacier}

There was no comparison of measurement techniques at Davis snowfield, Franz Josef glacier. Only a ground-based GPR survey was undertaken at this location. Snow depths of < $11 \mathrm{~m}$ made probing for the base accumulation surface impracticable. Logistics prevented an airborne survey at this location.

\subsection{Measurement variability in different terrain types}

In complex terrain the best relationship is found between airborne and manual probed methodologies. Where ground based GPR methodology is used in complex terrain there is less of a relationship between grid squares for both probed and airborne comparisons. In all but the ground based GPR and probed comparison the relationships between collection techniques are stronger at the $10 \mathrm{~m}$ scale.

The relationships in the simple terrain contrast that of the complex terrain. There is a good relationship between the ground based and airborne methodologies on the simple terrain at Annette Plateau. This terrain type produced the highest correlation coefficient with a slight improvement at the $20 \mathrm{~m}$ scale.

The relationship between the measured depths of airborne GPR and probed snow depth data with ground-based GPR suggests $25 \%$ deeper measurements of SWE from airborne and probed methods. Unfortunately the correlations between ground-based GPR and other methods are generally not significant.

\section{Jollie River valley}

Figure 3.1.11a-h ; (Next page) The methodological comparison correlations for the Jollie River valley and Annette Plateau as described in tables 3.1.5 and 3.1.6. At Jollie River valley Airborne GPR and probed depths compared most favourably. Comparison of airborne and ground-based GPR in gently sloping terrain indicates that terrain has an influence on the quality and accuracy of snow depth measurements. 
Jollie River valley

10m GRID

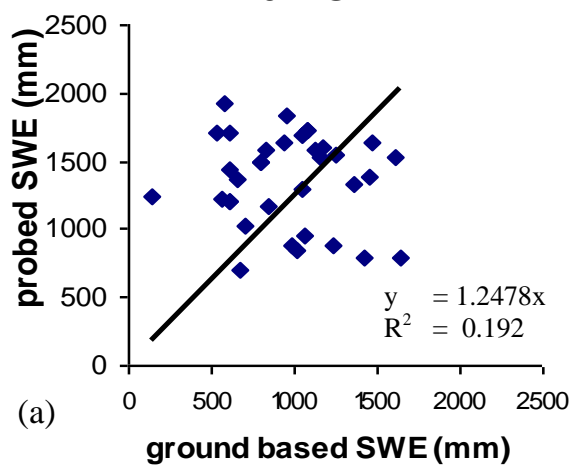

10m GRID
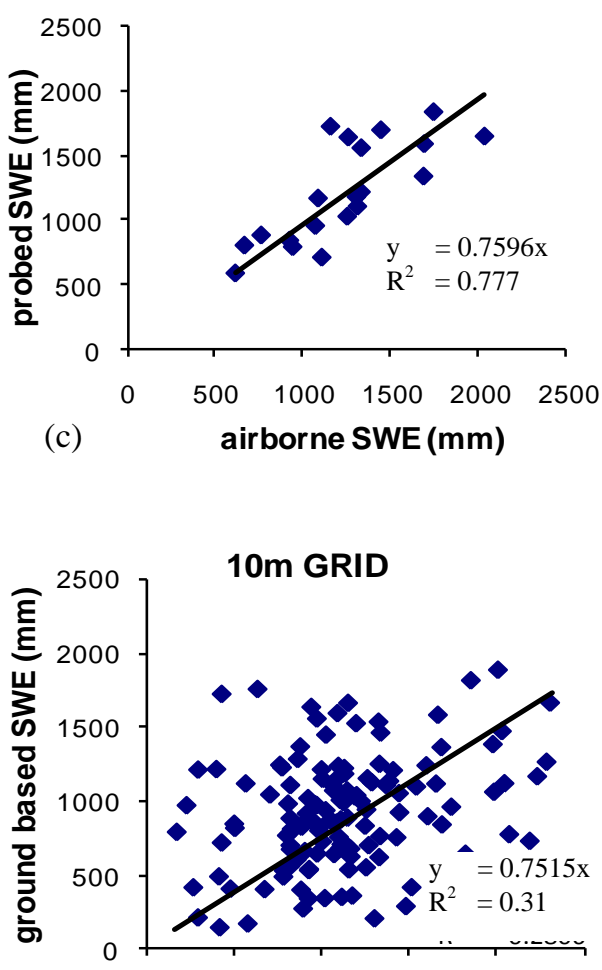

(e)

$\begin{array}{llllll}0 & 500 & 1000 & 1500 & 2000 & 2500\end{array}$ airborne SWE (mm)

\section{Annette Plateau}

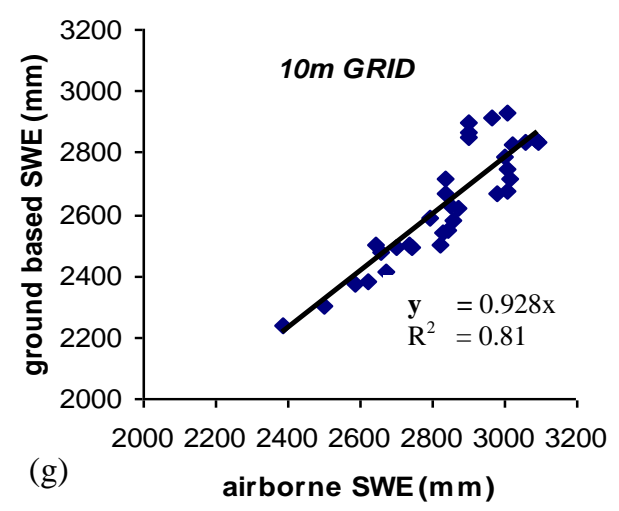

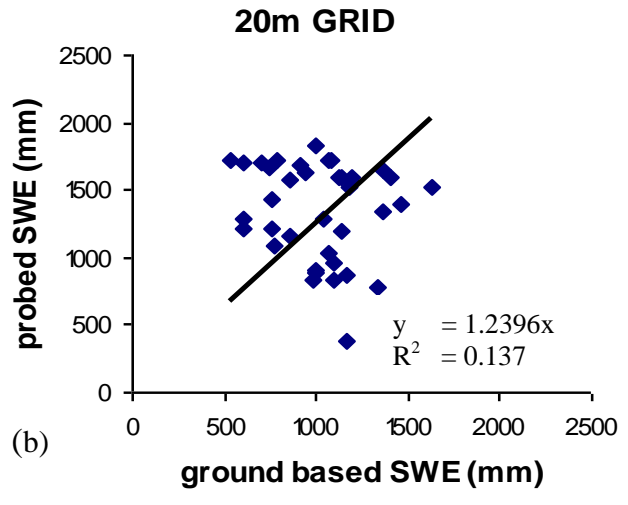
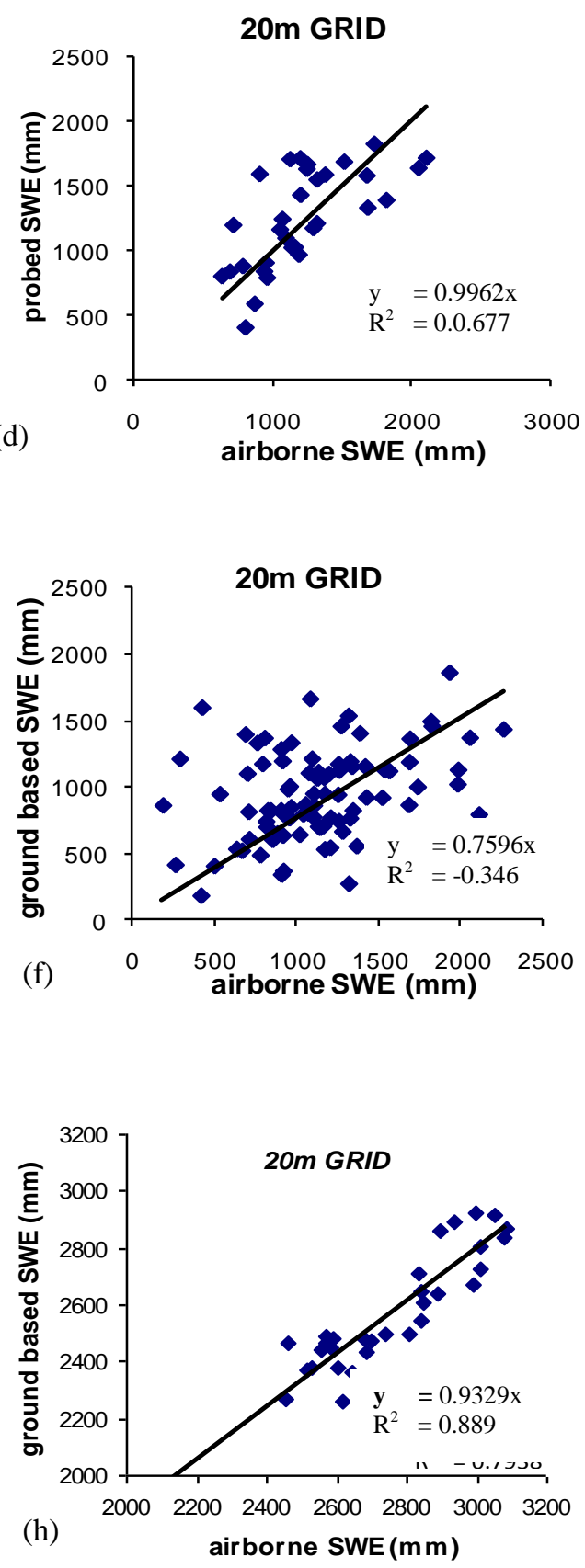


\subsection{Analysis of Precipitation Distribution}

\subsubsection{Trans-Alpine Accumulation Distribution}

Snow thickness and water equivalent were measured using ground-based GPR surveys at Davis Snowfield, Annette Plateau and the Jollie River valley. From west to east there is a clear decreasing trend in the measured snow depth and accumulated water volume accross the Southern Alps from the data derived at the study sites. Whilst in keeping with the expected trans-alpine precipitation gradient, the collected volumes at the Davis snowfield are considerably higher than previously calculated on the western side of the Main Divide (Anderson et al. 2006). Consequently the precipitation volumes down-wind and immediately in the lee of the main divide are potentially higher than previously estimated. Previously trialled methodology to measure these volumes is however inherently problematic (Kerr, 2009b) due to the potentially artificially high accumulation rates.

\subsection{Snow storage modelling}

Seasonal accumulation factors which relate lowland precipitation measurements to highaltitude snow accumulation were calculated for all sites in the trans-alpine transect. Average SWE depths were calculated for the three sites at Davis Snowfield, as was the average depth at Annette Plateau, and the sampled basin in the Jollie River valley by combining transects from $1800 \mathrm{~m}$ to $2200 \mathrm{~m}$ a.s.l. These data were used to confine a temperature index model in order to derive accumulation factors for the 2009 accumulation season for both individual accumulation events and the entire measurement periods.

The vertical resolution of the GPR data enabled the calculation of both a seasonal accumulation factor and a storm-scale accumulation factor. The precipitation accumulation events modelled were defined by the snow pack layering in the radargrams. The snowpack layers which are visible as IRH in the radargrams are interpreted as periods of no snow accumulation, these periods form the basis for which modelled accumulation volumes were constrained (Figure 3.2.4 and 3.2.5). The IRH are assumed to homogenously cover the spatial extent of the study plots. 
Storm scale accumulation factors were tuned to best represent the accumulation from each storm cycle and matched by time with the relevant synoptic circulation pattern that occurred during that period of time. The storm-scale time period is defined by the $12 \mathrm{hr}$ period Kidson (2000) indices for each synoptic classification (Figure, 1.6). The accumulation factors presented in these results represent the average accumulation factor of a succession of synoptic types that occur during an accumulation period. These were calculated for Davis Snowfield at the $2350 \mathrm{~m}$ a.s.l snow course and Annette Plateau (Figure 3.2.7, Table 3.2.6).

\subsubsection{Franz Josef Glacier}

Accumulation was greatest at the lowest elevation site on the Davis Snowfield, Franz Josef glacier. Accumulated snow depth decreased with elevation to the highest site at $2450 \mathrm{~m}$ a.s.1. (Table 3.2.1, Figure 3.2.1). The SWE figures recorded at Davis Snowfield are the highest recorded in this study. There are noticable differences in snow depth at the twokilometre spatial scale at Davis Snowfield. Accumulated precipitaion is found to decrease $600 \mathrm{~mm}$ over the $2 \mathrm{~km}$ distance between the lower and higher study plots, decreasing with reduced distance to the Main Divide (Figure 3.2.1). At the subgrid scale <100 m (Clark et al., 2011) a substantial variation $(<2 \mathrm{~m} \mathrm{SWE})$ is present at the $2050 \mathrm{~m}$ a.s.l. The subgrid variability decreases with elevation (distance to the topographic barrier) but with no noticable pattern.

\begin{tabular}{|c|c|c|c|c|}
\hline & Davis & Spencer- & Above & Below \\
\hline Statistical & All & Mallory & Icefall & Icefall \\
\hline moment & samples & 2450 & 2300 & 2050 \\
\hline count & 19271 & 6681 & 5430 & 7160 \\
\hline min & 4039 & 4039 & 4374 & 4467 \\
\hline max & 6455 & 5566 & 5751 & 6455 \\
\hline mean & 5094 & 4793 & 5064 & 5398 \\
\hline range & 2416 & 1527 & 1377 & 1988 \\
\hline Std dev & 440 & 374 & 304 & 379 \\
\hline Cv & 0.09 & 0.08 & 0.06 & 0.07 \\
\hline
\end{tabular}

Table 3.2.1. Snow distribution at in the Franz Josef Glacier within the three snow courses surveyed at the Davis snowfield region of the neve Statistical moment values are mm. There is a slight decrease around $600 \mathrm{~mm}$ of precipitation towards the main divide. Snow depth variation within the snow each snow course in significant. 
Over a 30 year period the May to end of Septenber precipitation accounts for $42 \%$ of the annual precipitation. The 2009 SWE depths (Table 3.2.1) are deemed to be a higher than normal precipitation year with the 30 year precipitation normal equating to $85 \%$ of the 2009 measured snow depth with a site average of $4600 \mathrm{~mm}$ w.e, $4200 \mathrm{~mm}$ w.e., $4100 \mathrm{~mm}$ w.e for each study site in ascending elevation order.

The underlying topography at Davis Snowfield, that is the snow surface at the end of the previous summer, is thought to be the main cause of spatial variation of snow depth at the slope scale. The presence of crevasses is expected to have influenced the spatial variation at this site. Exposure to wind and slope curvature are also known to be important in the regulation of snow distribution (Dadic et al., 2010). These sites were selected, in part, for their proximity to known crevasse stratigraphy measurements and as such a high degree of spatial variation is expected due to turbulent interactions of precipitation bearing air parcels and surface roughness.

Catchment scale snow depth variation is less than the range of variation within each snow course (Table 3.2.1). The variation of snow depths is higest at the highest recorded snow depth site but no clear pattern of decreasing variation in snow depth with elevation or distance to the Main Divide was identified. 

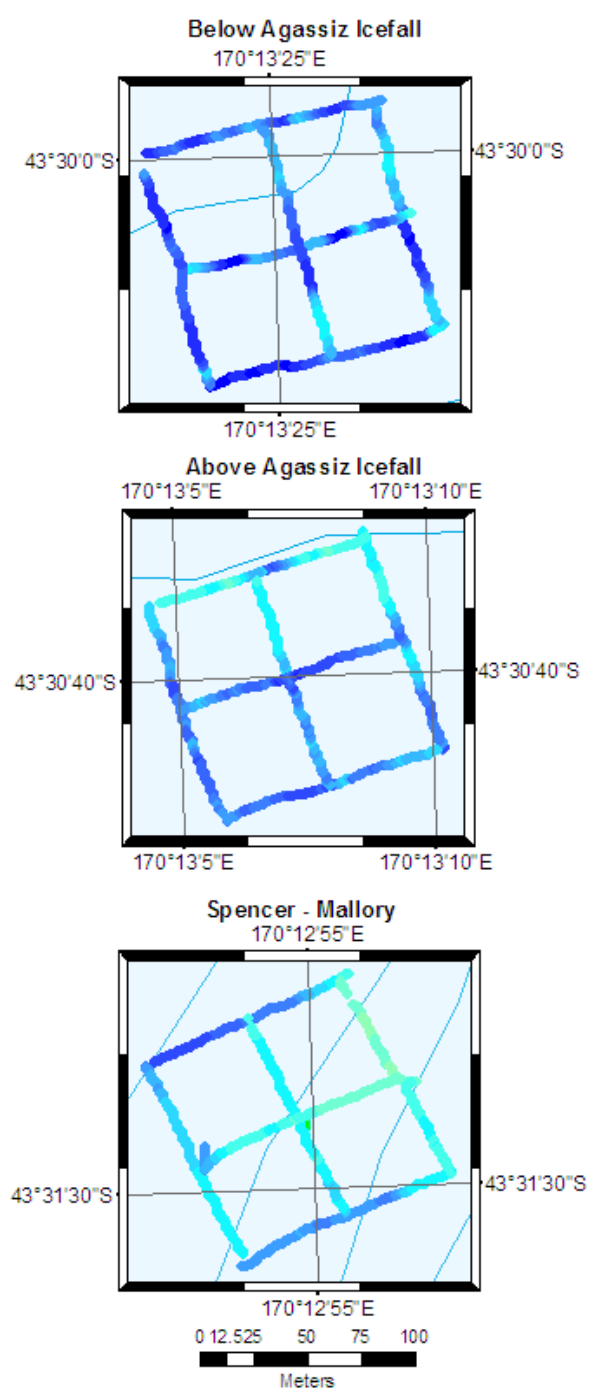

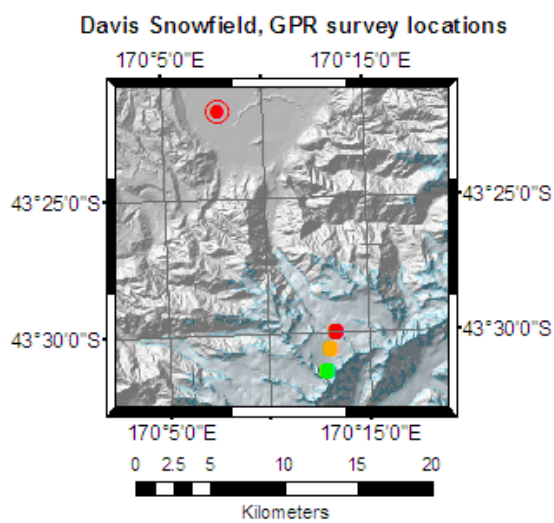

Legend

Study location; mean snow depth \& elevation S.W.E mm

- $4793 \mathrm{~mm}$ Spencer Mallory $2450 \mathrm{~m}$ a.s.l

- $5065 \mathrm{~mm}$ above Agassiz lœfall $2300 \mathrm{~m}$ a.s.

- $5398 \mathrm{~mm}$ below Agassiz lœfall $2050 \mathrm{~m}$ a.s.

Accumulation volume

SWE $\mathrm{mm}$

- $137-450$

- $451-703$

$704-911$
$-912-1104$

$1105-1341$

$1342-1641$

$1642-2010$

$1642-2010$

$2011-2327$
$2328-2511$

$2512-2695$
2696 - $2880 \square$ Glacier ice 2881 - 3063 — Elevation contour $3064-3336 \bigcirc$ AWS location $3337-3719$

$3720-4082$

$4083-443$

4431 - 4663

- 4664 - 4850

- $4851-4992$

- $4993-5106$

$5107-5211$

- $5212-5321$

- $5322-5456$

- $5457-5645$

- $5646-5933$

- $5934-6455$

Figure 3.2.1. Snow distribution plots for the transect along the Davis Snowfield from below the Agassiz icefall at $2050 \mathrm{~m}$ a.s.l to $2450 \mathrm{~m}$ a.s.l towards small col between two $2600 \mathrm{~m}$ a.s.l ridges to the north and south. There is a generally decreasing trend towards the divide, with noticeable variation within the snow course.

\subsubsection{Davis Snowfield seasonal accumulation factors}

Accumulation factors were calculated for all seasonal snow packs at all sites. The base IRH represents the end of summer surface from which these calculations were made (Table 3.2.4). It is known that seasonal accumulation factors may produce appreciably different snow depths at shorter time scales when calculated from a seasonal accumulation factor (Figure 3.2.4 and 3.2.5) (Anderson et al., 2006, Purdie et al., 2011b) than what is actually experienced at locations of interest. 
Resolving the discrepancy between the calculated product of seasonal accumulation factors and observed precipitation may be useful in general snow accumulation estimation. An assessment was made on an accumulation factor that best represented all SWE values derived from accumulation factors tuned to specific IRH. These accumulation factors were produced for the Davis Snowfield (Figure 3.2.6) and Annette Plateau (Table 3.2.6). Annual accumulation factors for the entire accumulation season volume, with no consideration to event scale accumulation are presented below. The accumulation factors used in this comparison were determined by a least mean squares best fit.

The resultant accumulation factor for Davis Snowfield (Figure 3.2.6) follows a similar relationship to that at Annette Plateau (Table 3.2.5) with seasonal accumulation factors, in that the accumulation factor that best suits all synoptic types is smaller than that of the entire accumulation season accumulation factor (Table 3.2.4).

\begin{tabular}{|c|c|c|c|c|c|c|c|c|c|c|c|c|c|c|c|}
\hline & \multirow{2}{*}{\multicolumn{3}{|c|}{$\begin{array}{l}\text { Davis } \\
2000\end{array}$}} & \multirow{2}{*}{\multicolumn{3}{|c|}{$\begin{array}{l}\text { Davis } \\
2300\end{array}$}} & \multirow{2}{*}{\multicolumn{3}{|c|}{$\begin{array}{l}\text { Davis } \\
2450\end{array}$}} & \multirow{2}{*}{\multicolumn{3}{|c|}{$\begin{array}{l}\text { Annette } \\
\text { Plateau }\end{array}$}} & \multirow{2}{*}{\multicolumn{3}{|c|}{$\begin{array}{l}\text { Jollie } \\
\text { Valley }\end{array}$}} \\
\hline & & & & & & & & & & & & & & & \\
\hline & $W_{m}$ & $f$ & $w_{c}$ & $w_{m}$ & $f$ & $w_{c}$ & $w_{m}$ & $f$ & $w_{c}$ & $w_{m}$ & $f$ & $w_{c}$ & $w_{m}$ & $f$ & $w_{c}$ \\
\hline$-\varepsilon$ & 4915 & 2.60 & 4831 & 4527 & 2.40 & 4513 & 4314 & 2.35 & 4432 & 2362 & 1.35 & 2423 & 870 & 0.53 & 894 \\
\hline SWE & 5429 & 2.90 & 5398 & 4969 & 2.65 & 4986 & 4718 & 2.55 & 4810 & 2601 & 1.45 & 2623 & 1007 & 0.58 & 1014 \\
\hline$+\varepsilon$ & 5932 & 3.20 & 5965 & 5398 & 2.85 & 5364 & 5111 & 2.70 & 5094 & 2974 & 1.65 & 3022 & 1139 & 0.63 & 1133 \\
\hline
\end{tabular}

Table 3.2.4. Contrast of measured accumulation $\left(w_{m}\right)$, calculated accumulation factors $(f)$ and calculated accumulation $\left(w_{c}\right)$ including the upper $(+\varepsilon)$ and lower $(-\varepsilon)$ boundaries of error for measured accumulation for all survey sites for the entire accumulation season.

Accumulation factors for the Davis Snowfield are all positive multipliers of precipitation at Franz Josef Glacier AWS. The accumulation factors decrease in size with reducing distance to the main divide. Such a pattern is expected given the orographic processes that occur in this region. 

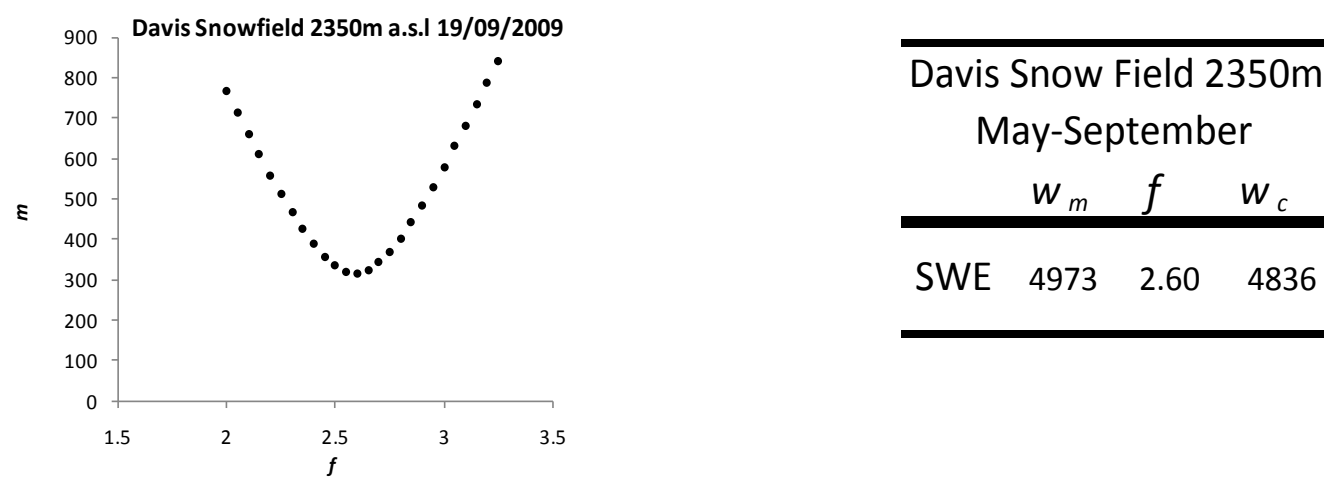

Figure 3.2.6. Contrast of measured accumulation $\left(w_{m}\right)$, calculated accumulation factors $(f)$ tuned to represent the best average accumulation factor for all accumulation periods and calculated the total calculated accumulation $\left(w_{c}\right)$ for the $2350 m$ a.s.l snow course at the Davis Snowfield for the time periods between 1 May 2009 and 20 September 2009

\subsubsection{Annette Plateau}

Average snow depth for all of Annette Plateau is $2625 \mathrm{~mm}$ SWE. Of the three sites in the trans alpine profile, Annette Plateau has the most spatial uniformity of SWE within and between profiles. The slight north-south (deeper to shallower) gradient in accumulation is a result of the local variability in transect 190 and the western end of transect 189 (Figure 3.2.2 a, Table 3.2.2).

\begin{tabular}{|l|c|c|c|c|c|}
\hline & Ground & Ground & Ground & Ground & Ground \\
\hline & 166 A1_A2 & 189 B1_B2 & 190 C1_C2 & 191 D1_D2 & All \\
\hline count & 3117 & 4636 & 3521 & 7038 & 18312 \\
\hline min & 2490 & 2230 & 2205 & 2162 & 2162 \\
\hline max & 2962 & 3379 & 3136 & 2943 & 3379 \\
\hline mean & 2601 & 2632 & 2723 & 2581 & 2625 \\
\hline median & 2580 & 2531 & 2811 & 2507 & 2577 \\
\hline Range & 472 & 1148 & 931 & 781 & 1217 \\
\hline Std dev & 73 & 312 & 283 & 205 & 245 \\
\hline Cv & 0.03 & 0.12 & 0.10 & 0.08 & 0.09 \\
\hline
\end{tabular}

Table 3.2.2. Statistical moments for the end of season snow survey at Annette Plateau. Refer to figure 3.2.2 for profile locations.

Annette Plateau is an area of relatively high accumulation. Over a 30 year period the winter time precipitation accounts for a similar proportion of the annual precipitation as the Davis Snowfield (42\%). The 2009 SWE for the accumulation period equated to $2.65 \mathrm{~m}$ w.e. 
Consequently 2009 is deemed as a higher than normal precipitation year with the 30 year precipitation normal equating to $65 \%$ of the 2009 volume at $1700 \mathrm{~mm}$ w.e. (Table 3.2.2)

The variation at Annette plateau is due largely to the shape of the surface topography resulting in preferential deposition due to topographical features of a convex nature. The generally smooth, crevasse-free nature of the end of summer accumulation surface was an important factor in the resulting snow distribution with changes in snow depth of low frequency and magnitude. Consequently, Annette Plateau allows the inference of relatively reliable long term estimates of precipitation because of the little variation in SWE at the site. Hence, it is deemed to be a useful site for longer term isotope based accumulation studies from ice core collection. The regular surface and wide-spread spatial uniformity of this site is useful for the extraction of ice-cores as any drill site at this location would be representative of the glacier-scale snow accumulation.

(a)

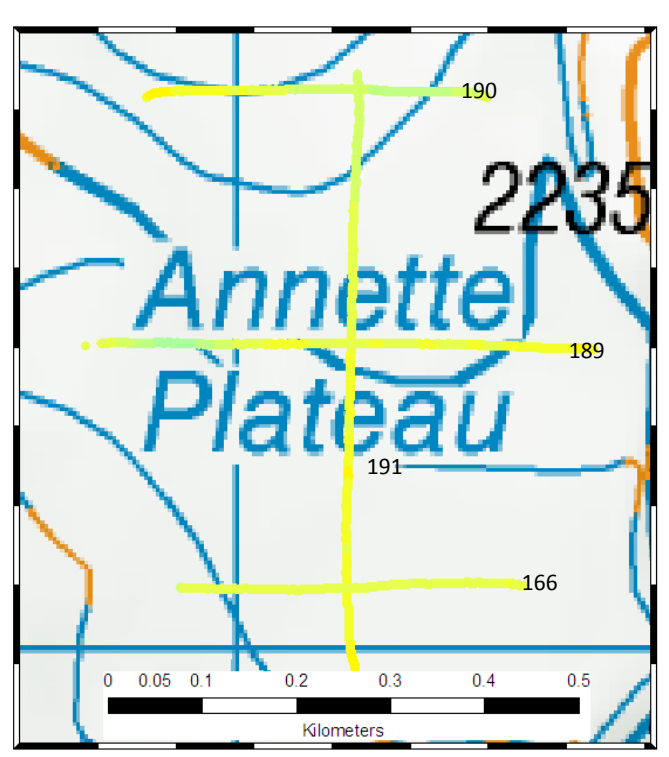

Annette Plateau

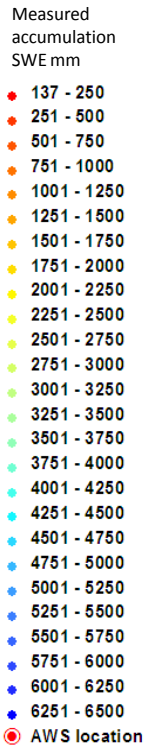

(b)

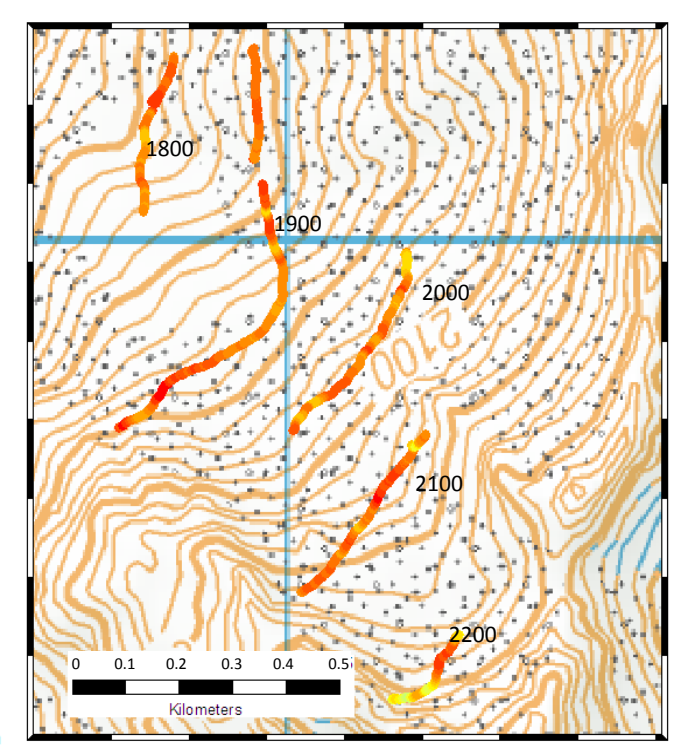

Figure 3.2.2. Measured snow distribution at Annette Plateau and the Jollie River valley at the end of the accumulation season. The variation of snow depth with the complexity of terrain is highlighted at the Jollie Valley over the minor localised variation at Annette plateau in the top right and mid left sections in the snow course.

\subsubsection{Annette Plateau time series}

Multiple site visits to Annette Plateau throughout the accumulation season allowed a time series of observations to be made. The three radargrams (Figure 3.2.3) below represent these 
data collected on the dates of May 5, June 17, and October 7 2009. Due to the lack of early season snow surveys at other study locations, only Annette Plateau was used for the relationships of synoptic weather types and snow accumulation volumes.
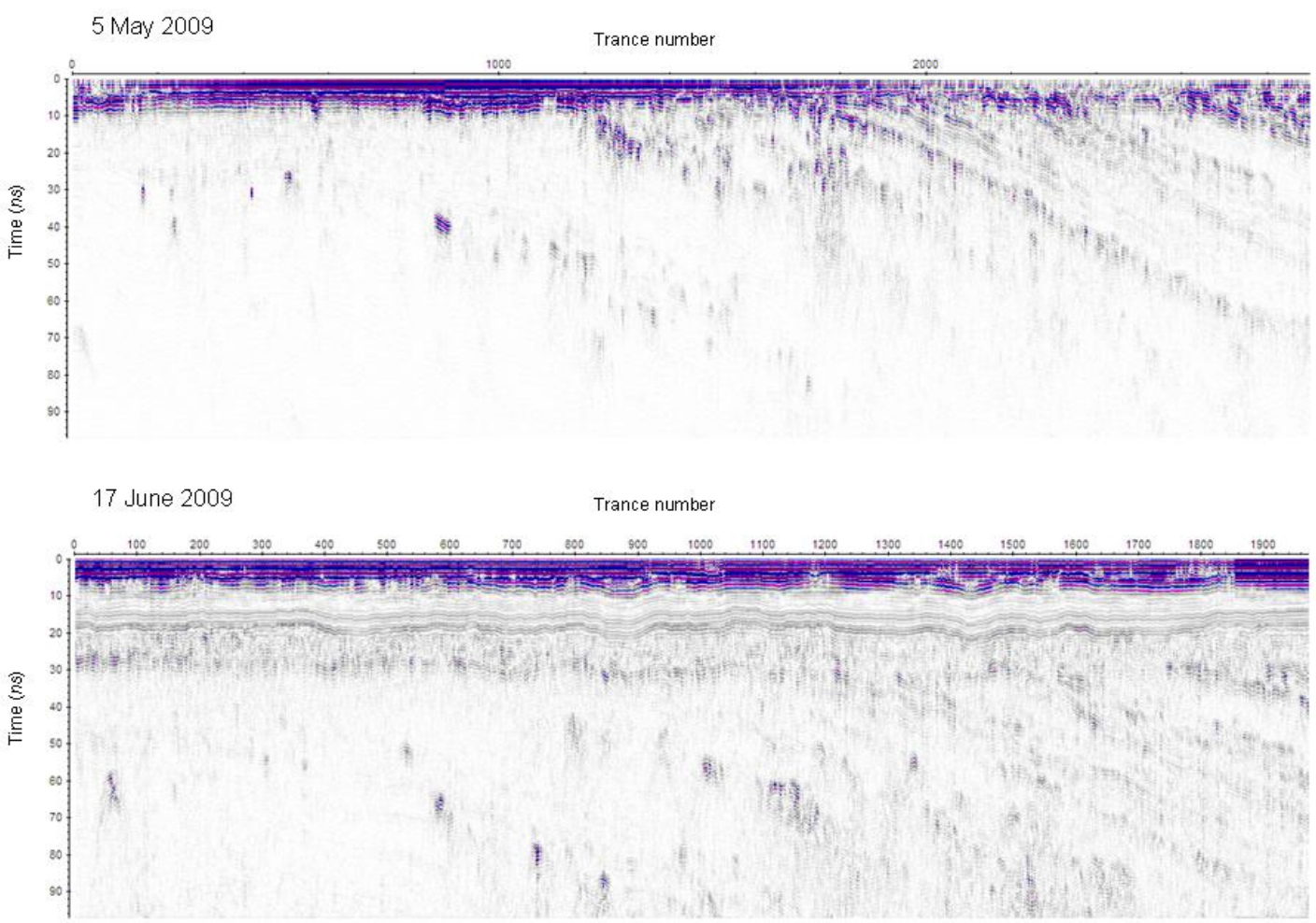

7 October 2009 Trance number

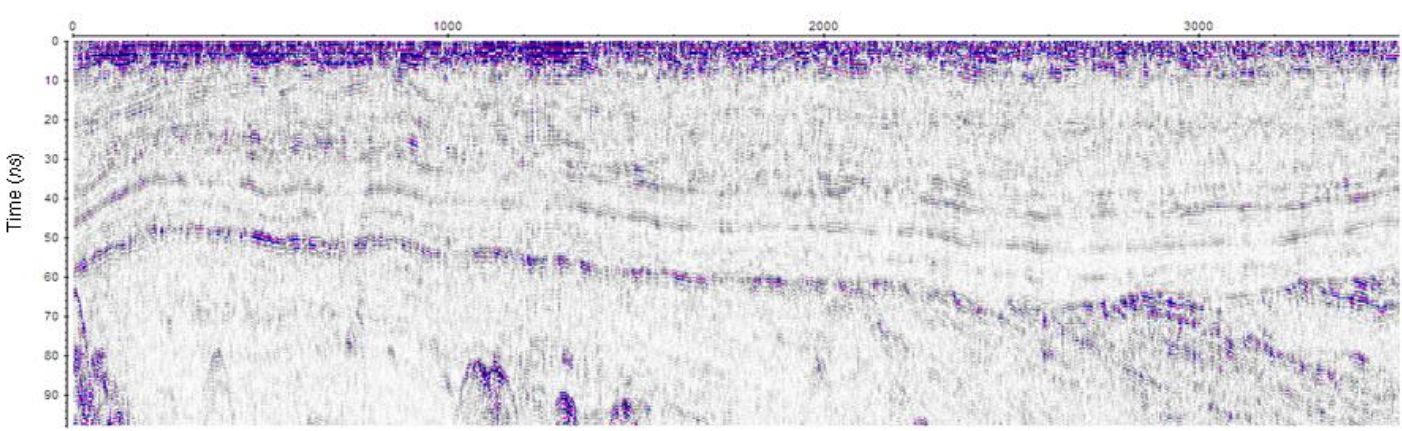

Figure 3.2.3. Radar grams for profile 190 (Figure 3.2.2) for the three GPR surveys throughout the accumulation season

Using the pre-accumulation early-season site visits a baseline temporal pattern of accumulation can be derived from the first radar survey. In the first six week period there were two major accumulation events as shown in the radargram (Figure 3.2.3 b) for the June 17. These same layers appear at the lower end of the October 7 snow survey in the range of 40 to 60 ns. Further precipitation deposition sequence layering can be observed throughout the end of accumulation season snowpack. 
The w.e. depths attributed to these depths of these sequence layering were extrapolated using the SWE/TWTT relationship derived from snow pits in the upper portion of the snow pack. Radio wave speeds were collected from a snow pit and probing. The June 17 snow pit was dug down to $1.75 \mathrm{~m}$ deep, at which point a hard ice layer was reached. Probing from the pit bottom yielded another $1.5 \mathrm{~m}$ until the probe hit another hard layer at what was interpreted to be the summer glacial surface. The October 7 survey was calibrated by a $4 \mathrm{~m}$ deep snow pit extrapolating the depth density relationship down for the extent of the snow pack using the unconfined linear extrapolation method (Figure 3.1.5).

\subsubsection{Annette Plateau accumulation rates}

The temporal spacing of surveys at Annette Plateau allowed for the calculation of accumulation factors for each survey period. Accumulation factors for Annette Plateau represent the average SWE of the entire surveyed area. Accumulation factors were calculated for the periods between May 1 and June 17, and June 17and 7 October (Table 3.2.5).

\begin{tabular}{|c|c|c|c|c|c|c|c|c|c|}
\hline \multicolumn{7}{|c|}{ Annette Plateau } & \multirow{2}{*}{\multicolumn{3}{|c|}{ May- October }} \\
\hline & \multicolumn{3}{|c|}{ May-June } & \multicolumn{3}{|c|}{ June-October } & & & \\
\hline & $w_{m}$ & $f$ & $w_{c}$ & $w_{m}$ & $f$ & $w_{c}$ & $w_{m}$ & $f$ & $w_{c}$ \\
\hline$-\varepsilon$ & 875 & 1.00 & 854 & 1411 & 1.50 & 1386 & 2362 & 1.35 & 2423 \\
\hline SWE & 1024 & 1.20 & 1030 & 1513 & 1.60 & 1499 & 2601 & 1.45 & 2623 \\
\hline$+\varepsilon$ & 1181 & 1.35 & 1162 & 1666 & 1.70 & 1612 & 2974 & 1.65 & 3022 \\
\hline
\end{tabular}

Table 3.2.5. Contrast of measured accumulation $\left(w_{m}\right)$ calculated accumulation factors $(f)$ and calculated accumulation $\left(w_{c}\right)$ including the upper $(+\varepsilon)$ and lower $(-\varepsilon)$ boundaries of error for measured accumulation for Annette Plateau for the time periods between snow surveys and the whole accumulation season.

The early season snow survey at Annette Plateau reveals that there was a $20 \%$ higher accumulated precipitation depth at Annette Plateau than at the Mount Cook AWS for the period between the 1 May and 17 June (Table 3.2.5; Figure 3.2.4). For the period 17 June to 7 October $60 \%$ more precipitation was accumulated at Annette Plateau than at the Mount Cook AWS culminating in an average of $45 \%$ more precipitation at Annette Plateau the entire accumulation season. 
The temporal scale of surveys at Annette Plateau allowed the least square method of calculating accumulation factors (Figure 3.2.6) to be applied at shorter time scales in order to better calculate SWE at the storm scale. The temperature index model shows Mount Cook village AWS as receiving more precipitation than the adjacent Annette Plateau during the early season trough regimes due to the lower ratio accumulation factor (Table 3.2.6).

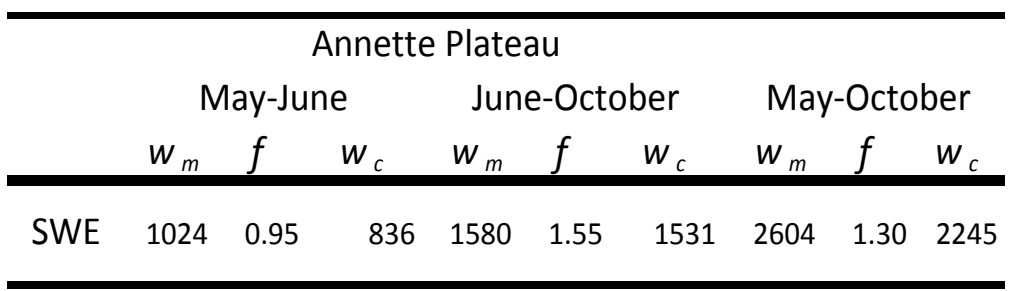

Table 3.2.6. Contrast of measured accumulation $\left(w_{m}\right)$, calculated accumulation factors $(f)$ tuned to represent the best average accumulation factor for all accumulation periods. Calculated total accumulation $\left(w_{c}\right)$ for Annette Plateau, for the time periods between 1 May and 17 June and 17 June and 7 October snow surveys and the whole accumulation season May to October are shown.

The ability of an average accumulation factor derived from the least square method to calculate SWE offers little extra accuracy over a bulk accumulation factor for the entire precipitation season (Figure 3.2.6; Table 3.2.6) . The variation is attributed to the type and frequency of precipitation bearing synoptic weather classifications (Table 3.2.6).

The accumulated precipitation and snow depth comparison charts use calculated IRH goverened snow depth values from the end of season GPR site survey (Figure 3.2.4 and 3.2.5). The snow depths and accumulation factors calculated for the May-June period use the snow depths estimated from that GPR survey of the same period (Table 3.2.5). The differences in the estimated snow depth for the IRH for June 17 are within the range of error for the IRH depth calculation. The Annette Plateau snow depths were left un-calibrated by the June GPR survey so snow depths and accumulation factors between Annette Plateau and Davis Snowfield would be directly comparable with the same magnitude of inherent error. 


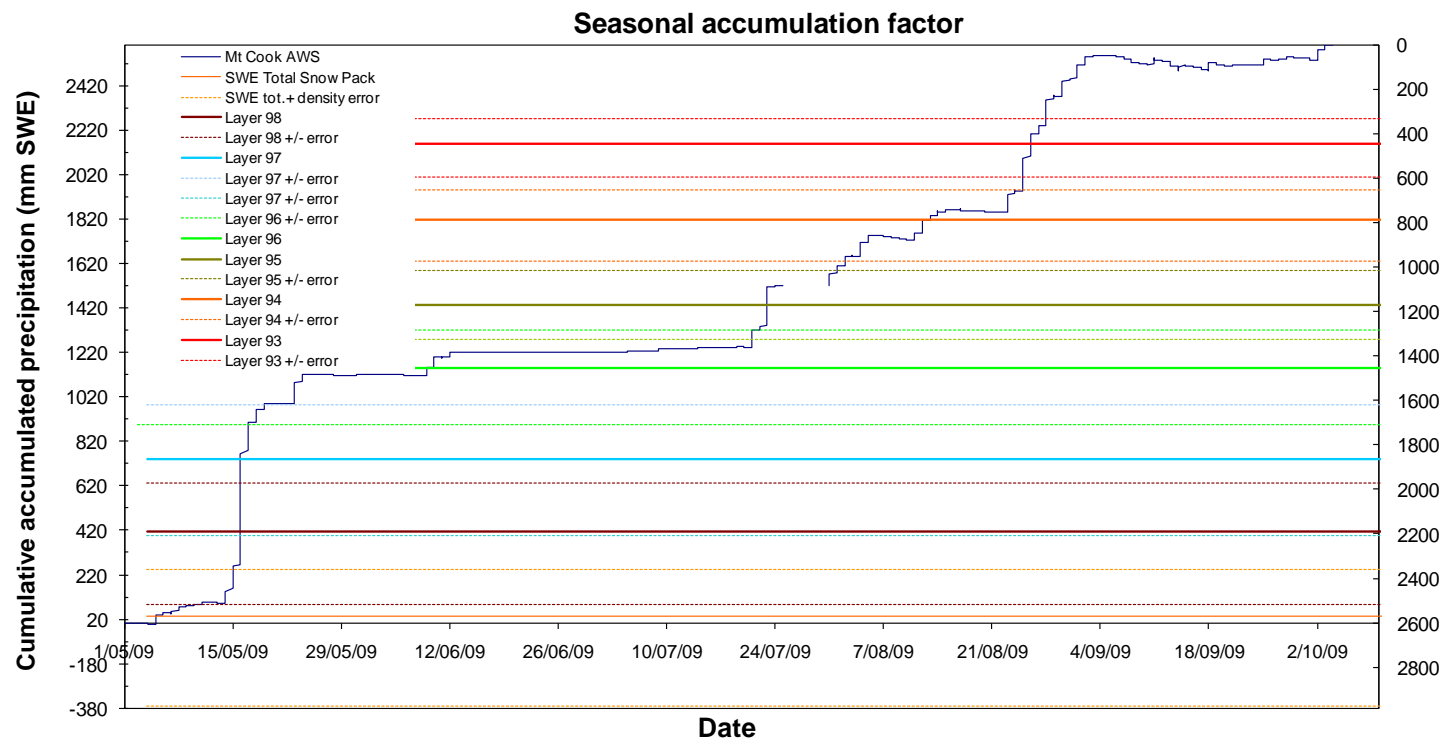

Figure 3.2.4. Internal reflection horizons at southern-most radar transect (Figure 3.2.2 Transect 166) at Annette Plateau is compared with scaled cumulative precipitation data for the entire accumulation season from the Mount Cook village AWS. A bulk seasonal accumulation factor is applied (Table 3.2.6). The x-axis is the end of the ablation season (summer) surface, the ages of each layer becoming progressively younger up to the red layer at the surface. Layer 97 (light blue) represents the 17 June snow survey from which density measurements were taken (Figure 3.2.3).

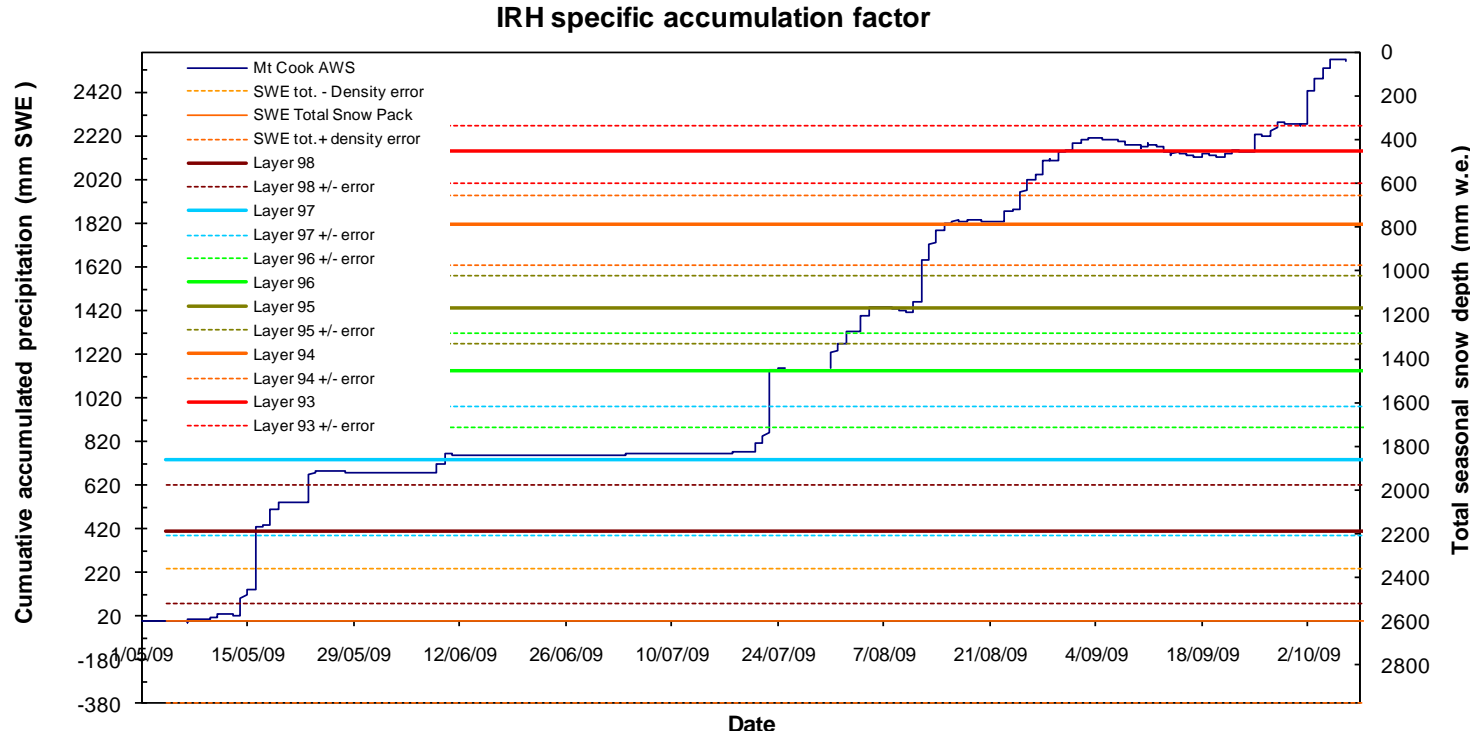

Figure 3.2.5. Internal reflection horizons at southern-most radar transect at Annette Plateau (Figure 3.2.2 Transect 166). Of note is the same number of accumulation events and IRH and the much improved short term calculation of accumulated precipitation compared with Figure 3.2.4. Accumulation factors for the Kidson synoptic (Kidson, 2000)scale accumulation events confined by IRH and presented in Table 3.2.8 and Figure 3.2.6. 
Accumulation factors were derived for each synoptic scale accumulation period at Davis Snowfield and Annette Plateau, as seen for Annette Plateau in Figure 3.2.5. The higher temporal resolution accumulation factors better estimate snow accumulation that larger time scale estimates. More results on synoptic scale accumulation rates are provided in chapter 3 , section 10 (3.10).

\subsubsection{Jollie River Valley}

Average precipitation was derived for the Jollie River valley site. Entire season snow depth values for the transects at $100 \mathrm{~m}$ elevation intervals between $1800 \mathrm{~m}$ a.s.l to $2200 \mathrm{~m}$ a.s.1 were combined. The average accumulation factor for the average study site elevation of $2000 \mathrm{~m}$ a.s.l. is 0.58 (Table 3.2.4). The derived average SWE for Jollie River valley is 1007 $\mathrm{mm}$ (Table 3.2.3). There is no strong pattern of snow depth with elevation for mean SWE at each transect elevation. The range of variation increases from increasing snow depth maximum values for each transect with an increase in altitude (Table 3.2.2). Across slope snow depth variation within each transect is much greater than that of the up/down slope variation (Figure 3.2.2 b). The surface roughness and complexity of the terrain at Jollie River valley is the cause of the observed variation in snow depth and can clearly be seen in radargrams (Figure 3.1.8 a and b).

\begin{tabular}{|l|c|c|c|c|c|c|}
\hline & Ground & Ground & Ground & Ground & Ground & Ground \\
\hline m a.s.I & 2223 & 2100 & 2000 & 1900 & 1800 & All \\
\hline count & 4049 & 6656 & 6656 & 12551 & 4049 & 33961 \\
\hline min & 255 & 161 & 396 & 137 & 256 & 137 \\
\hline max & 3132 & 2384 & 2164 & 1885 & 1621 & 3132 \\
\hline mean & 1309 & 892 & 1162 & 868 & 990 & 1007 \\
\hline median & 1158 & 831 & 1129 & 861 & 990 & 924 \\
\hline range & 2877 & 2223 & 1767 & 1749 & 1365 & 2995 \\
\hline Std dev & 818 & 378 & 445 & 342 & 286 & 473 \\
\hline Cv & 0.62 & 0.42 & 0.38 & 0.39 & 0.29 & 0.47 \\
\hline
\end{tabular}

Table 3.2.3. Statistical moments for the end of season snow survey at the Jollie River valley at each surveyed elevation.

The expected 30 year winter precipitation norm for the Jollie River valley was $65 \%$ of the 2009 measured total at $650 \mathrm{~mm}$ SWE. The 2009 measured SWE was $1007 \mathrm{~mm}$ SWE. This reinforces that the high accumulation rates of 2009 were experienced throughout the study region. 


\subsubsection{Jollie River valley accumulation rates}

Synoptic scale resolution of snow accumulation was not identified at the Jollie River valley study site. Whilst it was possible to identify IRH within the radargrams, these were in the form of a cross bedded accumulation sequence. Therefore it was not possible to accurately assume the sequencing for successive layering due to the interaction of snow redistribution in this complex terrain. The IRH became more homogenous and spatially extensive as the depressions in the slope filled in. Consequently there was no storm scale derivation of accumulation factors from synoptic cycles.

The reduction in accumulation in depth at the Jollie Valley with respect to the Mount Cook AWS (Figure 3.2.2) is to be expected given that it is a site further east and in the lee of two mountain ranges in comparison to the Mount Cook AWS. The pattern is in keeping with the pattern of known precipitation volumes (Henderson and Thompson 1999, Kerr 2009b) and orographic precipitation patterns (Zängl, 2005).

\subsection{Precipitation Volumes and Synoptic Regimes}

Investigation into the role of effect that each synoptic type has on the volume and frequency of precipitation was made by tuning AWS precipitation volumes to that which were observed within IRH. The hypothesis that IRH formed between periods of accumulation is implicit in this analysis. Periods of no accumulation result in snow metamorphism which is concentrated at the surface through the effects of solar radiation, wind and at times liquid precipitation (Alean et al., 1984). Subsequent accumulation events leave a density contrast at the location of the previously exposed surface.

These events were then compared with the Kidson (2000) synoptic types across each study period. The frequency of occurrence of synoptic type, frequency of time that precipitation occurs with each event, and the amount of time for each event that precipitation occurs were derived allowing calculation of average precipitation rates for synoptic sequences.

Calculations of synoptic precipitation volume were made for Annette Plateau for the early season survey, the entire season and for the $2350 \mathrm{~m}$ a.s.1 transect at the Davis Snowfield (Tables $3.2 .7 ; 3.2 .8 ; 3.2 .9$ ). The tables describe the number of each $12 \mathrm{hr}$ period synoptic type (Kidson, 2000) per study period. The number of synoptic types with precipitation are 
presented in the third row of the table (events with precipitation @ AWS), as are the hours of precipitation in each $12 \mathrm{hr}$ classification (hour's precip.). The accumulated precipitation volume (accumulated volume $\mathrm{mm}$ ) and $12 \mathrm{hr}$ (precipitation rate $\mathrm{mm} / 12 \mathrm{hr}$ ) and hourly (precipitation rate $\mathrm{mm} / \mathrm{hr}$ ) precipitation rates are described in the next rows. The average accumulation factor $(f)$ represents the average of the best fit accumulation factor to each accumulation sequence. The percentage of time that accumulation occurs with the presence of each synoptic type (\% of precipitation per synoptic type) and the percentage of time that precipitation persists within each precipitation bearing synoptic type (\% of time precip. occurs) provides perspective as to the likelihood of precipitation with each synoptic type.

\subsubsection{Annette Plateau}

Synoptic flow for the region during the study period is dominated by the trough type classification, bringing the highest average $12 \mathrm{hr}$ deposition rates and the largest precipitation volume. Blocking and zonal classifications occur $8 \%$ and $15 \%$ less frequent respectively (Table 3.2.7). Individual synoptic types may produce a higher proportion of precipitation for each regime. For instance the Westerly (8) zonal regime will produce precipitation over half of the time that the type occurs. Precipitation during the zonal synoptic type persisted, for the majority of time with the second greatest $12 \mathrm{hr}$ precipitation rate.

Average accumulation factors for each precipitation-bearing synoptic type vary between 0.8 and 1.8 of Mount Cook village precipitation in the early season study, although the SW classification has an accumulation factor of 2.4 (Table 3.2.7). The accumulation factors associated with ridge or zonal westerly accumulation events, usually associated with fine weather, may be higher for Annette Plateau as they are not as associated with spill over measured at low-land AWS and as such require higher accumulation factors to calibrate AWS data to measured accumulation depths. 


\begin{tabular}{|c|c|c|c|c|c|c|c|c|c|c|c|c|}
\hline & \multicolumn{4}{|c|}{ Trough } & \multicolumn{5}{|c|}{ Blocking } & \multicolumn{3}{|c|}{ Zonal } \\
\hline & TSW & $T$ & SW & $T N W$ & $N E$ & $R$ & $H W$ & $H E$ & HSE & $w$ & HNW & $H$ \\
\hline Classification number & 1 & 2 & 3 & 10 & 4 & 5 & 6 & 7 & 11 & 8 & 9 & 12 \\
\hline Kidson types (12hr) & 6 & 22 & 13 & 1 & 1 & 6 & 13 & 10 & 11 & 0 & 4 & 9 \\
\hline Events with precipitation @ AWS & 3 & 19 & 10 & 0 & 0 & 5 & 5 & 8 & 6 & 0 & 4 & 5 \\
\hline Hours precip & 15 & 109 & 28 & 0 & 0 & 3 & 6 & 59 & 28 & 0 & 4 & 1 \\
\hline Accumulation volume $(\mathrm{mm})$ & 40 & 755 & 72 & 0 & 0 & 0 & 2 & 75 & 79 & 0 & -5 & -1 \\
\hline Number of days & 3 & 11 & 6.5 & 0.5 & 0.5 & 3 & 6.5 & 5 & 5.5 & 0 & 2 & 4.5 \\
\hline Average accumulation factor (f) & 2.4 & 0.8 & 1.1 & 0.8 & 0.0 & 2.4 & 0.8 & 1.1 & 1.8 & 0 & 0.8 & 0.8 \\
\hline$\%$ of precipitation per synoptic type & $42 \%$ & $48 \%$ & $23 \%$ & $0 \%$ & $0 \%$ & $0 \%$ & $0 \%$ & $61 \%$ & $39 \%$ & $0 \%$ & $0 \%$ & $0 \%$ \\
\hline$\%$ of time precip. occurs & $50 \%$ & $86 \%$ & $77 \%$ & $0 \%$ & $0 \%$ & $83 \%$ & $38 \%$ & $80 \%$ & $55 \%$ & $0 \%$ & $100 \%$ & $56 \%$ \\
\hline
\end{tabular}

Table 3.2.7. Early season synoptic type, frequency and accumulation descriptors for Annette Plateau. Individual synoptic types are grouped into general classifications representing the trough, zonal and blocking synoptic regimes. Highest accumulation rates and volumes were delivered by the most frequent trough synoptic type. Ridge $(5)$ and zonal $(9,12)$ produced net ablation. Blocking and zonal classifications are $8 \%$ and $15 \%$ less frequent respectively.

\begin{tabular}{|c|c|c|c|c|c|c|c|c|c|c|c|c|}
\hline & \multicolumn{4}{|c|}{ Trough } & \multicolumn{5}{|c|}{ Blocking } & \multicolumn{3}{|c|}{ Zonal } \\
\hline & TSW & $T$ & SW & TNW & NE & $\boldsymbol{R}$ & $H W$ & $H E$ & HSE & $w$ & $H N W$ & $H$ \\
\hline Classification number & 1 & 2 & 3 & 10 & 4 & 5 & 6 & 7 & 11 & 8 & 9 & 12 \\
\hline Kidson types (12hr) & 26 & 53 & 32 & 20 & 4 & 14 & 22 & 27 & 39 & 22 & 16 & 45 \\
\hline Events with precipitation@AWS & 11 & 47 & 24 & 12 & 2 & 8 & 11 & 23 & 33 & 16 & 12 & 24 \\
\hline Hours precip & 51 & 245 & 96 & 56 & 3 & 9 & 26 & 115 & 92 & 106 & 32 & 38 \\
\hline Accumulation volume (mm) & 68 & 1172 & 311 & 124 & 0 & 7 & 11 & 165 & 259 & 301 & 62 & 75 \\
\hline Accumulation rate $\mathrm{mm} / 12 \mathrm{hr}$ & 6 & 25 & 13 & 10 & 0 & 1 & 1 & 7 & 8 & 19 & 5 & 3 \\
\hline Accumulation rate $\mathrm{mm} / \mathrm{hr}$ & 1 & 5 & 3 & 2 & 0 & 1 & 0 & 1 & 3 & 3 & 2 & 2 \\
\hline Number of days precipitation & 13 & 26.5 & 16 & 10 & 2 & 7 & 11 & 13.5 & 19.5 & 11 & 8 & 22.5 \\
\hline Average accumulation factor (f) & 2.1 & 2.3 & 2.4 & 0.9 & 1.8 & 2.6 & 2.3 & 2.4 & 2.0 & 2.6 & 0.9 & 1.9 \\
\hline \% of precipitation occurance per synoptic type & $39 \%$ & $43 \%$ & $33 \%$ & $39 \%$ & $13 \%$ & $9 \%$ & $20 \%$ & $42 \%$ & $23 \%$ & $55 \%$ & $22 \%$ & $13 \%$ \\
\hline$\%$ of time precip. occurs & $42 \%$ & $89 \%$ & $75 \%$ & $60 \%$ & $50 \%$ & $57 \%$ & $50 \%$ & $85 \%$ & $85 \%$ & $73 \%$ & $75 \%$ & $53 \%$ \\
\hline
\end{tabular}

Table 3.2.8. Entire season synoptic type, frequency and accumulation descriptors for Annette Plateau. Individual synoptic types are grouped into general classifications representing the trough, zonal and blocking synoptic genres. Highest accumulation rates and volumes were delivered by the most frequent Trough synoptic type. Blocking weather systems NE (4) and Ridge (5) produced the lowest net accumulation.

Early season accumulation rates (Table 3.2.7) are generally all lower compared with the later season study period (Table 3.2.8). There is notable reduction in $12 / \mathrm{hr}$ accumulation rates for TSW, T, SW, HE, HSE types between the intra-season and full-season surveys, most notably the trough $(\mathrm{T})$ regime. The frequency and precipitation depth associated with some synoptic events meant that intra-season comparison is not possible, i.e. for TNW, NE and $\mathrm{R}$ and zonal classifications (Tables 3.2.7; 3.2 .8 and Figure 1.6).

Variation in accumulation factors can be observed between some synoptic types for the inter-season and entire-season survey, for example the intra-seasonal variation in the Trough regimes T and SW, and blocking HE. Such intra-season variation is observed in other types, 
however the frequency of occurrence and the precipitation volumes do not provide a conclusive comparison with the early season data.

The nature of synoptic classifications is such that the location with respect to a landmass, and size of a synoptic system may not provide conclusive indication of the location of the origin of the front and associated wind direction. This was the case for the early season Trough regime at Annette Plateau. In this early season period the Trough from the south was directed further to the east of the divide, as such spillover was to the west of the divide, with higher precipitation totals in the east. In this portion of the accumulation season Annette Plateau accumulated around $66 \%$ of the precipitation for the Trough (2) synoptic type. With this synoptically implied atmospheric flow Annette Plateau is to the lee of a ridge and its elevation provides greater exposure to winds, compared to Mount Cook village. Consequently Annette Plateau accumulates less precipitation than the Mount Cook Village AWS. The later season Trough systems deposited more precipitation to the west of the divide (Table 3.2.11). The precipitation volumes at Annette Plateau are greater than those at Mount Cook AWS when precipitation volumes are biased to the west of the Main Divide, therefore a larger accumulation factor for the remainder of the accumulation season is to be expected to account for spillover from orographic distribution. The lack of application of wind direction data and the scale and variation of synoptic types is expected to influence the accumulation factors of the SW and HE systems in a similar way.

\subsubsection{Davis Snowfield}

Precipitation associated with Trough regimes is also a major factor in precipitation west of the Main Divide providing $40 \%$ of the precipitation total at the 2300 m Davis Snowfield snow course. The remainder of the precipitation is shared evenly between blocking and zonal synoptic regimes respectively. The highest precipitation volumes were produced by trough type (2) systems, which were also the most frequent synoptic type. However, the highest precipitation rates were accumulated by blocking (HE). The precipitation volume is close to that of trough type (2) the yet the frequency of occurrence is less, suggesting more intense storms.

The percentage of time that precipitation occurs with both $\mathrm{T}(2)$ and $\mathrm{HE}(7)$ is similar, when a precipitation producing HE (7) synoptic type occurs precipitation will last almost the 
whole duration of the synoptic type. The zonal HNW (9) accumulation rates are as intense as HE (7) however the HNW type occurs less frequently with much less likelihood of precipitation.

The highest precipitation rates were produced by the zonal regime HNW, and trough regimes T, and the blocking HE. Heavy precipitation rates can be considered the norm as half of the synoptic types produced accumulation rates in excess of $20 \mathrm{~mm} \mathrm{SWE} / \mathrm{hr}$.

\begin{tabular}{|c|c|c|c|c|c|c|c|c|c|c|c|c|}
\hline & \multicolumn{4}{|c|}{ Trough } & \multicolumn{5}{|c|}{ Blocking } & \multicolumn{3}{|c|}{ Zonal } \\
\hline & $T S W$ & $T$ & $s W$ & TNW & $N E$ & $\boldsymbol{R}$ & $H W$ & $H E$ & HSE & $w$ & HNW & $\mathrm{H}$ \\
\hline Classification number & 1 & 2 & 3 & 10 & 4 & 5 & 6 & 7 & 11 & 8 & 9 & 12 \\
\hline Number of Kidson types ( $12 \mathrm{hr}$ ) in stud & 24 & 39 & 31 & 11 & 4 & 12 & 20 & 25 & 38 & 22 & 15 & 43 \\
\hline Events with precipitation@AWs & 12 & 32 & 21 & 9 & 3 & 6 & 8 & 24 & 26 & 20 & 12 & 25 \\
\hline Hours precip & 33 & 224 & 92 & 62 & 5 & 1 & 5 & 155 & 61 & 122 & 45 & 47 \\
\hline Accumulation volume $(\mathrm{mm})$ & 78 & 1132 & 508 & 225 & 17 & -5 & 7 & 1014 & 378 & 629 & 496 & 206 \\
\hline Accumulation rate $\mathrm{mm} / 12 \mathrm{hr}$ & 6 & 35 & 24 & 25 & 6 & -1 & 1 & 42 & 15 & 31 & 41 & 8 \\
\hline Accumulation rate $\mathrm{mm} / \mathrm{hr}$ & 2 & 5 & 6 & 4 & 3 & -5 & 1 & 7 & 6 & 5 & 11 & 4 \\
\hline Number of days precipitation & 12 & 20 & 16 & 6 & 2 & 6 & 10 & 13 & 19 & 11 & 8 & 22 \\
\hline Average accumulation factor (f) & 2.9 & 2.3 & 2.8 & 3.7 & 2.4 & 2.6 & 2.7 & 3.5 & 3.1 & 1.8 & 3.7 & 3.5 \\
\hline$\%$ of precipitation occurance per synoptic type & $23 \%$ & $58 \%$ & $37 \%$ & $57 \%$ & $14 \%$ & $1 \%$ & $5 \%$ & $54 \%$ & $20 \%$ & $51 \%$ & $31 \%$ & $16 \%$ \\
\hline \% of time precip. occurs & $50 \%$ & $82 \%$ & $68 \%$ & $82 \%$ & $75 \%$ & $50 \%$ & $40 \%$ & $96 \%$ & $68 \%$ & $91 \%$ & $80 \%$ & $58 \%$ \\
\hline
\end{tabular}

Table 3.2.9. Entire season synoptic type, frequency and accumulation descriptors for the Davis Snowfield $(2350 m$ a.s.l). Individual synoptic types are grouped into general classifications representing the trough, zonal and blocking synoptic genres. Highest accumulation rates and volumes were delivered by the most frequent trough synoptic type. Blocking types HE and HSE also produced comparable accumulation rates to trough regimes although Kidson type Ridge (5) produced net ablation. Zonal classifications produced high accumulation rates especially $H N W(9)$ and the largest range between accumulation factors.

\subsubsection{Davis Snowfield - Annette Plateau Comparison}

Accumulation factors are all greater at Davis Snowfield than Annette Plateau over the course of the accumulation season except during $\mathrm{T}$ and $\mathrm{W}$ type circulation. This is due, in part, to the relationship of AWS to study sites and the Main Divide, and the direction of synoptic regimes. West of the Main Divide both trough (TNW (10)) and zonal (HNW(9)) regimes are associated with high accumulation factors. The high accumulation factors are attributed to orographic influences on a windward limb of an orographic precipitation curve. In particular the formation of a barrier jet flow, and seeder feeder mechanism, are considered a likely cause of considerably greater precipitation accumulation at the study site than at the Franz Josef AWS (Purdy, et al., 2005). East of the divide (TNW (10)), (HNW(9)) synoptic classifications are associated with accumulation factors which result in near equal values of precipitation at Annette Plateau and the Mount Cook AWS. The similar 
accumulation factors are attributed to the equal distance from the dividing ridge of Mount Cook AWS and Annette Plateau. A possible explanation of the slight reduction of accumulation at Annette Plateau is sites increased exposure to wind.

Comparison of the percentage of precipitation occurrence per synoptic type reveals that the $\mathrm{T}$ (2) produces similar volumes of precipitation either side of the main divide. All other trough classifications are more likely to provide greater accumulation to the snow pack in the West. Precipitation depths associated with blocking and zonal classifications are also biased to the west of the main divide; of note are the precipitation depths associated with HE classifications (Table 3.2.9). The HE classification is associated with warm N/NW flows with light winds, as such the precipitation is not expected to pass onto the east, and is largely orographic with a steep precipitation gradient, as associated with a high accumulation factor on the west.

Zonal classifications deposit much greater precipitation volumes on the west of the Main Divide than on the east. The distribution pattern is a direct effect of reduced wind speeds generally associated with zonal synoptic classifications. The effect on AWS locations to the lee of topography is evident in the accumulation factor translating Mount Cook AWS precipitation to Annette Plateau for the W synoptic classification (Figure 3.2.8). This pattern is in contrast to the HNW classification where both Mount Cook AWS and Annette Plateau are equally exposed to precipitation.

\subsubsection{Spillover; simultaneous accumulation events}

Assessment of precipitation spillover was made using the low-land precipitation data from the Franz Josef and Mount Cook AWS, scaled with synoptic weather type precipitation accumulation factors (Tables 3.2 .8 and 3.2.9). When cumulative snow accumulation is overlaid with a timeline of the three synoptic regimes, the pattern shows variation in accumulation volumes and timing for each side of the Southern Alps (Figure 3.2.6). The relationship illustrates the difference in trans-alpine simultaneous precipitation depths. Similar volumes of precipitation occurring in Trough (Greene et al. 1999) regimes on both sides of the Southern Alps. While blocking (mid blue) regimes yield greater precipitation volumes on the western flank. Some of the greatest accumulation rates occurred at the transition of zonal (light blue) and blocking regimes. Such high accumulation rates occur as 
east moving anticyclones transition ( $\mathrm{HNW} \rightarrow \mathrm{H} \rightarrow \mathrm{HSE} \rightarrow \mathrm{HE}$ ) over the South Island, such as that on the $18 / 9 / 2009$, with a larger differential between accumulated precipitation on the west and east.

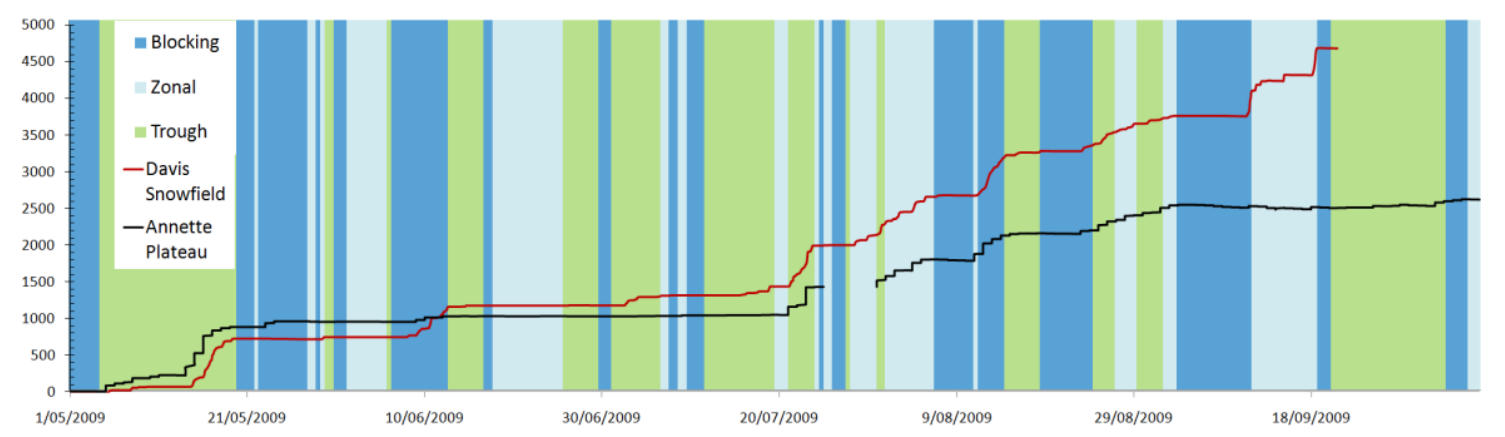

Figure 3.2.6. Cumulative precipitation for the Davis Snowfield and Annette Plateau for each respective study period; y axis mm SWE. Also shown is a colour coded representation of the three major synoptic classifications. There is a gap in precipitation record due to freezing and snow coverage of Mount Cook AWS rain gauge.

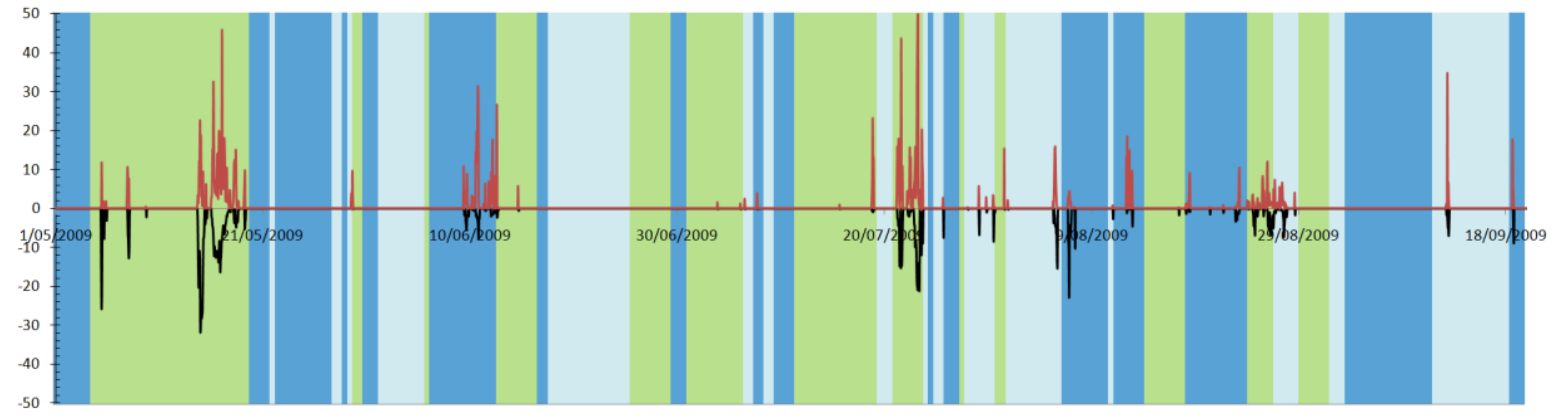

Figure 3.2.7. The difference in precipitation volumes for precipitation events that occurred at the same as time each other at Franz Josef AWS and Mount Cook AWS using GPR derived seasonal net accumulation values. Precipitation depth is in values of $\mathrm{mm}$ SWE. Positive Y-axis values denote a precipitation bias on the western side of the Main Divide. Negative Y-axis values denote a precipitation bias on the eastern side of the Main Divide. Red and black lines denote Davis snowfield and Annette Plateau respectively as per Figure 3.2.6. Analysis is of the time period with measured site accumulation record for both sites.

\begin{tabular}{|c|c|c|c|c|c|c|c|c|c|c|c|c|}
\hline & \multicolumn{3}{|c|}{ Trough } & & \multicolumn{5}{|c|}{ Blocking } & \multicolumn{3}{|c|}{ Zonal } \\
\hline & TSW & $T$ & sW & TNW & $N E$ & $R$ & $H W$ & $H E$ & HSE & $w$ & HNW & $H$ \\
\hline Classification number & 1 & 2 & 3 & 10 & 4 & 5 & 6 & 7 & 11 & 8 & 9 & 12 \\
\hline Number of Kidson types (12hr) & 24 & 39 & 31 & 11 & 4 & 12 & 20 & 25 & 38 & 22 & 15 & 43 \\
\hline DAVIS & 2 & 992 & 270 & 43 & 0 & 0 & 0 & 335 & 61 & 96 & 0 & 137 \\
\hline ANNETTE (mm) & 0 & 1003 & 155 & 0 & 0 & 0 & 0 & 79 & 92 & 62 & 0 & 56 \\
\hline$\%$ of Davis Total & $7 \%$ & $101 \%$ & $57 \%$ & $1 \%$ & $0 \%$ & $0 \%$ & $0 \%$ & $24 \%$ & $151 \%$ & $65 \%$ & $0 \%$ & $41 \%$ \\
\hline
\end{tabular}

Table 3.2.10. The table denotes volumes of lapsed precipitation for Franz Josef Glacier and Annette Plateau during simultaneous storm events and the Annette Plateau percentage of the predominantly windward precipitation total. Precipitation events are classified into individual synoptic type. 
Accumulated SWE spillover bias depths were derived and plotted over the corresponding synoptic type. The representation of the difference in accumulated depths for precipitation bearing synoptic events that occur simultaneously on each side of the Southern Alps provides confirmation that Trough (2) type synoptic events produced similar depths of precipitation on both sides of the Main Divide (Figure 3.2.7). All other synoptic classifications that spillover was associated with produced a depositional bias to the western side of the divide, with precipitation volumes to the east being $20 \%$ to $65 \%$ of the western divide accumulation with negligible spillover bias of up to 7\%. Blocking type HSE (11) produced $151 \%$ more precipitation to the eastern side of the divide (Table 3.2.10).

\subsection{Trans-Alpine snow distribution}

The trans-alpine precipitation values represent the winter study period of 2009 (Figure 3.2.8). This seasonal accumulation assessment needs to be viewed within a long term context as such these seasonal volumes are normalised to a 30 year average precipitation depth. This was done by multiplying the 30 year accumulation season precipitation totals by the derived accumulation factor. The result was tested against the GPR measured SWE multiplied by the percentage of annual accumulation that the accumulation season study over the 30 year precipitation norm, then multiplied by the proportion of annual accumulation that the study season represents in 2009 . The 30 year precipitation normal was $65 \%$ of the 2009 study accumulation season. The accumulation season represents $42 \%$ of annual accumulation for 2009. 


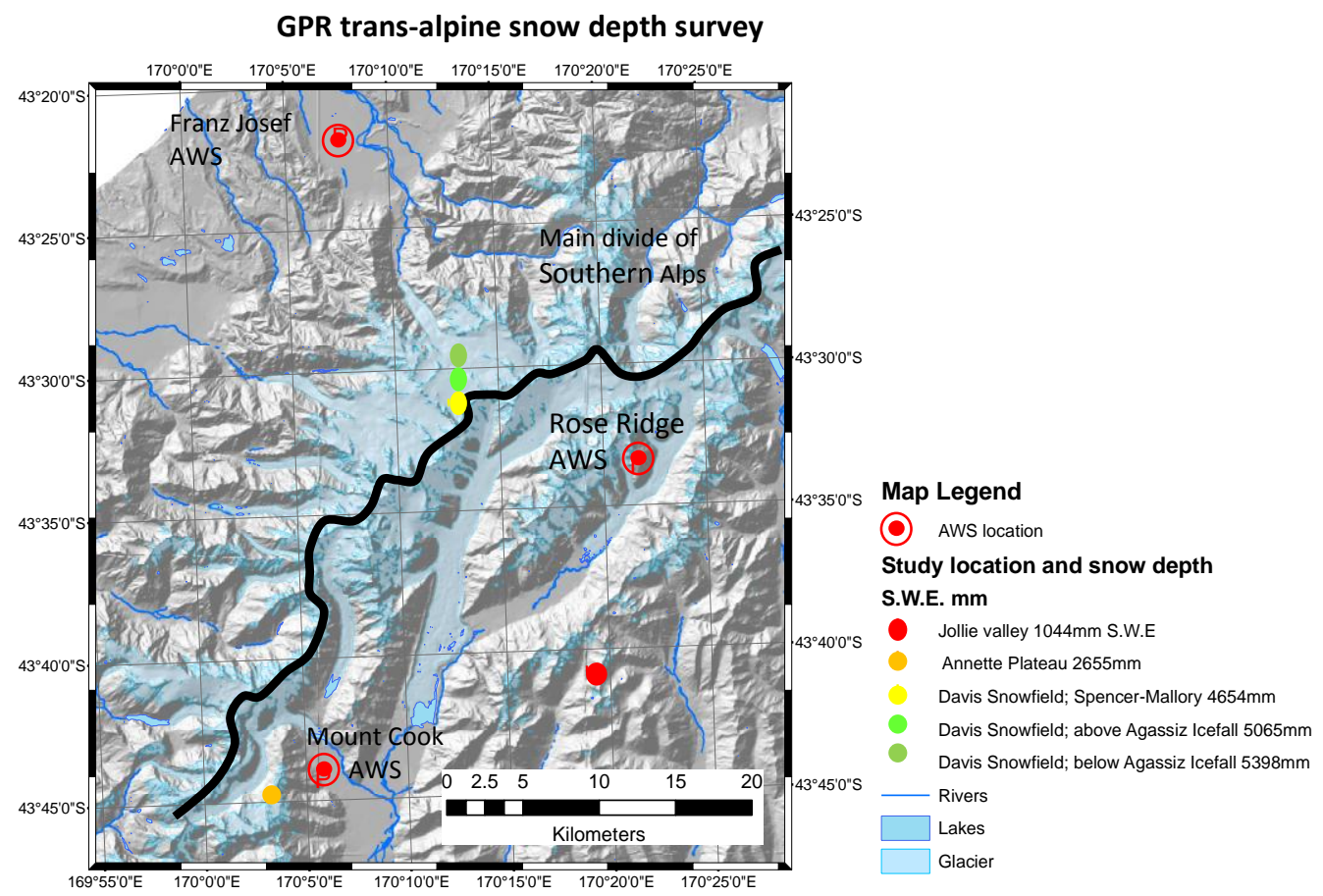

Figure 3.2.9. Accumulated precipitation at the study sites shows a clear trans-alpine accumulation gradient. Of note is the distance of the Mount Cook AWS from the main divide in comparison to Annette Plateau. Rose ridge climate station was used in the calculation of the 2009 seasonal lapse rate.

A spline interpolation was used to infer precipitation across the Southern Alps (Figure 3.2.9). The comparison of different previous studies shows that equally high volumes of precipitation can be found immediately to the east of the Main Divide (Figure 1.3) (Kerr, 2009b; Purdie, et al., 2011b) to what is thought to be near the precipitation peak west of the divide (Figure 1.2) (Anderson, et al., 2006; Ruddell, 1995). In construction of the spline curve, which approximates the precipitation distribution between known precipitation measurements, the GPR-derived 30-year precipitation norms were combined with other long- term estimates to generate a smooth interpolation between data points (Figure 3.2.9) allowing easier comparison with previous studies.

The GPR-derived precipitation measurements and calculations of 30-year climate norms provide a good fit with long term precipitation data sets. The study sites of Annette Plateau and Jollie River valley fall within the region of well constrained precipitation measurements and estimates (Kerr, 2009b). Such results provide some degree of confidence in relation to the less well constrained region of Davis Snowfield area of the Franz Josef Glacier. The 30-year normal precipitation curve reinforces the notion that a precipitation 
peak occurs around $5 \mathrm{~km}$ west of the Main Divide. The suggested precipitation peak is around $12 \mathrm{~m}$ w.e, around $75 \mathrm{~km}$ from the arbitrary precipitation baseline (Henderson \& Thompson, 1999).

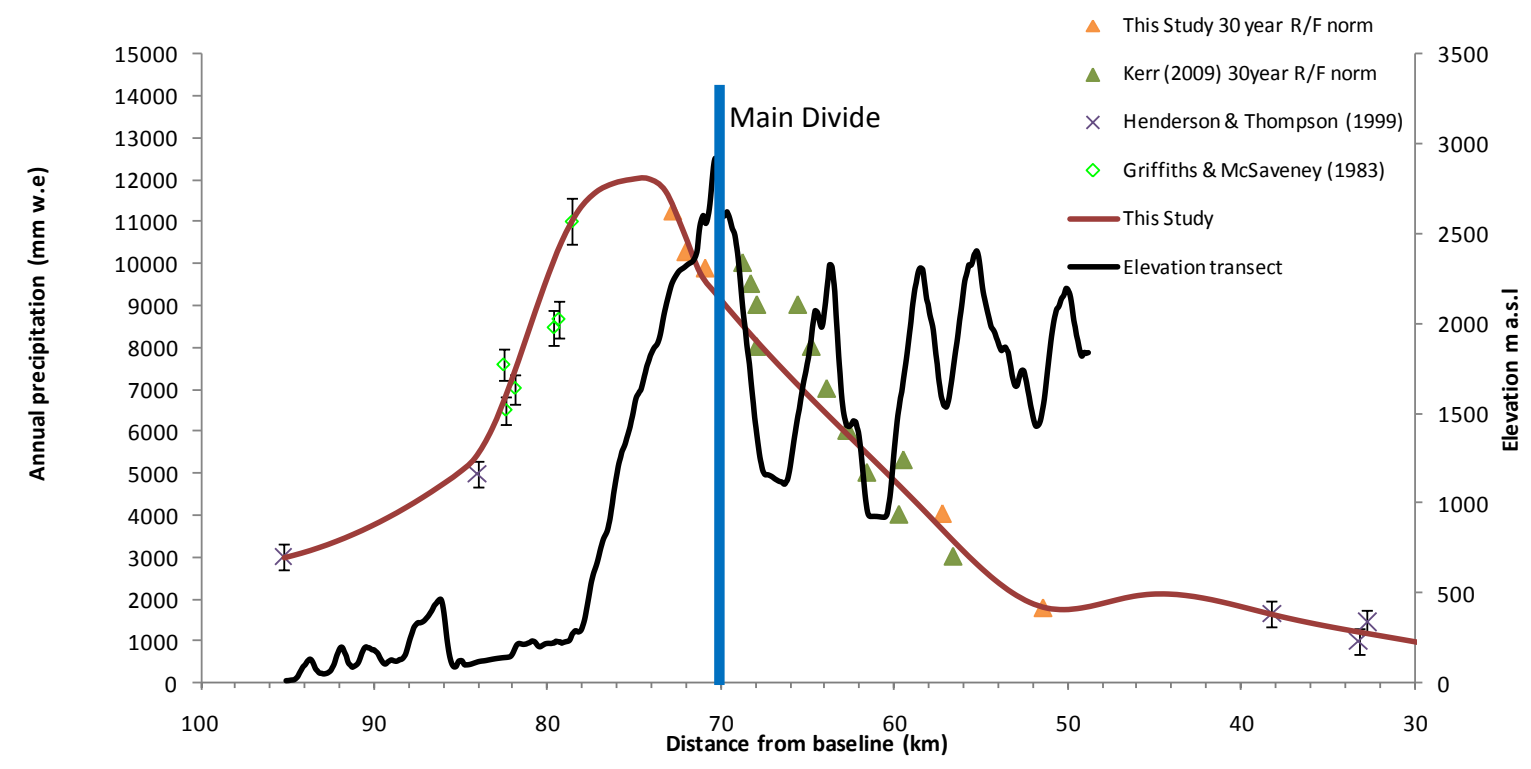

Figure 3.2.9. Snow distribution as estimated by cubic spline calculation incorporating the 30 year normalized selected points from this study, and selected points from the Kerr (2009b) 30 year rainfall normal surface and other previous long term studies. The terrain transect is a representation of a $100 \mathrm{~m}$ wide strip up the middle of the Franz Josef valley in a NW/SE orientation and is for descriptive rather than analytical purposes. 


\section{CHAPTER 4}

\section{Discussion}

\subsection{Techniques for measuring snow accumulation in maritime environments}

Snow depth measurement techniques are well established. This thesis incorporates several often used techniques and compares them against each other in order to establish the most efficient and accurate method of data collection. These comparisons are for snow depth as well as density. For the latter, a new technique was introduced to quickly measure snow density with the aim of increasing efficiency of GPR surveys.

Comparison is made between the results of this study and other investigations of precipitation distribution in the study catchments. West of the main divide snow depths are compared with results from a GPR investigation by Jol et al., (2004) at the Davis Snowfield. Crevasse stratigraphy measurements within the Franz Josef Glacier névé from Anderson et al., (2006) and Purdie et al., (2011, a) provide alternative methods for deriving accumulated precipitation distribution at annual, and synoptic scales (Purdie, et al., 2011b). East of the Main Divide in the Pukaki catchment comparison is made with the findings from Kerr (2009b) for the 2009 accumulation season (Kerr, 2010), these data are calculated for Annette Plateau and Jollie River valley. At the cross mountain scale, independent assessment of cross mountain precipitation distribution is made utilising results from Stuart (2011). 


\subsection{Snow depth measurement in deep snow packs}

\subsubsection{Davis Snowfield}

Measurements of winter time snow depths at Franz Josef glacier are limited in number and scope. The lack of snow depth data is attributed to the availability of techniques to reliably sample snow depths of $9<10 \mathrm{~m}$ (Jol, et al., 2004). The GPR measurements will offer useful comparison to the accuracy of the snow depth measurements used in this study upon the verification of the accuracy of the models used to calculate the ablation and accumulation portions of the calculated total snow pack.

The only directly comparable winter time snow depth measurements (Jol et al., 2004) reinforces the snow depth estimates derived from this study. In the investigation into the drainage patterns of snow a spatially limited $20 \mathrm{~m}$ x $12.5 \mathrm{~m}$ grid survey was made, and calibrated with a CMP (Common Mid-Point) survey. The comparison is useful to support the snow density extrapolation, and wave speed calculations employed in this study suggesting realistic depth measurements. Minor variations in wave speed and consequently estimates of snow depth are however expected given the different year (Fitzharris, 2004), although both 2004 and 2009 were El Nino. The calibration method, and location of the radar survey are not the same between Jol et al., (2004) and this survey, the radio wave speeds $(200 \mathrm{~m} / \mathrm{ns})$ and snow depths $(100+/-10 \mathrm{~ns})$ are similar to that experienced in this study (Figure 4.1). Further similarities between this work and Jol et al., (2004) are the identification of storm scale accumulation IRH. The significance of this is in the use of a $450 \mathrm{MHz}$ antennae through which these IRH were resolved. These observations support the application of synoptic classifications to IRH tuned temperature index accumulation modelling. 


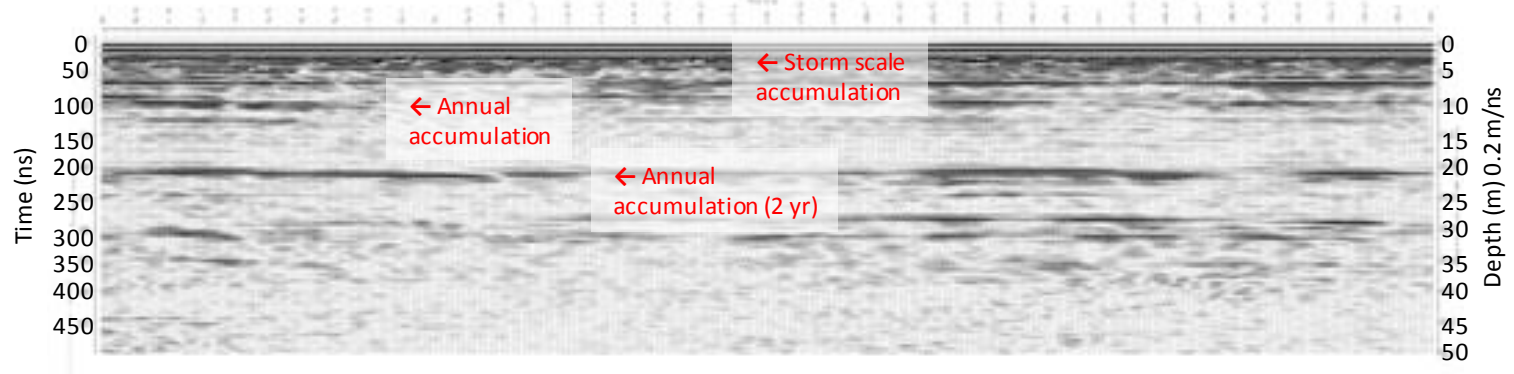

Figure 4.1. Radargram displaying closely spaced horizontal structures $<T=100 \mathrm{~ns}$ from Jol et al (2004). These are believed to be storm scale accumulation events. Annual end of summer IRH are observed at $100 \mathrm{~ns}$ and $200 \mathrm{~ns}$ respectively. This radargram closely resembled observations from the GPR investigations from this thesis.

The net annual snow accumulation derived from measurements of snow stratigraphy within crevasses at the end of the ablation season has been shown to vary $5.4 \mathrm{~m} \mathrm{SWE}$ over a $60 \mathrm{~m}$ elevation range (Anderson, et al., 2006). This variation is close to the accumulated snow that fell during the 2009 accumulation study of this study. The size of the surveyed snow courses at Davis snowfield are expected to encompass the expected snow depth variation across a slope on flat (Lapen \& Martz, 1996) and mountainous terrain (Erxleben et al., 2002; Marchand \& Killingtveit, 2005). The measured winter time snow variation measured at the snow courses in this study was 1.3 to $2 \mathrm{~m}$ SWE (Table 3.2.1). Variations in snow depth appear to be due to the influence of topography (Figure 3.2.1). The study snow courses were chosen for the proximity to crevasse stratigraphy measurement sites (Anderson, et al., 2006; Purdie, et al., 2011a). Snow depth variation with terrain during snow deposition is well recorded (Dadic, et al., 2010b; Dunse, et al., 2008; Elder, et al., 1991; Erxleben, et al., 2002). The increase in variability between snow depth measurements over summer suggests enhanced ablation and preferential snow melt over summer as a major influence on snow accumulation values (Purdie, et al., 2011a). In deep snow packs GPR proves to be a useful tool in reducing the uncertainty around accumulated precipitation depths by accurately measuring deep snow packs at the time of deposition. 


\subsubsection{Annette Plateau}

Although there are no historical measurements of precipitation volumes at Annette Plateau the combined results of the three surveys throughout the accumulation season enable the snow accumulation to be traced and a reliable measurement of seasonal accumulation to be made. Calculation of SWE from measured and linearly modelled snow densities accurately represent snow densities to the depths found in this snow pack (Figure 3.1.5).

The temporal frequency of snow surveying has been found to improve estimations of SWE over time, and consequently alter the amount of SWE calculated accumulation at the synoptic temporal resolution. The two cumulative accumulation traces generated for Annette Plateau (Figure 4.2) from this study show a deviation in estimated accumulated precipitation of around $300 \mathrm{~mm}$ SWE by 16 June 2009. The difference in volume was resolved at the mid season visit to Annette Plateau by snow pit calibration and GPR assessment. The discrepancy of SWE estimation at a seasonal scale is not significant, being within the range of accuracy when using GPR for the total snow pack estimation. When modelling the snowpack accumulation such a discrepancy will however, alter the accumulation factor when calculated for synoptic timescale accumulation sequences.

Improvements have been made in the calculation of SWE at shorter synoptic time scales. An example of this improvement is observed at Annette Plateau around the $9^{\text {th }}$ and $15^{\text {th }}$ of August. This period of blocking to zonal to blocking transition (HSE $\rightarrow \mathrm{H} \rightarrow \mathrm{HSE}$ ) (Figure 3.2.7) has $<20 \%$ likelihood of initiating the predominantly east to north east flow, and a > $60 \%$ likelihood of continuing back to HSE from $\mathrm{H}$. The precipitation associated with this event is associated with a strong eastern bias with a likely sheltering of the AWS in the lee of the prevailing easterly flow. Such a pattern is reinforced by the accumulation factor, $(a / f$ $=3.8 \mathrm{Mt}$ Cook AWS). This increase in site specific information is not otherwise available without the addition of a higher density alpine climate monitoring network, and may serve to calibrate alpine areas with no previous investigations to better calculate precipitation surfaces and climate trends.

The consequence of uncalibrated estimations of precipitation distribution is obvious when comparing the 2009 seasonal precipitation for Annette Plateau and Mount Cook (Figure 4.2). There is a considerable difference in the calculated SWE values of this study and the uncalibrated estimates for Annette Plateau (Kerr, 2010). Such discrepancies are important to 
remove from area wide precipitation models as the results may lead to considerable inaccuracies in the timing and volume of flood flow discharges from alpine basins or inaccurate glacier mass balance modelling.

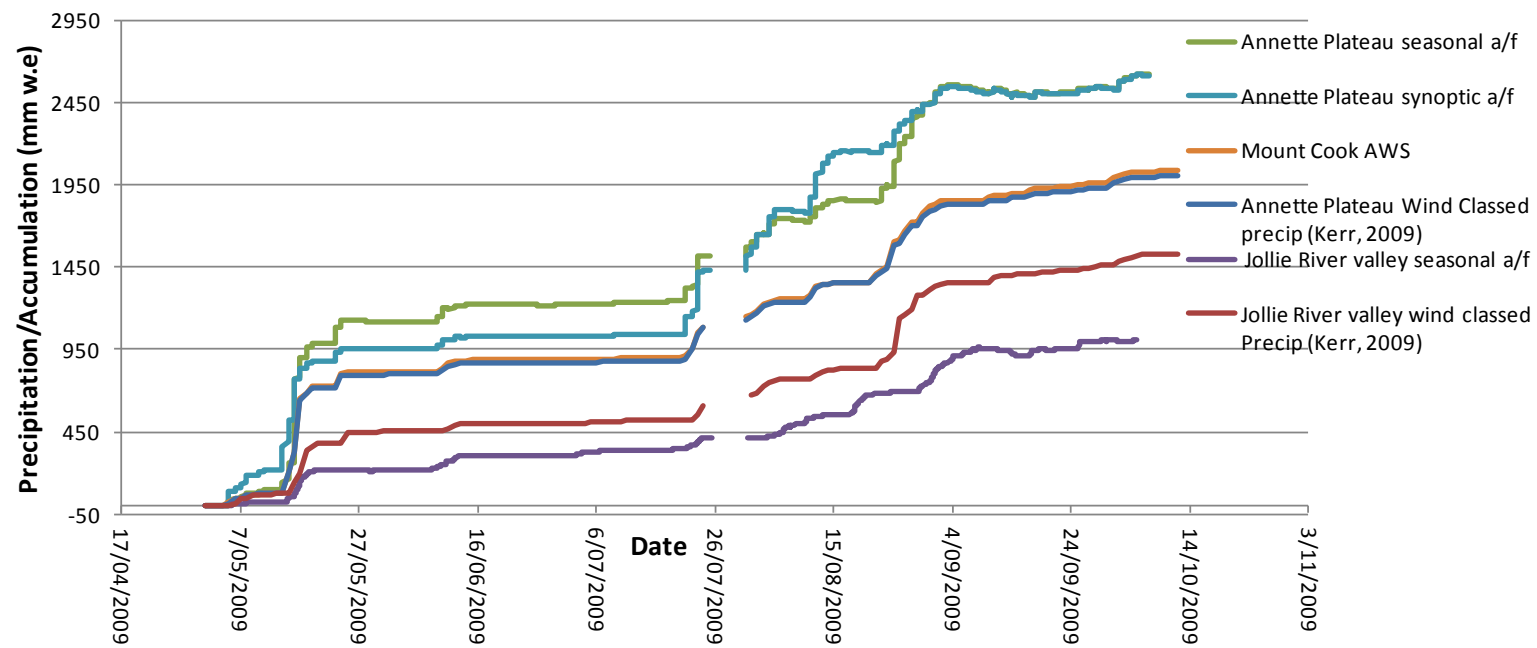

Figure 4.2. A comparison of wind classed cumulative precipitation (Kerr, 2010) for the study regions east of the Southern Alps, and the cumulative snow accumulation as defined by both seasonal and, where appropriate, synoptic accumulation factors. Considerable underestimation of site specific accumulation was made for Annette Plateau (Kerr 2010). Although a similar sized variation in estimates is seen at Jollie River valley.

\subsection{Snow depth measurements in complex terrain}

The precipitation estimates based on long term precipitation record (Kerr, 2009b) and the results derived from the GPR survey in complex terrain (Figure 4.2) do not compare well. The Jollie River valley has an associated rainfall record of over 30 years in length. The correction for rain gauge undercatch and likelihood of precipitation in relation to wind direction is believed to add to the accuracy of these data (Kerr, 2009b; Kerr 2010). Although the data sources are not at exactly the same location the distance between the location of the former Jollie River valley rain gauge and GPR survey site are not large enough to justify the $30 \%$ increase in precipitation. Possible explanations for these discrepancies by the measured snow fall data are; 1) the assumption of no through-flow of liquid precipitation or ablation within the snowpack is not correct. This is a feasible explanation for snow pack loss at the beginning of and end of the accumulation season where freezing levels are known to fluctuate; 2) combining the surveyed elevation snow depth data to create an average slope value is not an appropriate method to estimate site precipitation. The spatial extent of the GPR survey is large enough to encompass variation from all terrain influences on snow 
distribution. Bias in the measurement may be installed by the effects of through flow at lower elevations in the surveyed area.

At sub-seasonal time scales, the calculation of site specific precipitation values from an AWS some distance away from the location of interest is likely to be the major cause for discrepancy between measured (this study), and the modelled (Kerr, 2010) precipitation traces. The error introduced in precipitation estimations by using a precipitation record for a location some distance from the study location has been observed to produce discrepancies in the timing and rate of precipitation on top of the cumulative incremental seasonal time scale differences in measured and modelled precipitation. The shorter time scale variation is observed between (15/8/2009 - 4/9/2009) (Purdie et al., 2011b). These are due to differences in climatic state between the study location and the AWS location, which are corrected for in the comparative data set (Kerr, 2010).

If IRH were present within the Jollie River valley snow pack then the error associated with applying a seasonal accumulation factor to an AWS precipitation record of some distance away could be reduced. This type of error is also observed with similar effect at Annette Plateau as influenced by terrain and synoptic direction.

\subsection{Comparison of results from different techniques}

Killingvet et al., (1998) concluded that radar data was equally as reliable and sometimes more reliable than hand probed data. Considerably stronger correlations have been made between the two data collection techniques on other studies than what was found in this study for probed snow depths and ground-based GPR, i.e. 0.7 to 0.98,(Killingtveit \& Sand, 1998); 0.75 to 0.9 (Sand \& Bruland, 1998); and 0.97, (Bruland et al., 2001). The findings of this thesis found no significant correlation between this probed snow depths and groundbased GPR. The lack of relationship between the methodologies is expected to be a result of the high spatial resolution of the GPR comparing with the low resolution of the probed snow data averaged for the area of the comparative grid square. In contrast to ground-based GPR, the correlations between measurement methods of the above studies compare with the quality of the of the airborne / probed data comparison from this study (Figure 3.1.11).

The improvement of correlation between GPR data and probed calibrations is expected to be an artefact of spatial aliasing of data through increased foot print size of the radar during 
airborne surveys (Arcone, 2002). The increased foot print size and reduced signal to noise (SNR) ratio from environmental interference using airborne techniques translates to reduced vertical resolution of GPR data (Marshall, et al., 2008). Increased foot print size can also result in the inclusion of a wider range of terrain than ground-based GPR measurements. This horizontal smoothing of GPR data resulted in altered average snow depths due both the inclusion of more and overall smoothing of topography resulting in the reduced variation of snow depths in airborne surveys (Figure 3.1.8 and Figure 3.1.11) (Marchand, et al., 2003). Collecting airborne data therefore removes much of the small scale terrain features that can skew the average snow depth values for each grid cell. The small scale terrain is expected to create much of the variation between average snow depth for each grid cell using the high sampling frequencies of ground-based GPR, and the grid cell snow depth values derived by the relatively few probed measurements per grid square (Table 3.1.4).

An explanation of the systematic offset of snow depth measurements between ground-based and airborne GPR (Figure 3.1.6 and Figure 3.1.11) may be the viewing angle of the radar antennae (Marshall, et al., 2008). In airborne measurements the viewing angle of the radar antennae is assumed to be vertical, with no interference from the spherical spreading of electromagnetic (EM) energy. Probed snow depth measurements were also taken on a vertical plane. The vertical plane is in contrast to the ground based GPR. Skied traverses of the terrain are parallel with terrain isolines with the antennae emitting EM energy normal to the slope surface creating a shorter distance to the reflecting surface than that of a vertical EM energy path.

Small correlation coefficients between ground-based and airborne GPR collection techniques at the Jollie River valley and the statistically significant correlations between techniques at Annette Plateau indicate the influence of terrain roughness on comparison of snow depth measurements. Large sampled grid populations available for comparison reinforce a false representation of no real relationship between measurement techniques. The poor relationship between measurement techniques is countered at Annette Plateau where strong correlations between airborne and ground-based data are observed. In a comparison between ground-based and airborne data by Marchand et al., (2003) the coefficient of variation for airborne data is consistently less than that found in ground based surveys in the forest, with a more pronounced reduction in the open field environments. Such a finding reinforces the effect of accumulation surface type on snow depth variation, 
therefore supporting the necessity for accurate snow depth measurements of high sampling frequency when surveying small spatial areas.

The extrapolation of snow depth measurements of variable sampling frequency and spatial positioning to one average value for the grid area incorporates the influence of terrain variability on average snow depth varies with area. The area that sampling frequency and terrain variability influence is defined arbitrarily by the size of grid applied to the study region. A grid size of $20 \mathrm{~m}$ appears to provide the correct boundary of area for comparison of probed and airborne GPR methods with the scale of terrain complexity at the Jollie River valley (Figure 3.1.6 d) (Erxleben, et al., 2002).

At both the $10 \times 10 \mathrm{~m}$ and $20 \times 20 \mathrm{~m}$ grid scales ground based GPR were $24 \%$ to $25 \%$ (y = 0.7515; $y=0.7596 x$ ) less than that at airborne measurements on the steeply sloping Jollie River valley, an almost identical value to the difference between probed and ground-based GPR measurements $(\mathrm{y}=1.2478 ; \mathrm{y}=1.2396 \mathrm{x})$, although the correlation coefficient for probed and ground based GPR suggests the relationship is not significant (Figure 3.1.11). This comparison is important as it reinforces the effect that the viewing angle of the antennae when comparing snow depth data sets, and the spatial resolution of different GPR techniques in complex terrain. On the much more gently sloping Annette Plateau, groundbased snow depth measurements are around 7\% less than airborne measurements. Further investigation needs address the significance of slope angle on snow depth measurements. In particular, it would be useful to know the slope angle at which slope angle becomes more dominant than the inaccuracies of snow density measurement, static correction, and snow depth digitization of GPR data (Figure 3.1.5). Airborne GPR data has been observed to return shallower values of SWE than probed or ground-based measurements (Sorteberg, 2009; Ulriksen 1989). The comparison of Marchand et al., (2003) also yielded a reduction in snow depth from the airborne system in surveys of both forested and non forested terrain types. Other studies have found very similar snow depth estimates from each method (Negi et al., 2008) on flat, regular terrain with snow pack depth similar to that at the Jollie River valley . The results of this thesis suggest that interactions between slope angle and GPR viewing angle are greater than the effect of the variation of surface roughness.

Whether probed, ground-based GPR, or airborne GPR are used to measure snow depth, all are capable of collecting accurate snow depth data. For comparison of these data it is paramount to have very accurate spatial positioning data to enable accurate comparison of 
values from each collection technique. Given that all data are accurate with variations arising from viewing angle and terrain complexity, it is up to the user of the data to decide the most appropriate method of data collection, and possible extrapolation of that data across an area.

Discrepancies between measurements may be influenced by factors other than GPS positioning. Error introduced by multiple operators and processing programs, and differing methodology of SWE calculation have been observed to increase measurement variability. SWE for this study was calculated in the same way for both GPR techniques, and probed data, using the same depth dependant density relationship (Lundberg \& Bergstrom, 2000). The use of one radar operator and processor reduces the effects of the errors experienced with GPR data collection (Marchand, et al., 2003). In this study probed snow depths were made by multiple operators at various experience levels. Minimal training is required to obtain probed depth measurements. Inevitably some unknown random error will be incorporated into the results.

\subsection{Improvements in snow density calculation}

During data collection it has been possible to develop a technique to enhance the speed snow density data collection. The MARTYR technique was compared with manual measurements of snow density taken from an immediately adjacent snow pit (Figure 2.3)

Deriving bulk snow density values through the calculated and measured addition to the snow pack of a metallic reflector to the snowpack is not a new phenomenon. A system for identification of snow pack layers was used in 1982 while developing a snow radar system although no results were published (Fujino et al., 1986). The concept was visited again (Marshall et al., 2005) with the application of flat metal plate reflectors precisely at IRH within the snowpack. Both previous techniques required snow pits to be dug so as that the metal reflectors could be inserted horizontally into the snowpack. The advantage of the technique of (Marshall, et al., 2005) is that changes in snow density could be observed rather than measured directly. For snow accumulation estimates which would represent snow depth up to the survey date a continuous angled reflector, similar to that tested in this thesis would prove sufficient, and with multiple measurements on the horizontal plane a snow density profile could be constructed. 
The major source of error in the MARTYR method is the distance of the antenna from the origin of the snow probe at the snow surface to the along the snow surface. The picking (digitisation of IRH depth from radargrams) error can be accounted for, and it is possible to install a procedural consistency by maintaining a digitization protocol. The angle of the probe is able to be reasonably accurately measured to within a few centimetres, which is unlikely to have much quantitative effect when calculating the reflector positioning. Yet at shallow depths, placement of the antennae on the ground from the origin can have a dramatic effect on the density value from the MARTYR technique. The $66 \mathrm{~kg} \mathrm{~m}^{-3}$ outlier value (Figure 3.1.3) was obtained at a point $30 \mathrm{~cm}$ from the origin of the probe the surface. If the distance from the probe origin was $24.5 \mathrm{~cm}$ from origin then the resultant density would be $372 \mathrm{~kg} \mathrm{~m}^{-3}$ or a $561 \%$ increase in density. The effect of measurement error is considerably less if the same under measurement of radar from distance from origin is made at $180 \mathrm{~cm}$, the difference between the $180 \mathrm{~cm}$ value and the $175 \mathrm{~cm}$ value being $10 \%$.

Verification measurements of the angled steel reflector allows multiple point samples from which to calculate the reflector geometry within the snow pack, and therefore the assigning of a depth / distance relationship to provide the basis for density calculations from the probe reflector. Measurements of the probe reveal that there was some deviation from a linear probe trajectory, as might be expected from a relatively thin steel rod inserted at an angle. Such deviation is created by deflection from internal snow pack layering and user inaccuracies. To account for this a two point polynomial relationship to represent the probe shape within the snow pack (Figure 3.1.8). A linear probe reflector angle relationship was also used for comparison.

The polynomial relationship applied to the snow probe trajectory produced the most accurate SWE estimate (Figure 4.3). At shallower reflector depths of up to $83 \mathrm{~cm}(280 \mathrm{~mm}$ SWE) there was a large variation of density around those manually measured values of between $23 \%$ and $132 \%$. This error is largely apportioned to reflection digitization error, especially in the case of the shallower reflection $<30 \mathrm{~cm}$ depth as this reflection was difficult to separate from the first return ground and air wave saturation. Variation around the measured value by radar calculation is $+/-22 \%$ before settling to a deviation of up to $3 \%$ from the measured values. The results of this method at depth greater than $7 \mathrm{~ns}$ fall within the error of the depth dependant density methodology provided by Lundberg et al., (2000). 
The use of a linear probe trajectory produced more variation between modelled and measured snow density (Figure 4.3). The variation in shallow depth snow densities is not reduced using a linear probe trajectory. The relationship falls to within $7 \%$ of the measured SWE at the third sounding and replicating the measured SWE exactly at the fourth. From this point there is a deteriorating trend away from the measured values to one of underestimating SWE by up to $10 \%$. The errors experienced while employing the MARTYR density assessment compare favourably with other metallic reflector based surveys such as Marshall et al., (2005), from which error of up to $10.9 \%$ using reflector depth to calculate SWE and as little as $2 \%$ using the methodology of Lundberg et al., (2000) and are within the bounds of error associated with manual snow density measurement.

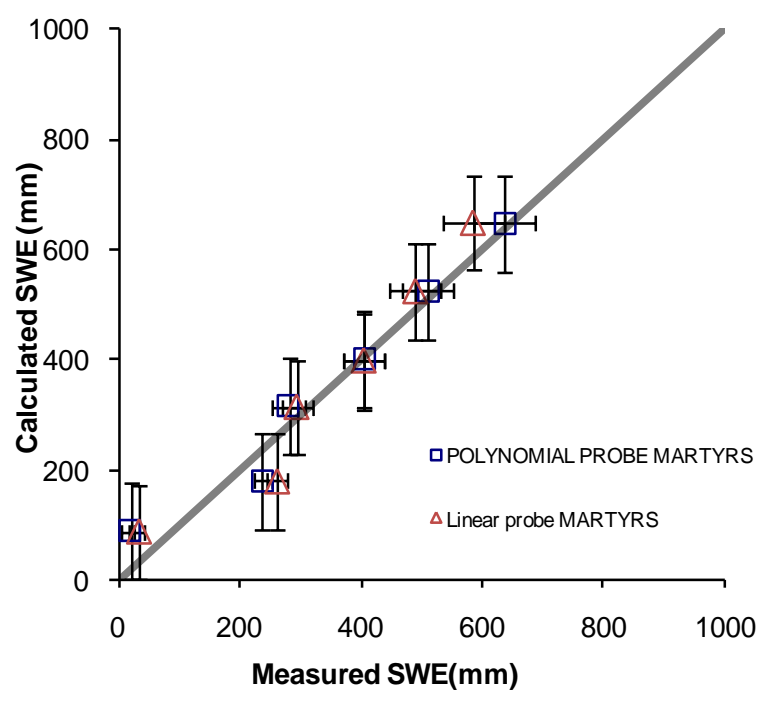

Figure 4.3. Comparison of measured snow density and MARTYR calculated snow density using both a $2^{\text {nd }}$ order polynomial probe trajectory projection, and a linear probe trajectory. The solid black line represents an ideal relationship between the two methods. Less deviation from the ideal is found using the polynomial probe trajectory to infer probe location within the snow pack.

The results and error estimates from this technique provide some confidence that the MARTYR technique can accurately calculate SWE in a quick and relatively non-invasive manner, allowing snow density to be calculated repetitively and quickly. The depths to which these measurements are made are relatively shallow in the context of New Zealand's alpine snowpacks, and this study with manually measured snow densities from snow pits. Consequently effort was made to project the MARTYR technique down to the depth of the snow pit and assess the projected relationship. 


\subsection{Defining the SWE/TWTT relationship}

Accumulation volumes are determined by the location of the IRH, these are identified in the radargram through the change in relative dielectric permittivity. All of the survey sites are subjected to wind exposure and therefore redistribution of snow. Baroclinicity is often a prerequisite to precipitation and spillover and accompanying winds can precede and continue throughout the storm cycle. Such climatic conditions have been observed to both deflate and inflate local snow depths (Dadic, et al., 2010a), although these processes are suggested to be limited to recent snowfalls (Purdie et al., 2011b)

The difficulty of determining the date of IRH is compounded by processes of melt percolation being absorbed into the snow pack. Melt water may refreeze in capillaries within the snow pack resulting in internal accumulation (Reimer \& Hock, 2008). The assumption of IRH representing periods of accumulation is implicit in defining synoptic accumulation signatures within the snow pack. Interspersing periods of precipitation and redistribution are periods where the exposed surface layer of the snow pack undergoes densification from radiative and turbulent heat exchanges (Alean, Haeberli and Schadler, 1983). Such exchanges result in densification of the upper layers of the snow pack through surface and subsurface melting (Koh and Jordan, 1995) and moisture vapour transfer within the snow pack as a consequence of snow pack temperature gradients. The redistribution of water is not possible to quantify using GPR (Woodward and Burke, 2007). This study assumes melt water redistribution refreezes within the snow pack and is therefore accounted for in the snow density measurements. The assumption of through flow of melting is also expected to be negligible due to temperatures below freezing point at study sites limiting the water available for through-flow.

The process of ice crust formation and IRH has been observed to be dependent on slope aspect. All study sites in this study are of west to north-west orientation. The complex terrain of the Jollie River valley, especially in early season before smoothing of terrain by infilling of terrain features by snow may alter the extent of the surface ice crust formation and subsequently the complex patterns of snow redistribution prevail in steep complex terrain. Both Annette Plateau and the Davis Snowfield contain relatively planar initial accumulation surfaces, with some crevassing at the Davis Snowfield. At both of these sites there were widespread near surface ice layers observed throughout the snow pack. Examples of these ice crusts can be seen at the Davis snowfield and Annette Plateau (Figure 4.4). 
Resting on this layer was a distribution of newly accumulated snow with some wind scouring down to the ice layer

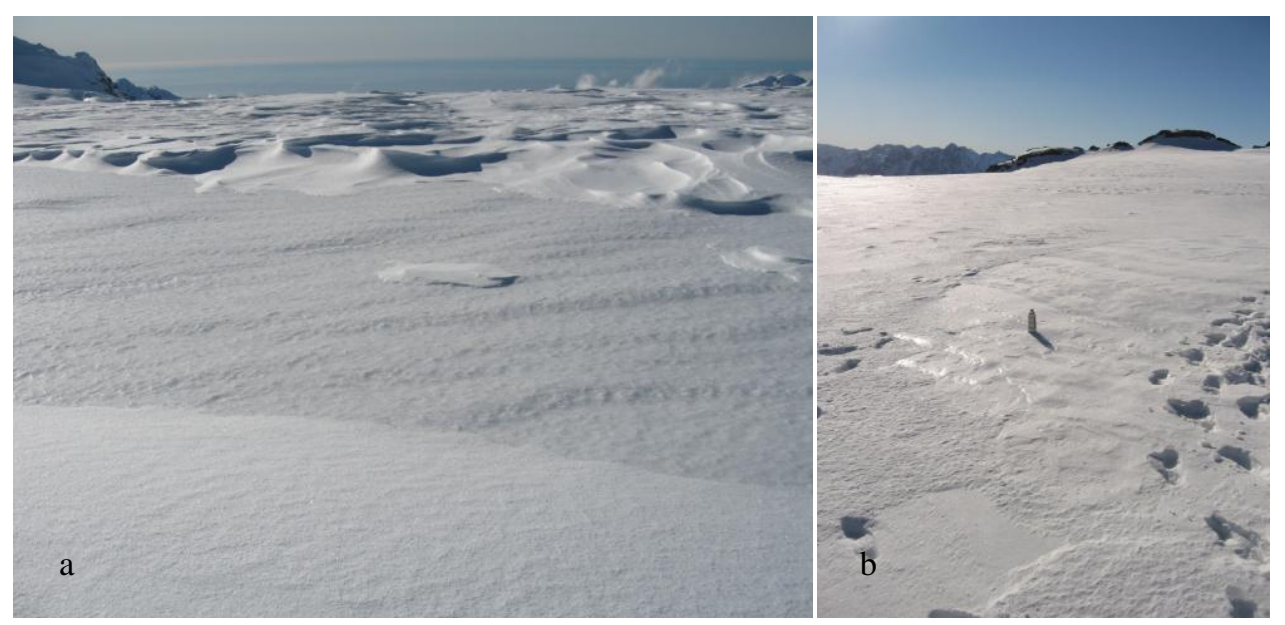

Figure 4.4. Davis Snowfield (a), Annette Plateau (b); ice crust formation with subsequently deposited snow and aeolian redistribution down to ice crust. A cheese grater is provided for scale in the mid-ground at Annette Plateau.

Ice layers within the snowpack, whilst not necessarily visible at the resolution of the radar, are taken to be indicative of a change in density and represent a defined boundary between accumulation cycles. Within the boundary of these accumulation cycles there may be cycles of accumulation with no spatially distinct IRH to infer a temporal boundary. It is concievable that these accumulation layers are therefore accounted for within deliniations of accumulation for subsequent time periods. The assigning of snow mass in this way provides scope for error in volume estimation, however it is very speculative to attempt to quantify the mass represented by this error. Consequently the error induced by surface roughness (Figure 4.4) is assumed to be accounted for by the error in picking and digitizing the accumulation layers and by the volume of error assigned to snow density quantification.

Despite the uncertainties with this method, the observed relationships of deposition volumes, accumulation factors, synoptic type and spillover characteristics are in comparable to manual observations (Purdie, et al., 2011b). The measured accumulation volumes therefore are the composite of visible density changes of the snow pack within the radargram. This methodology reinforces the notion of precipitation accumulation rather than a direct precipitation measurement.

The picking of total snow pack depth is dependent on the identification of the snow pack base through the change in relative dielectric constant within the survey profile (Berthling and Melvold, 2008). At the study sites such dielectric constant variations included snow and 
rock (Jollie River Valley) snow and ice (Annette Plateau) and snow and firn (Davis Snowfield). The multiple calibration methods and strong dielectric contrast between seasonal snow volumes and the talus surface on which snow accumulates provides strong evidence to support the GPR based snow depth measurements. Annette Plateau had complete loss of all seasonal snow by April 1 2009. At the beginning of May that year around $40 \mathrm{~cm}$ of new snow had accumulated, the subsequent two GPR surveys at Annette Plateau allowed the development of snow pack to be monitored, this provides some confidence in the digitization of snow depth for the end of season survey in conjunction with a spatially consistent and obvious deflection in the radar trace amplitude. Calibration of the Davis Snowfield site incorporated more subjectivity than the other two sites. The firn snow transition was less obvious and at times punctuated by crevasses, although a similar spatially contiguous deflection of returned electromagnetic signal to that of Annette Plateau was observed. Supporting evidence for the snow depths obtained for the Davis Snowfield providing a comparison of deflection similarity from the previous GPR survey the Davis Snowfield (Jol et al., 2004), and the synoptic signature of the snowpack comparing well with the Franz Josef AWS data, and with the derived accumulation factors from the more intensively monitored Annette Plateau.

\subsection{Using Snow accumulation estimates to estimate long term precipitation}

Extrapolation of seasonal precipitation data in order to represent annual volumes is likely to produce error in the annual estimate. Techniques to measure precipitation throughout the seasons often do not vary to best meet precipitation state. High altitude multi parameter meteorological sites incorporate do incorporate snow depth and weight of snow pack i.e. Rose Ridge climate station, these are of limited spatial distribution. Most studies of high altitude precipitation in the study region have relied on liquid precipitation measurements, or on collecting and melting snow within a storage rain gauge (Griffiths \& McSaveney, 1983; Kerr, 2009a; Stuart, 2011). Inclusion of data from seasonal precipitation measurements such, as the $1700 \mathrm{~m}$ a.s.l at Almer Hut, may adversely affect annual precipitation estimates.

An example of error in record is provided by the Almer Hut precipitation record. Summer time liquid precipitation measurement extrapolated out to an annual precipitation value was provided for a site of $1700 \mathrm{~m}$ a.s.l elevation in the Franz Josef valley. The rain gauge from 
which the precipitation record is derived is situated on a hut roof top on a ridge perpendicular to the Franz Josef glacier valley. This positioning is likely to cause considerable errors in liquid precipitation measurements. The rain gauge positioning is not a seasonal issue in itself. The positioning of the rain gauge in this location was necessary to avoid burial by snow in winter, as the winter snow line is less than $1600 \mathrm{~m}$ on the western flanks of the Southern Alps. The annual precipitation figure provided by this rain gauge at Franz Josef glacier do not compare well with the results of this thesis (Figure 1.2 and 4.1), in spite of a similar extrapolation of seasonal data to create annual volumes.

Similar shortfalls of data collection are experienced using GPR methodology, with wind redistribution of snow resulting in snow pack deflation (Jaedicke \& Sandvik, 2002) and the assumption of no through flow of melt water in the snow pack (Pfeffer \& Humphrey, 1998). This study attempted to minimise the adverse effects of small point measurements by utilising $100 \times 100 \mathrm{~m}$ grids as the smallest area surveyed, a size which incorporates all of the variation that occurs within the snow pack at a larger scale given similar elevation and topography (Clark et al., 2011). By doing this the GPR derived measurements minimise error introduced by under or over exposure wind, the effect of the latter is expected to be somewhat moderated by process of snow metamorphosis. The GPR based estimations also include liquid precipitation accumulation through the snow density measurements. Consideration of these factors in this study's methodology affirm the ability of GPR to provide precipitation measurement as reliable as liquid precipitation measurements, in a similar way to near real time manual measurements of winter time precipitation (Purdie et al., 2010 a).

\subsection{Trans Alpine Precipitation; location of the precipitation peak}

An objective of this study was to measure snow accumulation along a north-west to southeast orientation in keeping with the orographic flow experienced across the Southern Alps. Previous studies indicate a cross-mountain orographic precipitation distribution with a single peak and a western bias. The results of this study are based on five high elevation assessments of snow depth at locations which provide new data points, enabling further discussion on the shape and location of the precipitation distribution and location of the peak.

Deriving an inferred liquid precipitation value to represent the depth of snow is not the same as measuring rainfall directly. The accumulation factors calculated to extrapolate low 
altitude precipitation to the study site include the effects of removal of snow mass by wind and sublimation. The effects of each of these processes are not specifically quantified, but the sum of the effects forms the snow depth values for which the accumulation factors are included in the values of snow depth for each study site. Such processes are analogous to the effect of under or over catch at a rain gauge measuring liquid precipitation at a lowland rain gauge

"Precipitation measurements are the hooks on which precipitation estimates are hung" (Kerr, 2009b). Many such estimates incorporate a spline interpolation between measurements in an effort to best estimate the distribution of precipitation. The spline based representation of precipitation distributions in this study incorporate points selected to best represent a smooth curve across the Southern Alps whilst specifically including results from the GPR investigation (Figure 4.5).

The results of this study reinforce the model of a single precipitation peak (Griffiths and McSaveny, 1983; Henderson and Thompson, 1999; Anderson et al., 2006). The curve produced with measurements from this study (Figure 4.5) are of close resemblance to the most recent interpretation of cross mountain precipitation distribution (Stuart, 2010), who used data from several hundred precipitation gauges, including the Jollie valley in the South Island extrapolated over a 5km grid area. Comparing Stuart (2010) with the results of this study supports the GPR derived SWE values at sites with long historical data sets, such as the Jollie River valley. The compared results are within the range of error associated with the 30 year norm from GPR assessment. This shows that although the GPR results differ from that of Kerr (2009a) (Figure 4.2), the GPR data is comparable with other measurements of precipitation within the region.

The lack of measurements of snow accumulation, in lieu of precipitation measurements, for precipitation distribution modelling verification is apparent at the Davis Snowfield. The long term record distribution spline (Stuart, 2010) underestimates precipitation depth at the orographic precipitation peak by approximately $1 \mathrm{~m}$ SWE. The estimates from the distribution curve of Stuart, (2010), fall within the range of error associated with GPR derived snow depth estimation (Figure 4.5). However, as with Annette Plateau and the Jollie River valley (Kerr, 2010), winter time precipitation estimations are in need of calibration for areas with no history of accurate precipitation records, or to further examine the effect of snow fall and rain gauge record (Figure 4.2). 


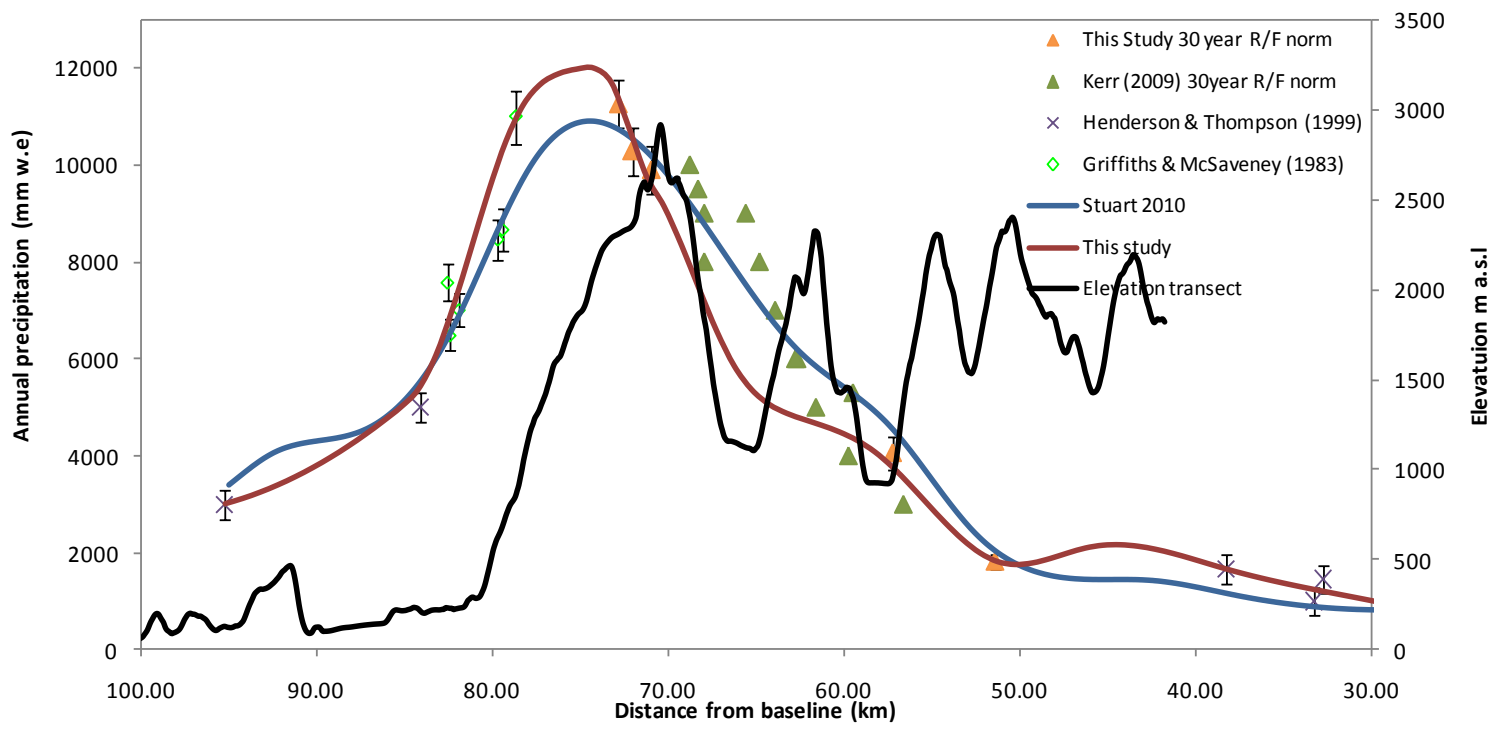

Figure 4.5. Spline interpolations from this study, with comparison estimation provided by Stewart (2010). The elevation scale on the secondary y axis refers to the black elevation transect line. The transect line represents a $100 m$ wide swath up the centre line of the Waiho valley up the Franz Josef Glacier and Southern Alps terminating at an arbitrary base line (Henderson and Thompson, 1999). Where possible error estimations are included for actual measurements of precipitation.

\subsubsection{Comparison with the precipitation measurements west of the divide}

No single relationship between snow accumulation and elevation could be defined by the results of this study. The locations of measurement sites have an influence on the precipitation estimates due to effects of local topography and climate. Processes controlling these relationships change at various scales, altitudes, and position in relation to the orographic divide (Nogues -Bravo and Lopez -Moreno, 2005; Zangl, 2005; Machguth et al., 2006; Purdie, 2010 a, and b). From the data collected, both a negative (Davis Snowfield) and weak positive (Jollie River valley) relationship of precipitation with altitude were observed. The process operating at each location to control this pattern of distribution is different for each location. The Davis Snowfield calculated air temperatures are negative almost all winter resulting in very little ablation. A similar pattern of snow distribution was described at Findler Glacier, Switzerland (Machguth et al, 2006). A clear positive trend of accumulation and altitude gave way to a slight negative trend with much variation attributed to snow redistribution. This redistribution could explain the broad precipitation peak in comparison to other studies (Anderson et al., 2006). The depth of precipitation is not known at a seasonal scale immediately east of the divide, although equal volumes for a short time period were recorded to reveal equal snow depths either side of the divide (Purdie, et al., 
2011b). The investigation of synoptic accumulation volumes from this study shows that given the right climatic influences, and the right frequency of occurrence of the correct synoptic weather type (T) (Figure 1.6) a short term may experience accumulation patterns that don't represent the larger precipitation patterns (Tables 3.2.8 and 3.2.9).

When considering snow accumulation processes it is also important to evaluate the extent to which snow pack deflation may occur by turbulent heat fluxes, especially in a maritime climate (Willis et al., 2002). The Davis Snowfield is the most exposed snowfield of the Franz Josef Glacier névé (Purdie, 2010 b). As a consequence the Davis Snowfield is likely to be subject to greater turbulent heat fluxes than more sheltered regions (Reba et al.; 1999). The exposure of a slope to turbulent heat fluxes, slope orientation to that of greatest insolation, and wind, have been observed to maintain higher snow depths than nearby less exposed areas (Alean et al., 1984). The increased exposure is believed to promote the formation of protective surface ice lenses, armouring the snowpack from wind erosion down to the depth of the ice lens. This process has previously been postulated as a reason for the positive temperature / elevation gradient at the annual time scale (Purdie et al, $2010 \mathrm{~b}$ ). The results of this study suggest a similar process operates at shorter time scales at both the Franz Josef Glacier and Annette Plateau.

Redistribution of snow has been found to be an influential factor in governing accumulation of snow (Liston and Sturm 1998; Jaedicke and Sandvike 2002, Dadic 2010), and at altitudes where little melt occurs (Machguth et al., 2006). Machguth et al. (2006) finds that in some instances there is in no clear relationship of precipitation distribution and altitude. The snow pack armouring is expected to be a good control of the amount of snow available for redistribution, limiting most distribution process to the time scale of the deposition event (Alean et al., 1984). The extent of redistribution is expected to be captured within the grid measurements of snow depth at Davis Snowfield as measurements of $100 \mathrm{~m}^{2}$ incorporate all of the snow depth variability of the larger local area scale (Clark et al., 2011).

Davis Snowfield is located at $2450 \mathrm{~m}$ a.s.l, in the middle of a col, very close to the main divide. In this type of topographic location, compression of the wind field through topographic constriction would offer the greatest potential for snow redistribution and removal, however differences between the mean snow depth of the other two Davis Snowfield sites is within the range of snow depth experienced at the $2450 \mathrm{~m}$ a.s.l. location 
(Table 3.2.1). This suggests that redistribution of snow is experienced above threshold wind induced snow distribution wind velocities at all sites, with precipitation volumes limited by snow pack armouring from surface snow metamorphosis (Alean et al., 1984).

Variation in seasonal stationarity is expected to influence the precipitation accumulation / elevation relationship. This study suggests that prior net mass balance estimates made by crevasse stratigraphy measurements at the end of the ablation season, which suggest a positive relationship of accumulation with altitude (Purdie et al, 2011 a). The described relationship reverses in winter becoming the reducing snow depth with altitude relationship found in this study at altitudes above $2000 \mathrm{~m}$ a.s.l. This distribution is not thought to be the result of continued accumulation during summer at altitudes above $2000 \mathrm{~m}$, rather an increased effect of ablation at lower altitudes. The location of the summer precipitation peak is still unclear. Speculatively, it could be suggested that the dramatic difference in between winter and net annual accumulation at $2000 \mathrm{~m}$ a.s.l. compared with the less dramatic intraseasonal accumulation changes at $2450 \mathrm{~m}$ a.s.l. is the result of enhanced ablation due to liquid precipitation during summer at elevations at and above $2000 \mathrm{~m}$ a.s.l.

\subsubsection{Comparison with precipitation measurements to the east of the divide}

IRH were observed on a large scale at Annette Plateau. As with Davis Snowfield, without direct measurements erosional processes can only be inferred. However the presence of a wind scoop separating Annette Plateau from Mount Annette suggests the presence of persistent high wind speeds originating from the west. Increased precipitation rates have been observed directly to the lee of topographic barriers (Dadic et al, 2010). It is expected that this process occurs in the study region; however its effect on Annette Plateau snow depth assessment will be minimal to net negative because of the distance of Annette Plateau from the Main Divide.

East of the divide the Jollie River valley is associated with a greater occurrence of positive temperatures throughout the accumulation season, especially at lower elevations. It is this relationship of temperature and elevation that causes the Jollie River valley to have the positive elevation snow / depth relationship (Archer 1970; Lopez-Moreno and NoguesBravo, 1995; Machguth et al., 2006). The elevation range measured on Annette Plateau revealed a slight negative correlation with elevation. The elevation range was only around 
$50 \mathrm{~m}$, reinforcing that elevation does not play a significant control on snow depth at elevation ranges of less than $200 \mathrm{~m}$ (Clark et al., 2011). This is especially the case when the scale of cross-slope variability of snow depth is large, such as at Jollie River valley.

East of the divide, at the Jollie River catchment, existing precipitation estimates (1.9 $\left.\mathrm{ma}^{-1}\right)$ (Stuart, 2011) are supported by the GPR measured snow depths (1.8 $\mathrm{ma}^{-1}$ ) providing certainty for current estimation techniques. These estimates are higher than other findings for the study period are $<23 \%$ less $(1.5 \mathrm{~m} \mathrm{SWE})$ (Kerr, 2010) than this studies estimates. In areas with no historic data such as Annette Plateau, existing estimates for the study season (2 m SWE) (Kerr, 2010) are not accurate despite the relatively close proximity to a long term precipitation record. The values estimated in this study are preferred for the study season (2.6 m SWE). At an annual time scale this study $\left(4.0 \mathrm{ma}^{-1}+/-500 \mathrm{~mm} \mathrm{SWE}\right)$ compares more favourably with other studies this , Kerr (2009b) $\left(\sim 4.5 \mathrm{ma}^{-1}\right)$, and Stuart (2011) $\left(4.9 \mathrm{ma}^{-1}\right)$.

\subsection{Double precipitation peak scenario}

The theory of a migratory precipitation distribution culminating in two precipitation peaks (Sinclair et al., 1997 Zangl, 2005; Kerr, 2009b) or alternatively, an eastward subsidiary peak (Griffiths and McSaveney, 1983), was not confirmed in previous cross mountain precipitation distribution studies. Similar amounts of precipitation have however been recorded either side of the divide over the course of several weeks within an accumulation season (Purdie et al, 2010b). The results of this study reinforce a single precipitation peak distribution (Figure 4.5), although the number and location of sampling points may not adequately represent the average processes in the region. Alternatively, winter time precipitation processes may not reflect a summer time distribution, and the reduced baroclinicity associated with orographic processes in the summer time (Sturman and Tapper, 1996). 


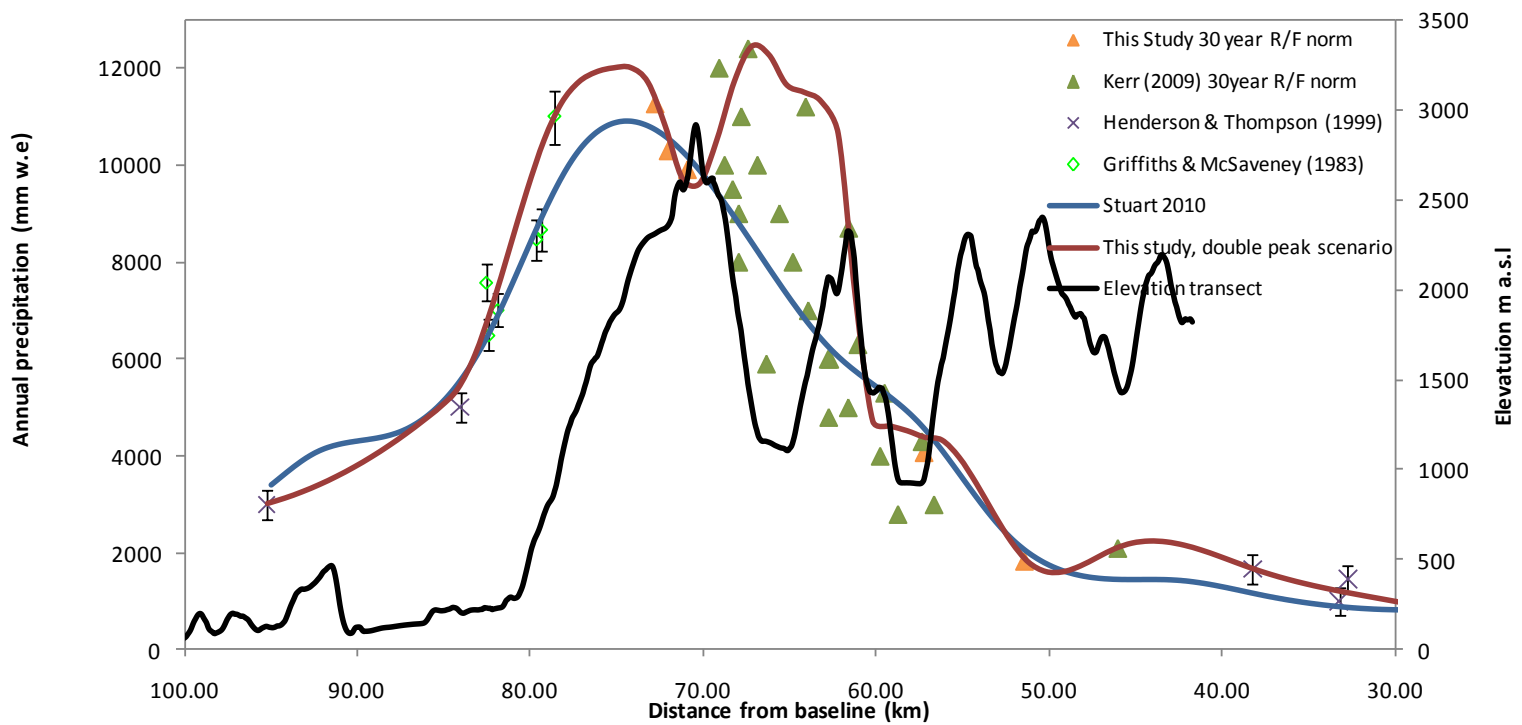

Figure 4.6. Spline interpolationsfor precipitation from Stuart (2010) and this study. Short term precipitation measurements (Kerr 2009b) are also incorporated for comparison. The transect line represents a 100m wide swath up the centre line of the Waiho valley up the Franz Josef Glacier and Southern Alps terminating at an arbitrary base line. It is therefore only indicative of the terrain profile in the transect (Henderson and Thompson, 1999).

An extrapolation of a double precipitation peak is shown in figure 4.6, with another peak on the eastern side of the Southern Alps. More precipitation data points were not included due the subjectivity of extrapolating precipitation from point to point in complex terrain and subjective selection from a terrain surface. The resultant two peak distribution is unlikely given the contrast to other work, and measured winter precipitation. More reasonable configurations of this relationship are possible, and with the magnitude and location of a double precipitation peak being site specific, this study does not rule out the possibility of one occurring.

\subsection{Relationship between synoptic type and accumulation volumes}

There is a proportional variation of site specific SWE values from the lowland AWS precipitation record with each synoptic weather cycle. Topography, orography, positioning and intensity of synoptic type and resulting climate parameters such as temperature and wind speed will all affect the accumulated precipitation value at a specific site for each precipitation event. In order to better model such variation, synoptic scale accumulation factors were calculated for Annette Plateau and Davis Snowfield. 


\subsubsection{Accumulation factors and precipitation volumes}

The relationship between lowland precipitation and high elevation snow accumulation has been quantified by the use of accumulation factors. Periods of the accumulation season were delineated by GPR surveys at Annette Plateau, and for the accumulation period as a whole for all three regional locations. Average accumulation factors varied across the survey periods (Table 3.2.5 and 3.2.6). Measurements of the pre-season, mid-season and end-ofseason GPR surveys calibrated the inferred dates of IRH formation within the snow pack. These calibrated IRH form the basis of the assessment of snow accumulation rates in relation to synoptic weather classifications.

When assessing the statistical descriptors of regional scale snow distribution and accumulation depths, it is important to recognise the factors that contribute to the distribution of snow and how they interact with each other up until the time of measurement. At the hill slope scale, the dominant processes are drifting (Fitzharris, 1977; Winstral, 2002, Jaedicke and Sandvick, 2003) sloughing and avalanching (Elder 1991; Lehning et al., 2008; Dadic, 2010), these are all implicitly accounted for within accumulation factors.

The derived synoptic accumulation factors are applicable to shallow angle snow slopes in Davis Snowfield, and Annette Plateau. The Jollie River valley is the only study site susceptible to redistribution through gravitational mass transport. The effect of this transport has been incorporated into the seasonal accumulation factor calculation through the averaging of all transects snow depth. Mass redistribution of snow and the aforementioned snow pack morphology variations mean that the Jollie River valley is the least suitable of the three regional locations for estimating regional scale precipitation depths and synoptic accumulation factors.

Due to the constraints of the measurement methodology the entire elevation range of the Jollie River valley was not able to be measured. Whilst recognising that gravitational mass transport occurs, it must be assumed that the inputs and outputs of snow volume through mass gravitational transport are in equilibrium at the slope scale, the likelihood of this being the case however, is slim. 


\subsubsection{Variations between synoptic types}

\section{Zonal}

When short-term (between IRH) accumulation factors are calculated, there is a clear pattern with synoptic type, as expected because atmospheric circulation is an important control on accumulation, and hence precipitation patterns.

Accumulation factors for Zonal types HNW and $\mathrm{H}$ are high compared to others observed to the west of the divide. Orographic enhancement of precipitation to the west of the divide means that accumulation rates are much higher at altitude than at the Franz Josef AWS. These patterns of precipitation, without the necessary climatic conditions to induce spillover, are evident for synoptic classifications $\mathrm{HNW}$ and $\mathrm{H}$. The lower accumulation factor for zonal type $\mathrm{W}$ implies that there is less of a precipitation gradient under these conditions. The lack of gradient, and spillover observed in these precipitation conditions indicates that $\mathrm{W}$ type synoptic states are more intense.

Previous research relating synoptic weather systems and precipitation accumulation to derive synoptically related accumulation factors, zonal synoptic types were not associated with high precipitation rates or spillover to the east of the divide. Low precipitation depth observations are due to the short length of study period of (Purdie et al., 2011b). In the first six weeks of the 2009 accumulation season, zonal synoptic classifications were not associated with precipitation events (Table 3.2.7). The intensity of synoptic types has been observed to change throughout the course of a season resulting in net accumulation rather than net deflation of the snowpack (Table 3.2.8). This is attributed to the variation in intensity of synoptic types over the course of the year (Jiang, 2010). In the latter part of the accumulation season (22/8/2009 - 30/8/2009), zonal classifications are associated with high precipitation bearing Trough synoptic type cyclonic circulations (Figure 3.2.11). This research reduces the error that can be made when assuming short term precipitation studies over longer time scales.

Zonal classifications are associated with some of the highest hourly accumulation rates in the west (Table 3.2.9). This may be attributed to lower wind speeds which are generally associated with these conditions (Purdie et al., 2011b) The west and north-west flows associated with W and HNW classifications are comparable to those experienced under the north-west and westerly wind conditions experienced with HE and T synoptic types. 
Observations of seasonal evolution of zonal types are not conclusive due to the infrequent occurrence of this synoptic type during the first six weeks of the study period. The frequency the three synoptic types is near the 30-year average (Kidson 2000, Jiang, 2010) implying that the distribution and timing of zonal conditions were near normal. It is apparent that the west to northerly winds during the early season Annette Plateau survey results in net ablation due to warmer temperatures under föhn conditions (Figure 3.2.7). Negative accumulation rates may be due to the use of an average temperature lapse rate for the accumulation season. Climate data of higher spatial and temporal resolution would be useful in determining lapse rates for specific climate circulations. The paradox of the situation is that climatic conditions at the study site necessitate the approach used in this study due to the difficulties of maintaining climate stations in the study region, even with despite daily maintenance (Purdie et al., 2011b). Consequently climatic conditions are inferred, not measured.

\section{Blocking}

Blocking synoptic regimes are associated with a predominantly easterly flow incorporating strong winds and consequently a deflation of the snow pack on both sides of the divide with often more pronounced deflation depths to the west (Purdie et al., 2011b). Synoptic scale wind direction for blocking weather types are; R, easterly wind; HW, southerly; NE, north east flow; HSE high to the southeast, westerly winds tending to north-east during the blocking transition and wind flow interaction with the Southern Alps west of the divide; HE, high to the east with north-west to north-east wind conditions due to blocking effect of the Southern Alps.

Accumulation rates calculated derived for the synoptic periods were observed up to $42 \mathrm{~mm}$ for a $12 \mathrm{hr}$ period under blocking regimes in this study. Net snow depths from the similar storm conditions showed a net snow depth of $-0.04 \mathrm{~cm}$ (Purdie et al., 2011b). Blocking classifications NE and R are not frequent, and are not associated with precipitation at either low altitude AWS. The frequency of HW is sufficient to allow contribution to snow pack accumulation, however like both $\mathrm{NE}$ and $\mathrm{R}$, no significant amount of accumulation is associated with this synoptic type.

Accumulation depths associated with these NE, R and HW are not expected to be significant due to the frequency of occurrence of the synoptic type. The calculated accumulation rates 
are insignificant despite being associated with accumulation factors that can produce very high accumulation rates. Accumulation factors derived from Franz Josef AWS indicate that orographic influence is considerable with HE and HSE events. The assumption of orography in the case of type HE is reinforced by Watts (1947) who observed that when weather associated with a common anticyclonic situation (such as HE) moves eastward, orographic cloud immediately forms to the west of the Southern Alps. Accumulation rates are higher to the west during blocking events (Figure 3.2.11 and Table 3.2.9). Evidence of a considerable orographic precipitation gradient is found with type HE and HSE types where high accumulation factors and rates west of the divide equate low precipitation volumes to the east of the Divide (Figures 3.2.8 and 3.2.9)

The north-westerly wind flow associated with the HE synoptic type is assumed to not have the high wind velocity associated with this other blocking synoptic classifications. Such blocking periods with low wind speeds have been observed on the Franz Josef Glacier (Purdie et al., 2011b). Under the assumption of low wind velocity, it seems possible that east of the divide receives $16 \%$ of the total and $24 \%$ of the HE spillover accumulating on Annette Plateau (Table 3.2.10). The results show a small western bias in accumulation within HSE synoptic types (Table 3.2.9). It may be reasonable to associate such an accumulation pattern with the weak NW flow associated with this synoptic type (Jiang, 2010). The calculated accumulation values for the HSE synoptic type are within the calculated range of error for the SWE estimates of the GPR derived IRH, which delineate the temperature index model accumulation factors (Figure 3.2.5).

Accumulation factors associated with synoptic regimes with ablation or no net accumulation offer little help in understanding of snow distribution characteristics. However the general pattern associated with net accumulation under blocking weather regimes are similar to those previously observed (Purdie et al., 2011b).

\section{Troughing}

Troughing weather systems bring near normal depths of precipitation to either side of the Southern Alps and cooler temperatures than normal over the entire region and are generally cloudy over the entire region (Jiang, 2010). Annually trough classifications account for $41 \%$ of synoptic classifications (Jiang, 2010), in the study period troughs accounted for $37 \%$ and $41 \%$ of observed classifications for the Davis Snowfield and Annette Plateau study periods respectively. The frequency of troughing is similar to that found by previous work (Purdie et 
al., 2011b). Trough synoptic types accounted for $42 \%$ of the accumulation on the West of the Divide and $65 \%$ to the east. This suggests that trough, associated westerly flow, and spillover are necessary for eastern glacier mass balance and seasonal water storage. These values are less than those found in (Purdie et al., 2011b) with an inverse relationship of proportion of accumulation/precipitation to either side of the divide. The results from this thesis provide an account of the entire accumulation season, and record of the seasonal variation of synoptic intensity and frequency.

The variation of synoptic intensity and orientation observed at Annette Plateau during the early season $\mathrm{T}$ synoptic type was associated with high accumulation rates measured at Mount Cook AWS. Mount Cook AWS accumulation rates were close to or slightly more that measured at Annette Plateau. As the season progresses (Table 3.2.8) accumulation factors for T reflect that of a more westerly flow regime such as SW, TSW and Blocking and Zonal westerly flows HE and W. Trough systems from the SW, TSW remained similar throughout the season. Accumulation factors for troughing from the north-west (TNW) matches the north-west flow associated with Zonal conditions (HNW).

Accumulation factors highlight the orientation of a weather system in relation to AWS and study site proximity to the main orographic barrier associated with each storm. West of the main divide, accumulation factors reflect the association of spillover and orographic precipitation distribution. Accumulation factors associated with spillover from the west are similar to those on the east for the TSW. However, orographic gradients again become evident with NW storms (TNW), and reflect the north-west flow associated with zonal classifications (HNW), with equal accumulation at Mount Cook AWS and Annette Plateau. Observations of these distribution patterns from the GPR data support the ability of GPR to capture accumulation volumes associated with specific accumulation events.

\subsubsection{Seasonality}

The highest accumulation rates of the accumulation season were calculated in during May and June (Table 3.2.7, Figure 3.2.11). The intensity of pressure gradients within synoptic classifications and the seasonal change in positioning of the synoptic weather systems has been observed to increase wind speeds and alter wind directions over the winter season (Sturman and Tapper, 1996; Kidson, 2000). Annette Plateau received proportionately 
greater amounts of precipitation early in the accumulation season compared to later in the accumulation season, and Davis Snowfield in the early season. This was largely due to the southerly orientated position of the T synoptic type producing local southerly to SE wind flow on east of the Alps. Precipitation volumes during events simultaneous to the east and west of the divide were biased towards the eastern side of the Alps at this point in the season.

Opposing snow distribution patterns in the latter part of the season were associated with considerably more accumulation to the west of the divide. This distribution is in keeping with the expected trans-alpine distribution, however the strength of the westerly flow weakens later in the season, and the association with less intense zonal circulations contributing much more precipitation to the west. The increase in westerly flow associated with spring (Kidson, 2000) is observed to bring small accumulation rates to the East. The westerly flow association likely meant that precipitation to the west was far greater, although these events were outside of the study period for the Davis snowfield. The variation and timing of snow distribution must be considered when associating short term climate studies with long term precipitation patterns. The consequence of bias introduced by such studies may promote unrealistic precipitation distribution patterns (Figure 4.2).

The observed example of variations in intensity of zonal synoptic classifications indicates that it may not be appropriate to apply accumulation factors from part of a season as representative of the entire season, or from year to year. Accumulation factors of 1.41 and 1.46 were applied to Franz Josef and Tasman glaciers respectively (Purdie et al., 2010 b). This observation may be especially pertinent to the west of the divide where considerably greater accumulation factors were calculated (Table 3.2.4). It is unknown if accumulation factors are more stable east of the divide than those on the west of the main divide, evidence suggests that the range of variation throughout the accumulation season at Annette Plateau is considerably less (Tables $3.2 .4,3.2 .5 ; 3.2 .6$ ) than the west-east variation, suggesting that orography is a moderating factor. 


\subsection{Implications for glacier mass balance and hydro lake inflow modelling}

If modelling of snow volume for hazard planning, glacier mass balance, and hydroelectric lake inflow is to be done with certainty these models need to utilise accurate information. Paradoxically, snow modelling generally faces the problem of data scarcity (Stanzel et al., 2008). Little information on snow redistribution and removal limits the applicability of physically based snow models and increases the importance of empirical snow models.

Empirical temperature index modelling of snow accumulation of alpine catchments is a common approach in New Zealand and international snow depth and glacier mass balance calculation, providing a useful tool for the estimation of snow volumes (Anderson et al., 2006; Machguth et al., 2006; Dunse et al., 2008; Stanzel et al., 2008; Kerr, 2009b). For the point records of climate parameters to be accurate within a large scale modelling application, such as for empirical models such as SnowSIM (Clark et al., 2011) a spatially appropriate distribution of climate stations is necessary. Such infrastructure is difficult to maintain in this environment (Purdie et al., 2011a), although necessary as the extrapolation of climate data from a point measurement across varying topography is not always appropriate, and is known not to accurately represent conditions at other points within the region. The procedures used in this study go some way to remove the assumptions from interpolations by providing an efficient and accurate method for the large spatial scale assessment of snow depth.

The implications of the findings of this study on empirical modelling show that seasonal snow pack development can be extracted from a single snow pack survey, providing a robust solution for the lack of climate station data at altitude. Synoptic scale accumulation can only be accurately applied to low angle glacial terrain until there is further research to correlate accumulation volumes on steep and low angled terrain with synoptic classifications.

Application of event scale, monthly and seasonal environmental variables such as temperature lapse rates have been suggested as a partial solution to better replicate accumulation processes in precipitation models (Ruddell, 1995; Stuart 2008). This improvement has been made with regard to likelihood of precipitation and wind classes (Kerr, 2009b). The synoptic time scale and resolution of detailed snow pack assessment may be useful for the provision of boundaries for the application of average values for varying 
climatic parameters in modelling applications, such as temperature lapse rates. The synoptic scale may be a useful climatic boundary to define model input variations, as higher temporal resolution studies produce results with high degrees of variation (Purdie et al., 2011b), and not necessarily significant increases in accuracy (Schuler, et al., 2008).

Modelling of snow volume, either by empirical or physical, will still require calibration. The suggestion from the results of this study of melt surface protected IRH that represent synoptic allows a level of volumetric and temporal detail not previously easily obtained over wide areas. The findings of this thesis further the ability to calibrate accumulation models by quick assessment of snow density data through the MARTYR snow density calculation technique once average snow density representative sites are found within the catchment (Lundberg et al., 2006).

\subsection{Implications of this data with patterns of IPO, ENSO and SAM}

Findings of this investigation indicate reduced accumulated precipitation totals due to the reduced likelihood of the increased frequency of blocking regimes. It is likely that reduced precipitation totals are the result of increased wind speed and consequently snow pack deflation (Purdie et al., 2011b).

The results of this study allow the volume of accumulation for each synoptic type to be calculated at elevation, in turn allowing an estimation mass balance and lake inflow volumes over a snow accumulation season. Whilst heavy snow falls have a hazard potential in the form of avalanches, the major benefit of the capability for improved water resource modelling that this study enables builds on findings of Kidson (2000) and Jiang (2010) that ENSO may play a part in the frequent or lack of occurrence of synoptic weather types resulting in extreme climatic conditions. The results of this thesis allow the calculation of the effect of such variation.

The non-stationarity of climatic states (Salinger and Mullan, 1999; Salinger et al., 2001) and the associated changes in rainfall and river volumes (McKerchar and Henderson, 2003) suggest that estimation of catchment discharges should take into account the effect of interannual variations. The synoptic classifications (Kidson 2000) are derived from a fifty year record of climate reanalysis data allows inferences of past and future behaviour of snow accumulation to be made and allows a better understanding of the effect of an oscillating 
IPO ENSO (SOI) state. Application of one accumulation seasons data for this purpose would however be dubious, despite results supporting the findings of similar shorter time scale studies, (Purdie 2010a) and fitting with the expectations of general precipitation distribution. Further repeated research of IRH defined snow depth will give greater understanding of inter-annual variation of synoptic accumulation factors. Therefore better enabling flood inflow potential to be calculated. 


\section{Chapter 5}

\section{Conclusions}

The overall goal of this study was to trial the technique of Ground Penetrating Radar (GPR) for estimating the volume and distribution of precipitation in the Southern Alps. This conclusion chapter is separated into four sections, each detailing the findings associated with my primary aims.

\subsection{Improvements over traditional snow measurement techniques}

\subsubsection{Measuring deep snow packs using GPR}

Ground-based radar was found to be a useful technique for accurately assessing snow distribution in the Southern Alps. The high sampling frequency and good vertical data resolution enable the mapping of bed topography, accumulation sequences, and actual snow depth. Detailed calibration of snow depths, using snow pits and manual density measurements were made to calibrate the GPR assessment. Improvements in the time taken for GPR calibration were also made by developing the MARTYR technique. The high vertical resolution of GPR is ideal for analysis of internal reflection layers within snowpack, which can be linked to synoptic-scale accumulation events. Much of the assessment and analysis undertaken in this study would unlikely to be possible using traditional snow distribution measurements. Traditional measurement techniques are able to capture similar data for analysis; however field campaigns over an accumulation season in such remote and variable conditions are not feasible.

Airborne GPR is as accurate as ground-based methods at assessing the distribution of snow in deep snow packs on gently-sloping homogeneous terrain. The sampling frequency is sufficient to map large terrain features, although the decreased signal to noise ratio (SNR) obscures the vertical resolution, reducing the applications for which the data can be used. Airborne GPR is particularly useful for assessing snow depth in terrain prone to avalanching 
in a safe and efficient manner. The vertical measurement plane of both probed and airborne survey methods is the likely reason for the good correlation between these methods.

Large variations in snow depth between measurement techniques occur when airborne GPR is used in steep mountain topography. Further research is necessary to determine critical slope angle above which topographic influence on airborne measurements becomes significant. This angle is expected to be $<30^{\circ}$ based on preliminary estimates made in this study.

Projection of snow densities down to $6 \mathrm{~m}$, necessary to determine the relationship between radio wave travel time and snow water equivalent, does not produce significant error in overall snow depth estimation. The $(\sim 10 \%)$ error in snow depth calculation is acceptable when assessing snow-pack depths over an entire season. However the extent to which this error affects shorter-time resolution and synoptic scale interpretation of snow accumulation from deep in the snow pack should be investigated. This error can be significantly reduced by increasing the number of GPR surveys carried out during the season. Three surveys during each winter appears to be sufficient to capture both the total seasonal snow distribution, and to map many of the synoptic-scale events within the snowpack.

\subsubsection{Constraining wavespeed using MARTYR}

A fast and accurate technique to assess snow density was developed. The MARTYR method is as accurate as manual snow density measurements in snowpacks to $<6 \mathrm{~m}$ depths. The errors associated with this technique compare well with manual and geophysical snow density measurement techniques, although it is most suited to snow depths $>0.6 \mathrm{~m} \mathrm{SWE}$. Utilising this methodology will greatly enhance both the speed of large scale snow depth assessment and the frequency of measurement, providing greater knowledge on snow density distribution patterns.

Further research needs to be completed to test the method in steeply sloping terrain, such as at the Jollie River valley. Increasing the size of the MARTYR reflector will also improve the ease of interpreting of the data. 


\subsection{Estimating precipitation at high elevation}

From the assessment of snow distribution at the main divide we can conclude that the precipitation maximum is located $5-10 \mathrm{~km}$ west of the main topographic divide between the surface elevations of $1700 \mathrm{~m}$ a.s.1 and $2000 \mathrm{~m}$ a.s.l. The peak precipitation is $\sim 12 \mathrm{~m} \mathrm{a}^{-1}$. This study provides the first empirical support to high precipitation rates that have previously only been estimated.

The derived seasonal accumulation factors should aid in glacier mass balance modelling of the Franz Josef Glacier. The techniques for snow distribution assessment now enable quick and accurate verification of accumulated precipitation estimates.

East of the divide, at the Jollie River catchment, existing precipitation estimates (1.9 $\left.\mathrm{ma}^{-1}\right)$ (Stuart, 2011) are supported by the GPR measured snow depths (1.8 $\left.\mathrm{ma}^{-1}\right)$, although these data are at odds with some other findings for this area (1.5m SWE) (Kerr, 2009b). No previous measurements have been made at Annette Plateau, although Kerr (2009b) estimated precipitation to be $2 \mathrm{~m}$ SWE during the 2009 winter (May - October) accumulation season. A higher value of $2.6 \mathrm{~m} \mathrm{SWE}$ was found for Annette Plateau in this study, but these differences are reduced when the annual totals derived in this study $(4 \mathrm{~m}+/-$ $0.5 \mathrm{~m} \mathrm{SWE}$ ) are compared to other estimates of $\sim 4.5 \mathrm{ma}^{-1}$ (Kerr, 2009b) and estimated 4.9 $\mathrm{ma}^{-1}$ (Stuart, 2011).

\subsection{Synoptic scale snow accumulation}

Synoptic-scale snow accumulation data can be extracted from the snow pack using GPR. A clear relationship of synoptic circulation type and accumulation totals was observed on either side of the divide, as interpreted through GPR-derived internal reflection horizons. The data are representative of glacier-wide distribution at Annette Plateau, although the Davis Snowfield accumulation values are not expected to be representative of other areas of the Franz Josef Glacier névé (Purdie 2011b). The derived precipitation accumulation totals and rates are consistent with our understanding of how precipitation distribution varies with topography, climate, and with respect to AWS source data locations. For instance, Low Pressure troughs provide similar precipitation totals (1100 mm SWE) on both the east and west of the divide. Less intense and zonal westerly flows were associated with 
predominantly westerly biased precipitation, e.g. for NE synoptic flows only $16 \%$ of the $1014 \mathrm{~mm}$ SWE westerly precipitation accumulates to the east of the Main Divide.

Accumulation factors representing each synoptic type will improve the ability of empirical models to estimate precipitation depths after a precipitation event. Synoptic-scale precipitation estimations will also improve modelled snow accumulation volumes over longer time scales.

Inter-annual climatic variations, accumulation rates, and timing of precipitation are associated with different atmospheric circulation patterns. It would, therefore, be an improvement to carry out this work again over several years so that synoptic-scale accumulation factors could be compared and tested with appropriate statistical methods.

\subsection{Implications for glacier mass balance and hydro inflow modelling}

Large amounts of snow accumulation on Franz Josef Glacier make it sensitive to temperature change (Oerlemans 1997; Anderson et al., 2006; Anderson and Mackintosh, 2006). This study has shown that accumulation at high elevation is higher than has been assumed by glacier modelling studies (Anderson et al., 2006, Oerlemans, 1997).

The methods provided in this study provide a foundation for increased monitoring of snow accumulation patterns. In doing so, better estimates of the water resource held in the seasonal snow pack and in glacier accumulation can be made.

The improved knowledge of snow fall and its relationship with low-elevation precipitation data allows for more accurate modelling of snow accumulation at seasonal and synoptic time scales. These refinements in snow fall estimation will be of particular value during the months from September-December when stream flow in the Southern Alps is more strongly influenced by snow melt. 


\section{Acknowledgements}

I am indebted to my ever patient advisors and friends, Brian Anderson and Andrew Mackintosh. For confusing enthusiasm with potential, I thank you.

This work was made possible with the financial assistance of the Tasmanalps icecore research grant, and with the help of the people who make the following organisations what they are;

\section{NIWA}

Thanks extend to Tim Kerr, for the enthusiasm and support. Jordy Hendikx and Martyn Clark for obliging me with helicopter time and data. Much of this work is the direct result of your generosity; Andrew Harper for the Rose Ridge data.

\section{GNS Science}

Uwe Morgenstern and Julian Thompson; thanks, I couldn't have imagined a better project.

NZAC

For 'The Onion', and the best accommodation rates in town I thank, Grant Pearson and Oli Clifton.

\section{Fox and Franz Heli services, Heliworks, and Mount Cook Ski planes}

For logistical support and a can do attitude I thank;

Mike, Jamie, Jerry, Brendon, Hamish, Mark, Trish and the respective teams.

\section{ScanTech Ltd}

Matt Watson; your idea did work. Thanks, I hope it comes in handy in the future.

To my friends in the field;

Alice Doughty, Thomas Lyttle, Joe Smith-Haddon, Kimberley Wallace, Heidi Godfrey, Chris Harrington. If it wasn't for you giving up your time at short notice to drive across the county for a helicopter ride, a bottle of wine, and the chance to dig snow pits, this work could not have happened. Cheers. Special gratitude is directed at Ben Gaston, and Jeanne Hutchison who are the backbones of many glaciological investigations in New Zealand, thank-you for the meals, libations, patience, and bed.

To my friends at the Antarctic Research Centre;

Alice Doughty (again) Amigo extraordinaire; stop pouring Bailies into that shoe.

Warren Dickinson; cheers for the chocolate, the dinner, the good humour; you have THE life.

Heather Purdie; It was treat to talk with someone who is interested in the now, thanks for the discussion, ideas, and knowledge.

Michelle and Tamsin; organisation personified.

Of particularly fond mention are my office mates; Rachel Rhodes, Katrin Sattler, Lana Cohen, and most recently and outrageously, Molly Patterson. I feel privileged to have worked alongside such talented people who are destined for greatness.

To my parents, Richard and Jan Kees; Thank-you.

Takk Synnøve for å ofre så mye for min sysler.

Help along the way in no particular order; Karl Crossman and family, Anna Leith, Stefan and Bec Beaumont-Strang, Becky Goodsell, Paula Wood, Hamish and Andy the knowledge hub of the $2^{\text {nd }}$ floor, Suzi Woelz, Ruscle Dadic, Petr Hlavacek. 


\section{References}

Alean, J., Haeberli, W., \& Schadler, B. (1984). Snow accumulation, firn temperature and solar radiation in the area of Colle Gnifetti core drilling site (Monte Rosa, Swiss Alps): Distribution patterns and interrelationships. Zeitschift fur Gletcherkunde und Glazialgeologie, 19(2), 131-147.

Anderson, B., Lawson, W., Owens, I., \& Goodsell, B. (2006). Past and future mass balance of 'Ka Roimata o Hine Hukatere' Franz Josef Glacier, New Zealand. Journal of Glaciology, 52, 597-607.

Anderson, B., \& Mackintosh, A. (2006). Temperature change as the major driver of late glacial and holocene glacier fluctuations in New Zealand. Geology, 34(4), 121-124.

Anderton, P. W. (1973). The significance of perennial snow and ice to the water resources of the South Island, New Zealand Journal of Hydrology (NZ), 12(1), 6-18.

Annan, P. A. (2005). GPR methods for hydrogeological studies. In Rubin. Y. \& S. S. Hubbard (Eds.), Hydrogeophysics (pp. 185-213). Netherlands: Springer.

Archer, A. C. (1970). Studies of snow characteristic of the north-eastern Ben Ohau mountains, New Zealand. Journal of Hydrology (NZ), 9(1), 4-21.

Arcone, S. A. (2002). Airborne-radar stratigraphy and electrical structure of temperate firn: Bagley Ice Field, Alaska, USA. Journal of Glaciology, 48(161), 317-334.

Arcone, S. A., Spikes. V.B., \& Hamilton, G. S. (2005). Stratigraphic variation within polar firn caused by differential accumulation and ice flow: interpretation of a $400 \mathrm{MHz}$ short-pulse radar profile from West Antarctica. Journal of Glaciology, 51(174), 407422.

Baker, G. S. (2007). An introduction to ground penetrating radar (GPR). In G. S. Baker \& H. Jol (Eds.), Stratigraphic analysis using GPR (Vol. 432). Boulder, Colorado: Geological Society of America.

Barrows, T., Stone, J., Fifield, L., \& Cresswell, R. (2000). Late Pleistocene glaciation of the Kosciuszko Massif, Snowy Mountains, Australia. Quaternary Research, 55, 179-189.

Barstad, I., Grabowski, W. W., \& Smolarkiewicz, P. K. (2007). Characteristics of largescale orographic precipitation: Evaluation of linear model in idealized problems. Journal of Hydrology, 340(1-2), 78-90.

Bradford, J. H., Harper, J. T., \& Brown, J. (2009). Complex dielectric permittivity measurements from ground-penetrating radar data to estimate snow liquid water content in the pendular regime. Water Resour. Res., 45.

Braithwaite, R. J., \& Zhang, Y. (1999). Modelling Changes in Glacier Mass Balance that may Occur as a Result of Climate Changes. Geografiska Annaler: Series A, Physical Geography, 81(4), 489-496.

Brock, B. W., Willis I.C., \& Sharp, M. J. (2006). Measurement and parameterization of aerodynamic roughness length variations at Haut Glacier d'Arolla, Switzerland. Journal of Glaciology, 52, 281-297.

Bruland, O., Sand, K., \& Killingtveit, ̊. (2001). Snow distribution at a high Arctic site at Svalbard. Nordic Hydrology, 32(1), 1-12.

Chasseriau, P., Lattion, V., Hammami, D., Marillier, F., \& Olivier, R. (2006). 3D modelling of the Tortin glacier (Switzerland) using gravity and geo radar data. Geophysical Research Abstracts, 8, 10146.

Chater, A. C., \& Sturman, A. P. (1998). Atmospheric conditions influencing the spillover of rainfall to lee of the Southern Alps, New Zealand. International Journal of Climatology, 18(1), 77-92.

Chinn, T. (1979). How wet is the wettest of the wet West Coast? .New Zealand Alpine Journal, 32, 85-88. 
Chinn, T. (1995) Glacier Fluctuations in the Southern Alps of New Zealand Determined from Snowline Elevations. Arctic and Alpine Research, 27(2), 187-198.

Chinn, T. (2009) pers comm. Paleoclimate conference, March 2009, Te PapaWEllington New Zealand.

Clark, M. P., Hendrikx, J., Slater, A. G., Anderson, B., Kerr, T., Hreinsson, E. O., \& Woods, R. A. (2011) Representing spatial variability of snow water equivalent in hydrologic and land-surface models: A review. Water Resources Research, 47, W07539.

Dadic, R., Mott, R., Lehning, M., \& Burlando, P. (2010a). Wind influence on snow depth distribution and accumulation over glaciers. J. Geophys. Res., 115(F1), F01012.

Dadic, R., Mott, R., Lehning, M., \& Burlando, P. (2010b). Wind influence on snow depth distribution and accumulation over glaciers. Journal of Geophysical Research, 8.

Dadic R., Corripio, J. G., \& Burlando, P. (2008). Mass-balance estimates for Haut Glacier d'Arolla, Switzerland, from 2000 to 2006 using DEMs and distributed mass-balance modeling. Annals of Glaciology, 49, 22-26.

Daniels, D. J., Gunton, D. J., \& Scott, H. F. (1988). Introduction to subsurface radar. IEE Proceedings, 135(F4), 277-320.

Dunse, T., Eisen, O., Helm, V., Rack, W., Steinhage, D., \& Parry, V. (2008). Characteristics and small-scale variability of GPR signals and their relation to snow accumulation in Greenland's percolation zone. Journal of Glaciology, 54, 333-342.

Dunse, T., Schuler, T. V., Hagen, J. O., Eiken, T., Brandt, O., \& Hogda, K. A. (2009). Recent fluctuations in the extent of the firn area of Austfonna, Svalbard, inferred from GPR. Annals of Glaciology, 50, 155-162.

Eisen, O., Wilhelms, F., Nixdorf, U., \& Miller, H. (2003). Identifying isochrones in GPR profiles from DEP-based forward modeling. Annals of Glaciology, 37, 344-350.

Elder, K., Dozier, J., \& Michealsen, J. (1991). Snow accumulation and distribution in an alpine watershed. Water Resources Research, 27, 1793-1808.

Erxleben, J., Elder, K., \& Davis, R. (2002). Comparison of spatial interpolation methods for estimating snow distribution in the Colorado Rocky Mountains. Hydrological Processes, 16(3627-3649).

Fitzharris, B. B., (1992). The 1992 electricity crisis and the role of climate and hydrology. New Zealand Geographer, 48(2), 79-83.

Fitzharris, B. B., \& Garr, C. E. (1995). Simulation of past variability in seasonal snow in the Southern Alps, New Zealand. Annals of Glaciology, 21, 377-382.

Fitzharris, B. B., \& McAlevey, B. (1998). Remote sensing of seasonal snow cover in the mountains of New Zealand using satellite imagery. Geocarto International 14(3), 33-42.

Fitzharris, B. B. (2004). Snow Accounts for New Zealand: Report prepared for NIWA, Ministry for the Environment, and Statistics New Zealand: Climate Management Centre, Department of Geography, University of Otago.

Fujino, K., Wakahama, G., Suzuki, M., \& Matsumoto, T. (1986). Snow stratigraphy observed by an FM-CW microwave system. IGARSS 1986 Symposium: Zurich, 8-11 September, 1986, IEEE, Cat.no.86CH2268-1(99-101).

Greene, E. M., Liston, G. E., \& Pielke, R. A. (1999). Simulation of above treeline snowdrift formation using a numerical snow-transport model. Cold Regions Science and Technology, 30(1-3), 135-144.

Griffiths, G. A., \& McSaveney, M. J. (1983). Distribution of mean annual precipitation across some steepland regions of New Zealand. N. Z. J. Sci., 26, 197-209., 26, 197 209.

Gruber, S. (2007). A mass-conserving fast algorithm to parameterize gravitational transport and deposition using digital elevation models Water Resources Research, VOL. 43, W06412, doi:10.1029/2006WR004868, 2007. 
Guinot, V., Gourbesville, P. (2003) Calibration of physically based models: back to basics? Journal of Hydroinformatics 5.4, p233- 244

Hagen, J. O., \& Reeh, N. (2004). In situ measurement techniques: land ice. In J. L. a. A. J. P. In Bamber (Ed.), Mass balance of the cryosphere: observations and modelling of contemporary and future change. . Cambridge: Cambridge University Press, 11-42.

Hall, D. K. (1988). Assesment of Polar climate change using satellite technology. Rev. Geophysics, 26, 26-39.

Halstead, I. (2009). Discussion on snow courses. 15-9-2009; NIWA field office; Tekapo, New Zealand.

Harper, J. T., \& Bradford, J. H. (2003). Snow stratigraphy over a uniform depositional surface: spatial variability and measurement tools. Cold Regions Science and Technology, 37(3), 289-298.

Harrison, W. (1986). Effects of snow fences on the snowpack of a block mountain in Otago. Journal of Hydrology (NZ), 25, 18-40.

Hawley, R. L., Brandt, O., Morris, E. M., Kohler, J., Shepherd, A. P., \& Wingham, D. J. (2008). Instruments and Methods Techniques for measuring high-resolution firn density profiles: case study from Kongsvegen, Svalbard. Journal of Glaciology, 54, 463-468.

Heilig, A., Schneebeli, M., \& Fellin, W. (2008). Feasibility study of a system for airborne detection of avalanche victims with ground penetrating radar and a possible automatic location algorithm. Cold Regions Science and Technology, 51(2-3), 178190.

Henderson, R. D. (1993, 1993). Extreme storm rainfalls in the Southern Alps, New Zealand. Paper presented at the Extreme hydrological events: Precipitation, Floods and Droughts, Yokahama Symposium.

Henderson, R. D., \& Thompson, S. M. (1999). Extreme rainfalls in the Southern Alps of New Zealand. Journal of Hydrology (NZ), 38(2), 309-330.

Hendrikx, J., Owens, I., Carran, W., \& Carran, A. (2005). Avalanche activity in an extreme maritime climate: The application of classification trees for forecasting. Cold Regions Science and Technology, 43(1-2), 104-116.

Hessell, J. W. D. (1983). Climatic effects on the recession of the Franz Josef Glacier. New Zealand Journal of Science, 26, 315-320.

Hock, R. (2005). Glacier melt: a review of processes and their modelling. Progress in Physical Geography, 29(3), 362-391.

Ibbit, I., Henderson R. D., Copeland, J. H., \& Wratt, D. S. (2001). Simulating mountain runoff with meso-scale weather model rainfall estimates: A New Zealand experience. Journal of Hydrology 239, 19-32.

Jaedicke, C., \& Gauer, P. (2005). The influence of drifting snow on the location of glaciers on western Spitsbergen, Svalbard. Annals of Glaciology, 42, 237-242.

Jaedicke, C., \& Sandvik, A. D. (2002). High resolution snow distribution data from complex Arctic terrain: a tool for model validation. Natural Hazards and Earth System Science 2, 3/4 (2002) 147-155.

Jo'hannesson, T., Laumann, T., \& Kennett. M. (1993). Degree-day glacier mass balance modelling with applications to glaciers in Iceland and Norway. Nordic Hydrological Programme Rep. 33.

Jol, H. M., \& Bristow, C. (2003). Ground Penetrating Radar in Sediments. London: Geological Society, London.

Jol, H. M., Goodsell, B., Nobes, D. C., Finnemore, M., Cussins, T., de Passille, B., \& Tealby, J. (2004). Preliminary results from high frequency gpr surveys and a $3 d$ grid: Davis Snowfield, Franz Josef Glacier, New Zealand. Proceedings of the Tenth 
International Conference on Ground Penetrating Radar; 21 -24 June, 2004, Delft, The Netherlands.

Kalnay, E., Kanamitsu, M., Kistler, R., Collins, M., Deaven, D., Gamndlin, L., Iredell, M., Saha, S., White, G., Woollen, J., Zhu, Y., Leetmaa, A., Reynolds, R., Chelliah, M., Ebisuzaki, W., Higgins, W., Janowiak, J., Mo, K. C., Ropelewski, C., Wang, W., Jenne, R., \& Joseph, D. (1996). The NCEP/NCAR 40 year reanalysis project. Bulletin of the American Meteorological Society, 77(3), 437-471.

Kanagaratnam, P., Gogineni, S. P., Ramasami, V., \& Braaten, D. (2004). A wideband radar for high-resolution mapping of near-surface internal layers in glacial ice. Geoscience and Remote Sensing, IEEE Transactions on, 42(3), 483-490.

Keary, P., \& Brooks, M. (1991). An introduction to geophysical exploration. Second edition: Blackwell Scientific Publication.

Kerr, T. (2005). Snow storage modelling in the Lake Pukaki catchment, New Zealand: An investigation of enhancements to the SnowSim model. Unpublished MSc, Canterbury University, Christchurch, New Zealand.

Kerr, T. (2009a) pers comm. Discussion on Snow sampling techniques at the Jollie River valley field campaign. Glentanner Mount Cook New Zealand.

Kerr, T. (2009b). Precipitation distribution in the Lake Pukaki catchment. Unpublished Phd thesis, Canterbury University, Christchurch, New Zealand.

Kerr, T. (2010) pers comm. Comparitive model runs of precipitation for Pukaki catchment for 2009; precipitation estimate testing using wind classed method (Kerr, 2009). Kidson, J. W. (2000). An analysis of New Zealand synoptic types and their use in defining weather regimes. International Journal of Climatology, 20(3), 299-316.

Kidston, J., Renwick, J. A., \& McGregor, J. (2009). Hemispheric-Scale Seasonality of the Southern Annular Mode and Impacts on the Climate of New Zealand. Journal of Climate, 22(18), 4759-4770.

Killingtveit, A., \& Sand, K. (1998). Snow-radar: An efficient tool for areal snow pack assessments. Paper presented at the The Northern Research Basins Symposium and Workshop, Ilulisat, Greenland.

Kjøllmoen, B. (2005 ). Glaciological investigations in Norway. The Norwegian Water Resources and Energy Directorate, Report 2-2005, NVE, Oslo, 2005.

Kohler, J., Moore, J. C., Kennett, M., Engeset, R. V., \& Elvehoy, H. (1997). Using groundpentrating radar to image previous years summer sufaces for mass-balance measurements. Journal of Glaciology, 24, 355-360.

Lamont, G. N., Chinn, T. J., \& Fitzharris, B. B. (1999). Slope of glacier ELA's in the Southern Alps of New Zealand in relation to atmospheric circulation patterns. Global and Planetary Change, 22, 209-219.

Lapen, D. R., \& Martz, L. W. (1996). An investigation of the spatial association between snow depth and topography in a prairie agricultural landscape using digital terrain analysis. Journal of Hydrology, 184, 277-298.

Lehning, M., Lowe, H., Ryser, M., \& Raderschall, N. (2008). Inhomogeneous precipitation distribution and snow transport in steep terrain. Water Resour. Res., 44.

Lehning, M., Völksch, I., Gustafsson, D., Nguyen, T. A., Stähli, M., \& Zappa, M. (2006). ALPINE3D: a detailed model of mountain surface processes and its application to snow hydrology. Hydrological Processes, 20(10), 2111-2128.

Liston, G. E. (1999). Interrelationships among Snow Distribution, Snowmelt, and Snow Cover Depletion: Implications for Atmospheric, Hydrologic, and Ecologic Modeling. Journal of Applied Meteorology, 38(10), 1474-1487.

Liston, G. E., \& Sturm, M. (1998). A snow transport model for complex terrain. Journal of Glaciology, 44(148), 498-516. 
Liston, G. E., \& Sturm, M. (2002). Winter Precipitation Patterns in Arctic Alaska Determined from a Blowing-Snow Model and Snow-Depth Observations. Journal of Hydrometeorology, 3(6), 646-659.

López-Moreno, J. I., \& Nogués-Bravo, D. (2005). A generalized additive model for the spatial distribution of snowpack in the Spanish Pyrenees. Hydrological Processes, 19(16), 3167-3176.

Lundberg, A., \& Bergstrom, J. (2000). Impulse radar snow surveys - influence of snow density. Nordic Hydrology, 31(2), 89-106.

Lundberg, A., Richardson-Näslund, C., \& Andersson, C. (2006). Snow density variations: consequences for ground-penetrating radar. Hydrological Processes, 20(7), 14831495.

Machguth, H., Eisen, O., Paul, F., \& Hoezle, M. (2006). Strong spatial variability of snow accumulation observed with helicopter-borne GPR on two adjacent Alpine glaciers Geophysical Research Letters 33, L13503, doi:10.1029/2006GL026576.

Marchand, W.-D., \& Killingtveit, A. (2005). Statistical probability distribution of snow depth at the model sub-grid cell spatial scale. Hydrological Processes, 19(2), 355369.

Marchand, W.-D., Killingtveit, Å., Wilen, P., \& Wikstrom, P. (2003). Comparison of ground-based and airborne snow depth measurements with georadar systems, case study. Nordic Hydrology, 34(5), 427-448.

Marshall, H., Birkeland, P., Elder, K., \& Meiners, T. (2008). Helicopter-based microwave radar measurements in alpine terrain. Paper presented at the Proceedings of the International Snow Science Workshop, Whistler, Colorado.

Marshall, H., Conway, H., \& Rasmussen, L. A. (1999). Snow densification during rain. Cold Regions Science and Technology, 30(1-3), 35-41.

Marshall, H., Koh, G., \& Forster, R. (2005). Estimating alpine snowpack properties using FMCW radar. Annals of Glaciology, 40(157-162).

Maurer, J. A. (2006). Local-scale snow accumulation variability on te Greenland ice sheet from ground-penetrating radar (GPR). Unpublished MSc, University of Colorado.

McCauley, M. P., \& Sturman, A. P. (1999). A study of orographic blocking and barrier wind development upstream of the Southern Alps, New Zealand. Meteorology and Atmospheric Physics, 70, 120-131.

McKerchar, A. I., \& Henderson, R. D. (2003). Shifts in flood and low-flow regimes in New Zealand due to interdecadal climate variations / Variations dans les régimes de crue et de basses aux en Nouvelle-Zéland dues à des variations climatiques interdécennales. Hydrological Sciences Journal, 48(4), 637-654.

McKerchar, A. I., Pearson, C. P., \& Moss, M. E. (1996). Prediction of summer inflows to lakes in the Southern Alps, New Zealand, using the spring Southern Oscillation Index. Journal of Hydrology, 184(3-4), 175-187.

Meier, M. F., Armstrong R., \& Dyurgerov. M.B. (1997). Correspondence; Comments on "Annual net balance of North Cascade glaciers, 1984-94'” by Mauri S. Pelto. Journal of Glaciology, 43(143).

Morris, E. M., \& Cooper, J. D. (2003). Instruments and Methods Density measurements in ice boreholes using neutron scattering. Journal of Glaciology, 49, 599-604.

Negi, H. S., Snehmani, N. K., \& Sharma, J. K. (2008). Estimation o fsnow depth and detection o fburied objects using airborne Ground Penetrating Radar in Indian Hmalaya. Current Science, 94(7), 865-870.

NIWA. (2009). The National Climate Database; climate station records. Retrieved 10-12, 2009 from http://www.cliflo.nizwa.co.nz

NZMS. (2008). Maps and rain radar. Retrieved 8-10, 2002, from http://metservice.co.nz/default/index.php?alias=allnzrainradar; In Kerr, T. (2009b). 
Precipitation distribution in the Lake Pukaki catchment. Unpublished Phd, Canterbury, Christchurch.

Oerlemans, J. (1997). Climate Sensitivity of Franz Josef Glacier, New Zealand, as Revealed by Numerical Modeling. Arctic and Alpine Research, 29(2), 233-239.

Pälli, A., Kohler, J. C., Isaksson, E., Moore, J. C., Pinglot, J. F., Pohjola, V. A., \& Samuelsson, H. (2002). Spatial and temporal variability of snow accumulation using ground-penetrating radar and ice cores on a Svalbard glacier. Journal of Glaciology, 48, 417-424.

Pälli, A., Moore, J. C., \& Rolstad, C. (2003). Firn-ice transition-zone features of four polythermal glaciers in Svalbard seen by ground-penetrating radar. Annals of Glaciology, 37, 298-304.

Pelto, M. S. (1997). Correspondence. Reply to comments of Meier and others on "Annual net balance of North Cascade glaciers,1984-94' ' by Mauri S. Pelto. Journal of Glaciology, 43(143), 193-196.

Pfeffer, W. T., \& Humphrey, N. F. (1998). Formation of ice layers by infiltration and refreezing of meltwater. Annals of Glaciology, 26, 83-91.

Pinglot, J. F., Hagen J.O., Melvold K., Eiken T., \& Vincent, C. (2001). A mean net accumulation pattern derived from radioactive layers and radar soundings on Austfonna, Nordaustlandet, Svalbard. Journal of Glaciology, 47, 555-566.

Purdie, H., Anderson, B., Lawson, W., \& Mackintosh, A. (2011a). Controls on spatial variability in snow accumulation on glaciers in the Southern Alps, New Zealand; as revealed by crevasse stratigraphy. Hydrological Processes, 25(1), 54-63.

Purdie, H., Mackintosh, A., Lawson, W., \& Anderson, B. (2011b). Synoptic Influences on Snow Accumulation on Glaciers East and West of a Topographic Divide: Southern Alps, New Zealand. [10.1657/1938-4246-43.1.82]. Arctic, Antarctic, and Alpine Research, 43(1), 82-94.

Purdy, J. C., \& Austin, G. L. (2003). The role of synoptic cloud in orographic rainfall in the Southern Alps of New Zealand. Meteorological Applications, 10(04), 355-365.

Purdy, J. C., Austin, G. L., Seed, A. W., \& Cluckie, I. D. (2005). Radar evidence of orographic enhancement due to the seeder feeder mechanism. Meteorological Applications, 12(03), 199-206.

Refsgaard, J. C. 1996 Terminology, modelling protocol and classification of hydrological model codes. In Distributed Hydrological Modelling (ed. Abbott, M. B. \& Refsgaard, J. C.). Kluwer, Dordrecht.

Reimer, C. H., \& Hock, R. (2008). Internal accumulation on Storglciaren, Sweden, in a multi-layer snow model coupled to a distributed energy- and mass-balance model. Journal of Glaciology, 54(184), 61-72.

Revell, M. J., Copeland, J. H., Larsen, H. R., \& Wratt, D. S. (2002). Barrier jets around the Southern Alps of New Zealand and their potential to enhance alpine rainfall. Atmospheric Research, 61(4), 277-298.

Rodda, J. C. (1995). Guessing or Assessing the World's Water Resources? Water and Environment Journal, 9(4), 360-368.

Ruddell, A. R. (1995). Recent glacier and climate changes in the New Zealand alps. Unpublished PhD, University of Melbourne, Melbourne.

Salinger, J. (1981). New Zealand climate: the instrumental record. Unpublished Ph.D, Victoria University of Wellington, Wellington.

Salinger, M. J., Renwick, J. A., \& Mullan, A. B. (2001). Interdecadal Pacific Oscillation and South Pacific climate. International Journal of Climatology, 21(14), 1705-1721.

Sand, K., \& Bruland, O. (1998). Application of Georadar for snow cover surveying. Nordic Hydrology, 29(361-370). 
Sarker, R. P. (1966). A dynamic model of orographic rainfall. Monthly Weather Review 94(9), 555-572.

Schuler, T. V., Crochet, P., Hock, R., Jackson, M., Barstad, I., \& Johannesson, T. (2008). The distribution of accumulation across Svartisen (Norway) assessed by a model of orographic precipitation. Hydrological Processes., 22, 3998-4008.

Sinclair, M. R. (1996). A Climatology of Anticyclones and Blocking for the Southern Hemisphere. Monthly Weather Review, 124(2), 245-264.

Sinclair, M. R., Wratt, D. S., D., H. R., \& Gray, W. R. (1996). Factors Affecting the Distribution and Spillover of Precipitation in the Southern Alps of New Zealand - A Case Study. Journal of Applied Meteorology, 36, 428-442.

Sinclair, M. R., Wratt, D. S., Henderson, R. D., \& Gray, W. R. (1997). Factors Affecting the Distribution and Spillover of Precipitation in the Southern Alps of New Zealand; A Case Study. Journal of Applied Meteorology, 36(5), 428-442.

Sinsalo, A., Grinstead, A., Moore, J. C., Karkas, E., \& Petterson, R. (2003). Snowaccumulation studies in Antarctica with ground-penetrating radar using 50, 100 and $800 \mathrm{MHz}$ antenna frequencies. Annals of Glaciology, 37(1), 194-198.

Sirguey, P., Mathieu, R., \& Arnaud, Y. (2009). Subpixel monitoring of the seasonal snow cover with MODIS at $250 \mathrm{~m}$ spatial resolution in the Southern Alps of New Zealand: Methodology and accuracy assessment. Remote Sensing of Environment, 113(1), 160-181.

Sorteberg, H. K. (2009). Snow estimation based on manual snow measurements and airborne snow surveys (GPR system from helicopter). Geophysical Research Abstracts, 11(EGU2009-13984-1, 2009).

Sorteberg, H. K., Engeset, R. V., \& Udnaes, H. C. (2001). A national network for snow monitoring in Norway: Snow pillow verification using observations and models Physics and Chemistry of the Earth, 26(C), 723-729.

Stanzel, P., Halerl, U., \& Nachtenebel, H. P. (2008). Modelling snow accumulation and snow melt in a continuous hydrological model for real-time flood forecasting. Paper presented at the XXIVth Conference of the Danubian Countries.

Stuart, S. (2009). Influence of synoptic climate upon near-surface temperature lapse rates in the region of Franz Josef Glacier, and Aoraki Mount Cook. Unpublished GradDipSc, Victoria University of Wellington, Wellington.

Stuart, S. (2011). Modelling precipitation in the Southern Alps of New Zealand. Unpublished MSc, Victoria University, Wellington.

Sturm, M., Holmgren, J., \& Liston, G. E. (1995). A seasonal snow cover classification scheme for local to global applications. Journal of Climate, 8(5, Part 2), 1261-1283.

Sturman, A. P., \& Tapper, N. J. (1996). The Weather and Climate of Australia and New Zealand. Melbourne: Oxford University Press.

Taurisano, A., Schuler, T. V., Hagen, J. O., Eiken, T., Loe, E., Melvold, K., \& Kohler, J. (2007). The distribution of snow accumulation across the Austfonna ice cap, Svalbard: direct measurements and modelling. Polar Research, 26(1), 7-13.

Thompson, S. M. (2002). River discharges from mountains with frequent rainfall. Journal of Hydrology (NZ), 41(2), 125-144.

Tiuri, M. E., Sihvola, A. H., Nyfors, E. G., \& Hallikainen, M. T. (1984). The complex dielectric constant of snow at microwave frequencies. IEEE Journal Ocean. Engineering, 9(5), 377-382.

Ulriksen, P. (1989). Radar measurements of equivalent water content in snow, measured from a helicopter. Paper presented at the EARSeL workshops and symposium programmes, Helsinki University of Technology, Espoo, Finland

Watson, M. (2008). Ground and Airborne GPR measurements of ice thickness, Minarets, Mt Cook Range. Whangarei: ScanTech Ltd. 
Watts, I.E.M. (1947). The relations o fNew Zealand weather and climate: an analysis of the westerlis. New Zealand Geaographer, 3: 115-129.

Watson, M. (2008). Ground and Airborne GPR measurements of ice thickness, Minarets, Mt Cook Range. Whangarei: ScanTech Ltd.

Winstral, A., Elder, K., \& Davis, R. E. (2002). Spatial Snow Modeling of WindRedistributed Snow Using Terrain-Based Parameters. Journal of Hydrometeorology, 3(5), 524-538.

Winstral, A., \& Marks, D. (2002). Simulating wind fields and snow redistribution using terrain-based parameters to model snow accumulation and melt over a semi-arid mountain catchment. Hydrological Processes, 16(18), 3585-3603.

Winther, J.-G., Bruland, O., Sand, K., Killingtveit, A., \& Marechal, D. (1998). Snow accumulation distribution on Spitsbergen, Svalbard, in 1997. Polar Research, 17(2), 155-164.

Woo, M.-k., \& Fitzharris, B. B. (1992a). Reconstruction of Mass Balance Variations for Franz Josef Glacier, New Zealand, 1913 to 1989. Arctic and Alpine Research, 24(4), 281-290.

Woo, M., \& Fitzharris, B. (1992b). Reconstruction of mass balance variations for Franz Josef Glacier, New Zealand, 1913 to 1989. Arctic and Alpine Research, 24(4), 281290.

Woodward, J., Ashworth, P. J., Best, J. L., Smith, G. H. S., \& Simpson, C. J. (2003). The use and application of GPR in sandy fluvial environments: methodological considerations. In C. S. Bristow \& H. M. Jol (Eds.), Ground Penetrating Radar in Sediments (Vol. 211, pp. 127-142). London: Geological Society.

Wratt, D. S., Revell, M. J., Sinclair, M. R., Gray, W. R., Henderson, R. D., \& Chater, A. M. (2000). Relationships between air mass properties and mesoscale rainfall in New Zealand's Southern Alps. Atmospheric Research, 52(4), 261-282.

Wratt, D. S., Ridley, R. N., Sinclair, M. R., Larsen, H., Thompson S.M., Henderson R.D., Austin, G. L., Bradley, S. G., Auer, A., Sturman, A. P., Owens, I., Fitzharris B.B., Ryan, B. F., \& Gayet, J.-F. (1996). The New Zealand Southern Alps Experiment. Bulletin of the American Meteorological Society 77(4), 683-692.

Yamaguchi, S., Sato, A., \& Lehning, M. (2004). Application of the numerical snowpack model (SNOWPACK) to the wet-snow region in Japan. Annals of Glaciology, 38, 266-272.

Yamamoto, T., Matsuoka, K., \& Naruse, R. (2004). Observation of internal structures of snow covers with ground-penetrating radar. Annals of Glaciology, 38, 21-24.

Zängl, G. (2005). The impact of lee-side stratification on the spatial distribution of orographic precipitation. Quarterly Journal of the Royal Meteorological Society, 131, 1075-1091.

Zängl, G. (2008). The temperature dependence of small-scale orographic precipitation enhancement. Quarterly Journal of the Royal Meteorological Society, 134(634), $1167-1181$. 
